\title{
DESIGN FOR THE CYCLE
}

\author{
by \\ Jeffrey Mitchell \\ Bachelor of Architectural Science, Ryerson University, 2012 \\ A thesis \\ presented to Ryerson University \\ in partial fulfillment of the \\ requirements for the degree of \\ Master of Architecture \\ in the Program of \\ Architectural Science
}

Toronto, Ontario, Canada, 2015

(C) Jeffrey Mitchell 2015 



\section{AUTHOR'S DECLARATION FOR ELECTRONIC SUBMISSION OF A THESIS}

I hereby declare that I am the sole author of this thesis. This is a true copy of the thesis, including any required final revisions, as accepted by my examiners.

I authorize Ryerson University to lend this thesis to other institutions or individuals for the purpose of scholarly research

I further authorize Ryerson University to reproduce this thesis by photocopying or by other means, in total or in part, at the request of other institutions or individuals for the purpose of scholarly research.

I understand that my thesis may be made electronically available to the public. 



\section{ABSTRACT}

Design for the Cycle investigates, evaluates, and aligns contemporary ideas to propose a system for the design of fabric buildings that respond to social and cultural changes through the manipulation of form and materiality over time. In doing so, a building's continued relevancy over time allows a project to reduce its need for embodied energy associated with demolition and repurposing due to premature obsolescence. This can be done through communities driving co-ownership development and tractable design strategies, enriched by the study of existing buildings that have evaded demolition and successfully been repurposed. These elements are brought together to establish a set of guidelines for designing the life-cycle of fabric buildings within an urban context. Using the guidelines, the following thesis proposes a new process for designing and constructing fabric buildings woven into the city with a foundation of resiliency and values reflecting the importance of our earth's finite resources. 



\section{ACKNOWLEDGMENTS}

The most sincere gratitude is directed to my supervisor Professor Jurij Leshchyshyn who, with every question and exercise over the past year, continuously broadened my understanding of the world in which we build. This thesis would not have been possible without his unique criticality to every detail and skill in challenging me so that I may never take any action for granted. It is a philosophy I first witnessed 6 years ago in my undergraduate design studio and since then, I have tried to embody these characteristics. I also sincerely thank Professor Marco Polo and Professor Jennifer McArthur, my supporting committee members, who went above and beyond in openly sharing their knowledge, encouragement, and a continuous perspective of seriousness towards my ideas as they developed throughout the year.

I would also like to thank all of the professors and staff at the Ryerson University Department of Architectural Science for willingly entertaining and answering my questions, whether they were through chance meetings in your offices or on the steps of the Atrium. As well, a special thank you to Frank Bowen and the staff in the Shop who indulged my - often - ridiculous requests for model-making.

I must also thank the people outside of the Ryerson community. Chris Radigan, Janna Levitt, Michael McClelland, and Tom Mitchinson, who were willing to speak with me about their projects that I studied, documented, and learned from throughout the past year. For their shared time and experience I am grateful.

Finally, I thank my family and friends, especially my parents Mike and Karen Mitchell, Aunt Irene McMurray, and partner Ericka Song for their continued support and encouragement. 


\section{TABLE OF CONTENTS}

Author's Declaration iii

Abstract v

Acknowledgments vii

Table of Contents viii

List of Figures xi

LIFE-CYCLE THINKING

Introduction 1

Repurposing and Demolition 2

$\begin{array}{ll}\text { Future Ready } & 7\end{array}$

Design For Deconstruction 8

Sustaining Urbanity Through Culture 10

New Regulation and Ownership Models 11

DESIGN FOR THE CYCLE

Dynamic Typologies 15

Typology Related To The City 19

Fabric Buildings $\quad 21$

Typology Matrix 23

Backcasting 26

DESIGN FOR THE CYCLE GUIDELINES 33

Guideline Sources 33

Avenues and Mid-Rise Study Analysis 34

Building Analysis 35

DESIGN STRATEGIES

Structural Grid $\quad 41$

Vertical Division 43

Interior Depth $\quad 45$

Horizontal Run of Façade 45

Party Wall $\quad 47$

Through Site Access $\quad 47$

Laneway $\quad 49$ 
Privately Owned Public Space 49

Stair Core 51

Elevator Core 53

Opening Ratio 54

Component Based Envelopes 55

Mechanical Systems $\quad 57$

MATERIALS 61

$\begin{array}{ll}\text { Structure } & 61\end{array}$

Interior Horizontal Surfaces 65

$\begin{array}{ll}\text { Envelope } & 67\end{array}$

Interior Vertical Surfaces 68

ANALYSIS ON SITE

College Ossignton $\quad 78$

King Dufferin 80

$\begin{array}{ll}\text { CONCLUSION } & 104\end{array}$

Appendix A - Effects of Regulation 107

Appendix B - Additional Drawings 113

Appendix C - Building Analysis pt. 1

Appendix D - Building Analysis pt. 2

Appendix E - Typology Matrix Database 155

Appendix F - Interview Transcripts 163

Bibliography 186

Glossary 190 



\section{LIST OF FIGURES}

Figure 1.1: Progression of waste associated with renovation over 50 years. Source: Jeffrey Mitchell

Figure 1.2: Potential of material conservation.

Source: Jeffrey Mitchell

Figure 1.3: Willis Faber \& Dumas Insurance Headquarters

Source: Foster + Partners <http://Ih6.ggpht.com/_Uzm9uY6In_c/TG8ys9vPJxl/

AAAAAAAB_A/7mWAu97r9bk/s1600-h/image\%5B37\%5D.png, accessed 2014.09.08>

Figure 1.4a \& b: Future Development of Honest Eds Building

Source: The Globe and Mail <http://www.theglobeandmail.com/news/toronto/redevelopment-of-honesteds-in-toronto-holds-several-surprises/article23274452/>

Figure 1.5: Illustration of co-ownership relationship model.

Source: Jeffrey Mitchell

Figure 2.1: Open Air School in Amsterdam

Source: Jose Garcia <http://www.mimoa.eu/projects/Netherlands/Amsterdam/Eerste\%20

Openluchtschool>

Figure 2.2: Photograph of Leutschenbach School in Zurich

Source: Leonardo Finotti <http://archrecord.construction.com/projects/Building_types_study/K-12/2012/

The-Leutschenbach-School-slideshow. asp?slide=2>

Figure 2.3: Leutschenbach School forth floor

Source: Christian Kerez <http://archrecord.construction.com/projects/Building_types_study/K-12/2012/

The-Leutschenbach-School-slideshow.asp?slide=22>

Figure 2.4: Sketch of Fabric Buildings

Source: Matthew Frederick, 101 things I learned in Architecture School, pg. 88

Figure 2.5: Photograph of UBC Campus Center for Interactive Research

Source: Martin Tessler < http://www.archdaily.com/343442/centre-for-interactive-research-on-

sustainability-perkins-will>

Figure 2.6: Photograph of Kentlands Neighbourhood

Source: Ann Forsyth, <lj.uwpress.org/content/28/1/56.full.pdf+html>

Figure 2.7: Pre-Retrofit Typologies Matrix

Source: Jeffrey Mitchell

Figure 2.8: Post-Retrofit Typologies Matrix

Source: Jeffrey Mitchell

Figure 2.9: Kiesler's Correalsim

Source: Frederick Kiesler, <http://works.bepress.com/cgi/viewcontent.cgi?article=1013\&context=william_ braham>

Figure 2.10: The Star's Toronto City Map.

Source: Jeffrey Mitchell 
Figure 3.1: WA Drummond

Source: Jeffrey Mitchell

Figure 3.2: Queen s Quay Terminal Building Source: Jeffrey Mitchell

Figure 3.3: Barrymore Building

Source: Jeffrey Mitchell

Figure 4.1: Structural primary and secondary unit grid.

Source: Jeffrey Mitchell

Figure 4.2: Vertical Divisions

Source: Jeffrey Mitchell

Figure 4.3: Maximum Interior Depth.

Source: Jeffrey Mitchell

Figure 4.4: Maximum Horizontal Street Frontage.

Source: Jeffrey Mitchell

Figure 4.5: Continuation of Party Wall

Source: Jeffrey Mitchell

Figure 4.6: Through Site Access

Source: Jeffrey Mitchell

Figure 4.7: Laneway Boundary

Source: Jeffrey Mitchell

Figure 4.8: Privately Owned Public Space Source: Jeffrey Mitchell

Figure 4.9: Stair Placement Study 1

Source: Jeffrey Mitchell

Figure 4.10: Stair Placement Study 2

Source: Jeffrey Mitchell

Figure 4.11: Stair Disassembly

Source: Jeffrey Mitchell

Figure 4.12: Elevator Placement Study

Source: Jeffrey Mitchell

Figure 4.13: Component Based Envelopes.

Source: Jeffrey Mitchell

Figure 4.14: Transfer of Façade Panels

Source: Jeffrey Mitchell

Figure 4.15: Proposed Mechanical System

Source: Jeffrey Mitchell

Figure 4.16: Mechanical System Study

Source: Jeffrey Mitchell 
Figure 5.1: Structural Frame Source: Jeffrey Mitchell

Figure 5.2: Structural Slabs Source: Jeffrey Mitchell

Figure 5.3a \& b: Photographs of Evergreen Brickworks Façade System

Source: Diamond Schmitt Architects <http://www.dsai.ca/projects/centre-for-green-cities-evergreen-brickworks>

Figure 5.4: OBC Comparison Graph

Source: Ontario Building Code, Major Occupancy Fire Separations, Table 3.1.3.1

Figure 5.5: 1:20 Scale model of a single primary unit in 3m F2F configuration. Source: Jeffrey Mitchell

Figure 5.6: 1:20 Scale model of a single primary unit in 4m F2F configuration. Source: Jeffrey Mitchell.

Figure 5.7a \& b: Photo collage of 1:100 and 1:20 models. 1/2 unit. Source: Jeffrey Mitchell.

Figure 5.8a \& b: Photo collage of 1:100 and 1:20 models. Expansion to 1 unit Source: Jeffrey Mitchell.

Figure 5.9a \& b: Photo collage of 1:100 and 1:20 models. Expansion Vertical, multi unit. Source: Jeffrey Mitchell.

Figure 6.1a to e: Richmond Street East and Victoria Street Source: Jeffrey Mitchell.

Figure 6.2a to c: Danforth Ave. and Broadview Ave. Source: Jeffrey Mitchell.

Figure 6.3a to g: King Street and Dufferin Street Source: Jeffrey Mitchell.

Figure 6.4: Map of College Street and Ossignton Ave. Source: Jeffrey Mitchell.

Figure 6.5: College Ossignton 2017 Source: Jeffrey Mitchell.

Figure 6.6: College Ossignton 2037 Source: Jeffrey Mitchell.

Figure 6.7: College Ossignton 2060 Source: Jeffrey Mitchell.

Figure 6.8: Map of King Street and Dufferin Street Source: Jeffrey Mitchell.

Figure 6.9: Massing Diagram of King and Dufferin Building Source: Jeffrey Mitchell.

Figure 6.10: South Façade along King Street.

Source: Jeffrey Mitchell. 
Figure 6.11: Primary Unit 1, (+0m)

Source: Jeffrey Mitchell.

Figure 6.12: Primary Unit 2, $(+12 \mathrm{~m})$

Source: Jeffrey Mitchell.

Figure 6.13: Primary Unit 3, (+24m)

Source: Jeffrey Mitchell.

Figure 6.14: Roof Level, (+36m)

Source: Jeffrey Mitchell.

Figure 6.15: Atrium looking to the North Source: Jeffrey Mitchell.

Figure 6.16: Atrium looking to the South Source: Jeffrey Mitchell.

Figure 6.17: Green roof garden looking North West Source: Jeffrey Mitchell.

Figure 6.18: Garden void looking North East Source: Jeffrey Mitchell.

Figure 6.19: Base Façade

Source: Jeffrey Mitchell.

Figure 6.20: Steel Frame

Source: Jeffrey Mitchell.

Figure 6.21: Active Façade Elements Source: Jeffrey Mitchell.

Figure 6.22: Sectional Perspective of Courtyard Source: Jeffrey Mitchell.

Figure 6.23: Courtyard looking North East.

Source: Jeffrey Mitchell.

Figure 6.24: Office space converted from the courtyard. Source: Jeffrey Mitchell.

Figure 6.25: Programmatic Plan +0m (years 2016 to 037). Source: Jeffrey Mitchell.

Figure 6.26: Programmatic Section BB (years 2016 to 2037). Source: Jeffrey Mitchell.

Figure 6.27: Programmatic Plan +0m (years 2037 to 2060). Source: Jeffrey Mitchell.

Figure 6.28: Programmatic Section BB (years 2037 to 2060). Source: Jeffrey Mitchell.

Figure 6.29: Programmatic Plan +12 m (years 2016 to 2037). Source: Jeffrey Mitchell. 
Figure 6.30: Programmatic Section AA (years 2016 to 037). Source: Jeffrey Mitchell.

Figure 6.31: Programmatic Plan $+12 \mathrm{~m}$ (years 2037 to 2060). Source: Jeffrey Mitchell.

Figure 6.32: Programmatic Section (years 2037 to 2060).

Source: Jeffrey Mitchell.

Figure 6.33: Residential unit changing to double height.

Source: Jeffrey Mitchell.

Figure 6.34: South façade after initial construction phase (years 2016 to 2036). Source: Jeffrey Mitchell.

Figure 6.35: South façade conversion from commercial to industrial (years 2036 to 2046). Source: Jeffrey Mitchell.

Figure 6.36: South façade conversion from residential to office (years 2046 to 2056). Source: Jeffrey Mitchell.

Figure 6.37: South façade after two primary units addition (Years 2056 and beyond). Source: Jeffrey Mitchell. 



\section{LIFE-CYCLE THINKING Introduction}

Life-cycle thinking has become the prevailing direction towards achieving the ultimate net zero energy goals for our future. In 1990, Francis Duffy wrote an article for Facilities magazine titled, "Measuring Building Performance" in which he pointed out the prevailing nature of contemporary architecture as being "synchronic" and discussing "nothing about the ongoing reality of building use" (F. Duffy, 1990, p.17). Around the same time that Duffy was writing about his observations on issues related to the building industry, Bruce Sterling released his first blog post transcribing the first lecture that he gave on his Viridian Design Movement. With the release of the first Viridian Design Notes, Sterling's long-term ambition to bring the green design movement to the mass consumer began, which consequently changed the public's view of human activities in relation to energy and material use, and the need to reduce greenhouse gas emissions. Sterling continued to update his work as his green agenda became mainstream, releasing his final Viridian Note in 2013 to conclude his twenty-two years of writing on this topic. He proposed that a design must be conceived of as a sustainable object, being able to "navigate successfully through time and space" (B. Sterling, 2013).

Relating sustainability to time is not a new idea. In 1995, (five years after the beginning of the Viridian Design Movement) author Stewart Brand proposed a new way to regard the sustainability of architecture through a perspective of constant change by acknowledging that buildings are dynamic in their form and function over time changing with renovations, additions, and new occupancies. In his book, How Buildings Learn, he argues that buildings must be preemptive with how they are designed as related to their life-cycle and unknown future. Designing for transformation to occur must be incorporated into the design, thereby reflecting the true nature of buildings as there cultural and functional relevance changes over time. Since the first introduction to life cycle thinking, there have been many variations on how to approach this concept. The approach Brand proposed was to consider the design of a new building to accommodate for all conceivable future uses, with plentiful storage and flexible design of space (S. Brand, 1995). The main critique of this approach is the impossibility of predicting all of the possible outcomes of 
changes that might occur throughout a building's life. Such unpredictability has a high initial energy and material cost associated with it. Despite such an approach the buildings may still become obsolete due to simple changes in "human taste and investment environments. Essentially buildings become obsolete when they no longer fulfill human needs" (P. Graham, 2003, p. 168). Unfortunately, "the long term shell, foundations, walls, roof and structure - turns out to be nugatory in comparison to the gradual accretion of huge expenditure on ductwork and furniture,". Thus the fleeting opinions of the occupants' tastes of their interior environments ultimately determine the length of a building's existence. Many buildings in London, England, were prematurely demolished and replaced with new buildings in order to update the "services and scenery" "that matched the occupants' immediate needs (F. Duffy, 1990, p.18).

"Rather than describe and measure buildings in material terms - amounts of concrete, glass and steel - it is necessary to describe them in terms of time: shells that last up to 50 years, services that last 15 years before they must be replaced, scenery which, these days, has a duration of five years or even less." (F. Duffy, 1990, p.17)

\section{Repurposing and Demolition}

When a building is deemed obsolete and no longer serves its initial use, a decision must be made to either repurpose the building, demolish and build something new, or leave it abandoned (to be demolished or repurposed at a later time). An alternative approach is to deconstruct a building instead of demolishing as highlighted in paper titled, "Design for Deconstruction and Materials Reuse" by B. Guy and S. Shell. This paper states: "The US EPA has estimated that the materials debris from building renovation and demolition comprise $25 \%$ to $30 \%$ of all waste produced in the US each year" (B. Guy, \& S. Shell, n.d., p.1). The bulk of this waste is due to poor planning and a failure to accommodate unforeseen circumstance within a building's life that initiates a renovation for new use. Peter Graham states that a building's structural life can extend from 50 to 100 years, yet this is often not

$1 \quad$ Scenery is referred to in F. Duffy's article as the interior partitions, furniture, and other space defining features. 
realized due to major issues of obsolescence. Changes that occur to a building can be defined by building components and timelines: exterior cladding approximately every "20 years, wiring, plumbing and climate control systems are replaced every 7-15 years, while floor plans last as little as 3 years before they are changed," making it easy to imagine how the accumulated 25 to $30 \%$ of waste was reached (P. Graham, 2003, p. 168).

The critical issue of waste produced through the life-cycles of the building industry has had a major impact on the past 20 years of discussion regarding the green agenda and sustainable architecture. The energy input into a material's creation, installation, and maintenance constitutes the total embodied energy of a specific material over its life. The total of these materials' energies constitutes the embodied energy of a building. The periodic and reoccurring accumulation of embodied energy, figure 1.1, is now being recognized as a fundamental concern for environmentally responsible design as it has the potential to exceed triple (325\%) the total embedded energy of initial construction over a building's life (R.J. Cole, \& P.C. Kernan, 1996, p. 312). The decision to repurpose a building has a substantial effect on the potential to lengthen the life of all the materials embedded into the building, thus dispersing the initial energy needed to create the materials over a longer timeframe. Repurposing delays the creation of new materials, ultimately decreasing the total embodied energy of all the materials in the building. Other benefits include the reduction of carbon emissions released into the atmosphere, and the rate at which waste is created and dumped into landfills (G. Penoyre \& S. Prasad, 2014). However, Graham cautions designers that the retrofit of a building to defer its demolition can result in higher energy expenditure than the continued use and management of the existing building (P. Graham, 2003, p. 170). A process of careful planning is needed to ensure that embodied energies are kept low, waste is minimized, and the building successfully avoids service life obsolescence. Ideally, as demonstrated in figure 1.2, buildings have the potential to successfully reduce and limit the reoccurring buildup of embodied energy through proper implementation of initial design strategies, allowing for the minimization of waste and overall embodied energy over a life-cycle. 
Increase Over Time of Embodied Energy Using

Current Construction and Renovation Processes.

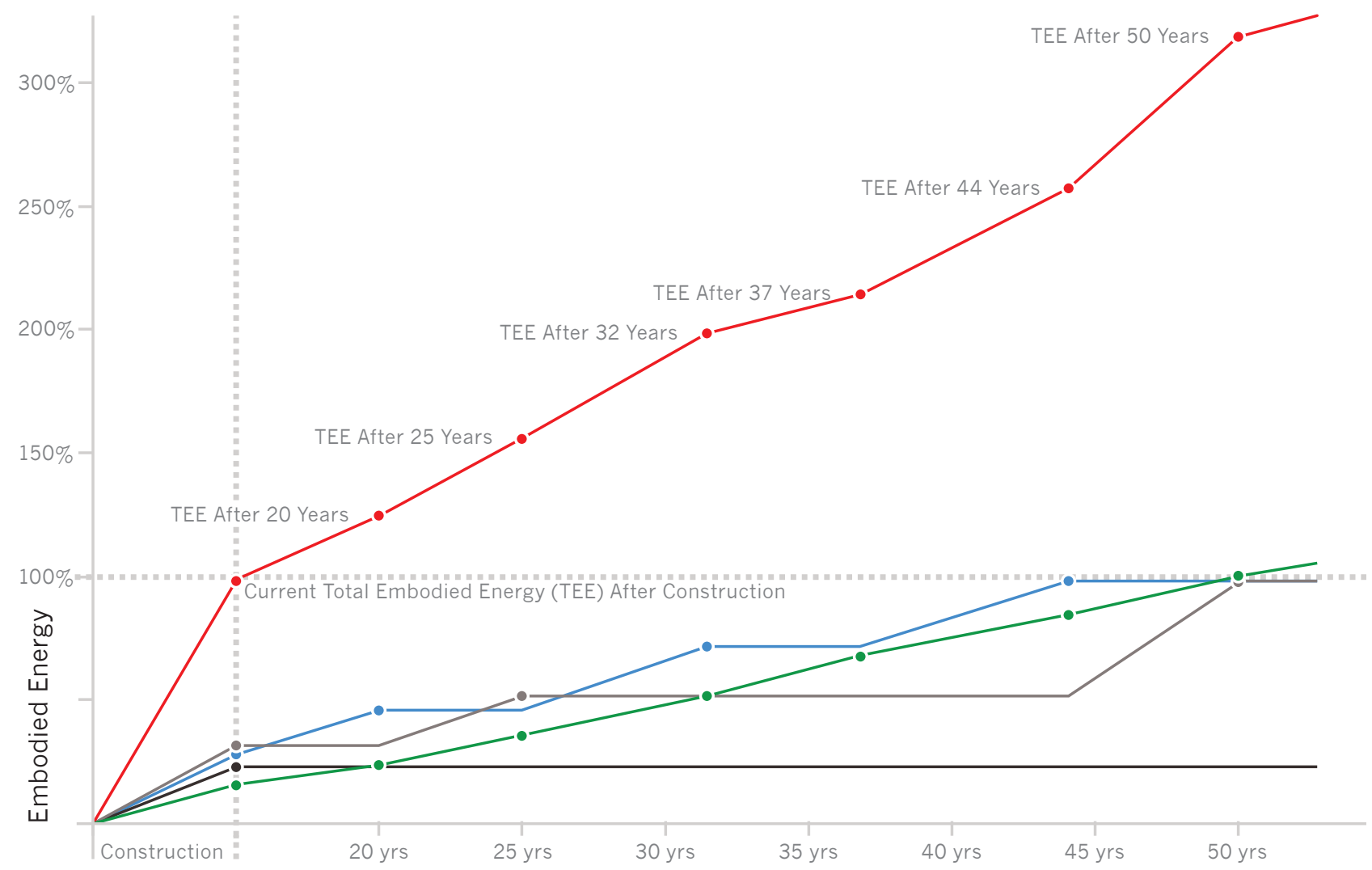

Time

- Total Embodied Energy

- Structural

- Skin

- Services

- Interior Finish

Figure 1.1: Accumulation of embodied energy associated with current renovation practices over 50 years. Showing a combined embodied energy of a typical office building from R.J. Cole and P.C. Kernans' study divided across a typical cycle of renovations as described by F. Duffy. 
Estimated Increase Over Time of Embodied Energy Using

Design for the Cycle Construction and Repurposing Processes.

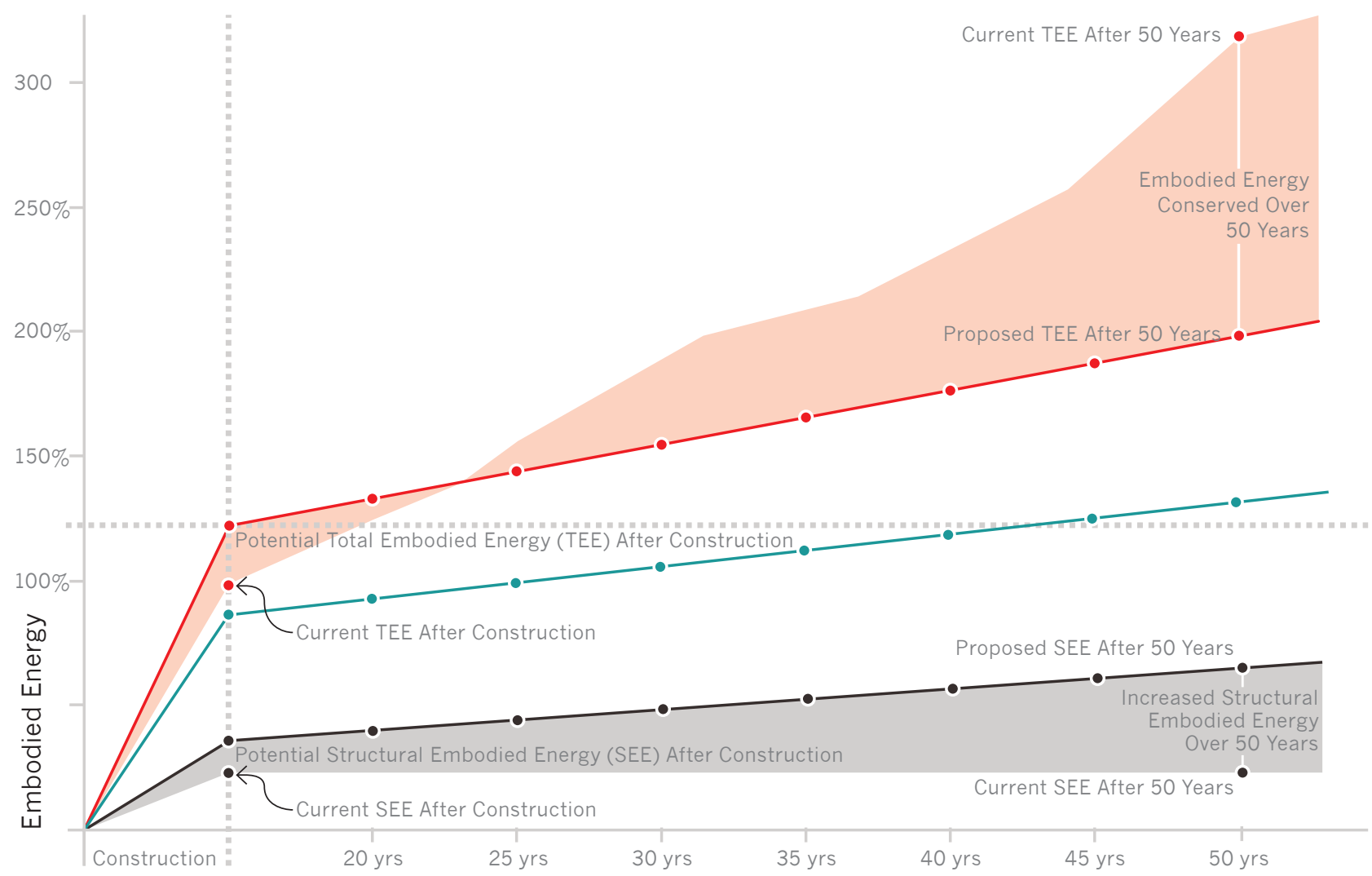

Time

- Total Projected Embodied Energy

- Structural

- Combined Skin, Services, and Interior Finish

Figure 1.2: An estimate of the potential embodied energy conserved over a 50 year lifecycle due to an increased initial energy investment during the construction of the building. 


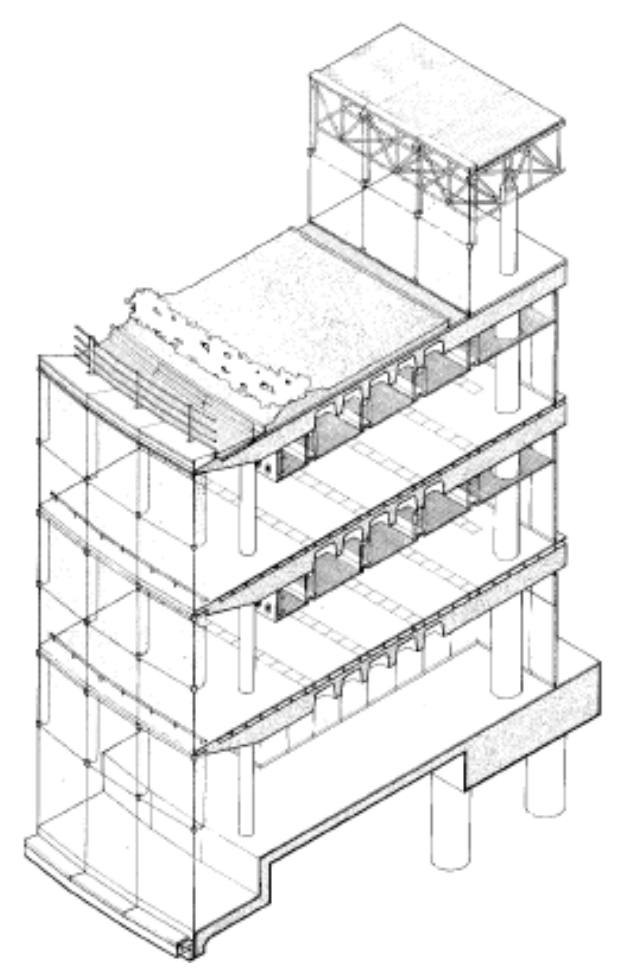

Figure 1.3: Willis Faber \& Dumas Insurance Headquarters. The decision to include plenum spaces into the design was made before the common use of telecommunication and computer networking. This allowed for the building to facilitate their installation and remain functionally relevant to the changing office needs over time . 


\section{Future Ready}

In 2008, architect Norman Foster gave a speech introducing the idea of "Future Proofing" as a preemptive planning strategy, which he claimed to have successfully used in designing the Willis Faber \& Dumas Insurance Headquarters building located in Ipswich, England. "Future Proofing," at the early stage of design, allowed for the accommodation and integration of networked computers and other data services into the physical structure as discussed at the conference called Digital-Life-Design (DLD) and seen in Norman Foster's drawing, figure 1.3. This single preemptive strategy significantly changed how the company managed its information systems many years after initial construction (N. Foster, 2007). The concept of "Future Proofing" aligns with Stewart Brand's book, How Buildings Learn, and his ideas of preemptive design. The unifying thread between these concepts is that buildings are not static. The designers working within these concepts have applied "life-cycle thinking to create buildings that are resilient to environmental conditions and can cater to a diversity of human needs. In this way, they ensure their buildings protect biological diversity, ${ }^{2}$ and minimize resource consumption and waste by avoiding obsolescence" (P. Graham, 2003, p. 7). Although we have been repurposing buildings for a millennia, complying to a standardized model of repurposing with any form of efficiency, as attempted by the "green movement," has been disregarded and attempted sparingly. Penoyre \& Prasad concede that, "There are so many variables with the current building stock within even a limited matrix of typologies, which makes a standard retrofit option difficult and unlikely" (G. Penoyre \& S. Prasad, 2014, p.6). For this reason, standards for repurposing has not yet successfully been developed or implemented. Preemptive design must be pushed at the schematic stage.

2 The phrase 'biological diversity' is used by Graham to show a sensitivity to the ways in which resources are used in the built world and a responsibility to ensure that our extraction of such resources are done so responsibly to maintain a healthy biosphere. 


\section{Design for Deconstruction}

The response by the architectural industry to Steward Brand's book after it was released in 1995 was the creation of the Design for Deconstruction (DfD) movement. The movement allowed for a specific kind of flexibility in buildings through the tractability of components to allow for disassembly. Prior to this, designs with the intention to increase the useable life of a building were achieved through the creation of highly specific spaces designed to accommodate for all the possible needs of a very specific use (B. Guy, \& S. Shell, n.d., p.3). The DfD movement is summarized well by Guy and Shell:

"Design for Deconstruction (DfD) is an emerging concept that borrows from the fields of design for disassembly, reuse, remanufacturing and recycling in the consumer products industries. Its overall goal is to reduce pollution impacts and increase resource and economic efficiency in the adaptation and eventual removal of buildings, and recovery of components and materials for reuse, re-manufacturing and recycling." (B. Guy, \& S. Shell, n.d., p.1)

The Design for Deconstruction movement has resulted in the creation of many strategies, details, and example projects that use different methods to allow for the building to be constructed and deconstructed without creating waste product. It flourished into an architectural design niche taking advantage of mass production and the open floor plates from the modernist era (B. Guy, \& S. Shell, n.d., p.1). Guy and Shell indicated that four important strategies were learned about how to deconstruct buildings through the experiences recorded during the process of dismantling older buildings. Many of the documented strategies resulted in the need for: 1. eliminating chemically welded materials, 2. simplifying HVAC and other services, 3. exposing the connection methods, and 4. allowing for easily accessible areas. Using these strategies, a deconstruction crew is able to dismantle a building without the destruction of materials, so that they can be reused elsewhere (B. Guy, \& S. Shell, n.d., p.2).

A key element that is generally overlooked and rarely exercised in a Design for Deconstruction project is the deconstruction plan. Guy and Shell envisioned this 
as a set of drawings developed durring the design and construction drawing phases and maintained on record durring the buildings life for future reference (B. Guy, $\&$ S. Shell, n.d.). In order for this to be successful, they asked to have "bar codes for materials so that the deconstruction contractor will have 'handling' instructions for the material or component upon removal" (B. Guy, \& S. Shell, n.d., p.2). The deconstruction plan is one method of dealing with the disassembly of buildings, but due to changes that every building undergoes throughout its life, plans may easily become obsolete after even one mis-documented renovation.

Implementing a concept of design hierarchies would be highly effective in the development of projects if materials are to be accurately and successfully reused, disassembled and recycled back into the larger system (B. Guy, \& S. Shell, n.d., p.5). The principle of hierarchical design starts by creating a plan to establish hierarchies within a building depending on the scale and components of an individual systems. These hierarchies are:

1) design for reuse,

2) design for remanufacturing, and

3) design for recycling.

Design for reuse is intended for the reuse of components directly into another building; design for remanufacturing is proposed for components to be remanufactured and altered for use in another system; design for recycling is intended for traditional raw material reuse (B. Guy, \& S. Shell, n.d., p.5). It is the purpose of this thesis to propose a fourth tier to the hierarchy that precedes the initial three proposed by Guy and Shell. "Design for Repurpose" intends to establish opportunities at the onset of a building's design phase that would allow for complete changes of use to occur throughout its life, while minimizing waste. By designing the building to have very loose programmatic intentions, a set of guidelines driving proportions, spatial arrangement, as well as material and service selection, the useful life of a building could be extended without the destruction and reconstruction of a partially new building causing the typically wasteful practice of current renovation practices.

"If a sustainable built environment maximizes the ability to operate in a hierarchical and flexible manner, buildings will need to be multi-faceted storages of energy and materials, able to work within temporal and cultural currents of economic, social and natural environmental conditions.” (B. Guy, \& S. Shell, n.d., p.4) 


\section{Sustaining Urbanity Through Culture}

Acknowledging flexibility and transient building use, the Design for Deconstruction movement establishes itself into the dialogue of architectural practice as a possible method to achieve a level of sustainable urbanity. Alternatively, there is an idea to create buildings that last "forever". In an article published in Traditional Buildings Magazine, Samantha L. Salden writes that the idea of "lasting" must be emphasized within communities who are currently persuaded that visually spectacular buildings will diminish over time. "The residents may no longer be able to look to that one striking vision. Sustainability must be internalized in the community's consciousness and incorporate flexibility" (S.L. Salden, 2010, p.12). Community consciousness is an important component within the dialogue of sustainable urbanity, considering that a building designed to the highest of efficiency standards can become a massive energy sink if it is merely destroyed and replaced a decade later (unless principles of DFD are followed and successfully implemented upon its obsolesce). Salden states that a sustainable building within the context of cultural relevancy is one that is a part of a durable and "walkable" place that "people will love and care for through generations" (S.L. Salden, 2010, p.12).

Norman Foster promotes his building, The Willis Faber \& Dumas Insurance Headquarters, both as "Future Proofed" against technical changes, and resilient due to its cultural connection to its city. Primarily conceived of as a celebratory space for the community, the scheme was enhanced with an accessible roof garden that successfully engages its community members, thereby creating support for the building's care and longevity (N. Foster, 2007). In her article, Salden proposes that these integral components are not arbitrary or accidental, but can be implemented and studied with a "design toolkit through a typological approach" (S.L. Salden, 2010, p.12). Through the creation of the toolkit, common elements (implied to be geographically specific and thus not discussed in detail) can be identified, such as the "scale of a window or thickness of a wall," as it relates to appropriately managing the climatic needs of a specific area (S.L. Salden, 2010, p.12). For example, she would favour managing heat loss in a cold climate through the reduction of apertures on a building façade versus specifying an energy intensive HVAC system to warm up a floor-to-ceiling window wall. For Salden, the advancement of passive systems that 
have evolved over many years specific to local conditions, mixed with the current scientific and technical opportunities available today, would work well to support culturally relevant buildings in our society.

\section{New Regulation and Ownership Models}

One of the main factors contributing to a buildings obsolescence is the constant change in ownership that occurs within a property or across large expanses of land within a city. The full utilization of a building may be irrelevant to a new owner who has different needs than the user for whom the building was initially designed. Therefore, to discuss the life-cycle of a building and design one with the intent of reducing the chance of complete obsolescence, we must start at the beginning of preschematic design, giving attention to specific ownership and the effects of regulatory zoning and bylaws.

The regulations imposed by local government policies on areas of land greatly influence the texture of built fabric that develops from it. As Toronto developed over time, the initial subdivisions of land that occurred in the 1800 s have now made it difficult to acquire land for the purposes of larger development projects (D. LeBlanc, 2014). However, these new full-block developments resulting from the amalgamation of property have defined a specific articulation of buildings different than those developed under the previous regulatory property lines and ownership situations. Through the study of differences in massive block articulation versus a fine grain fabric, the variances and their effects on the livability of the city are well documented (S. B. Sørensen, \& A. Dalsgaard, 2013). The texture of these buildings created a language of individual, closely spaced lot sizes that provided highly variable façades along city streets. ${ }^{3}$ To aid in maintaining this variable language in Toronto guidelines such as the Toronto Avenues and Mid-Rise Study represent an attempt to maintain a level of this façade variation through proportion, setback, and façade articulation strategies.

3 Refer to Appendix A for studies on the effects that regulation has on the texture of a cities fabric buildings. 


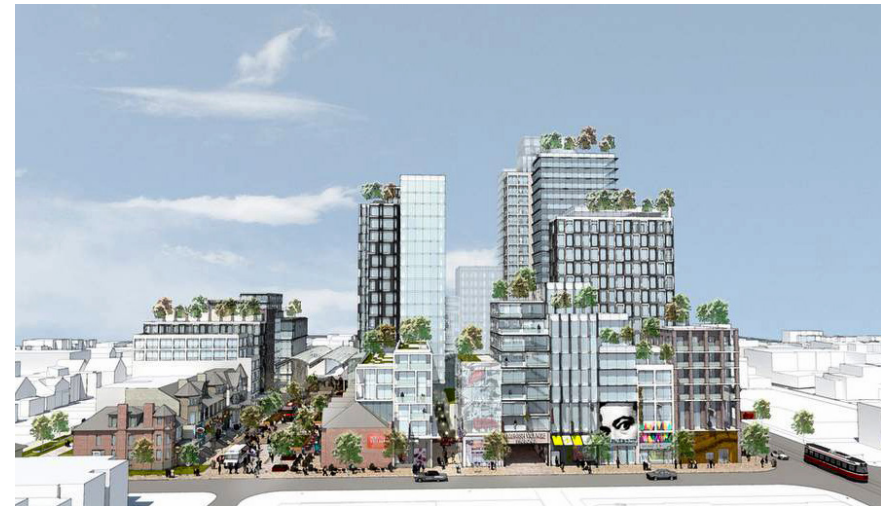

Figure 1.4a

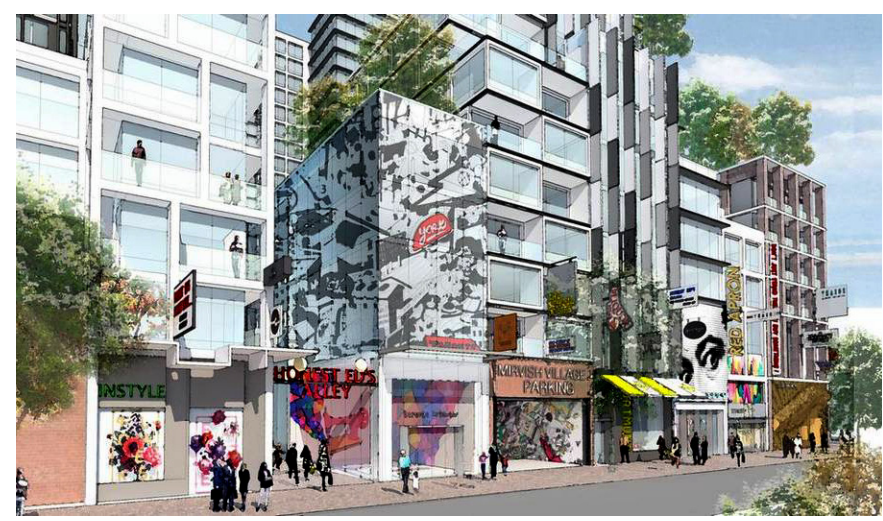

Figure 1.4b: Redevelopment proposal for the current site of the historic Honest Ed's building in Toronto, Ontario, Canada, by architect Gregory Henriquez. 
An alternative to the styles that have emerged from amalgamation of property can be achieved through a change in how ownership is seen and represented in our buildings through their façades. For example, the proposal for the new development at the existing site of Honest Ed's in Toronto, Ontario, Canada, by architect Gregory Henriquez was released in February 2015. This project, figure 1.4 shows a new approach to large-scale city block development by a single owner attempting to regain lost texture in the streetscape through the creation of a connected series of "small buildings" that use façade divisions to "break up the monotony of large-scale development" (A. Bozikovic, 2015).

One way to execute this, and all of the ambitions of the Design For The Cycle principles in the city is through a new ownership model that engages with the currently emerging sharing economy of hacker spaces, community organized transportation, housing rental and many others. Co-ownership development, figure 1.5 , is a further continuation of the ambitions within the sharing economy to allow for the occupants and users of a building to participate in the design, development, and funding of their own building (B. Metcalfe, 2013). This could ensure that the inhabitants specific needs are considered and provides them with the access to influence the design of their spaces directly as an active member of the design team. ${ }^{4}$

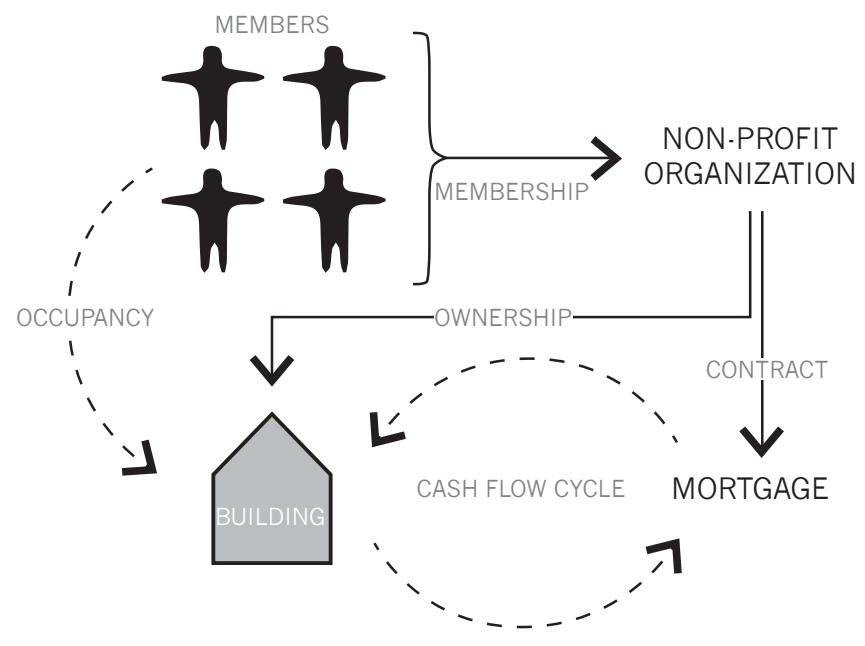

Figure 1.5: Illustration of Co-ownership relationship model.

$4 \quad$ Refer to the email transcripts in Appendix F with Tom Mitchinson, a tenant and member of the board of directors for 2 Sultan Street, a co-owned building located in Toronto Ontario. 


\section{DESIGN FOR THE CYCLE Dynamic Typologies}

The concept of typology, having existed since the late eighteenth century, has progressed through history as two distinct definitions. The first, typology based out of functional properties, defines the programmatic similarities between different buildings such as a house, school, or office building. The second, typology based out of formal properties, defines the physical characteristics that are common among buildings such as a row house, barn, or point tower (W. Braham, 2000, p.1). Rafael Moneo's article, "On Typology," published in 1978 in the magazine, Oppositions: A Journal for Ideas and Criticism in Architecture, defines type as a "group of objects characterized by the same formal structure," and discusses the meaning of "type" as "the act of thinking in groups" (R. Moneo, 1978, p.23). Furthermore, Moneo criticizes how the concept of typology has pigeonholed designers into thinking that its use is static and prescriptive. Moneo describes this as the "frozen mechanism" that architects of his time worked toward repeating endlessly. He challenges this concept with a revision of typology (functional or formal) to act only as the base block by which repetition can be explored, while avoiding the "mechanical reproduction" of ideas (R. Moneo, 1978, p.24). Adding support to Moneo's statements of typology or "type" as something other than a static mechanism, is a more contemporary paper written in 2000 by William Braham, "After Typology: The Suffering of Diagrams". In this paper, Braham illustrates the issue of how the idea of type, even during the post-modernist era of the 20th century, failed to move past the static functionality of its own diagram. By fixating on the reproduction of historical types instead of repetition of underlying concepts, as commonly criticized in Aldo Rossi's work, the designers of the post-modern era "imagined that each historically derived type could invoke the institutions and subjectivities in which it had been originally formed," leading to the reform away from post-modernism (W. Braham, 2000, p.4). For this reason, Braham quotes Quatrèmere de Quincy's work in “Type”:

"The word 'Type' presents less the image of a thing to copy or imitate completely than the idea of an element which ought itself to serve as the rule for a model." (W. Braham, 2000, p.1) 


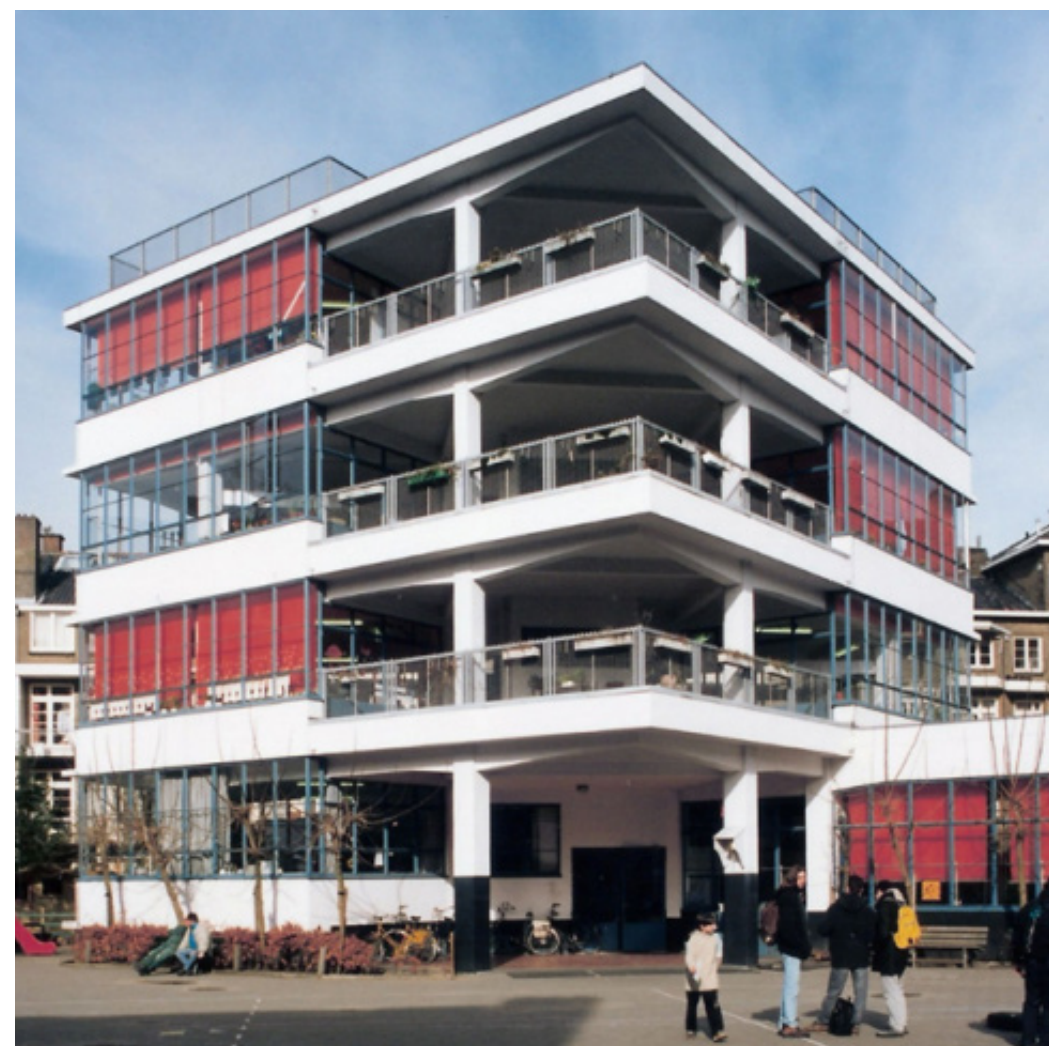

Figure 2.1: Open Air School in Amsterdam. After many renovations the classrooms, once open to the outside balconies, have been enclosed due to issues related to noise and mechanical HVAC. 
We have not yet seen typological forms representing the dynamics of common building life-cycles that include designs for repurpose. Braham questions if this is even possible in any capacity until "every element of the equation is understood [as] interrelated and changeable, from buildings and their context to the designers and their practices" (W. Braham, 2000, p.4). However, it is conceivable to explore the repetition of a typological model that represents, even abstractly, the combined lifecycle of a building's existence.

"The diagrammatic or abstract machine does not function to represent, even something real, but rather constructs a real that is yet to come, a new type of reality." (G. Deleuze \& F. Guattari, 1987, p.142)

In 2012, Christian Kuhn wrote an article for Architectural Review as a part of a series on typologies in architecture. His review on the progression of schools as an architectural type outlines a developing change in the traditional school type to focus on dynamic, flexible, collaborative spaces for contemporary learning styles. Kuhn indicates that this trend in educational design is following principles published by the Organization for Economic Co-operation and Development (OECD) titled, "Key Qualifications for a Successful Life of Well-Functioning Society" that "identified a set of three essential qualifications: 'Act Autonomously,' 'interact in heterogeneous groups,' and 'use tools interactively" (C. Kuhn, 2012, p.61). Kuhn uses this article to discuss the recent trend that is common to both schools and new office spaces that utilize open spaces as interactive and team-oriented work/learning environments. He defines this as "space for teams," based on the OECD guidelines featuring flexibility, clustering, a common core and connectivity (C. Kuhn, 2012, p.60). Kuhn reviews many examples including the Open Air School in Amsterdam, figure 2.1, which features open floor plans to outdoor classrooms, and the Leutschenbach School in Zurich, figure 2.2, with loosely controlled classrooms open to the whole school via a common core, figure 2.3. Unfortunately, many of his reviews indicate that these spaces have been plagued with issues related to internal acoustical control and a lack of daylighting in the deep interior spaces. It becomes very difficult to manage these spaces for user comfort and HVAC control (C. Kuhn, 2012). 


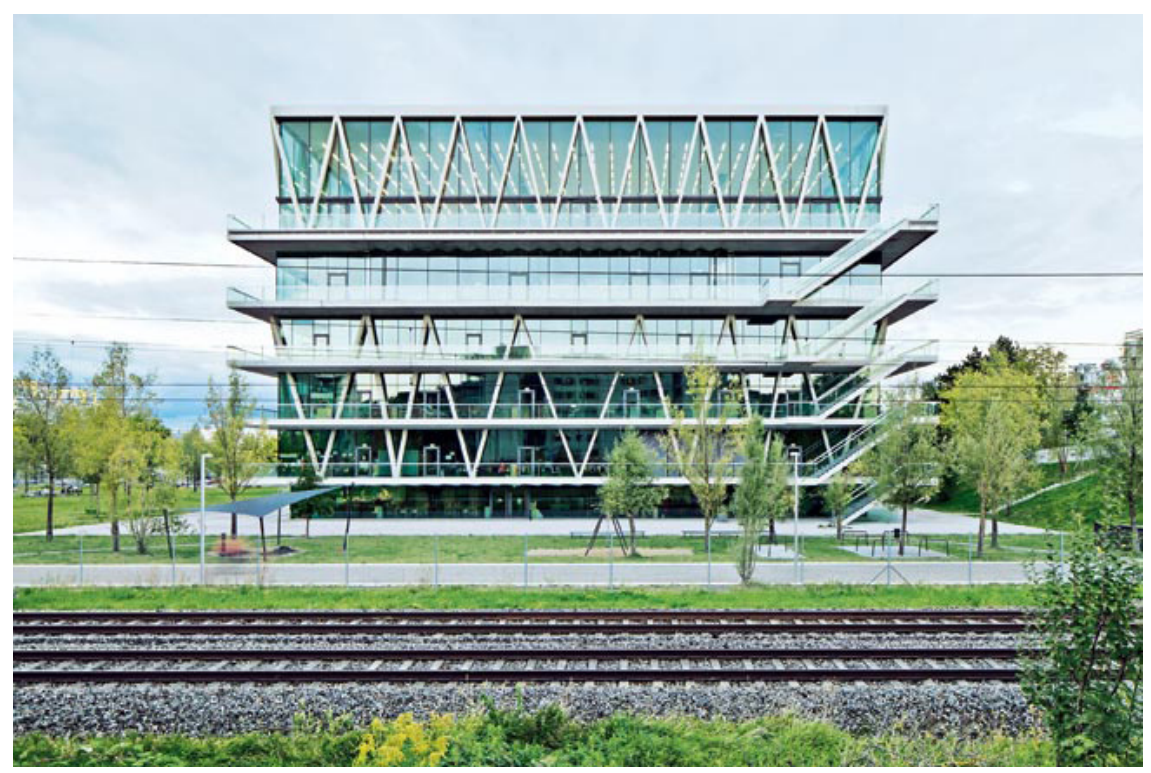

Figure 2.2: Leutschenbach School in Zurich successfully demonstrates the OECD principles of flexibility, clustering, a common core and connectivity.

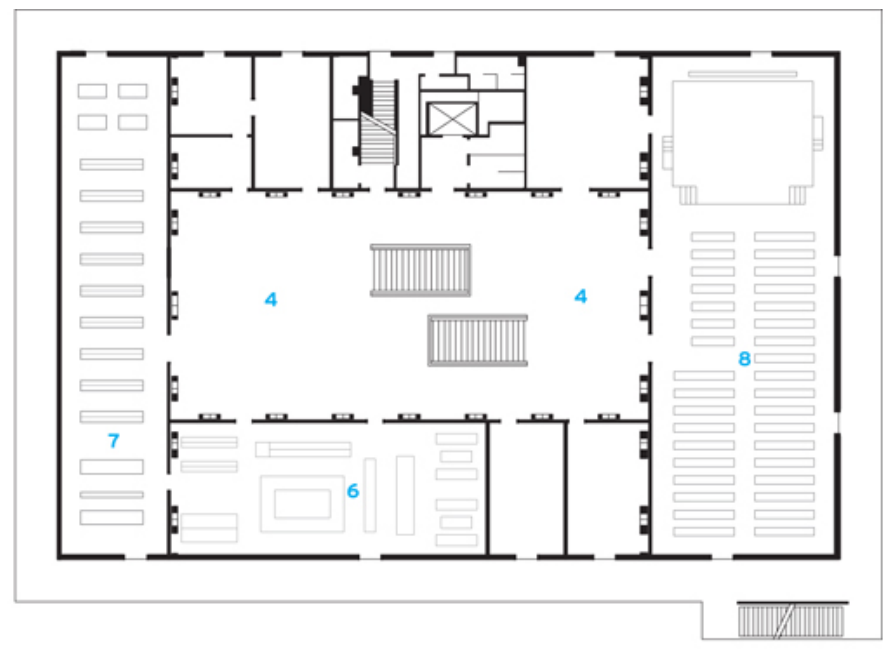

Figure 2.3: Leutschenbach School fourth floor. The school's common hallway (4) opens to above, connecting all of the perimeter classrooms and support rooms $(6,7, \&$ 8) to each other through door-less thresholds. 


\section{Typology Related To The City}

The discussion of Typology is generally understood to be a site-less endeavor. However, if a conceptual model of a specific type is to be successful, some level of contextual understanding must first be established. This is the position that Christ and Gantenbein support in the introduction to their book, Typology - New York, Hong Kong, Buenos Aires, Rome. Their position states, "every architectural design is simultaneously always also an urban design. We cannot design a building without considering the city" (E. Christ, \& C. Gantenbein, 2012, p.4). In doing so, we engage in discussions of how the type of building under consideration responds to its greater context. Christ and Gantenbein claim that type is inseparable from location, and to change the location of the type actively changes the relationship between architecture and its context (E. Christ, \& C. Gantenbein, 2012). Christ and Gantenbein understand typology to be more than just a physical image of form or program, and thus by removing location from typology, the underlying meaning of the type changes as well. For typology to exist without context, it would have to be based solely on the standalone, unalterable, physical image. This immovable image is the central argument against post-modernism revival in William Braham's essay, "After Typology: The Suffering of Diagrams". When a whole typology of buildings within the context of one urban setting becomes "locally calibrated," as Professor Salden would claim, the overall result ends in "good urbanism" (S.L. Salden, 2010, p.12). Salden states, "The solutions must grow out of the conditions of the place topography, climate, material and culture," and in doing so we will have created a "new urbanism" (S.L. Salden, 2010, p.12).

"When the building becomes involved with the city, it can, as it were, grow beyond itself and radiate far into the urban space. The true spatial dimension of the building is then, in the final analysis, the city itself." (E. Christ, \& C. Gantenbein, 2012, p.6) 


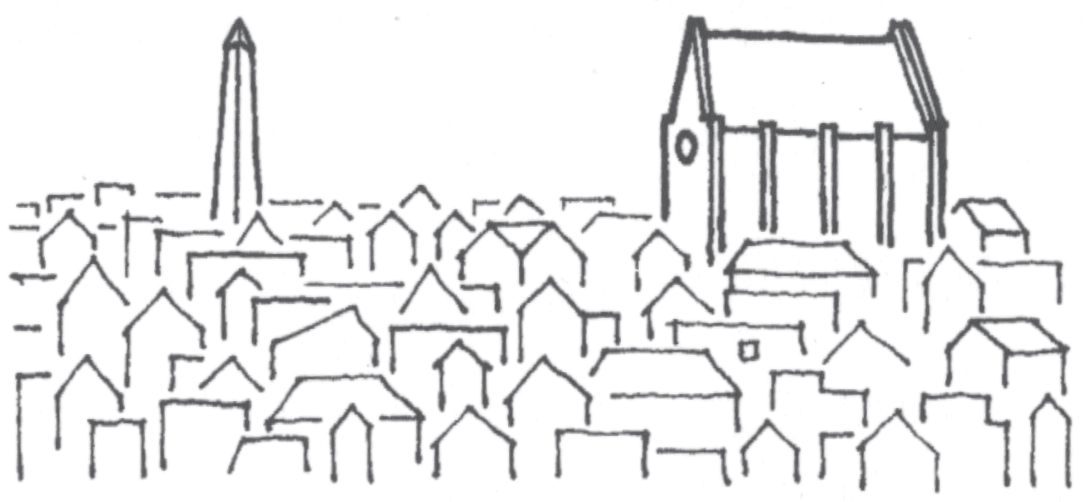

Figure 2.4: Object buildings vs. fabric buildings: "Fabric buildings, or background buildings, are the more numerous buildings of a city. Object or foreground buildings are buildings of unusual importance."

- Matthew Frederick 


\section{Fabric Buildings}

Some of the most persuasive implementations of the typological diagrams are the buildings within a city that form the background fabric of the urban landscape. Having many names such as background buildings, fabric buildings or polite buildings, they exist to accommodate their inhabitants' needs while maintaining the integrity of the urban fabric. In his book, 101 Things I Learned in Architecture School, Matthew Frederick summarizes the usefulness of fabric buildings, figure 2.4, as a way to "form a physically cohesive texture that is indicative of an underlying social fabric" (M. Frederick, 2007, p.89). The cohesiveness of the fabric allows for a robustness to form around the buildings as they forego the need to establish their own individual community connection. The fabric also forms robustness against style and trend, which are highly susceptible to change over time. Lawrence Burton points out this trend in his book, A Choice Over Our Heads, stating that, "predominant architectural themes have typically had little effect on 'polite' architecture," and reviews many examples, including the effect that Gothic architecture had on the overall urban fabric buildings within a city (Burton, 1979, p.28). The minimal elements that are picked up from each stylistic era have resulted in a robust, timeless diagram indicating that the fabric structures of a city may contain values that could lead to a naturally sustainable matrix of typologies, as suggested by Professor Salden.

Forsyth and Crewe, two urban design researchers, published their work in the Landscape Journal of 2009 titled, "A Typology of Comprehensive Designed Communities Since the Second World War". In this article, they indicate the importance of paying particular attention to things that are generic in nature, yet frequently overlooked. Too often, the standout projects of symbolic importance that 


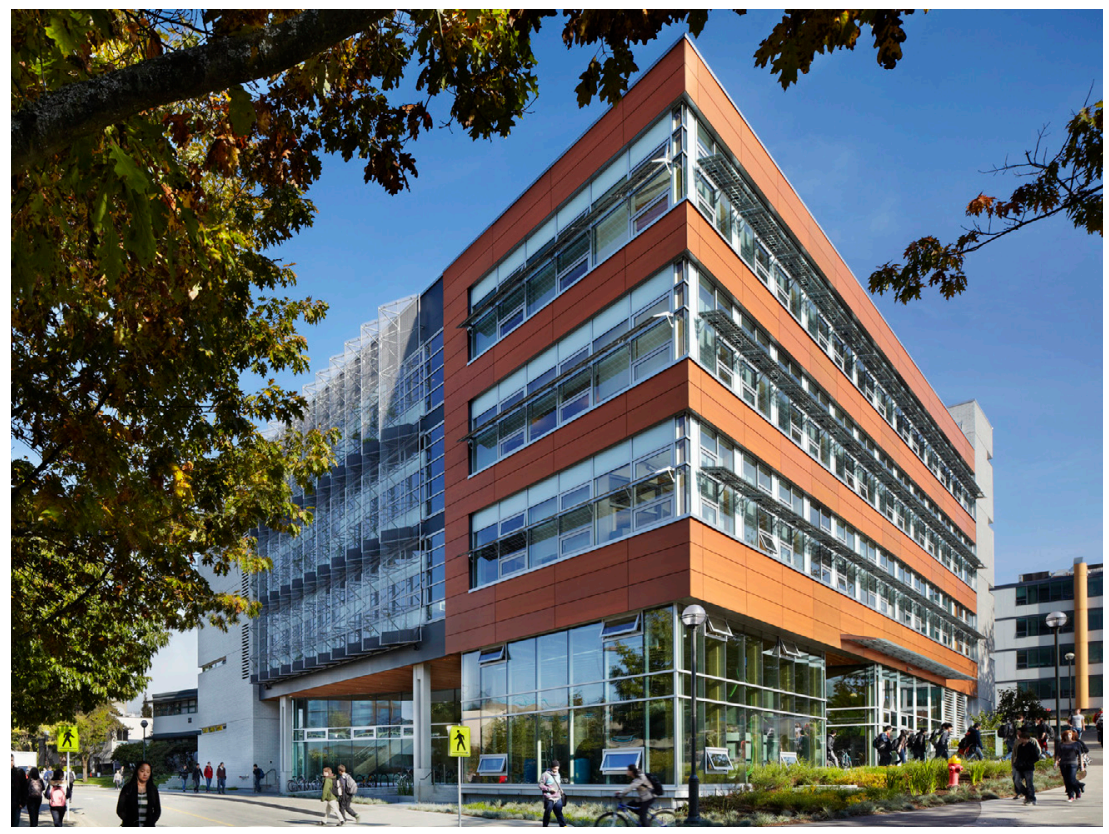

Figure 2.5: The UBC Campus Centre for Interactive Research is an iconic demonstration project showing off the of the capabilities of heavy timber construction and advanced environmental design.

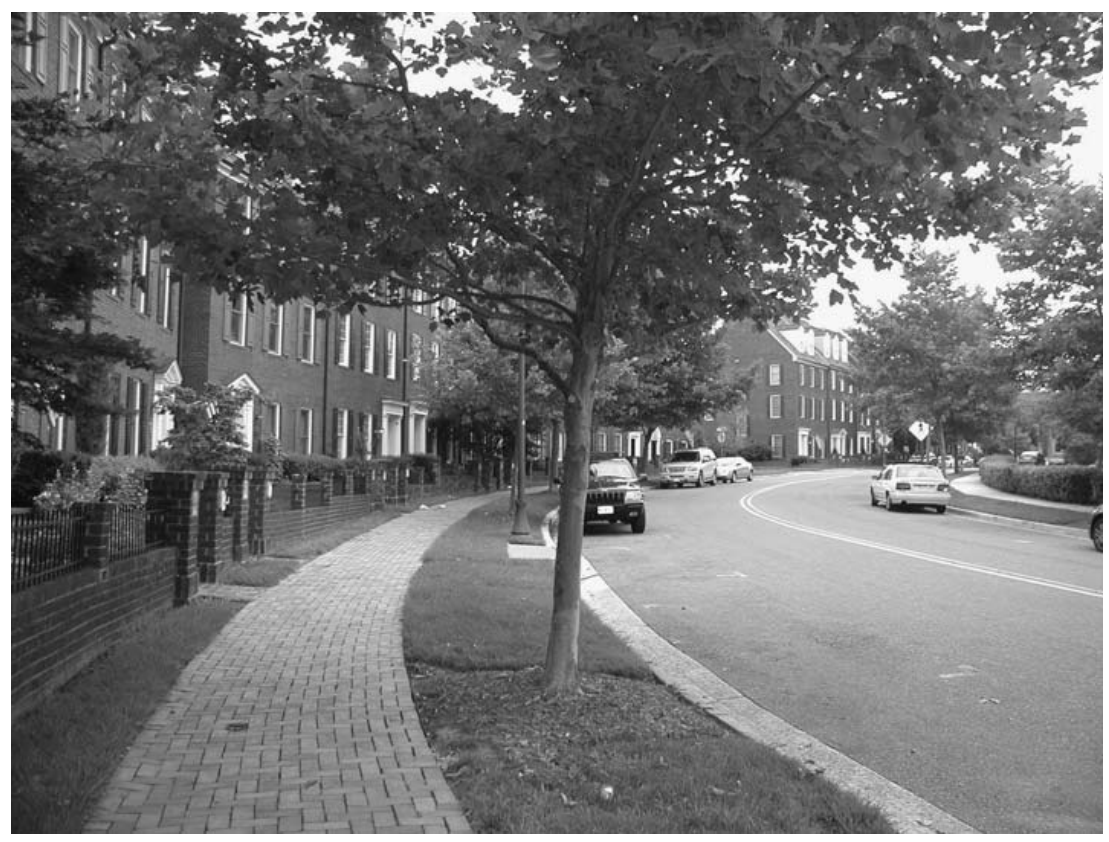

Figure 2.6: Located in Maryland, the neighbourhood Kentlands, is one of the focus studies for Forsyth \& Crewe due to its generic organization and properties. 
gain recognition are over-criticized due to their celebratory status, such as the UBC Campus Center for Interactive Research, figure 2.5. In contrast, case studies of generic development, such as Forsyth and Crewe's study of the Kentland community neighbourhood in Prince George's County, Maryland, figure 2.6, are in need of such attention, and require stricter criticism and study to improve conditions for the mass scale (A. Forsyth \& K. Crewe, 2009). The overall fabric and individual buildings imbedded within have developed their robustness over time, and it is through their study that we can successfully establish and implement guidelines that work towards approaching a sustainably viable urban fabric.

\section{Typologies Matrix}

A Typology Matrix, based on the suggestions of Professor Salden's "naturally sustainable matrix of typologies" has been assembled for this project in the city of Toronto. It consists of information gathered from approximately 6000 buildings located in the Toronto core area, organized by programmatic typologies. The building data, retrieved from the TOBuilt.com website, has been consolidated and organized based on buildings that have undergone repurposing in the city of Toronto resulting in a change of occupancy type, reducing the 6000 total buildings to 422 retrofitted projects (B. Krawczyk, 2010). Through the extrapolation of this information, 144 buildings were selected as feasibly relevant for further study based on building scale and appropriateness of their typological category, figure 2.7. The analysis done on these 144 buildings revealed that 41\%, the highest percentage of post-repurpose program resulted in residential occupancy. The post-repurpose residential occupancy is also the most diverse, comprised of many different programmatic and formal typologies when compared to the other categories of post-repurposed program types, figure 2.8.

The collection of these buildings, having undergone at least one change of use, can be studied to learn what successes and failures occurred that allowed them to proceed through their life-cycle to overcome threats of obsolescence, and to further understand how we might design new buildings that may have similar successes throughout their own life-cycles. 


\section{Pre-Retrofit Program Type}

Industrial

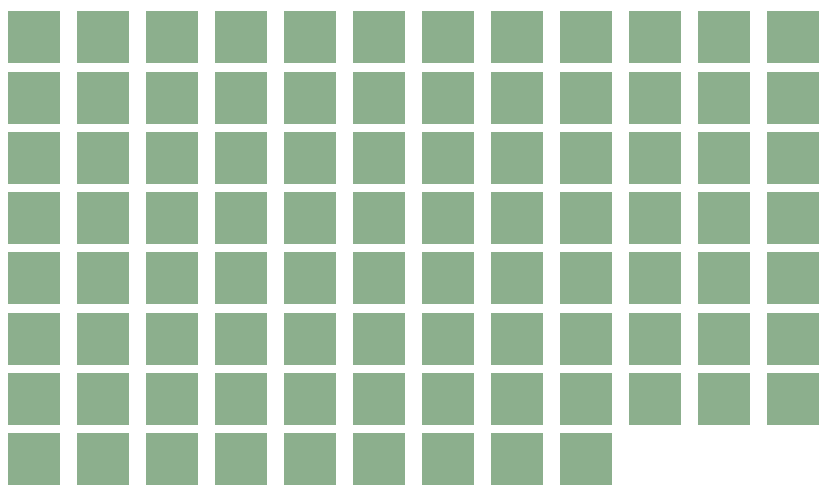

Office

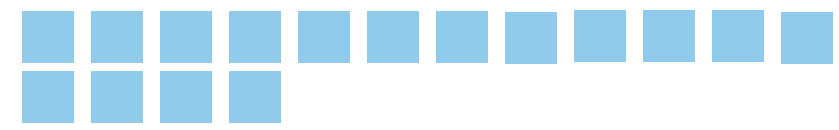

Religious

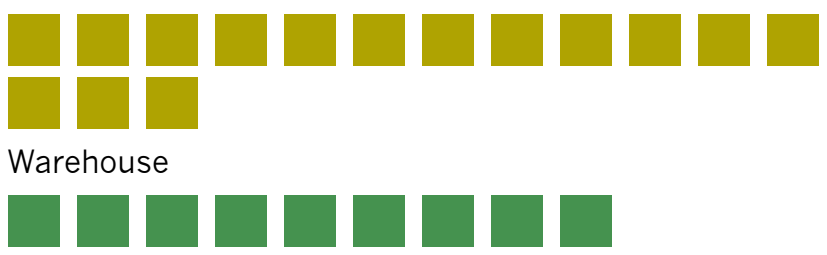

Miscellaneous

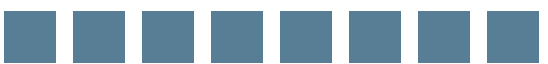

Educational

Figure 2.7: Pre-Retrofit, the matrix shows 144 selected building from the Typologies Matrix Database in Appendix E. 


\section{Post-Retrofit Program Type}

Residential

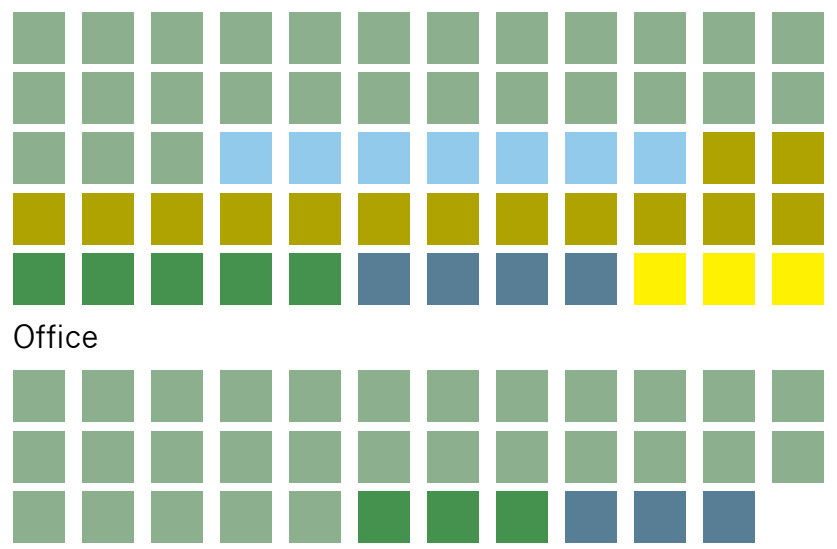

Commercial

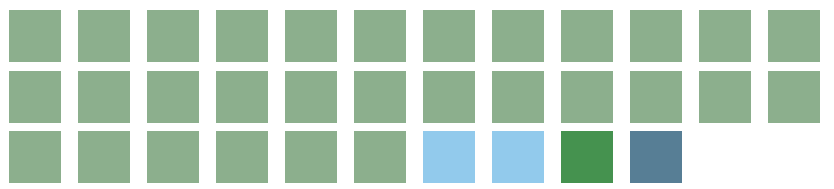

Cultural

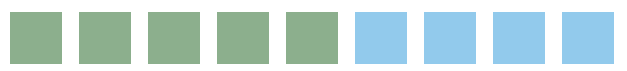

Educational

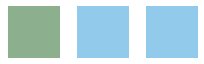

Miscellaneous

Figure 2.8: Post-Retrofit, the matrix changes to show the resultant programs of the selected 144 buildings. The residential program contains the highest number of buildings from the most diverse subheadings in figure 3.7 


\section{Backcasting}

In order to understand how studying the trends in existing buildings can help to develop future tools for building design, a process of backcasting was used to understand the problems and possible solutions that could occur over a new building's life-cycle. As described in Mattias Höjer, Anders Gullberg, and Ronny Petterssons' book, Images of the Future City, the process of backcasting can be described through 4 steps: "establish criteria and goals," "investigate if the goals and criteria formulated are far from today's situation," "developing images of the future," and the "implementation [of] paths to reach the images of the future" (M. Höjer, A. Gullberg, \& R. Petterssons, 2011, p.13-14). By projecting forward 100 years, to a time when the buildings we've erected today are seen as historical fixtures within the fabric of a city, we can hypothesize how these buildings will be perceived and what the nature of their relevance to the city's fabric throughout their life-cycle will be. Without attempting to accurately predict what the specific futures of these buildings will be, the following section will project a scheme of idealized desires based on contemporary eco-movement initiatives to provide a framework for a scenario in which an equilibrium is reached between our built environment and the biosphere.

In a lecture delivered at Ryerson University, November 20, 2014, Professor Alexander Hay reviewed a similar strategy of backcasting as a way of building in today's context for resiliency against natural and man-made disasters. His strategy seeks to update our definition of politically defined regions of land, and further break down neighbourhoods into community focused areas that bear their own defined identity. Infrastructure and leadership organize into a robust network of inter-community links that provide resiliency for an entire city from disaster events, such as flooding and power outages. In this model, disaster evasion is the primary goal for the synthesis of communities and allows for a new typology of buildings to accommodate this change. By expanding the purpose of this network to include, for example, how ownership may be dealt with, greater societal problems can also be tackled at a neighbourhood scale across the city. By manipulating the purpose for the design of a building as the measure for a successfully implemented typology, a new typology for fabric buildings can be proposed. It is comparable to Frederick Kiesler's 1930's theory of Correalism, which William Braham used to show "the limitations of a functionalism based on fixed needs" determining that 
the direct implementation of a typology does not necessarily result in the successful reanimation of the typology's history, associative meaning, or purpose (W. Braham, 2000 , p. 5). Braham uses Kiesler's work in his essay, "After Typology: The Suffering of Diagrams" to criticize post-modernism's failed attempt at recalling the lost history and memory of pre-modernism movements. According to Braham, the purpose of any attempt to rebuild something in a specific typology was doomed due to the inflexibility of the physical image of that typology as the resulting purpose for design. Kiesler's theory, figure 2.9, was noted as addressing the health of the occupant, not the physical typology, as the intention of any design, thus foregoing formal and programmatic type altogether.

"Man = Heredity = Environment. $\mathrm{M}=\mathrm{Man}, \mathrm{H}=$ Human Environment, $\mathrm{T}=$ Technological Environment"

"No tool exists in isolation. Every technological device is coreal: its existence is conditioned by the flux of man's struggle"

Figure 2.9: Frederick Kiesler's statements of intent for his theory on man and his well-being the center focus for design. Reproduced as seen in W. Braham's Essay Correalism and Equipoise

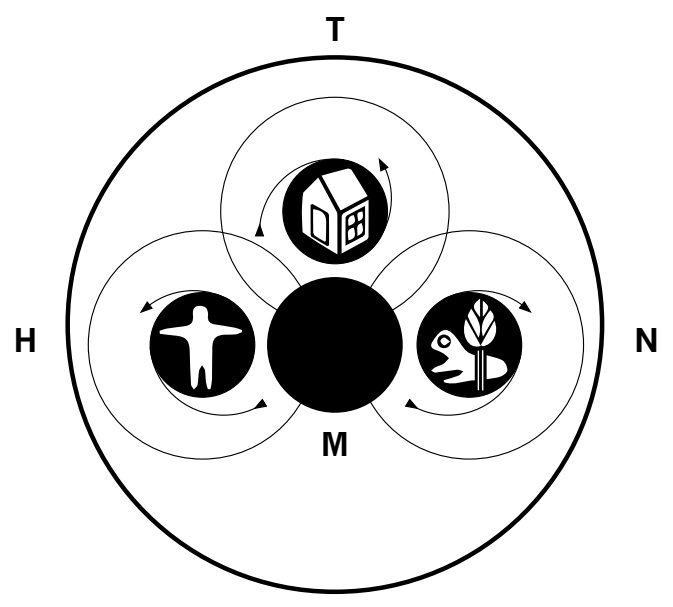


The success of a typology relies on the purpose for which it is built, thereby creating a new typology through the change in purpose for which a building was conceived. Hay's future exists with a purpose of shared robustness throughout a city in a familiar form of community identity, commonly acknowledged in the Toronto neighbourhoods, which has been defined and mapped by the Toronto newspaper company, The Toronto Star, continuously since 2009 through shared consensus of "broad patterns" of cultural division and community input. By using the Toronto neighbourhoods seen in the map, figure 2.10 on the following page, as a means to divide the city, community models of ownership, heating/cooling, energy production, recycling and manufacturing can be proposed at a realistic scale of implementation within these boundaries.

The purpose of this future projection is to determine a path for achieving an equilibrium between communities for sustaining urban development. A mixed-use building integrates a co-ownership economic model into the community to share and actively partake in structural, energy, space conditioning, waste and manufacturing decisions as an invested group. This is an idealistic 100 year projection that raises the questions regarding what needs to occur now to push this goal forward.

Working from the principle of designing first for human habitation, the program of a building that acts as city fabric for residential and commercial office spaces can be defined by four new categories defined either by grey space intended for hardscaped urban environment or by green space intended as a garden oasis environment: 1 , Grey spaces for human function; 2, Grey spaces for human leisure; 3, Green spaces for human leisure; and 4, Green spaces for human function. Each of these four program principles can exist within the primary grid of the fabric, or be brought outside of the grid to express an important moment in the expression of the project, or provide the inhabitants with a contrast point to the rigidity of the set dimensions. 
1. Grey Spaces for human function: are programmed spaces that incorporate the usual function of fabric buildings within a city. The placement of flexible space through tractable primary units contain the functions of living, working and mercantile use and are distributed along the avenues as a continuous urban fabric.

$2 \& 3$. Grey and green spaces for human leisure: are leisure garden spaces that are reclaimed public spaces. These areas would take the place of small parks and existing backyards at both the levels of private tenant and public user, depending on location and intended access. The management of green spaces in the city would then shift from government operated to private partnerships with the building developers. These green and grey communal spaces would allow for shared backyard and front yard areas to exist in a more evenly distributed scheme across a neighbourhood, and at a more personalized scale for the inhabitants within the building on the street. These spaces can occupy the city fabric as voids between the grid systems or as a void unit within the grid. ${ }^{5}$

4. Green spaces for human function: are garden spaces within the building that function for the greater purpose of the biosphere and our human relationship to it. This program element can manifest as a community garden, a backyard garden or, in general, a space for food production and preservation urban wildlife habitats. Similarly, as discussed in numbers $2 \& 3$, where personal outdoor space is typically lost in the densification of a neighbourhood, this functional green space is aimed at recapturing the lost growing potential and habitat of such spaces. If managed properly as a neighbourhood resource, the growing potential of the green spaces could join together across the building fabric greatly increasing their growth potential.

5 Refer to chapter "The Design Toolkit: Private Owned Public Space" 


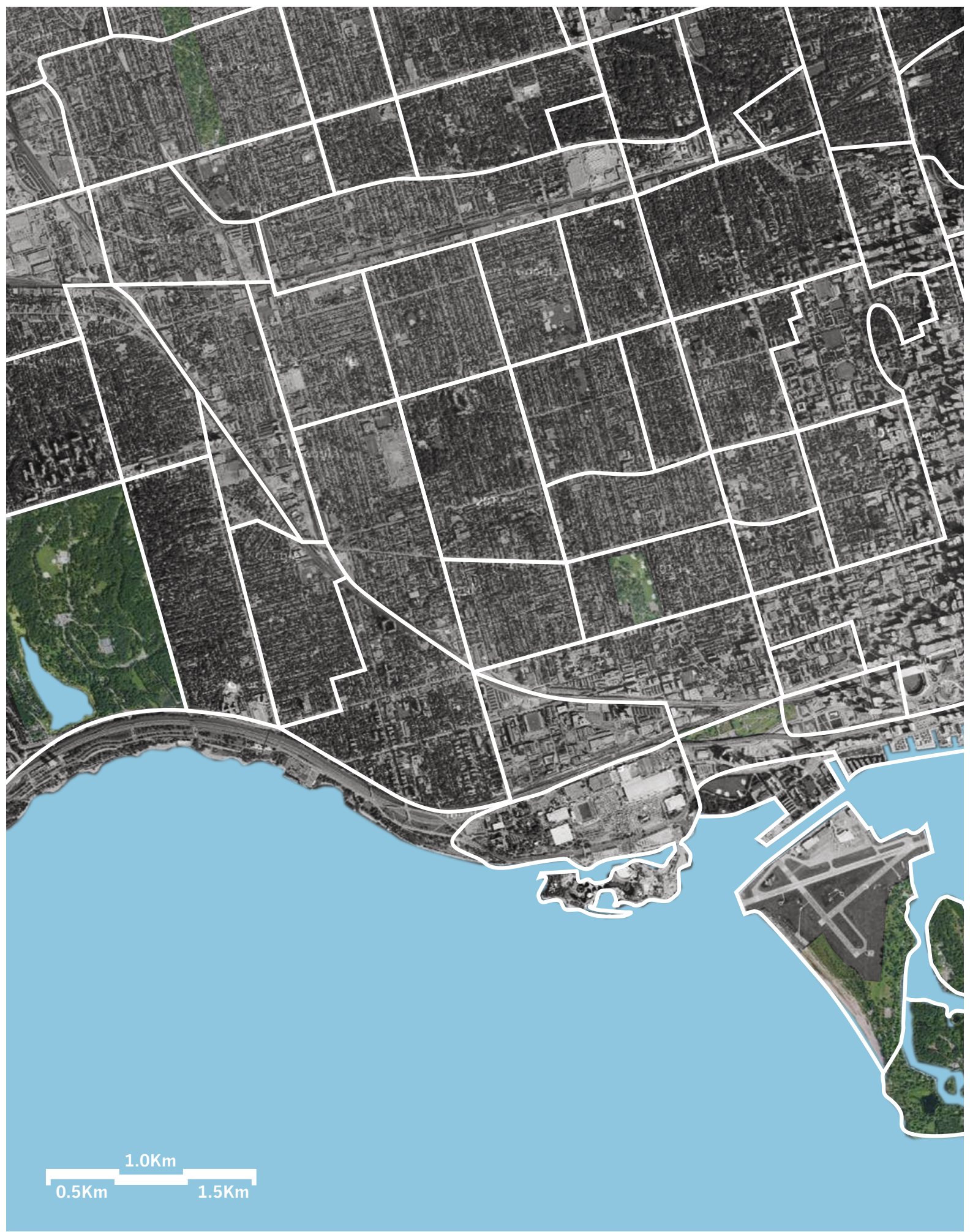

Figure 2.10: Toronto neighbourhood boundaries as defined by The Toronto Star Newspaper. 


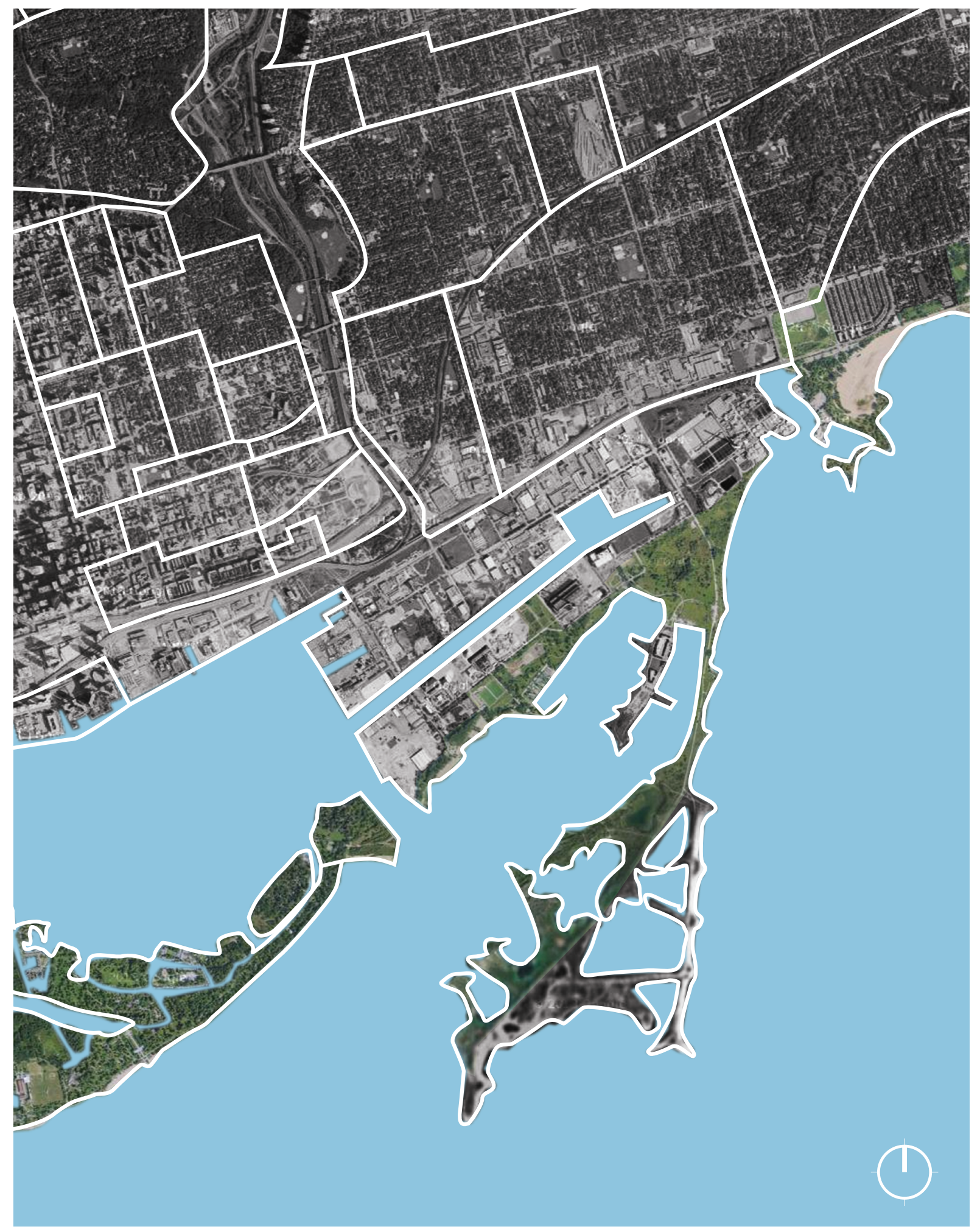




\section{DESIGN FOR THE CYCLE GUIDELINES Guideline Sources}

Based on current thinking concerning urban resiliency and design for repurposing, guidelines to establish a new typological framework for fabric buildings are proposed through the exploration of repurposing patterns in Toronto. A set of principles and its relevant applications will be formulated into typological patterns by further analysis of the forthcoming investigations. These strategies allow for a basic framework of architectural intervention to develop. Their development is intended to architecturalize the city's fabric by inserting underlying principles that represent the cycles of material, energy, and cultural values of the neighbourhoods and city in which they exist.

The development of these guidelines is a direct reflection of the outcomes from the review of thirty-two Toronto buildings studied in the Building Analysis for key proportions, design process interviews, and their relationship to the city policies that govern new buildings and how they are designed and constructed. The Avenues and Mid-Rise Study, the government policy that is reviewed in this thesis, already discusses many strategies related to a building's massing and street presence, many of which support a continuous building fabric across Toronto's main arterial streets. Much of the analysis derived from the Avenues and Mid-Rise Study can be further refined through the developed dimensional proportions found with the Building Analysis that support an overall tractability within a building's structure and interior layouts that are accommodating to changing needs over time. 


\section{Avenues and Mid-Rise Study Analysis:}

The Avenues and Mid-Rise Study published for the City of Toronto sets up boundary conditions, adjacencies and visual rhythm to the fabric building of the city. The guidelines located in the Performance Standards chapter of the document, first review the height maximums and minimums governed by a localized street crosssection. Reflecting on the building analysis in the previous section of this thesis it is recommended that the Avenues and Mid-Rise Study be revised to re-align their numerical guidelines such as minimum heights, that reflect the averages found from the existing buildings in the analysis. (Brook Mcllroy Planning + Urban Design/ Pace Architects et al., 2010, p. 42).

Referring to guidelines 8 and 9 of the Avenues and Mid-Rise Study, which deal with adjacencies of mid-rise buildings, further focus can be placed on the arrangement of shared party walls so that the thermal resistance properties of an adjacent building can be incorporated into the development of new adjacent buildings (2010, p. 72). By panelizing the adjacent wall's cladding with a curtain wall system, the direct integration between shared property lines may be used. As already defined by guidelines, the panelizing of such walls would allow for pattern-based surfaces to stimulate visual interest while the building wall is left exposed. The extension of the building street wall along an avenue through the development of adjacent sites shall also be revised to match the outcomes of the building analysis. This is further discussed and illustrated as a design strategy in the following chapter.

Guideline 10 of the Avenues and Mid-Rise Study discusses the convertibility of nonretail space, such as ground-level residential units, to be used for potential retail programs in the future, and promoting an end goal of mixed-use developments (2010, p. 78-79). This strategy speaks to a broader intent for the types of spaces designed into the mid-rise fabric buildings, defined by this study as having the potential for various configurations of program and ownership throughout each site. It is proposed that this guideline not be isolated to just the ground floor, but should extend upward through the building to create a system of tractable "loose program" for every major space within the fabric buildings of the city. 


\section{Building Analysis}

The thirty-two buildings in the detailed analysis were selected to cover a range of typologies that represent the larger data set of the typologies matrix. All of them, having successfully undergone a process of repurposing at least once in their lifecycle, were evaluated for their versatility of space, adaptability to program, and various proportions that limited the ability for changes within the process of their conversion. For evaluation, this detailed analysis looked at twenty-five of the buildings primary massing proportion, height, bay sizes, floor-to-floor heights, as well as ratio of openings on the building's façade, figures 3.1 to 3.3. The projects selected for this analysis were exemplary illustrations of the minimum and maximum ratios of the proportions deemed worthy of saving. The conversion of these projects showed, in many cases, atypical yet successful examples of work and living spaces that oftentimes had proportions of fenestration, floor heights, etc., deeming them inappropriate in newly constructed projects.

Appendix B contains the building names and numerical findings from the study. Appendix $\mathrm{C}$ contains the photographs, sketches, and drawings of the study.

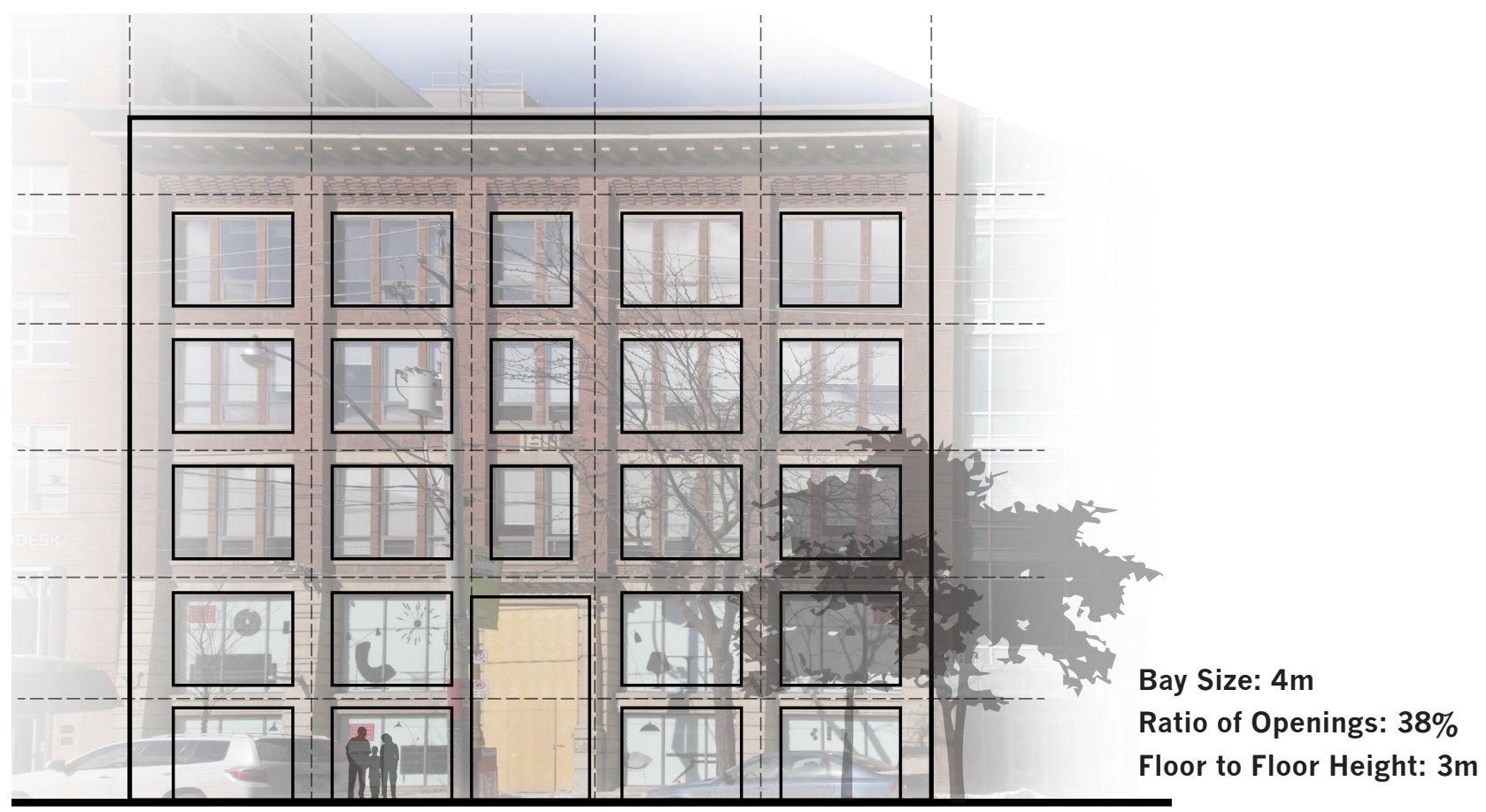

Figure 3.1: W.A. Drummond \& Company Dairy Supply Warehouse, 214 King Street East, Toronto Ontario. 
In addition to the numerical study of proportions and ratios inherent in the selected buildings, their architects were contacted to discuss additional properties that existed within the organization of the buildings and the designs for repurposing. The first interview was conducted on October 20, 2014 with Chris Radigan of Teeple Architects at their office in Toronto, Ontario, to discuss the repurposing of the 180 Shaw Street school to the Youngplace Artscape building. The interview focused primarily on a strategy of "program-less design" due to the unknown nature of the tenants and possible uses of the building during the design phase. Mr. Radigan suggested that the structural base of the building or the "basic image" of the building, is what allowed for the successful conversion of a project already integrated into the community through its deep connection to the neighbourhood's history.

The second interview was conducted on October 27, 2014 with Janna Levitt of LGA Architectural Partners at their office in Toronto, Ontario, to discuss the repurposing of an industrial building to the noteworthy project Strachan House. Janna Levitt suggested that the project's continued success hinged on the appropriate management of the social aspects within the building. In addition, the ability to

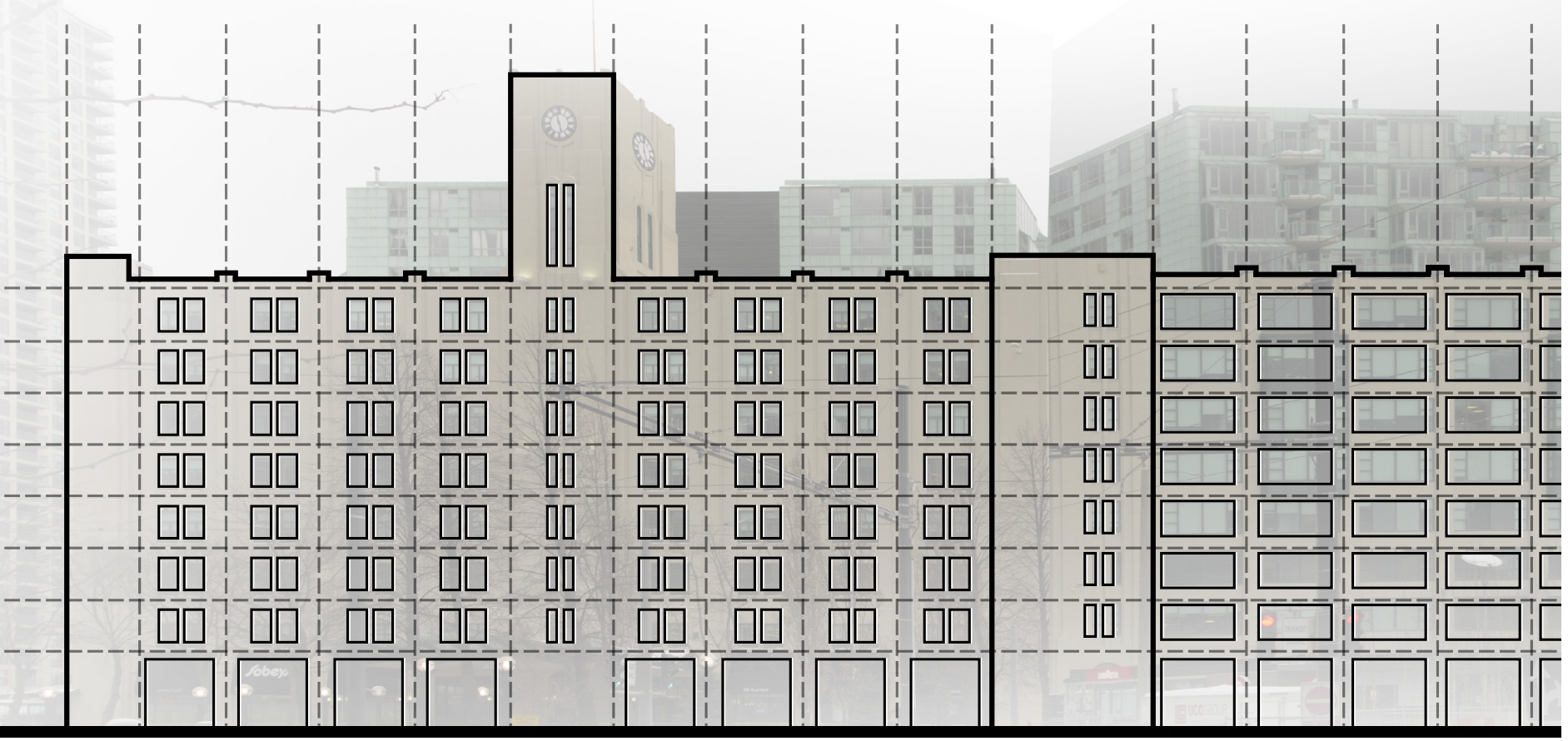

Figure 3.2: Queens Quay Terminal Building Analysis, 207 Queens Quay West, Toronto Ontario. 
cut slabs and structural elements in order to reconfigure the space provided the flexibility needed to pull off a "town hall" type of space organization, completely changing the landscape of the interior of the building. This strategy proved difficult due to the permanence of the cast-in-place concrete structure, but allowed for an urban design strategy of meandering public streets to permeate through the building from King Street and Tecumseth.

The third interview was conducted on October 29, 2014 with Michael Mclelland of ERA Architects at their office in Toronto, Ontario, to discuss the repurposing of 3 projects within the detailed building analysis of this thesis. The conversations of Wychwood Barns, The Abbey Lofts, Gemini House and various other ERA projects opened a discussion on the importance of breathable, activity-based designs that rely on low-tech approaches to provide flexible space.

Overall, each of the three interviews brought insight into the general need for robustness throughout structure and a flexibility, what Michael McClelland calls "loose program," that allows for the value of a successful conversion to be considered over the building's demolition.

Appendix E contains a full transcript of each interview.

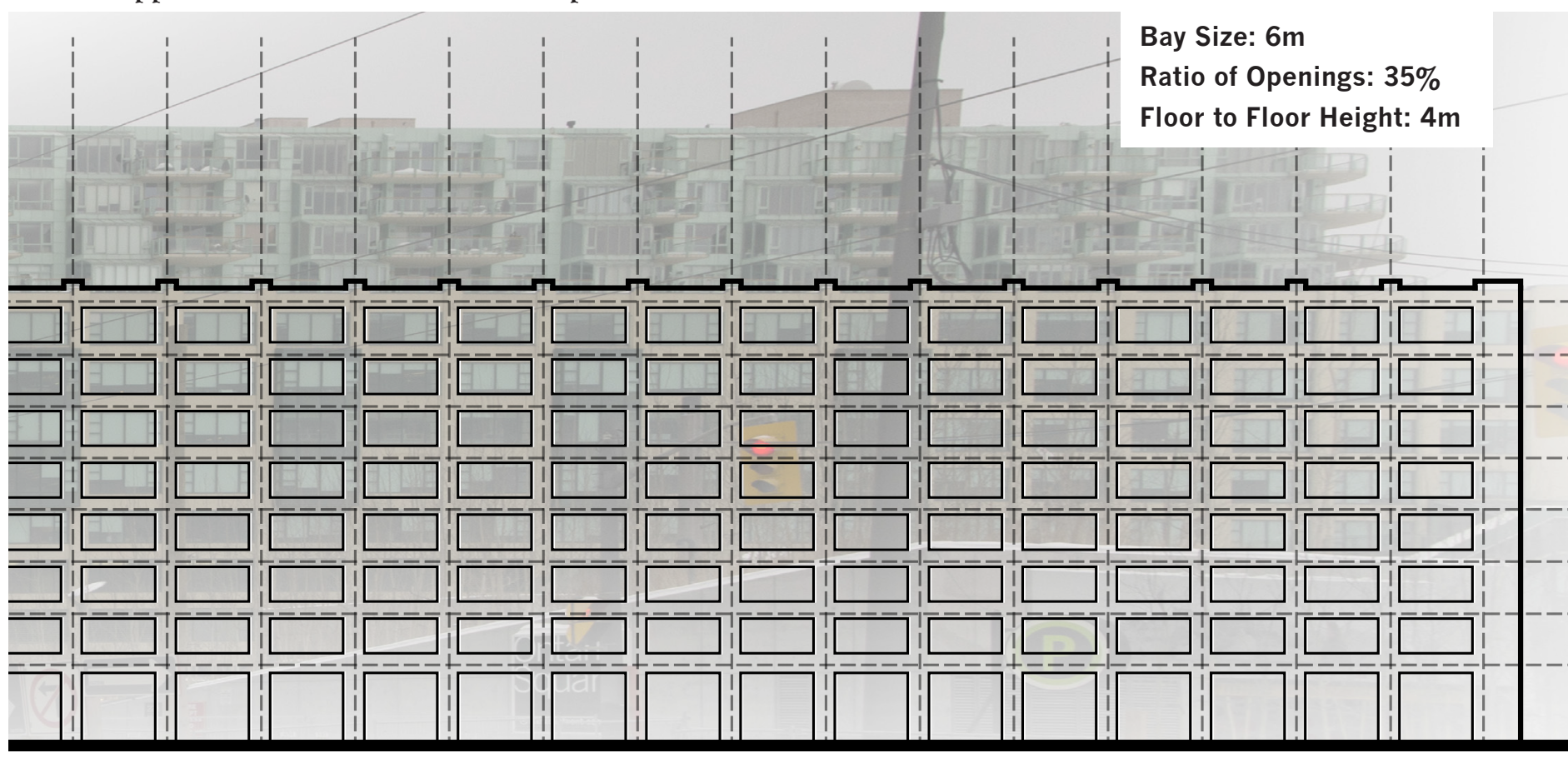


Utilizing this study, design strategies were created to place priority on the parameters reviewed from each building in order to establish a hierarchy for the ultimate goal of creating successful conditions for repurposing a new building at various times throughout its life-cycle. Versatility of the overall enclosed building space through the manipulation of components allowed for this to happen, and guided the direction of the design strategies. This strategy allowed for a range of different material systems to be applied, establishing that the overall scheme was not dependent on specific technologically driven components. Ultimately, the tractability of overall structure and individual structural components were established to reduce the need for future material input and waste during a changeover of program or space use.

The following series of strategies deal with suggested proportion of floor area and height, massing and building expansion, public access, and componentization. The floor area and height of the proposed strategies were a first and necessary step to organizing the overall Design For The Cycle system through the discussions with designers from the within the city as well as the Building Analysis. The findings of these processes indicated that a rigid unchangeable structural system was one of the greatest limiting factors within a renovation for repurposing. This drove a unit of measurement for the massing capabilities of a building designed using this

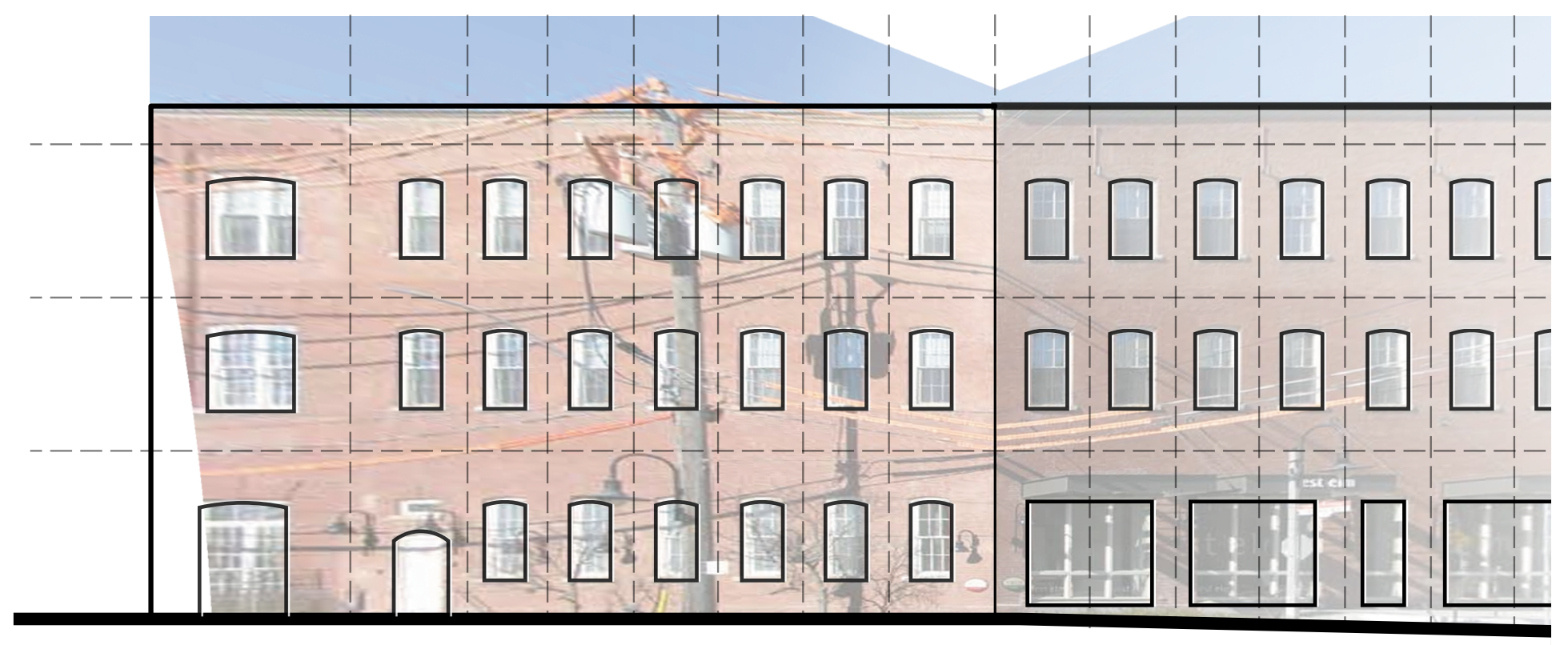

Figure 3.3: Barrymore Building Building Analysis, 109 Atlantic Avenue, Toronto, Ontario. 
system and suggested possible ways in which a building could expand outward from its site. Realigning the Avenues and Mid-Rise Study guidelines to match with these proportions further informed the developed strategies to accommodate for the many reasonable intentions that were proposed by the City for mid-rise buildings in Toronto. In addition to dealing with structure and massing, the following strategies take on a further ambition that was established through the backcasting exercise in a previous chapter. The accommodation for public space owned by private developers and access through the site to laneways behind the building fabric was the result of the potential for sustainable urban lifestyles achieved through cultural and regulatory ownership models. Through a change in how these buildings are integrated into the city there is potential for shared space that can help to reinforce the community aspects necessary for urban sustainability. By focusing on the reorganization of components as a tool for development, the componentization of materials as a strategy further reinforces the intentions of the Design For the Cycle system. This is done by shifting energy expenditure from the creation and destruction of single use components into the creation of components for movement and continuous reinstallation. With the intent of developing various scales of strategies within the Design For The Cycle system, the city's future resiliency and efficient repurposing will be addressed for mid-rise city fabric buildings along the Toronto Avenues.

Bay Size: 3m

Ratio of Openings: $24 \%$
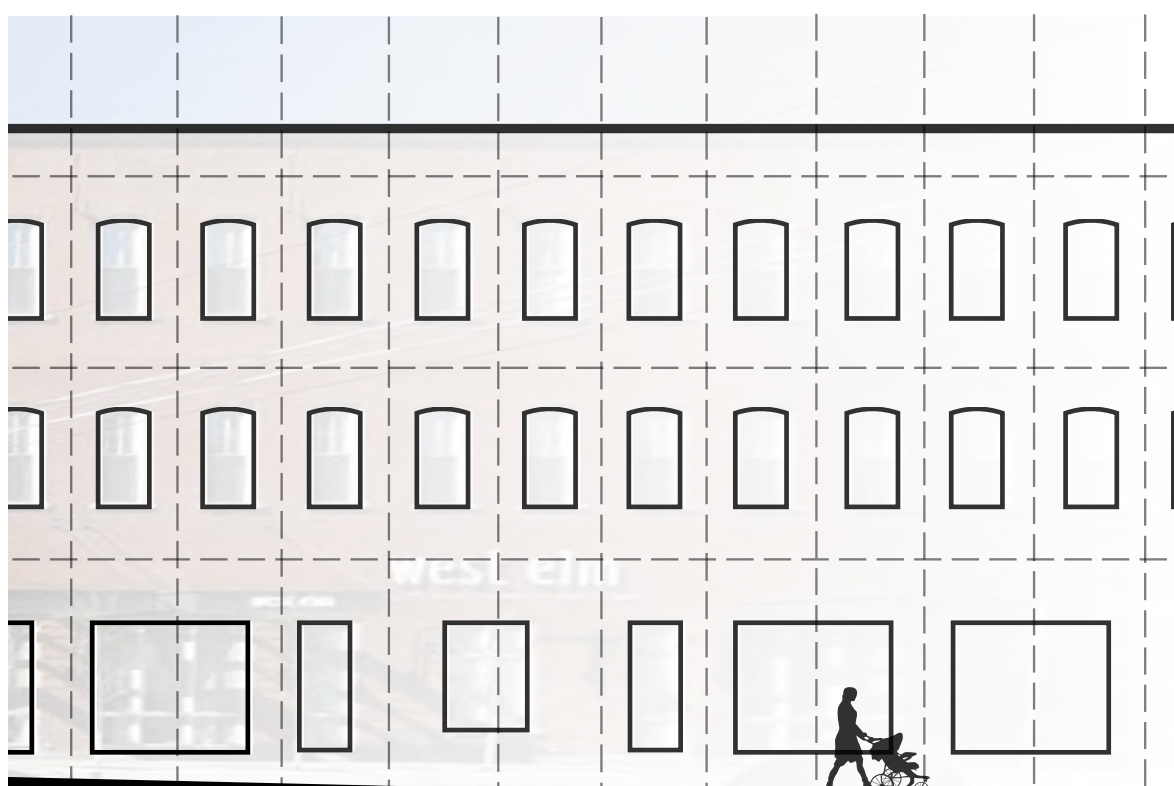

Floor to Floor Height: $3 \mathrm{~m}$
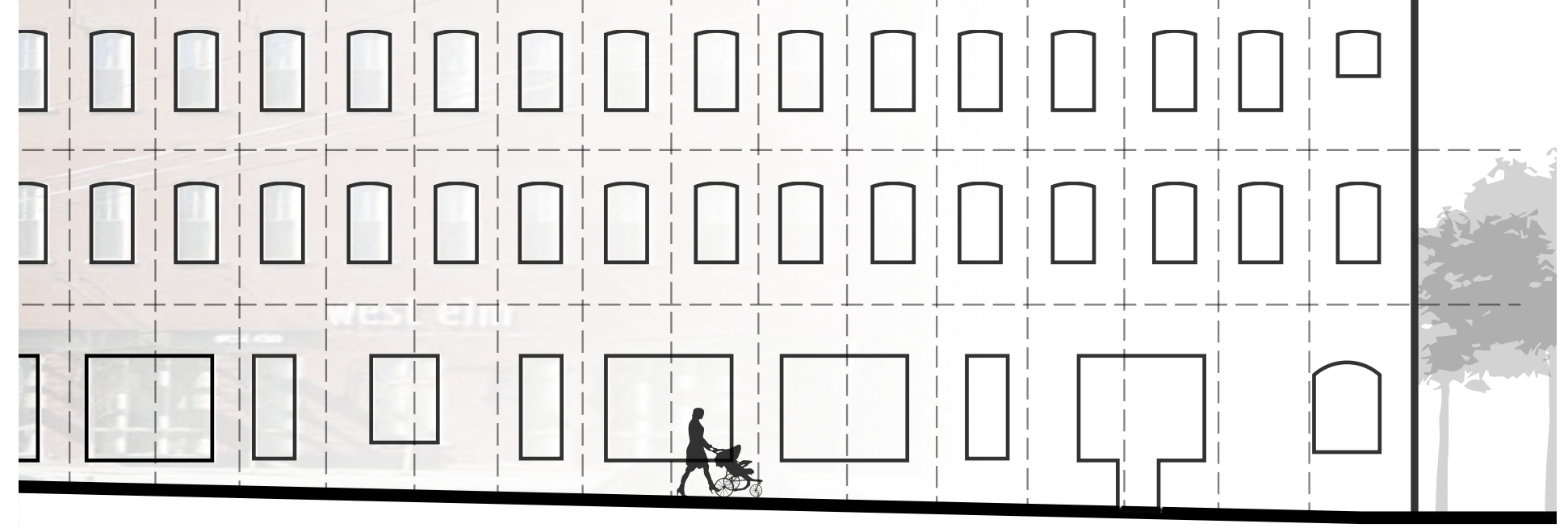


\section{DESIGN STRATEGIES}

\section{Structural Grid}

\section{Description:}

Placed on site is a uniform grid, optimized to facilitate the most flexible breakdown of space. Working with this initial unit, the grid is applied to the entire volume of the intended enclosed space. The major grid lines indicate a primary unit, and secondary units divide each primary into 4 segments. The primary unit, set to $12 \mathrm{~m}$ $\mathrm{x} 12 \mathrm{~m}$, is therefore divided into $6 \mathrm{~m} \times 6 \mathrm{~m}$ cubes indicating the secondary unit, figure 4.1. Load bearing structure is located at the primary structure intersections. Secondary units are defined as interior space divisions that are suspended from the major structural components. This variation allows for combinations of $6 \mathrm{~m} \times 6 \mathrm{~m}$ floor areas to be defined, removed and joined into larger $12 \mathrm{~m}$ spaces.

\section{Rationale:}

In the Typological study, it was found that the articulation of bays on the façade indicated grids divisible by $12 \mathrm{~m}$ allowed for the most versatile use of space. The $6 \mathrm{~m} \times 6 \mathrm{~m}$ configuration, specifically found in the Queens Quay Terminal building, provided a robustness in structure, yet offered enough flexibility to be organized into office, residential and work areas for the commercial spaces below (D. Shalden, 1983, p.14). Buildings are structured and designed with very specific structural requirements to accommodate the intended first use of the building. The strategy proposed allows for multiple configurations of space within the greater $12 \mathrm{~m}$ bay sizes, and thus may accommodate much greater flexibility throughout the underlying grid. The use of structural columns and beams along the grid axis to provide lateral support through the use of moment connections also reinforces the idea of space accommodating change over time, and is accomplished by the elimination of shear walls that limit the usability of space throughout the grid.

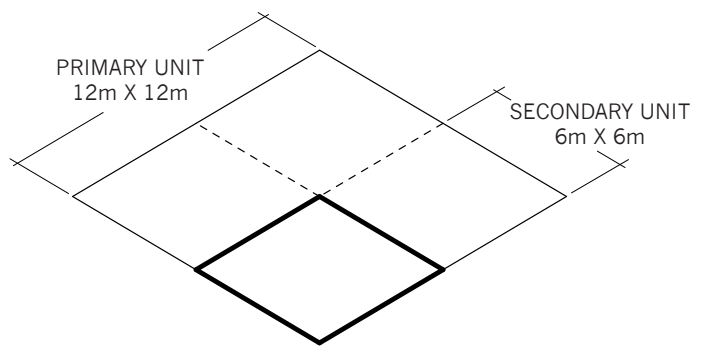

Figure 4.1: Primary and secondary structural unit grid. 

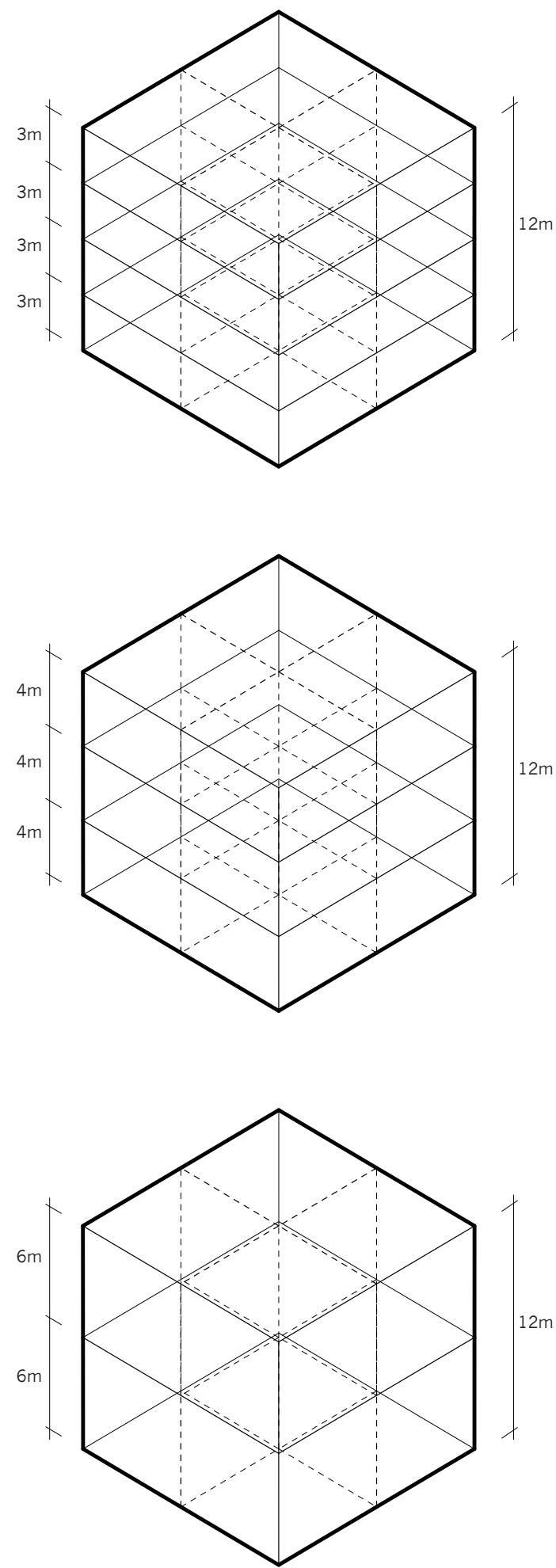

Figure 4.2: Vertical Divisions of primary unit showing secondary unit structural lines 


\section{Vertical Division}

\section{Description:}

The primary unit shall be contained within a volume $12 \mathrm{~m}$ high, figure 4.2 . This allows for the division of the primary unit into a combination of floor levels to accommodate various occupancies and floor-to-floor heights. When maximum space efficiency for residential occupancy is required, a floor-to-floor height of $3 \mathrm{~m}$ can be achieved over 4 floors. By creating a component based primary grid, the $12 \mathrm{~m}$ height can further accommodate $4 \mathrm{~m}$ high spaces across 3 floors for the use of office occupancy. For even greater floor heights and various sectional configurations, the ability to remove segments from within the primary unit offers the means to create double, triple and atrium spaces, as well as solar spaces for light and energy benefits.

\section{Rationale:}

In the analysis of the existing buildings in Toronto, it was found that ceiling heights between floors are consistent across all repurposed projects at approximately $4 \mathrm{~m}$ high. Through discussions with architects from the city, it was determined that these ceiling heights typically provide difficult maneuverability regarding traditional mechanical systems. By providing a range of floor segments that can be removed to accommodate various configurations, repurposing offers opportunities that were previously wasteful or too energy intensive to implement. The specific heights for occupancies indicated above allow for contemporary residential floor heights currently designed in the City of Toronto as a minimum height option to ensure there is a balance between economy of space, as well as provisions for change over time. 


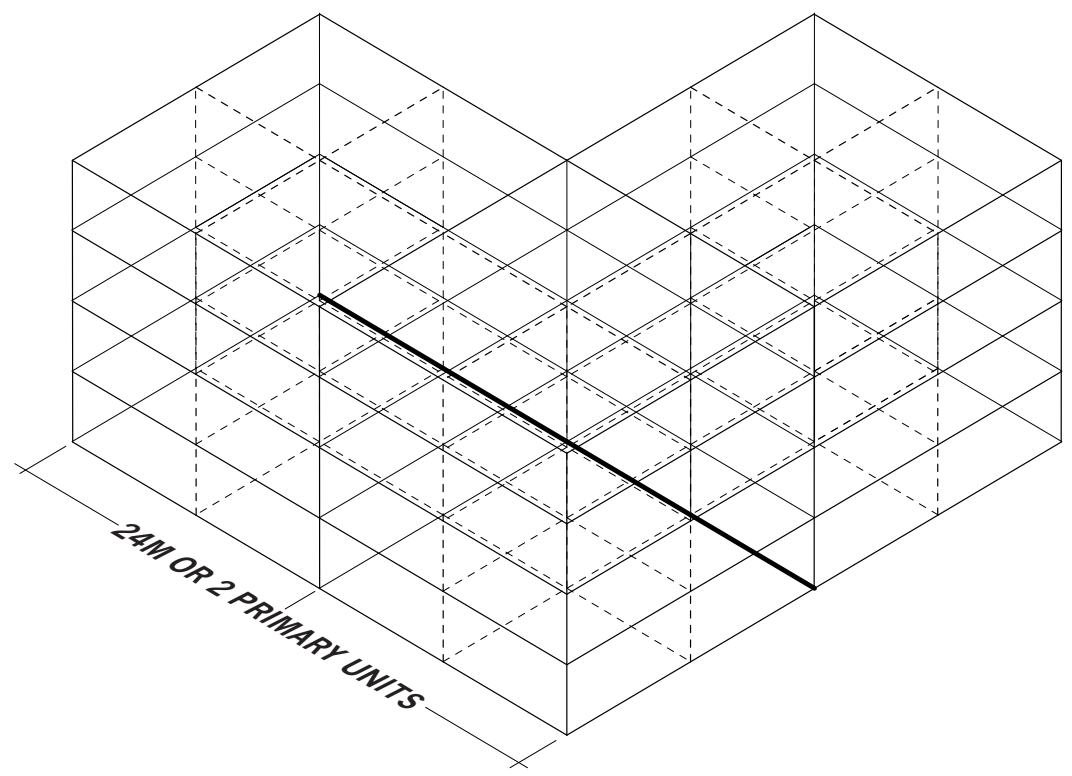

Figure 4.3: Maximum interior depth.

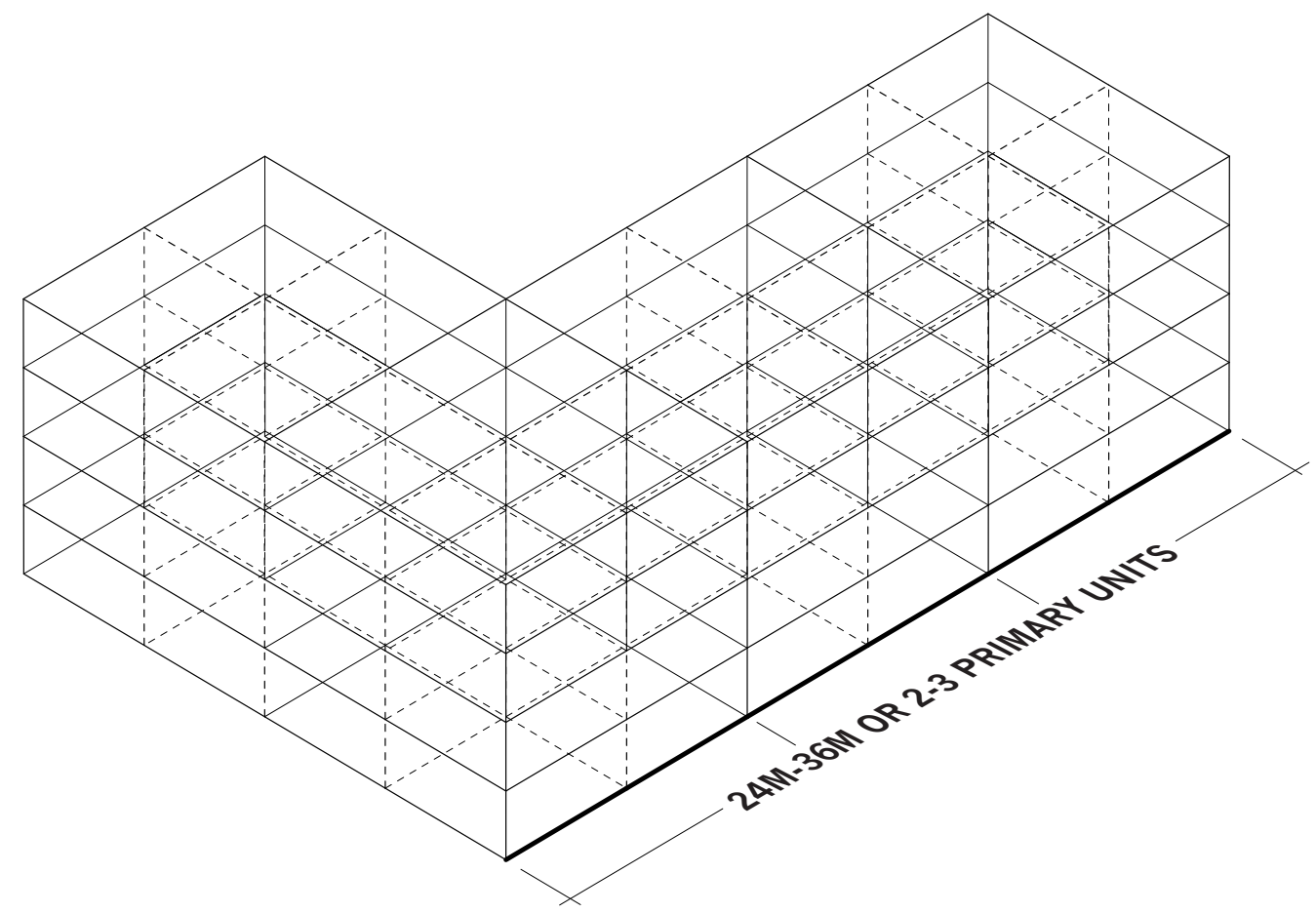

Figure 4.4: Maximum Horizontal Street Frontage. 


\section{Interior Depth}

\section{Description:}

Provisions shall be made for the depth of spaces greater than 24 meters to accommodate either an interior atrium or exterior courtyard in the event of a residential occupancy conversion, figure 4.3. This allows for units to be provided with adequate daylight, and for the building volume to be divided into double loaded corridors if desired. The building can be designed with continuous spaces at the time of construction as specified by current programmatic needs, but the ability to remove indicated volumes of space vertically allows for repurposing to residential occupancy at a later time if required.

\section{Rationale:}

In many of the case studies seen in the typology analysis, the floor plates were cut into in order to provide a depth range of approximately 24 meters. This allowed the deep spaces of the warehouses, such as The Merchandise Building and the Tip Top Tailor Condo, to bring natural light into areas that would otherwise have no access to it.

\section{Horizontal Run of Façade}

\section{Description:}

The run of a continuous façade across primary units along a street frontage shall not exceed 2 units, or a distance of $24 \mathrm{~m}$ if the building exceeds 3 primary units in length, figure 4.4. This can be facilitated through a change in façade articulation, style, or material use and must have a visibly different representation than the neighbouring façades. Horizontal lines such as cornices or other defining features shall be maintained across the complete façade. Attempts shall be made to tie into horizontal lines that already exist on the street façade.

\section{Rationale:}

As indicated through various studies into the livability of cities, as well as the Toronto Avenues and Mid-Rise Study, street façades should be broken up into segments to reduce the continuous nature of façades that full block ownership tends to produce (2010, p. 84-85). This strategy updates the guideline imposed by the Avenues and Mid-Rise Study to align with the proportions of the primary grid, as well as reflect potential benefits of large building ownership with artificially articulated façades. 


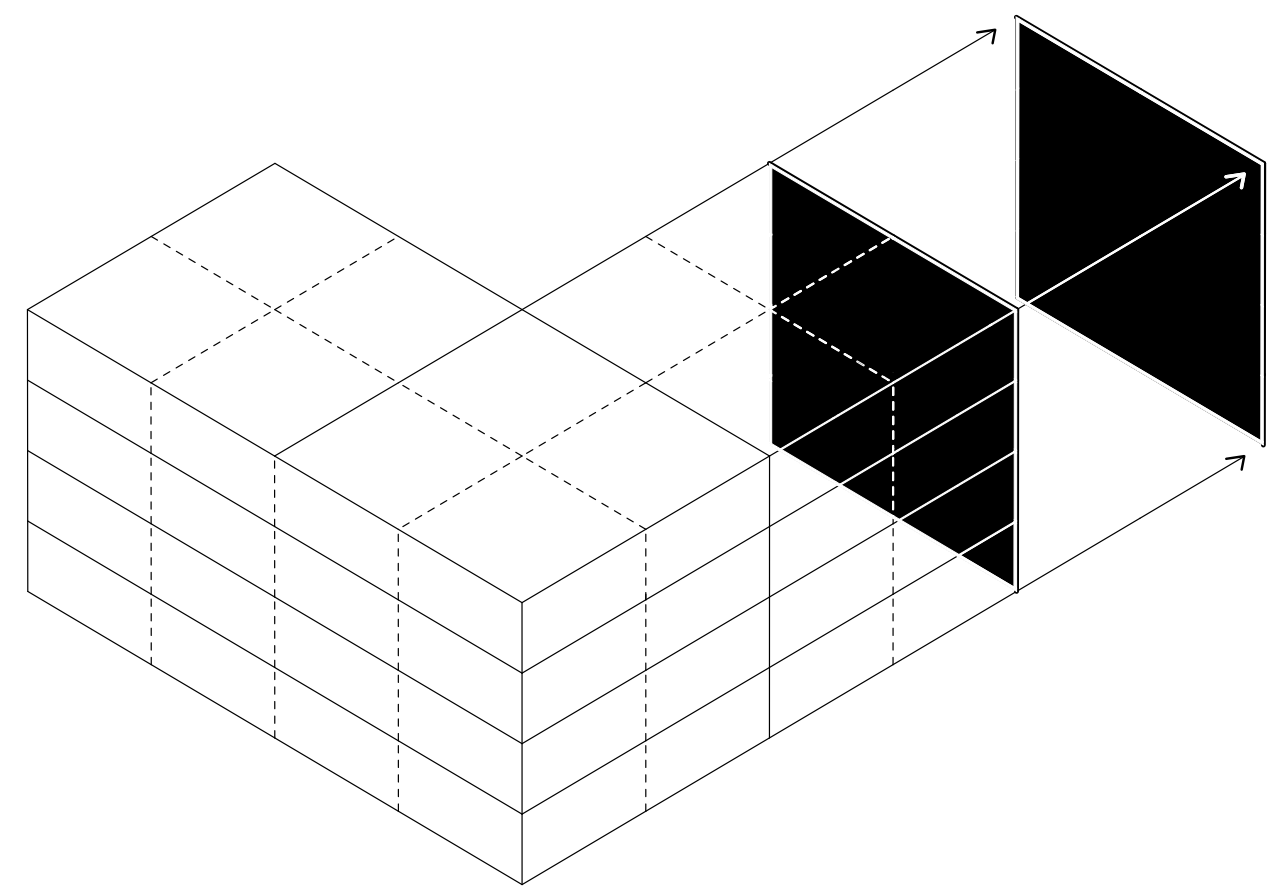

Figure 4.5: Continuation of party wall

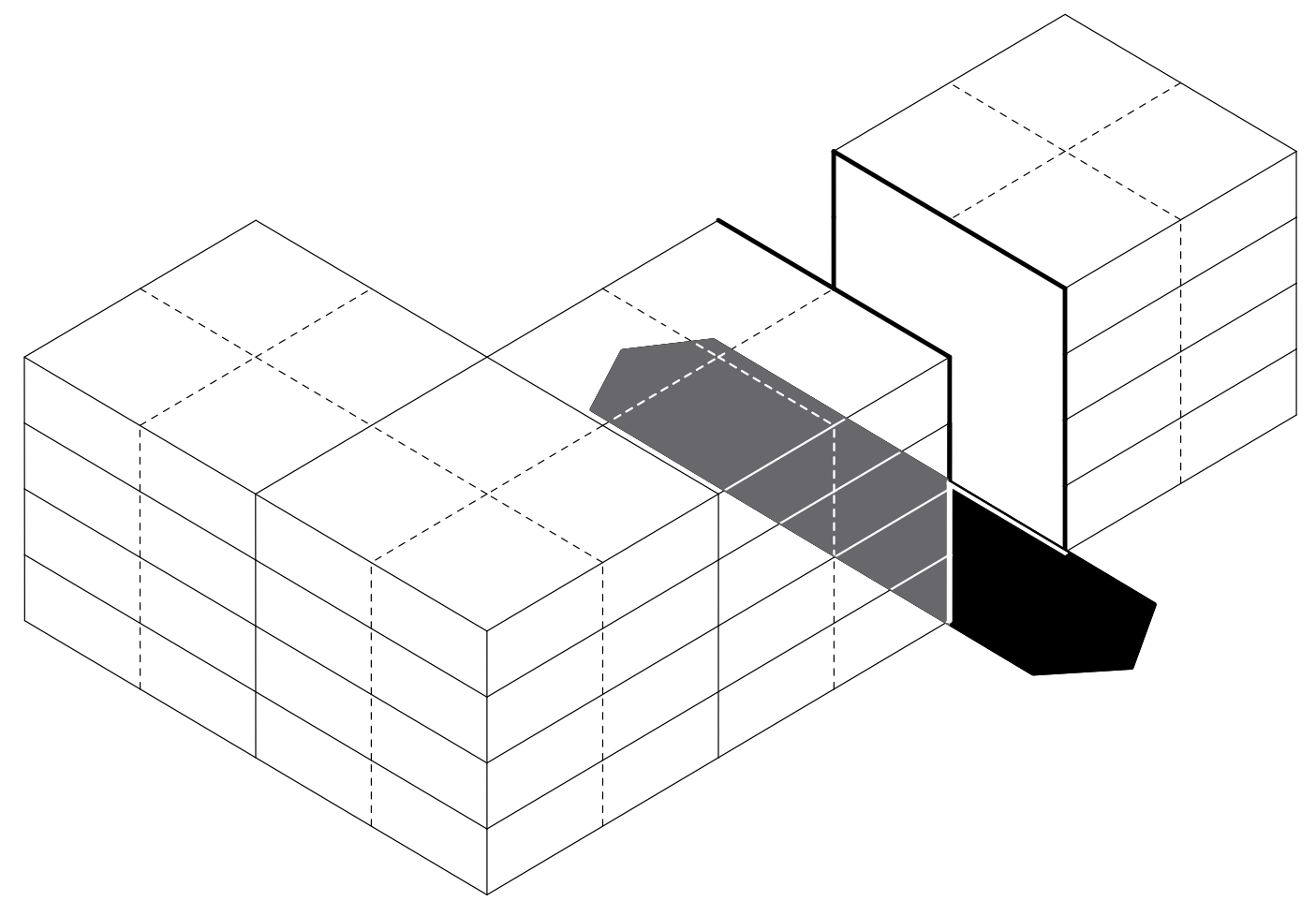

Figure 4.6: Through site access 


\section{Party Wall}

\section{Description:}

Party walls shall be built at adjacent property lines so that a continuous street wall is created, figure 4.5. The party wall shall accommodate the removal of the outermost layer of the envelope to seamlessly integrate with the expansion of the primary grid laterally to adjacent sites.

\section{Rationale:}

This strategy emphasizes the overall guideline's intent of utilizing tractable components as an important feature for the potential expansion of a building horizontally along a street, a suggestion that is mirrored throughout the Avenues and Mid-Rise Study. By allowing for the exterior walls adjacent to neighbouring property lines to disassemble and allow for expansion, the idea of continuous positive growth is reinforced, and the boundaries typically associated with exterior walls be reconsidered as non-permanent, tractable thresholds that do not limit the needs of enclosed space.

\section{Through Site Access}

\section{Description:}

Through the development of a larger site where street walls have the potential to run longer than 8 primary units or $96 \mathrm{~m}$, the building shall be interrupted so that access through the site to the laneway, located at the center of the city block, may be accessed, figure 4.6. This can be facilitated by a courtyard, atrium, or connection through an open-air park located through the building site.

\section{Rationale:}

By creating a void within the primary grid, public-private relationships can be developed to reinforce the mixing of use within the building fabric. As an open space, frontage is created off of a street that can allow for pedestrianized areas and breakout spaces. Laneways are also an important part of building function. By providing a break in the street wall, the laneways can be accessed and activated not just for service uses, but can also be opened up as additional public and semi-public space located off of the main avenues from the mid-block frontages created within the building. 


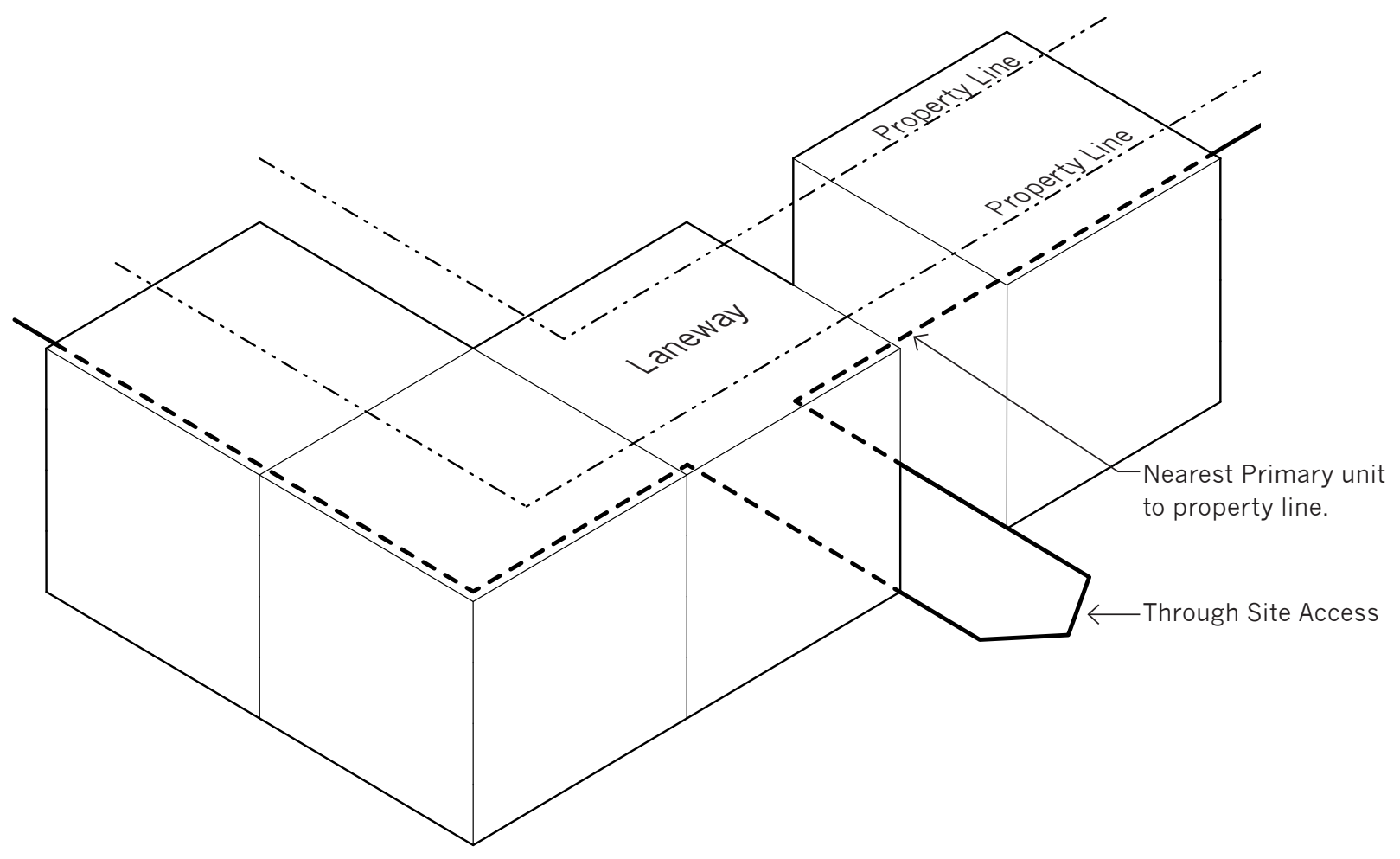

Figure 4.7: Laneway boundary

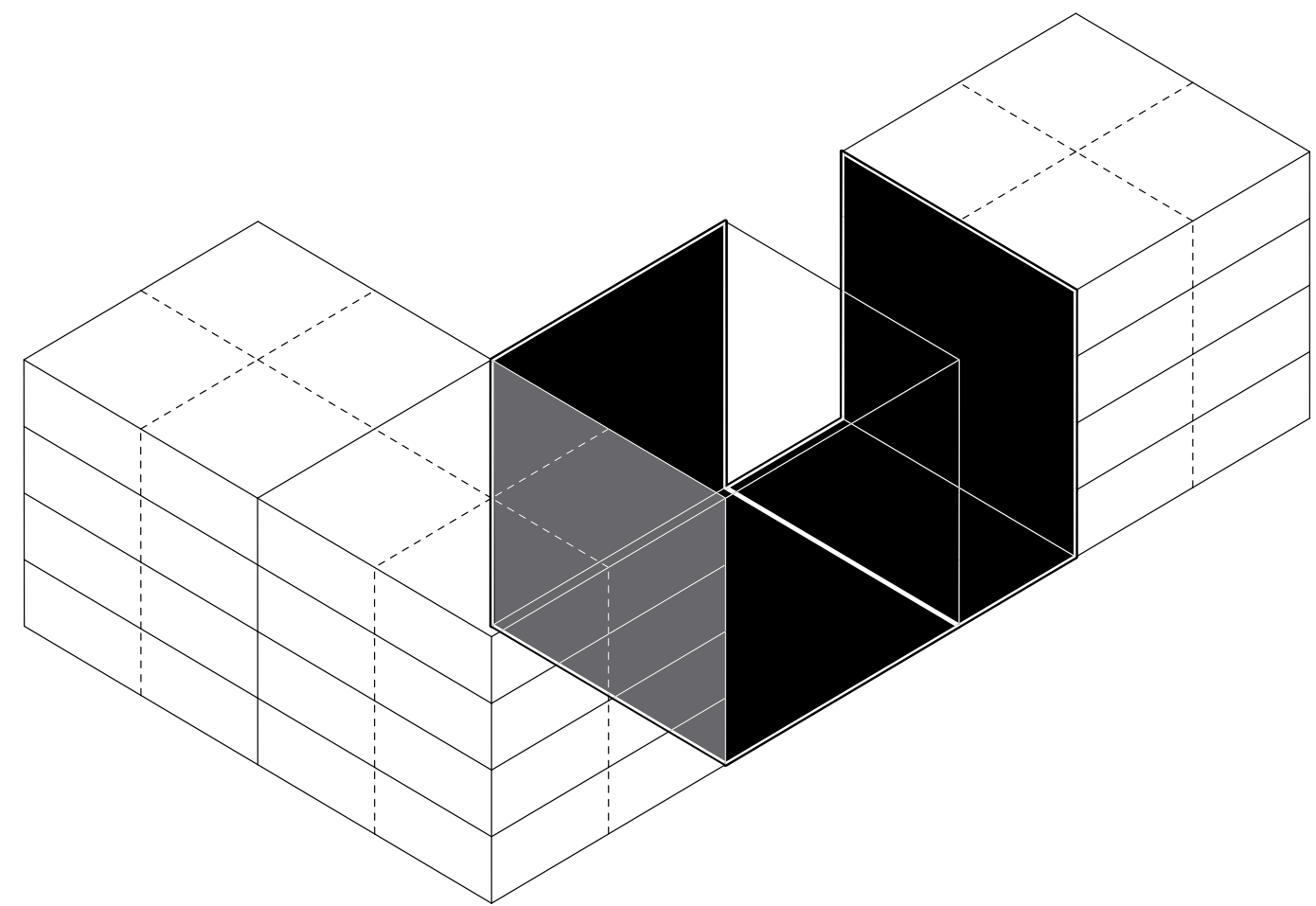

Figure 4.8: Privately owned public space 


\section{Laneway}

\section{Description:}

Along the shared property lines of adjacent owners, the primary grid shall be built out to the laneway to the nearest complete $12 \mathrm{~m}$ grid, figure 4.7 .

\section{Rationale:}

Studying the development of a whole block using the grid structure of primary and secondary units, laneways currently play an important role in providing at-grade, semi-private, outdoor space serving a "back of house" function along many streets in Toronto. This strategy, in opposition to the Avenues and Mid-Rise Study, proposes that buildings are built out to the laneway property lines provided that all of the other organizing strategies of space are followed. Vehicular and service access through city blocks is still provided; however, increased density is afforded without breaking the standard height limitations. There are advantages to the space utilization of the block by increasing density because it reduces the risk of a future development demolishing the existing outdoor space in order to "fill out" the site horizontally. When done effectively, with a robust structural system at-grade, accommodation for future expansion can occur vertically by tying into the existing grid of the street fabric.

\section{Privately Owned Public Space (POPS)}

\section{Description:}

Two types: the first is set outside of the grid; the second exists within the grid as void space within the building. This space can be either green or grey garden spaces. If it is within the grid, all services must be allowed to pass through the primary unit to accommodate any change of occupancy type. If it is set outside of the grid, it is treated as a void within the street wall, figure 4.8 .

\section{Rationale:}

The purpose of this guideline is to facilitate the needs of human inhabitation as a first priority for the construction of any enclosed space. By its inclusion co-existing as a function of the building primary uses alongside other primary uses such as work or residential living space, true public-private mixing can occur. This integration can, for example, facilitate a managed redevelopment of underutilized urban streets typically seen as 3 storey street frontage, detached or semi-detached homes and allow the semi-public front yard spaces and backyard spaces for leisure to be retained and better integrated into the community. 

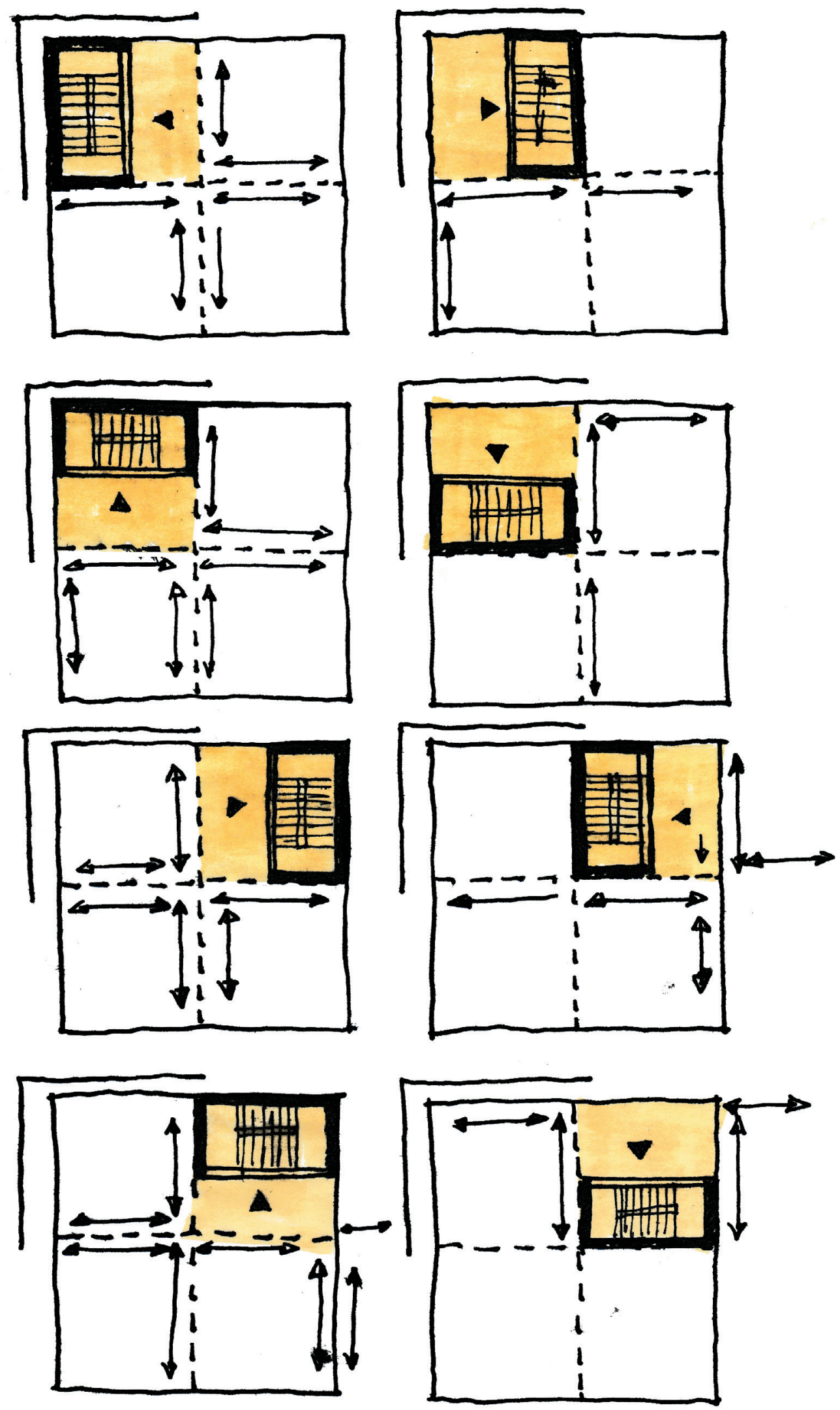

Figure 4.9: Stair placement study 1. Scale 1:250 


\section{Stair Core}

\section{Description:}

A minimum of 2 exit stairs, as required by the Ontario Building Code for fire safety in all buildings, shall be facilitated in one of a possible number of locations dependent on the location of the façade, figure 4.9. The stair core shall be placed in the secondary unit located away from the façade that is parallel to a major street. This is to allow access to the area of the façade in front of the stair core and adjacent to the street on upper floors. If the building is located on a corner site, the stairs shall be placed on exterior walls facing toward the middle of the street block containing the core. If the building is located on a mid-block site, with a lane or secondary street at the back, one stair core shall be located within a primary unit that is adjacent to each street. If the site does not contain a back laneway or street, the second stair core will be located on the opposite side of the building in the primary core facing the only accessible street, 4.10 .

\section{Rationale:}

The placement of stairs allows for an optimal use of space, either with a single occupancy or multiple occupancies, accessed with double or single loaded corridors on both upper and ground floor levels. The stair core, as it is located in the study, is optimally positioned to sit within a corner of the primary unit's structural line.
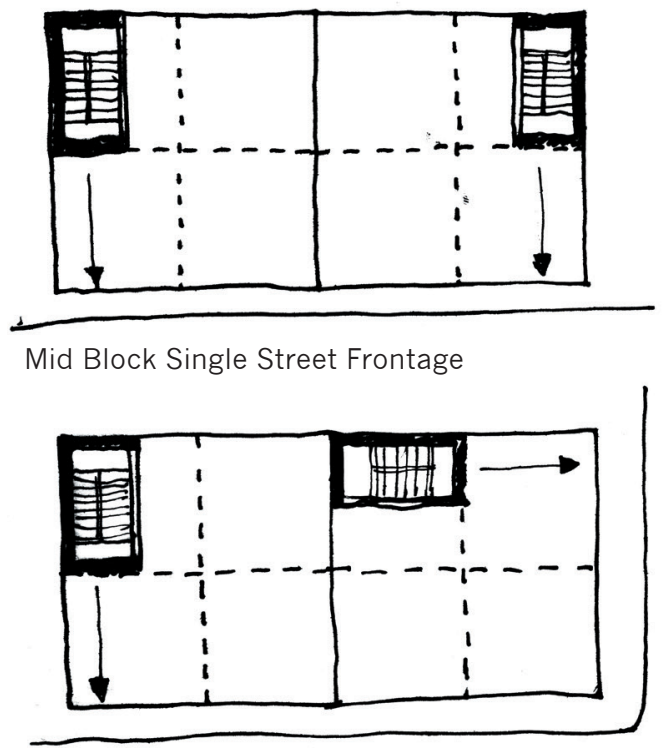

Corner Site

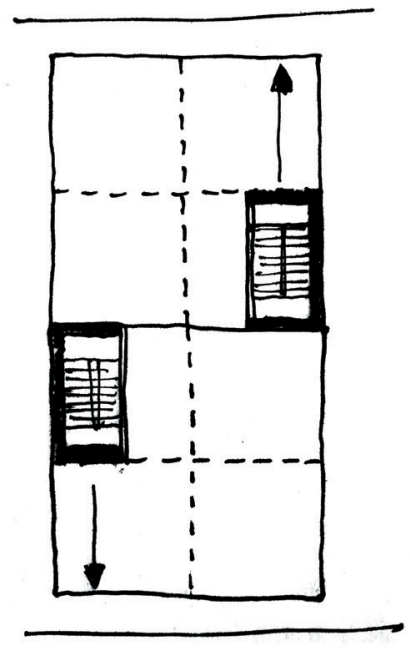

Mid Block Double Street Frontage

Figure 4.10: Stair placement study 2. Stair core position related to street orientation. 
The stair core shall be constructed as a permanent fixture on the site and within the building that fits in one half of a secondary unit grid. The physical stairs, located within the permanent stair core, shall accommodate access to each of the potential floor height locations by using component-based assemblies, figure 4.11. The tractability of structural components shall also be accommodated through structural tie-in capabilities at $3 \mathrm{~m}, 4 \mathrm{~m}$, and $6 \mathrm{~m}$ intervals along the outside walls of the stair core. This allows for access to adjoining secondary units at any division of vertical arrangement.
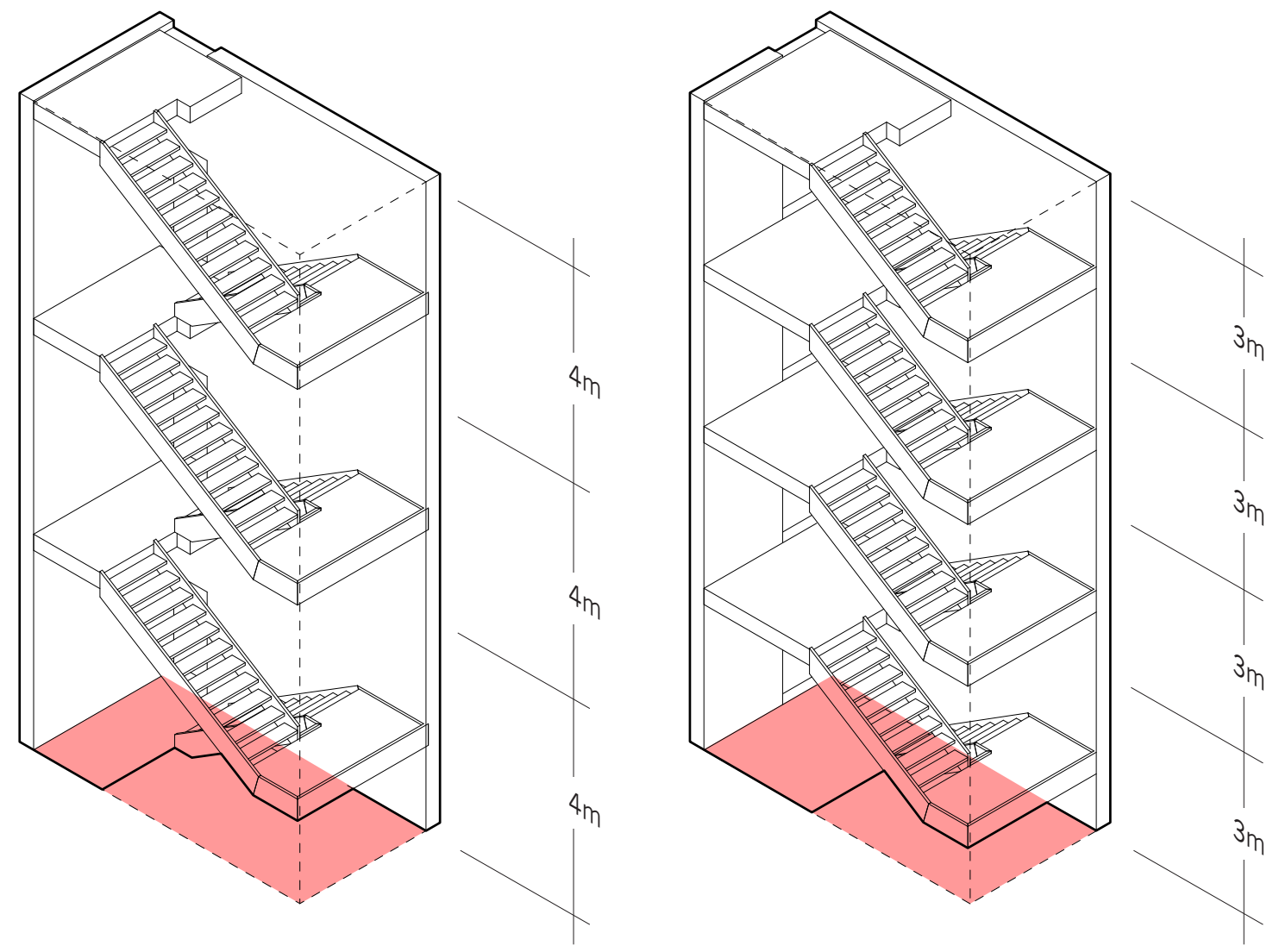

Figure 4.11: Stair Disassembly. Construction of stair shall be made of dissassemblable materials to reconfigure should a floor to floor height change occur. 


\section{Elevator Core}

\section{Description:}

The elevator core shall be located along an exterior wall and be oriented to exit directly onto the spaces contained within the primary unit in which the core is located, figure 4.12. If there is a choice in location, preference shall be given to providing the spaces facing south with the most unobstructed floor space.

\section{Rationale:}

The location of the elevator core is intended to not hinder the functionality of the entire space, while still being located within reasonable distance to the major street. It is to be constructed as a permanent fixture on site with the capability of servicing all level divisions with a primary unit at $3 \mathrm{~m}, 4 \mathrm{~m}$, and $6 \mathrm{~m}$ intervals.
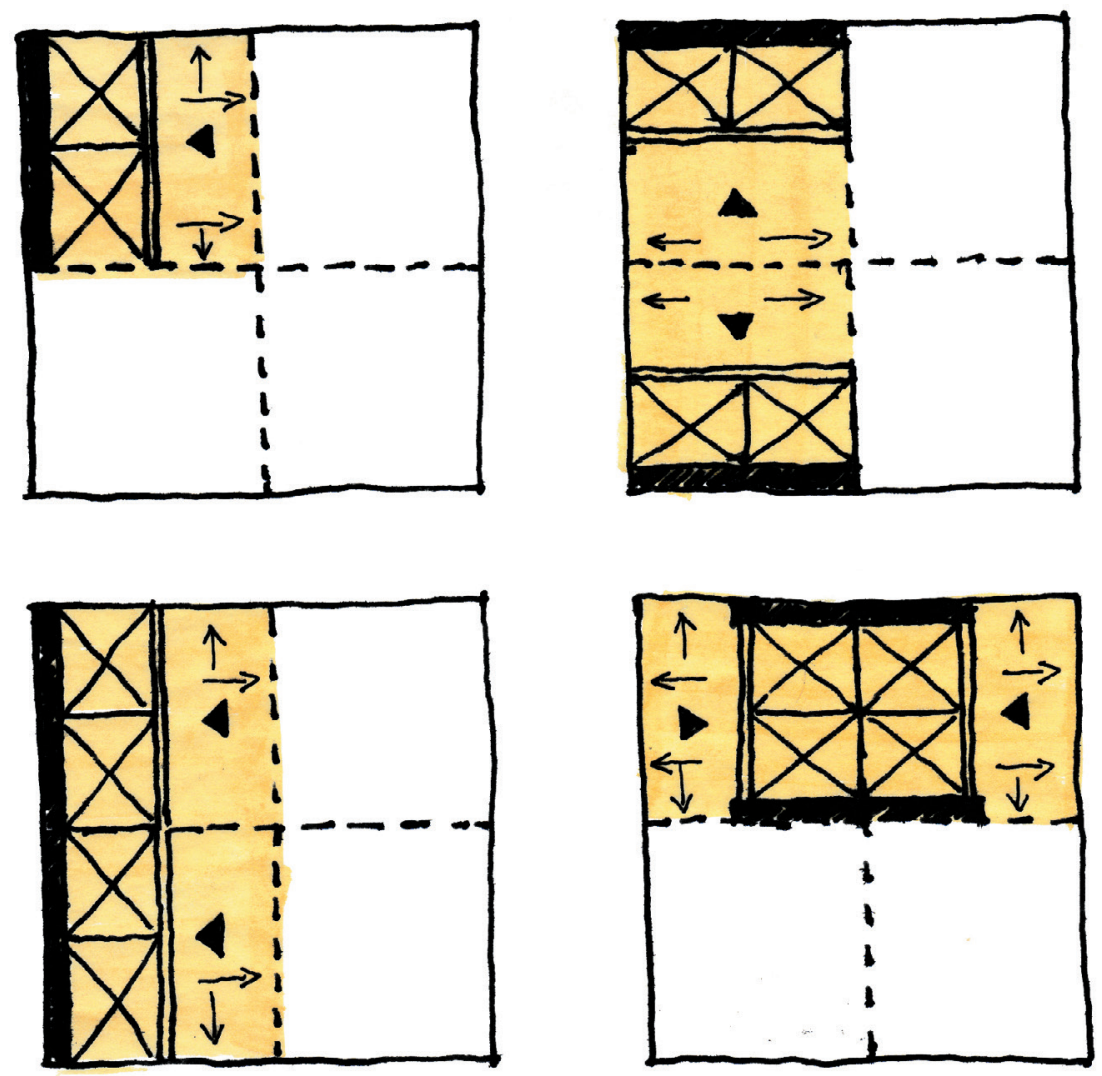

Figure 4.12: Elevator placement study. Scale 1:250 


\section{Opening Ratio}

\section{Description:}

The façades of functional primary units shall have an opening ratio no greater than $30 \%$.

\section{Rationale:}

Through the existing building study of Toronto, it was found that all of these projects function, on average, within a small range of window and door opening percentages compared to the greater façade surfaces. The $30 \%$ opening ratio found among existing buildings may be due to the maximum allowable percentage that technology could provide at the time of construction. Nevertheless, the continued success and desirability of these buildings for residential, office and commercial space demonstrates that a reduction of façade transparency to $30 \%$ should not affect the use of the spaces inside. The greater area of opaque walls allows for a substantial increase of insulation or with the installation of translucent highly insulated glazing panels in comparison to the typically all-glass window wall and high transparency building façades .
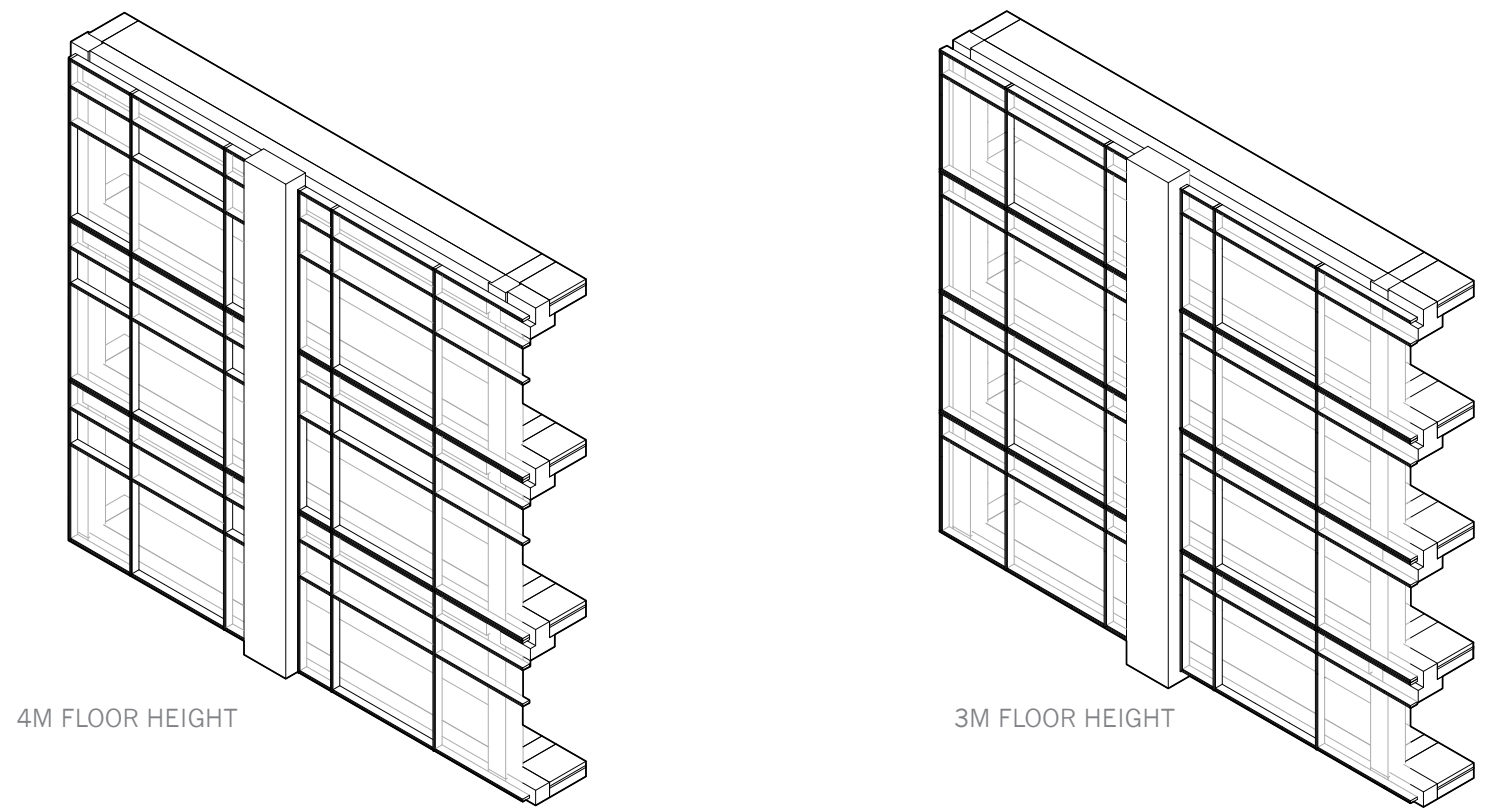

Figure 4.13: Façade is composed of a curtainwall grid that allows for modifications across floor heights of $4 \mathrm{~m}$ and $3 \mathrm{~m}$. 


\section{Component Based Envelopes}

\section{Description:}

The envelope is to be designed to follow the intention of design for repurpose, figure 4.13. It shall be designed to have the ability to be disassembled and for its components to be repurposed throughout the building.

\section{Rationale:}

By creating highly energy efficient façades that act in a similar way to traditional curtain wall systems through the panelization of the façade, it can allow for units to be replaced, updated, or reconfigured depending on the internal layouts of the building. The façade can be seen as a layering of materials of smaller components combined to create full systems that can be disassembled and used across any combination of vertical or horizontal divisions. Full façade replacement, or any part of a component-based façade, would allow the majority of individual materials to be kept intact through its disassembly and reuse elsewhere on the façade. For example, if the building changes the floor height division, the façade panels can be disassembled and reconstructed to match the new reconfiguration, figure 4.14.

Similarly, this can be applied to the roofing system and its components, which sit above and below the required continuous membranes, to allow for future expansion without the complete destruction of roofing materials. This allows the materials, used in the original roof, to be moved up to the new roof levels and reinstalled, continuing their functional use through the building.

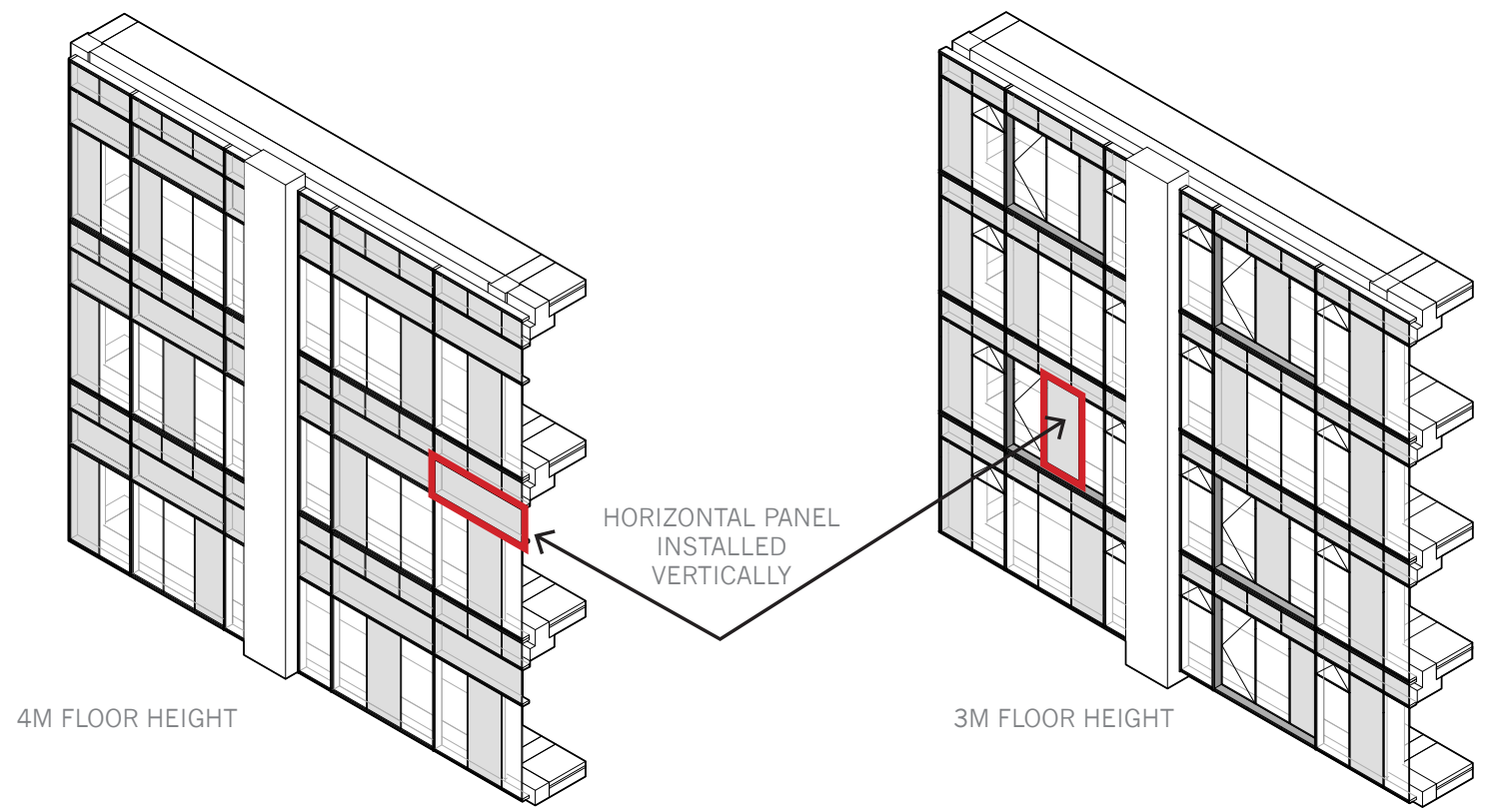

Figure 4.14: Transparent (white) and translucent (grey) panels divide the curtainwall grid in a modular system, allowing for the transfer of panels between floor division types. 


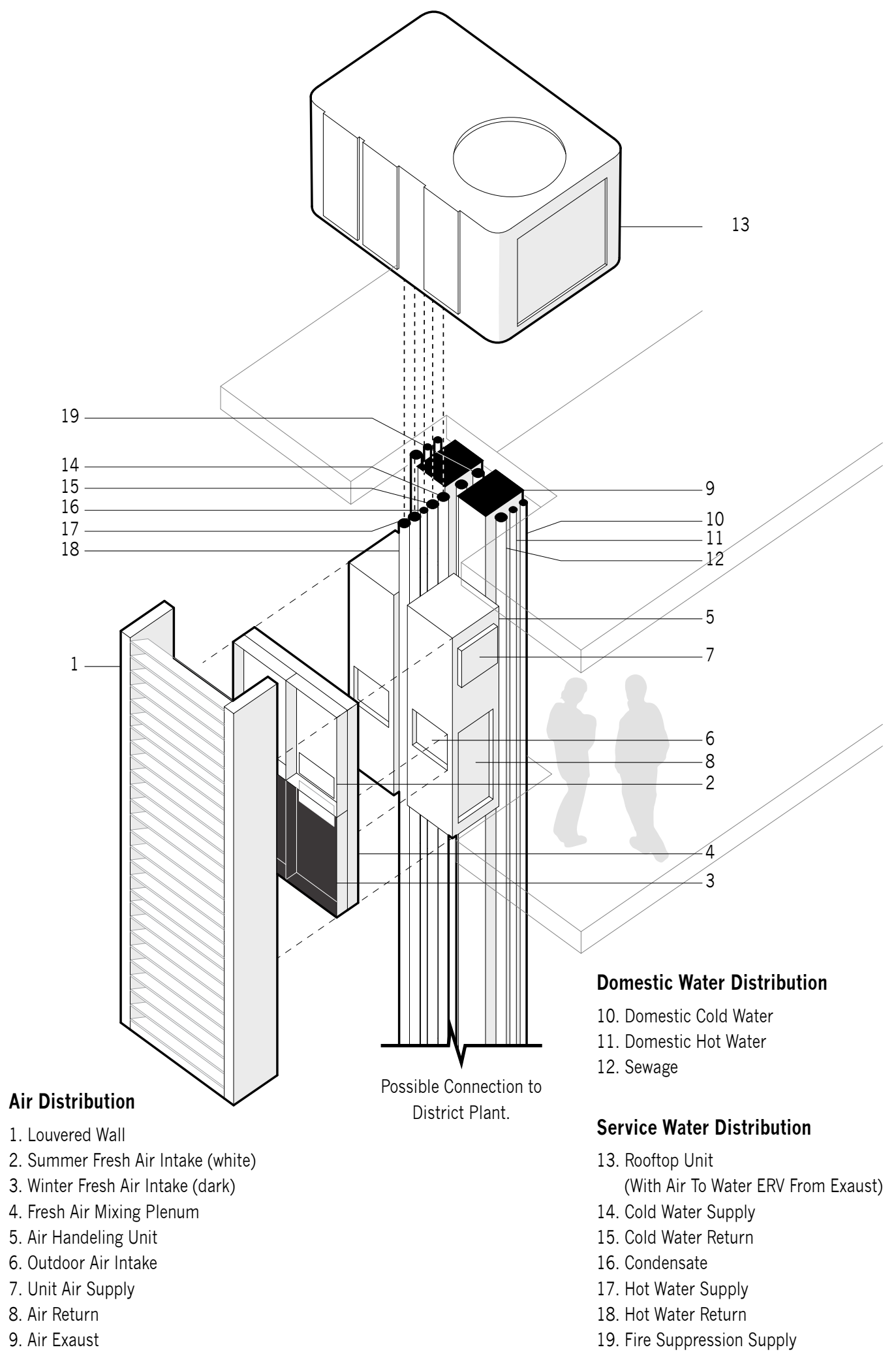

Figure 4.15: Proposed mechanical system which connects to rooftop and district-wide heating and cooling plants supplying conditioned water to in-unit air handling units. Fresh air is preconditioned naturally and brought into the building directly at each unit through the louvered wall shown above. 


\section{Mechanical Systems}

\section{Description:}

Various HVAC, domestic and sprinkler water distribution methods were reviewed for the purpose of identifying a mechanical system that is derived from an architectural intention for repurpose, figure 4.15. The variations in the analysis examine a range of options from full air supply through central distribution ducts to point-of-use systems that would be contained within each primary unit. By studying the function contained within each primary unit, space flexibility and organization limitations are very high when centralized systems are ducted into each unit. Alternatively, installing a system where each unit is provided with its own heating, cooling and water supply would allow for a completely contained system within vertical stacks of primary units, eliminating any cross-unit servicing. This would allow for the complete freedom of interchangeability of adjacent units without the disruption of their conditioned spaces.

The study further looks at the placement of the system at the exterior or at the centre position of the unit to increase both façade access and day lighting, or to reduce ductwork in occupied spaces. Bringing the mechanical systems together at a point on the exterior of the envelope allows for the full useability of the primary units and for the systems to be clearly represented on the façade. This vertical penetration would contain all of the circulation for domestic and fire service water pipes, as well as HVAC requirements to reduce the crossover of mechanical components between adjacent units. As seen in the left column of the sketches, figure 4.16, an open office continues over primary unit lines. The vertical elements within the space would define the original $6 \mathrm{~m}$ secondary unit divisions between the primary structure, yet still allow for continuous, unobstructed spaces throughout the interior. Additionally, services that pass vertically through open voids are intended to penetrate these exterior spaces and visually present the functionality of the system throughout the building. 


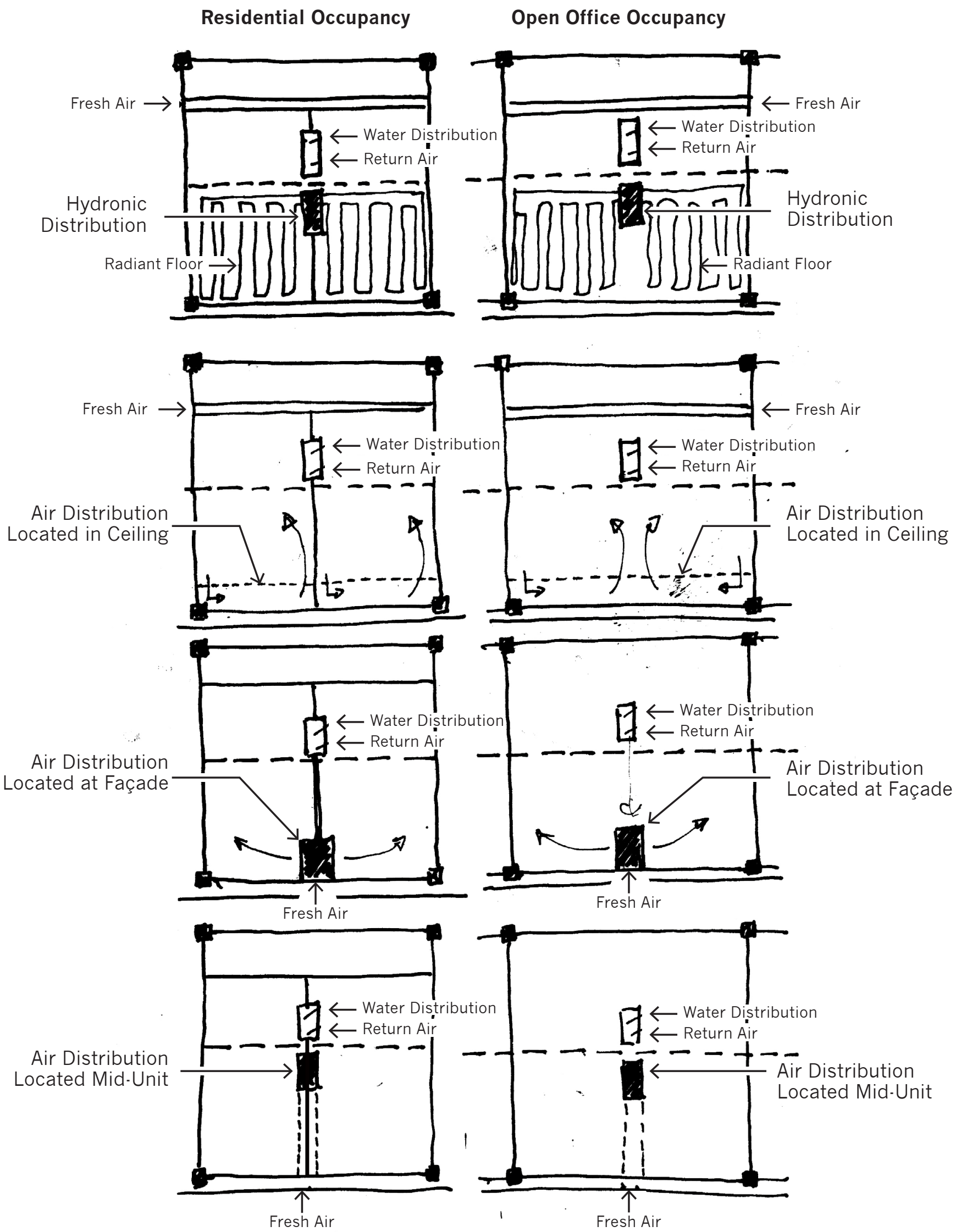




\section{Rationale:}

This scheme, which locates mechanical systems within each set of primary units, allows for the complete maneuverability, expansion and reconfiguration of each unit independently as the building evolves over time. The location of the mechanical system within the unit creates a union between the hidden systems necessary for active atmospheric control of living and working, and a direct spatial relationship within the $12 \mathrm{~m} \times 12 \mathrm{~m}$ grid. As revealed in the study, the system's deliberate placement at the mid-point of the grid lines along the exterior perimeter allows for the maximum usability of the space as either divided for residential use or fully integrated as an open, continuous space. 


\section{MATERIALS}

The next chapter looks at the benefits and application of specific materials to the strategies outlined in the previous chapter. The strategies were intentionally discussed without the application of specific materials as a means to separate the performance of the system with current technologies. By looking at the potential for material application to the assembly of system of guidelines, a prototype can be established to demonstrate the intent of the strategies in our current context within Toronto using available technologies and systems.

\section{Structure}

Located along the grid lines, the primary unit contains all of the major structural elements for the building. Different systems can be selected depending on which materials are used for the structure and how they are designed to achieve disassembly.

A hybrid beam of precast concrete with steel connections, when used as the primary structural spanning member, allows for a high level of maneuverability of the components due to the combined benefits of each material. It also minimizes the depth requirement of members spanning long distances, such as for the $12 \mathrm{~m}$ bay sizes. The columns of the structure in concrete would have flanges set at $3 \mathrm{~m}$, $4 \mathrm{~m}$, and $6 \mathrm{~m}$ intervals so that inverted $\mathrm{T}$ beams, with a depth of $700 \mathrm{~mm}$, can span column to column. The inverted T, figure 5.1 would facilitate the floor assembly to sit within the depth of the beam, reducing the effective depth of the whole system (E. Allen, \& , J. Iano, 2009). Beams that are located at the perimeter along property lines that do not allow horizontal building expansion can be cast as an $L$ to create a flat surface on the exterior face, in line with the column. Consistent with the results of the typology study, using concrete would be ideal for a building with the intended underlying principles of a residential unit. Due to concrete's inherent fireproofing capabilities and reduction of sound transmission, its use within a building represents the potential for this system to accommodate residential occupancy as a core unit of definition. Its use allows for exposed concrete to be specified as the finished interior surface and reduce the additional materials needed to wrap structure in other assemblies to achieve required fire resistance ratings. Since the concrete can 


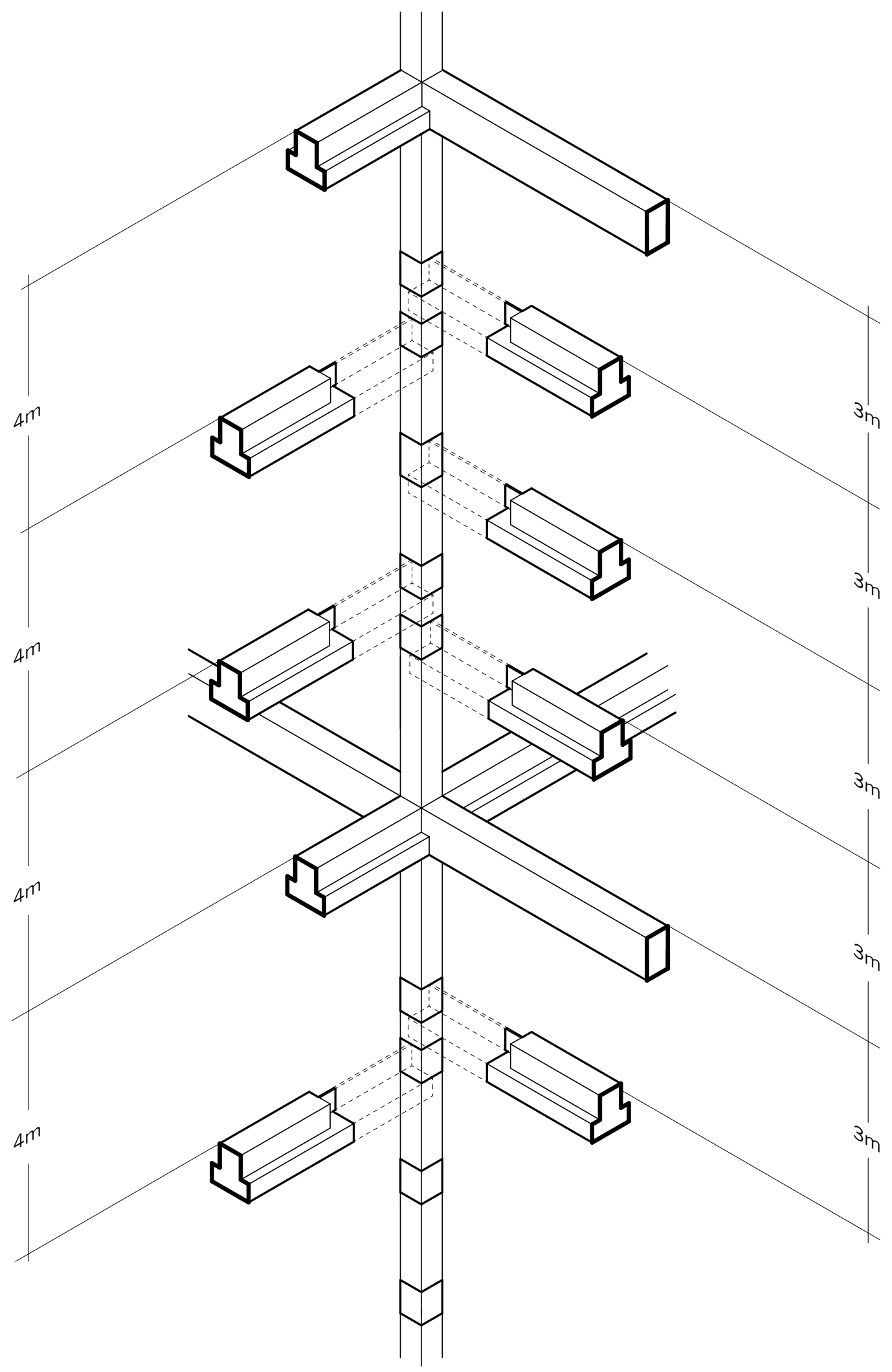


be exposed, the underlying system of structure can be highlighted and users of the space can come in direct contact with the beams and columns that provide the primary support for the spaces. In addition to this, the exposure of these elements can help simplify renovation plans for easy identification throughout the building. Concrete however, is not a very recyclable material, as it must be down-cycled to gravel after its first use in a building. Used in the primary structural unit, this material would be the least likely component to be removed from the building in the future; therefore, if the building continues to be in use for more than a century, the primary structure can remain unchanged. This is true of all material systems chosen to fulfill the needs of the primary structure.

Other materials that are suitable for use with the primary structure are steel and heavy timber. For example, the assembly of heavy timber as a structural element would have an effect on the perimeter spacing of each primary unit because such extensive spanning distances are not yet economically or dimensionally feasibility (beams would be very deep). Therefore, flexibility of space would be lost due to the added columns along the structural lines of the unit. Alternatively, the assembly of steel as a structural element would allow for similar spans to the concrete option; however, transmission of sound and vibration through steel is quite high and it would require added fire protection to wrap each member, resulting in greater waste production over time if fireproofing required removal and re-application at each stage of renovation. 


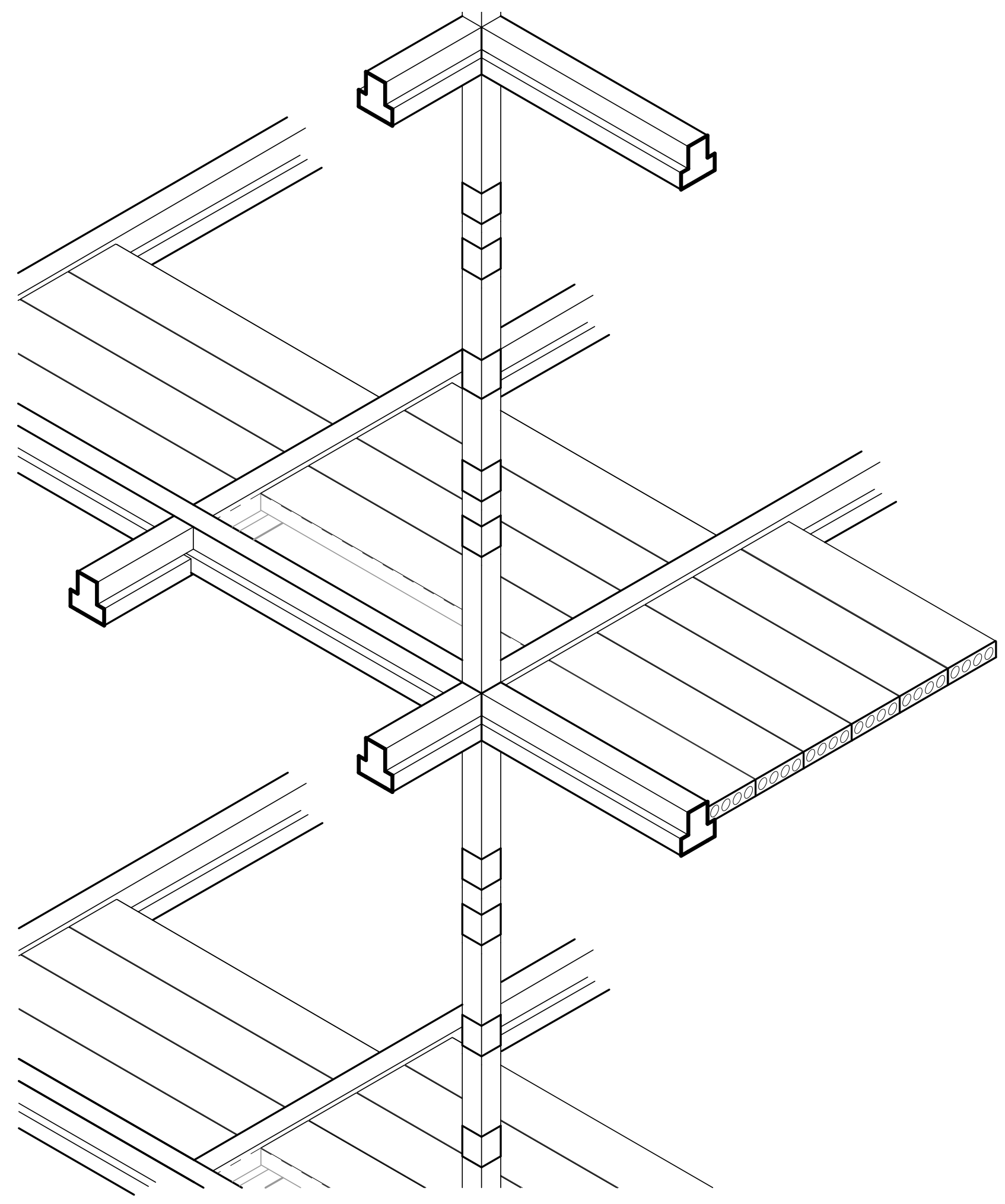




\section{Interior Horizontal Surfaces}

Hollow core, precast concrete slabs provide a versatile option for the assembly of horizontal surfaces that can be disassembled and reconfigured within the building, figure 5.2. The precast option allows for efficient spanning distances to be achieved, and is robust enough to be reused after a sectional change of occupancy type. Floor panels can be inserted at $6 \mathrm{~m}$ lengths and supported on the primary structural beam and a secondary beam spanning the primary unit, perpendicular to the slab direction. If the slabs are positioned perpendicular to the exterior façade during a renovation for repurpose, the façade can be opened (due to its disassembly properties) and the precast slabs can be moved out of the building or to a different interior level with mini-cranes as required. To maintain the tractability of the floor assembly, it should have a finishing material that can be removed and reused in its new location within the unit, without the downgrading of quality. A wood floor finish that sits level with the top of the primary structural beam allows for the assembly to be stripped down when needed, as well as representing both the underlying structural frame and a surfacing material conducive with up-cycling intentions. Predicting a timeline based on Duffy's study, Cumulative Expenditure on Shell, Service, and Scenery, the earliest estimated time the floor assemblies may need to be maneuvered would be around 20 years, or at the point of a major occupancy change within the space (F. Duffy, 1990, p. 18). This assembly would allow the building to remain relevant through the occupancy changes, well after multiple reconfigurations. 


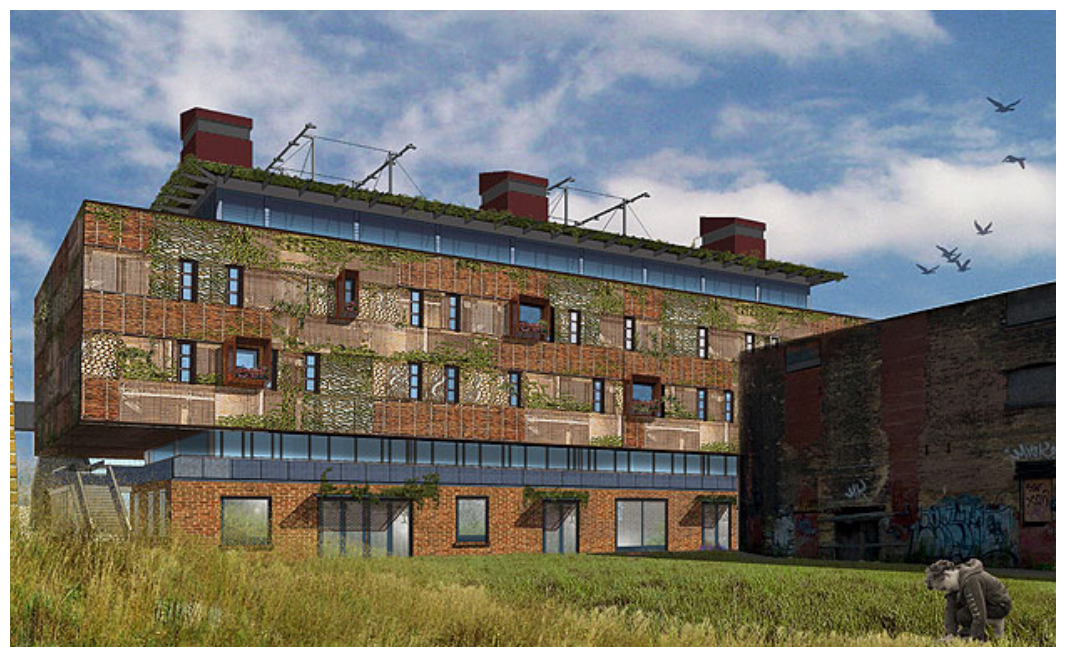

Figure 5.3a: Evergreen Brickworks design rendering of the proposed façade with de-mountable screen elements.

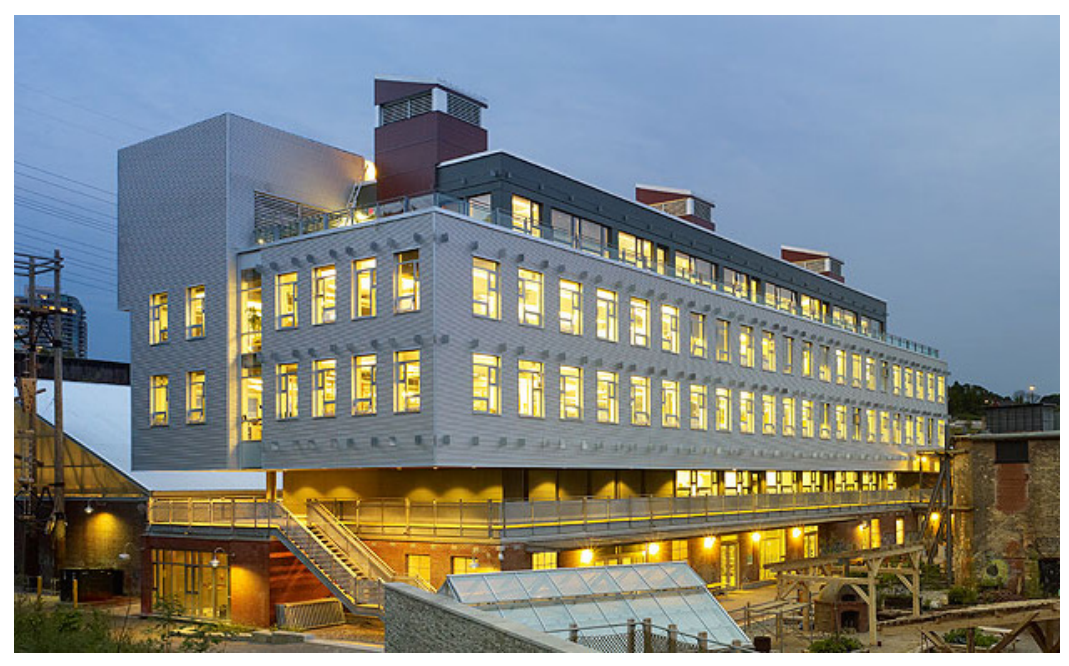

Figure 5.3b: Completed project showing vertical clips for the screens that were never implemented due to budget constraints. 


\section{Envelope}

The primary envelope of the building should be designed in such a way that allows for improvement over its life-cycle, as technologies improve and materials degrade. In this respect, the modernist perspective of standardized modular components is a successful initiative that allows for the replacement, deconstruction and reuse of materials owing to the standardization of components. The materiality of the envelope should facilitate the ability to up-cycle the components, reuse them directly within the building, or allow them to decompose back into organic matter (M. Braungart \& W. McDonough, 2002).

Surfaces, where possible, shall be made to be regenerative to the surroundings. This implies the implementation of green roof requirements in Toronto is one such example of regenerative building envelopes. Currently, the city of Toronto does not allow for modular green roof application. By limiting modularity, it is ensuring that owners do not remove the green elements after construction. ${ }^{6}$ However, an effort must be made to install modularized assemblies so that they may be easily disassembled and remain functional if adapted and moved to new locations, on or within the building over time.

An unrealized vision of a regenerative surface in Toronto is the façade scheme for the Evergreen Brickworks office building, figure 5.3. In 2013, during a guided tour with Architect Walton Chan of Diamond Schmitt Architects, their scheme of a panelized, green exterior wall was described but, ultimately, not realized due to budget cuts. The remnants of this design scheme can be seen on the current façade, as clips protrude from the wall's surface in hopes of installing the panels at a future date. The scheme can also be experienced through the drawings and Visitor Information available on display within the building.

Other exterior materials that support direct reuse and repurposing on site, as suggested by Craig Applegath of Dialog Architects during his Symbiotic Cities lecture at Ryerson University on November 20, 2014, are glass, aluminum, and wood materials. These materials, when panelized into a curtain wall system, can be extremely durable and provide the option for removal and reconfiguration across the building as needed.

6 This information was presented at a city council meeting where the applications of green roofs were questioned for industrial buildings in 2011. 


\section{Interior Vertical Surfaces}

There are many ways in which to define the interior space of a building. According to Francis Duffy's study of building life-cycles, what he defines as scenery (ie: partition walls, furniture and other space defining features), are what change most frequently. The repurposing of space occurs due to changing needs and personal styles. With a good framework, the changing needs of the occupants no longer affect the relevancy of the whole building, but frequent changes to interior space definition can still result in excessive use of new materials required for each renovation.

Detailed in the Ontario Building Code (OBC), basic relationships are already set up between major occupancies based only on fire protection (OBC, 2014, 3.1.3.1). By looking at the types of materials needed to separate different occupancies compared to the existing materials already within the building, an obvious spatial relationship can exist between high-risk occupancies (requiring 2 hour fire protection) across different floors because they are already separated by concrete in the floor, figure 5.4. Changing the occupancy mix within a building would require an extensive reorganization of material for fire separation. Therefore, a system of organizing principles can be easily adapted by looking at a building's existing properties. Since concrete is a good fire separator, it makes sense for occupancies that require 2 hour

\begin{tabular}{c|c|c|c|c|c|c|c|c} 
& A1 & A2 & A3 & A4 & C & D & E & F3 \\
\hline Assembly 1 (A1) & n.a. & 1 & 1 & 1 & 1 & 1 & $\mathbf{2}$ & 1 \\
\hline Assembly 2 (A2) & 1 & n.a. & 1 & 1 & 1 & 1 & $\mathbf{2}$ & 1 \\
\hline Assembly 3 (A3) & 1 & 1 & n.a. & 1 & 1 & 1 & $\mathbf{2}$ & 1 \\
\hline Assembly 4 (A4) & 1 & 1 & 1 & n.a. & 1 & 1 & $\mathbf{2}$ & 1 \\
\hline Care (B; 1,2,3) & $\mathbf{2}$ & $\mathbf{2}$ & $\mathbf{2}$ & $\mathbf{2}$ & $\mathbf{2}$ & $\mathbf{2}$ & $\mathbf{2}$ & $\mathbf{2}$ \\
\hline Residential (C) & 1 & 1 & 1 & 1 & n.a. & 1 & $\mathbf{2}$ & 1 \\
\hline Business (D) & 1 & 1 & 1 & 1 & 1 & n.a. & n.a. & n.a. \\
\hline Mercantile (E) & $\mathbf{2}$ & $\mathbf{2}$ & $\mathbf{2}$ & $\mathbf{2}$ & $\mathbf{2}$ & n.a. & n.a. & n.a. \\
\hline Industrial Low (F3) & $\mathbf{1}$ & $\mathbf{1}$ & $\mathbf{1}$ & $\mathbf{1}$ & $\mathbf{1}$ & n.a. & n.a. & n.a. \\
\hline
\end{tabular}

Figure 5.4: Adjacencies between major occupancies can influence the flexibility of spaces due to necessary materials to maintain proper fire separation. Using natural fire resistance in the building to separate between 2 hour rating (red) greater adjacency potential can be established. 
fire separation to be divided through the building where concrete already exists. This means, for example, that in order to reduce the comprehensiveness of repurposing a primary unit, commercial spaces (referred to as mercantile spaces in the OBC) should not be brought into a building that are horizontally adjacent to office, residential or assembly spaces. By organizing and establishing space relationships using the inherent properties of materials already within the building, selective repurposing of spaces can reduce material use and waste associated with the renovation.

A solution is needed for reducing the massive inherent waste of repeated interior renovations, specifically for that of drywall, which is associated with the frequent changing needs of office spaces. Moveable walls that make use of a component based structure allows for "unitized construction [with] moveable panels to be relocated without disassembly for faster installation and reconfiguration timelines" (Brownell, 2006, p.69). This method of modularity, which is currently limited to the office typology, can be modified for a base wall structure that matches with the two primary height dimensions of the design for repurpose system. The structure of the wall panels can furthermore be rotated to define spaces in both the $3 \mathrm{~m}$ floor height divisions and $4 \mathrm{~m}$ floor height divisions within a primary unit as explored in the physical model photos, figures 5.5 and 5.6. The full length of the space would not be completely enclosed and infill walls would be needed to eliminate the gaps. This allows for a hybrid of modularity for large spans of walls, while still ensuring that the system be sealed in place for acoustic, fire, and privacy concerns. Additionally, the full spans of wall-structure needed for the replacement of partitions during a renovation are reduced.

Combining this system with the ability for vertical maneuverability inherent within the structural composition, the possibility for promoting the joining or expanding of spaces horizontally, vertical connections up and diagonally across units were explored through the combination of two scales of physical model, figure 5.7 to 5.9. The outcome of this study shows the potential for unique and integrated possibilities of space configuration due to the combined tractability of the structural components and the partition systems in place. 


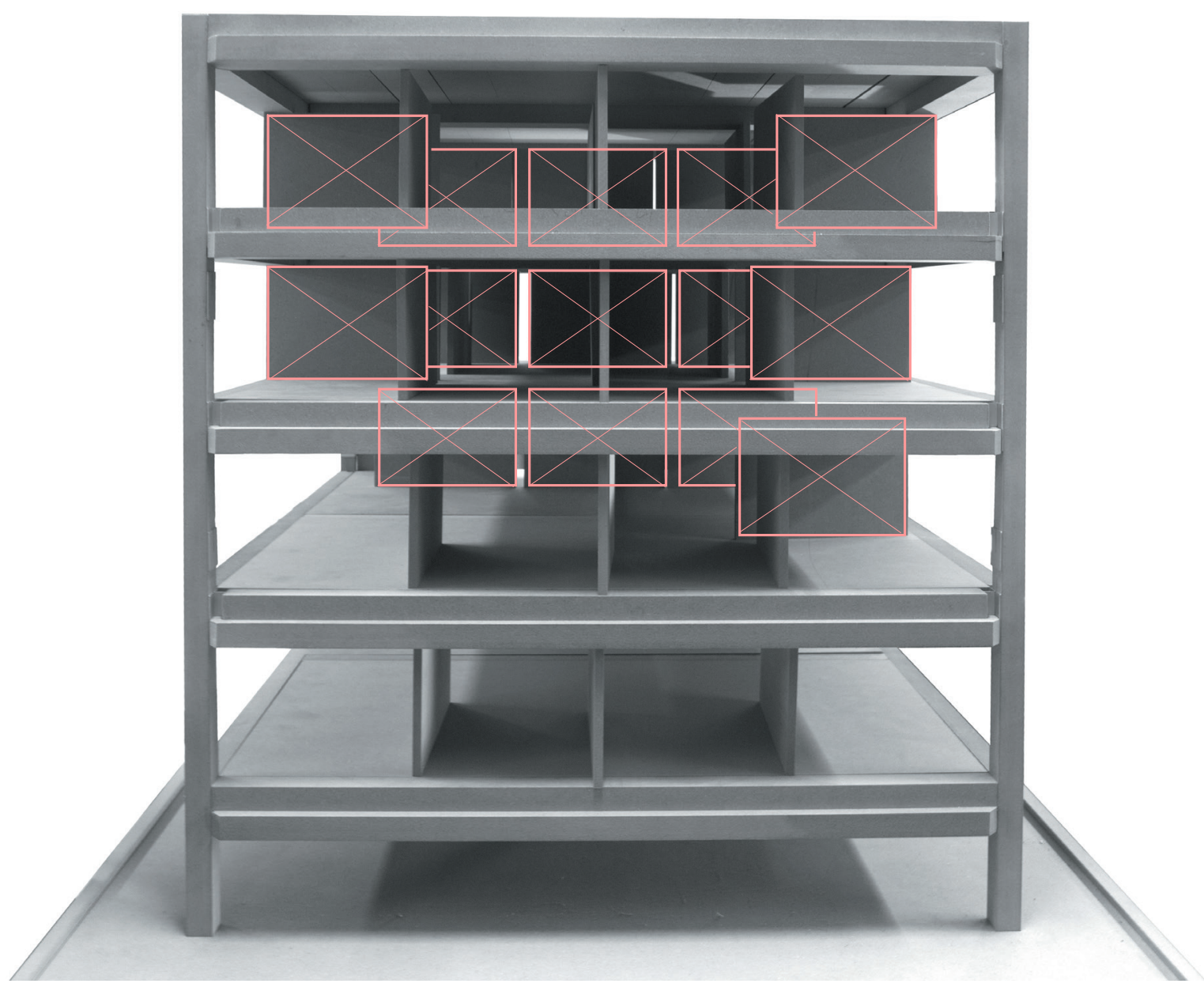

Figure 5.5: 1:20 Scale model of a single primary unit in $3 \mathrm{~m}$ floor to floor configuration. The moveable wall panels are positioned in their $3 \mathrm{~m}$ orientation. Gaps would be filled on site. 


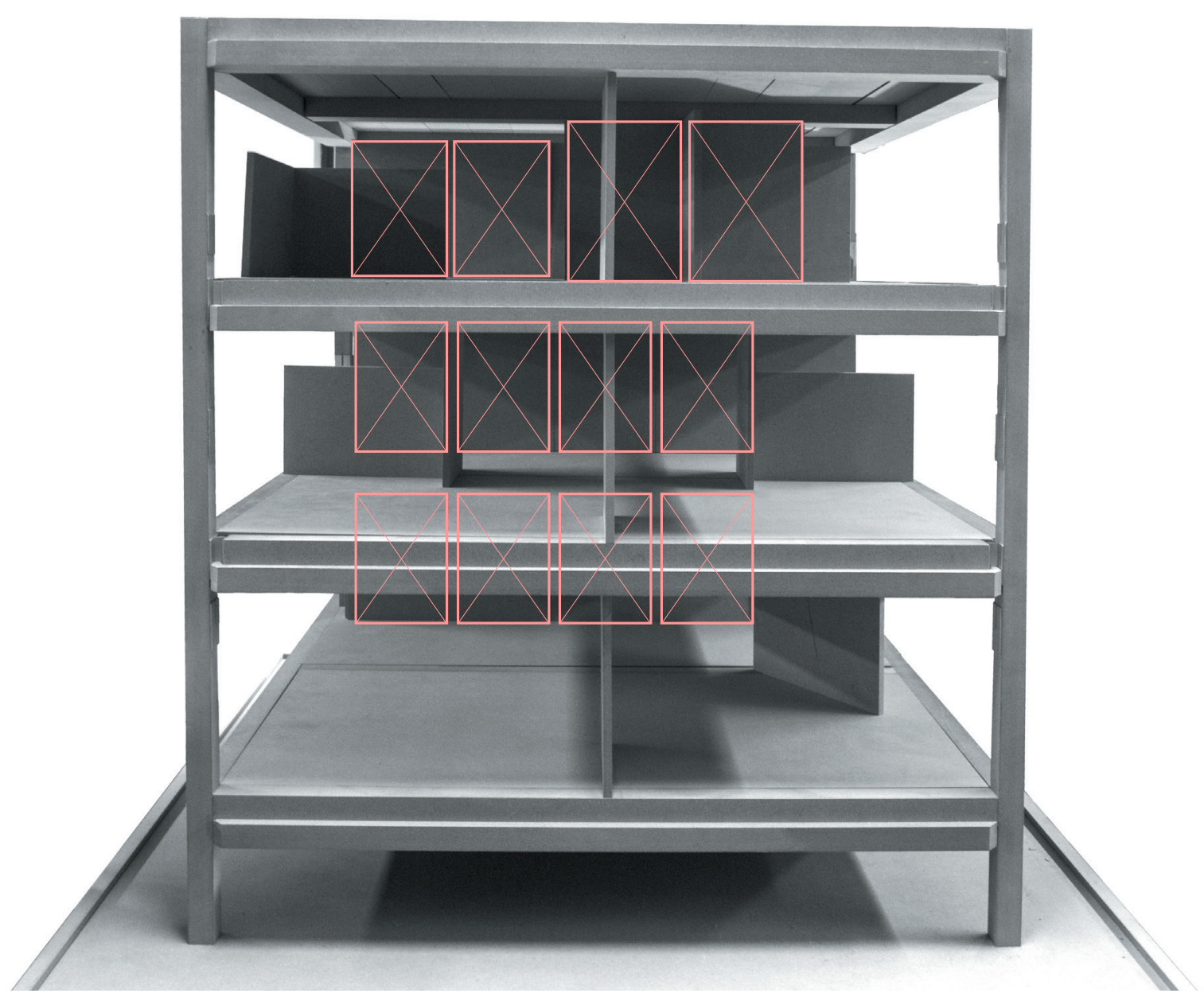

Figure 5.6: 1:20 Scale model of a single primary unit in $4 \mathrm{~m}$ floor to floor configuration. The moveable wall panels are positioned in their $4 \mathrm{~m}$ orientation. Gaps would be filled on site. 

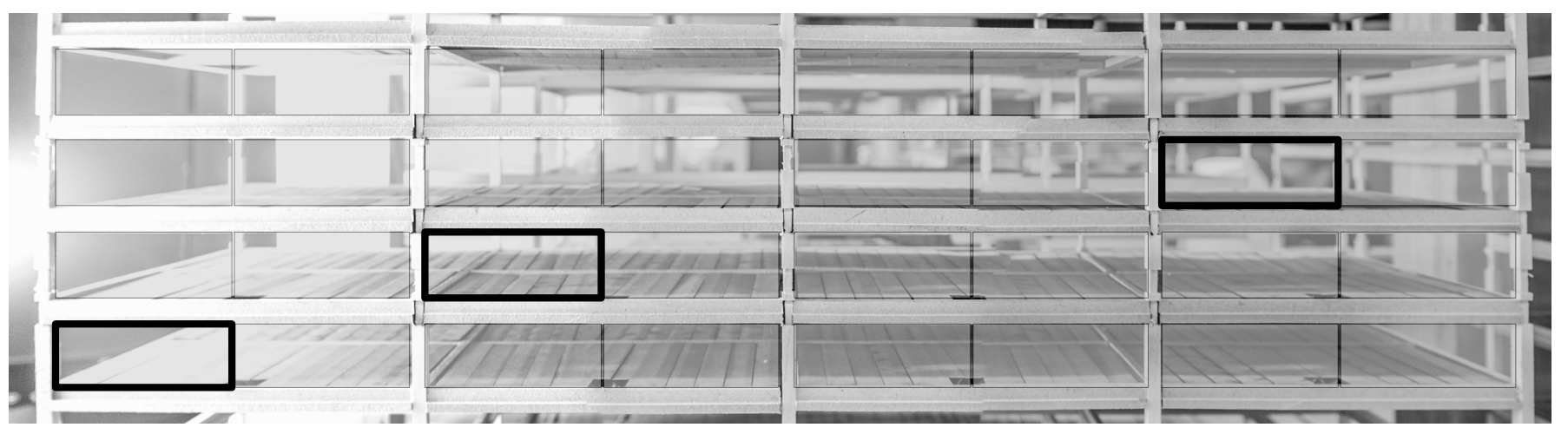

Figure 5.7a: 1/2 primary unit occupancy is 6 precast floor slabs wide and 1 level high divided by modular wall panels.
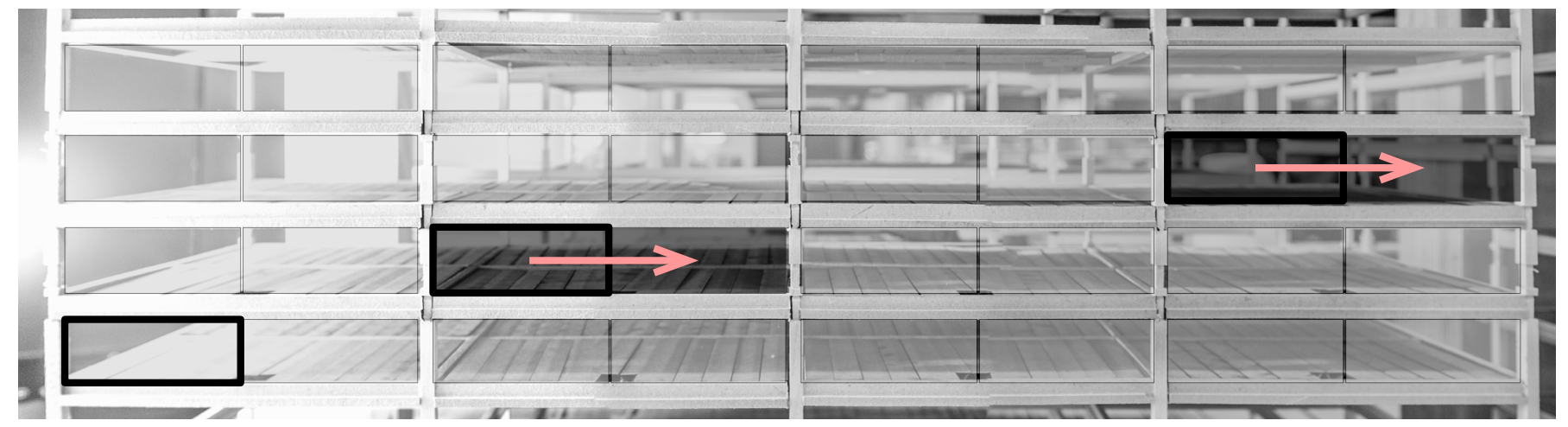

Figure 5.8a: Full primary unit occupancy is 12 precast floor slabs across and 1 level high divided by modular wall panels.
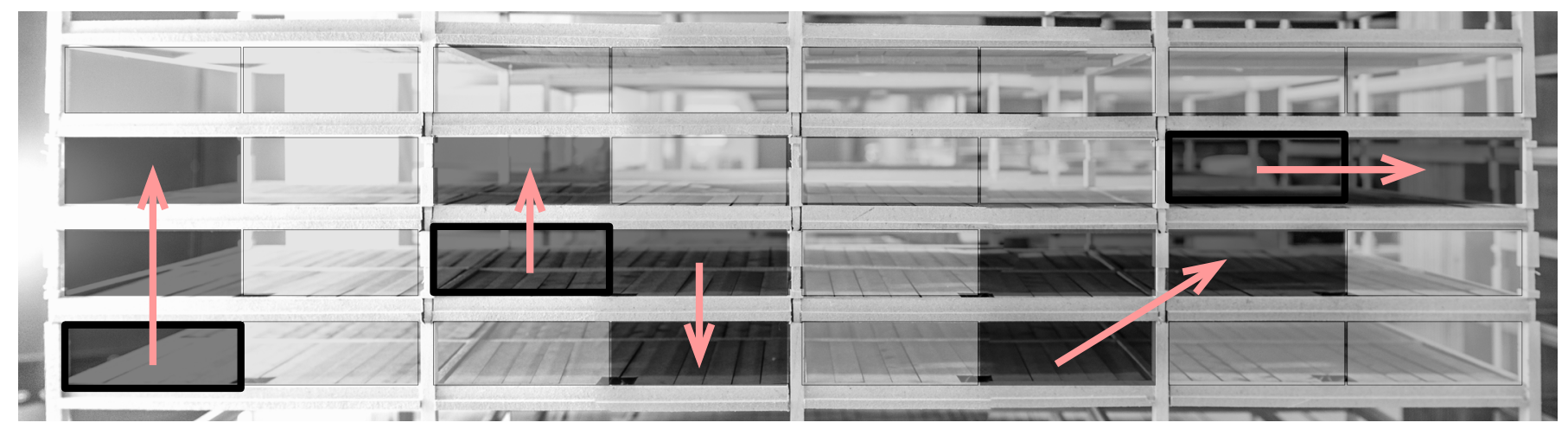

Figure 5.9a: 3-5 primary unit occupancy is 12 to 24 precast floor slabs wide and 1 to 3 levels high. Vertical expansion is achieved through the removal of 3 precast floor slabs for every level that is occupied. 


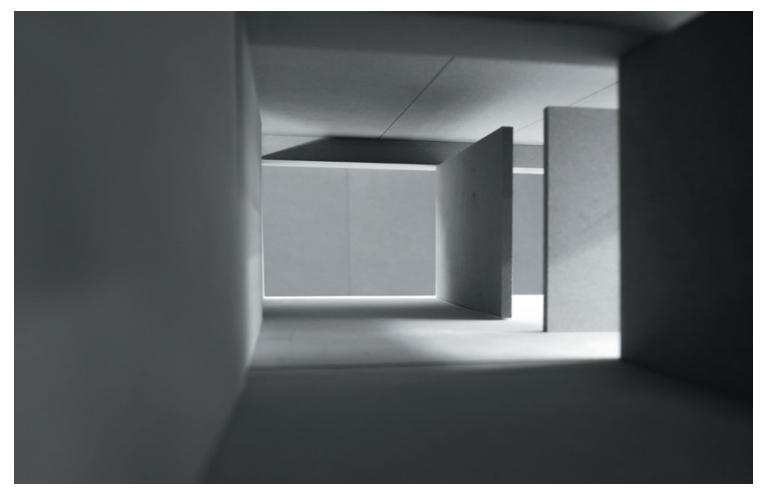

Figure 5.7b: Photograph showing possible layout of interior modular wall panels for $1 / 2$ occupancy.

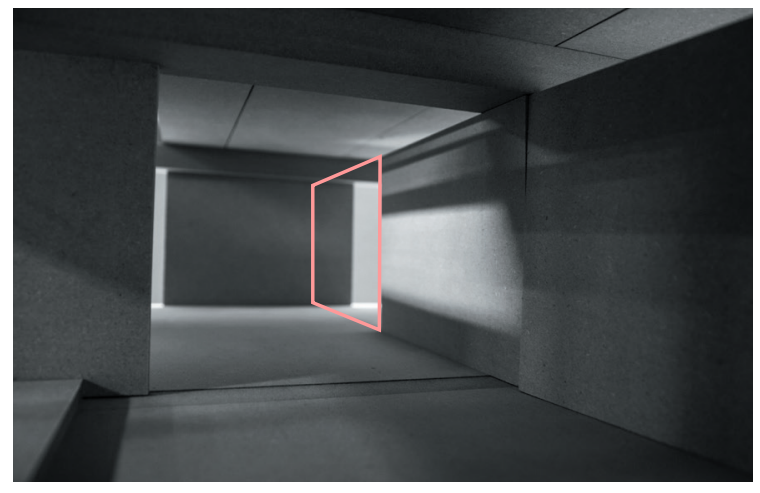

Figure 5.8b: Photograph showing the removal of one modular wall panel for horizontal expansion.

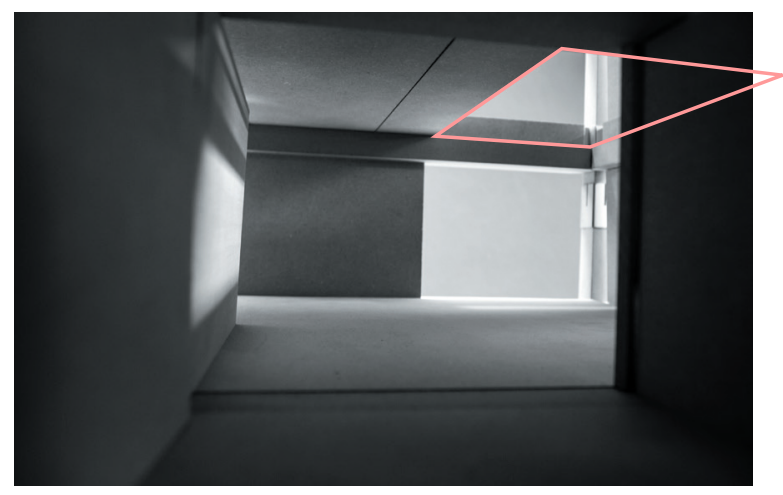

Figure 5.9b: Photograph showing removal of 3 precast floor slabs to increase occupied space vertically.

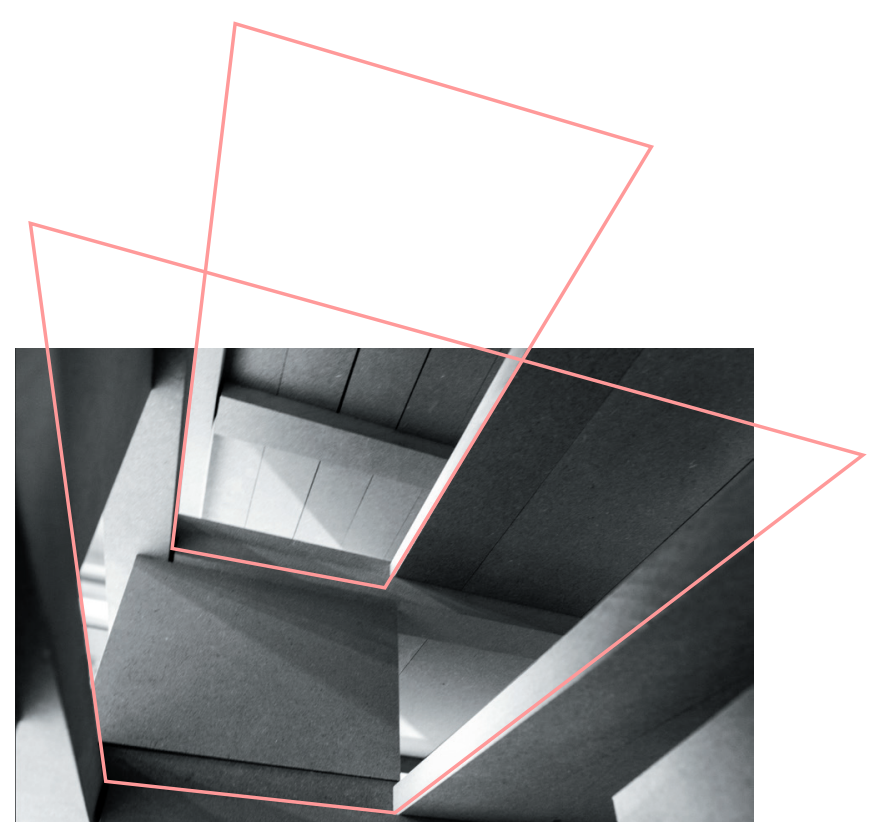

Figure 5.9c: Photograph showing extension upwards over multiple units. 


\section{ANALYSIS ON SITE}

When looking for sites to test the guidelines within the city of Toronto, a range of contexts were considered. Three sites were initially proposed that covered a range property sizes located in areas with a range of low to high density.

The first, figure 6.1, located at Richmond Street East and Victoria Street was explored for its large and dense urban infill. The second, figure 6.2, located at Danforth Avenue and Broadview Avenue, was explored to test the limits of how small of a site the system could be applied to. The third, figure 6.3, located at King Street and Dufferin Street, was explored for its relationship to the corner condition and historical context of industrial buildings. On each of these three sites, Chris Radigan and Michael McClellan's concepts of "loose program" or "program-less designs" were tested through massing studies and rough "free" floor plan explorations to test the flexibility of the system in various contexts, determining which of the 3 sites fit best with the system. The King and Dufferin Street site proved to provide the most realistic scale of implementation due to its site depth and linearity in comparison to the extreme constraints of site size and intense density of the other two sites that were proposed.

Having established an appropriate scale and context on which to test the guidelines, a fourth site was proposed in order to further the study of the guidelines outward, through the development of a city block over time. Located on the south side of College Street midway between Ossignton Avenue and Dovercourt Road, the proposal reached outside of its initial property lines to show the potential for future development over time, exploring the connection between the guidelines established in this thesis and the Avenues and Mid-Rise Study guidelines. 


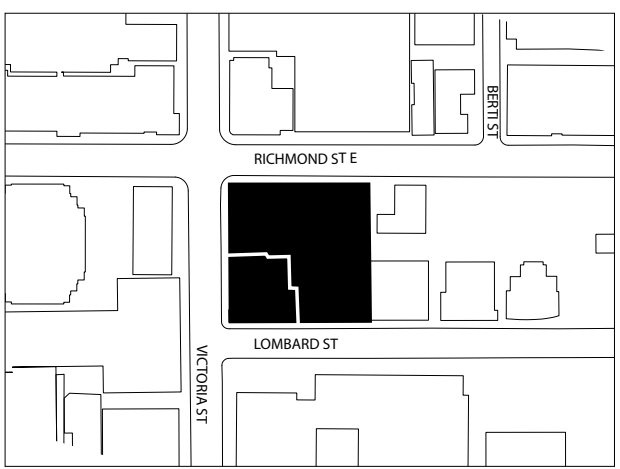

Figure 6.1a: A selection of drawings from the Richmond Street East and Victoria Street design test. This test revealed how the strategies would be delt with in a dense urban context within the city core. It shows the potential for wrapping the structural system around existing building and expansion over time yet highlights the obvious height cap on this system.

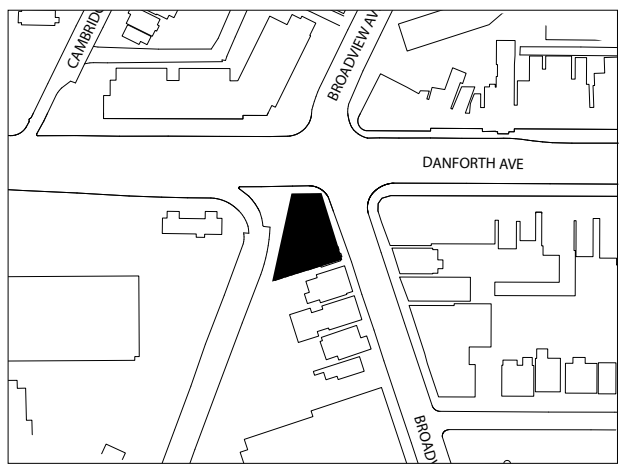

Figure 6.2a: A selection of drawings from the Danforth Ave. and Broadview Ave. design test. This test demonstrates restriction on site size to accommodate variations within the massing based on the structural proportions. Due to this, internal organization of circulation is limited.
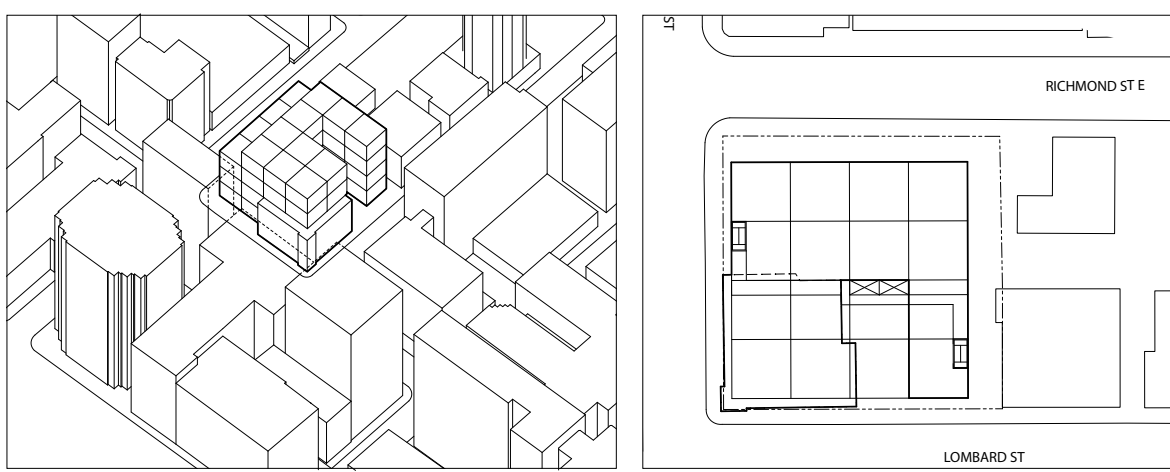

Figure 6.1b: Massing exploration with courtyard along the North-South Axis providing sunlight to the buildings interior.

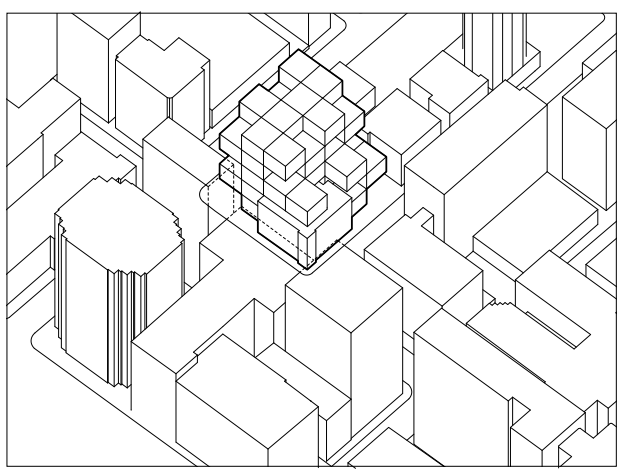

Figure 6.1d: Massing exploration with varied solid void relationships

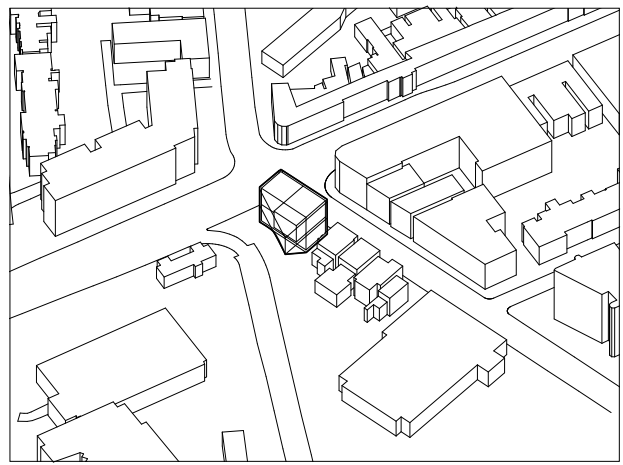

Figure 6.2b: Massing exploration on a small site.

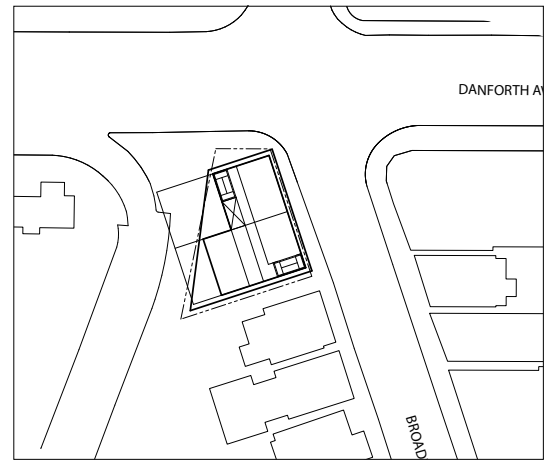

Figure 6.2c: Floor plan itteration of potential locaitons for circulation. 


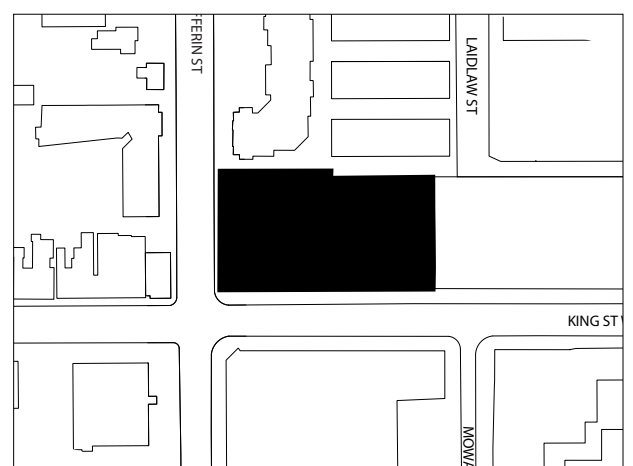

Figure 6.3a: A selection of drawings from the King Street and Dufferin Street design test. This test proved successful at demonstrating a realistic scale in which the Design For The Cycle system excels, allowing for multiple massing and floor plan organizations on site.

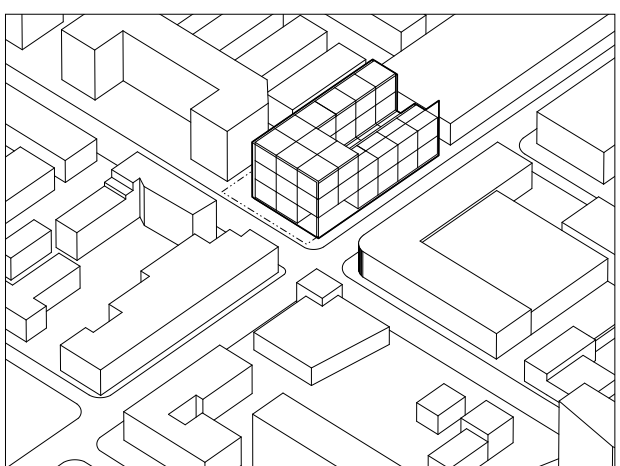

Figure 6.3b: Massing exploration with courtyard along the East-West axis providing sunlight to the North set of primary units.

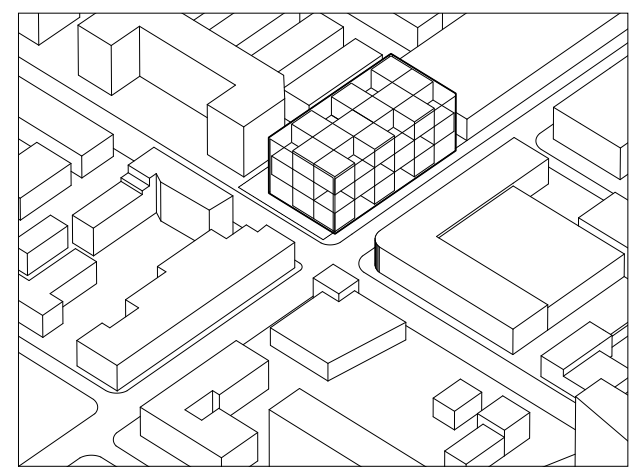

Figure 6.3d: Massing exploration with varied solid void relationships.

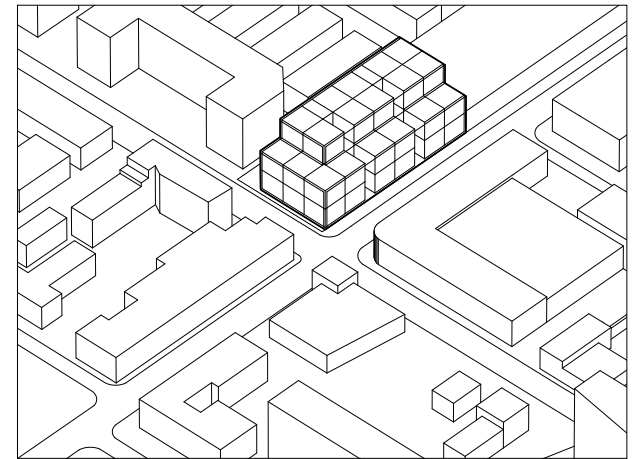

Figure 6.3f: Massing exploration with interior atriums parallel to North-South axis breaking up the volume into separate buildings.

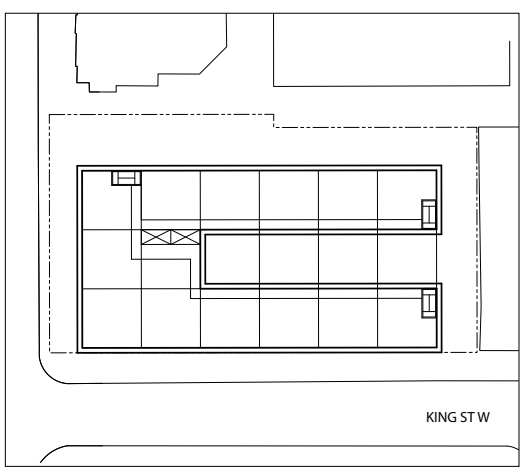

Figure 6.3c: Floor plan itteration of potential locaitons for circulation.

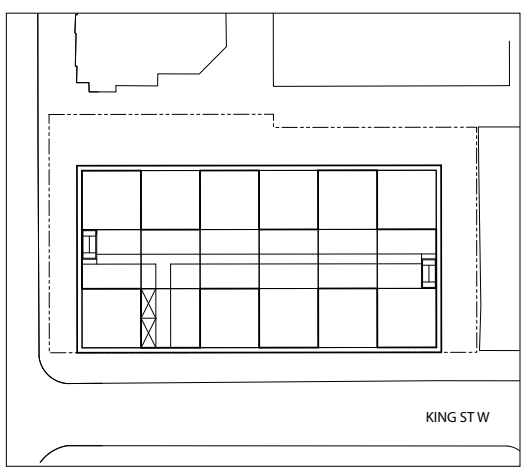

Figure 6.3e: Floor plan itteration of potential locaitons for circulation.

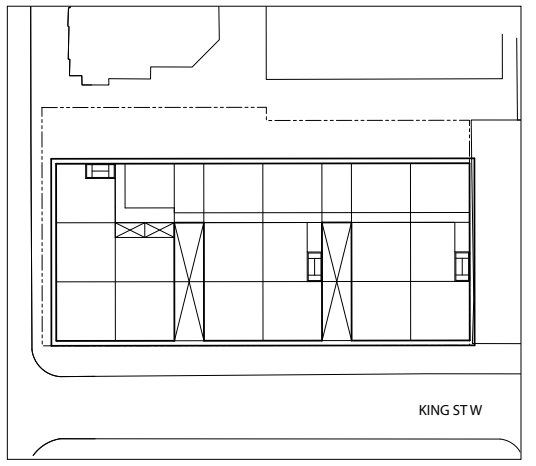

Figure 6.3g: Floor plan itteration of potential locaitons for circulation. 


\section{College Ossington}

Located on the south side of College Street, between Ossington Avenue and Dovercourt Road in Toronto, Ontario, Canada, figure 6.4, a city block master-plan of co-ownership development has been established to test the guidelines' tractability over time.

The first building on site, figure 6.5 , is capable of relocating $70 \%$ of the density of the entire block. As the development grows over time, similar developments under different ownership bodies can establish their own structures based on the same design principles, thereby interlocking the grids together as a complete fabric of built form, figure 6.6 and 6.7. Taking into account the strategies related to the façade development, the existing texture of College Street is maintained.

Throughout the development of the city block, leisure spaces are distributed within the grid, as well as through block public access to the laneway behind the built form on College Street. The laneway, intended for street level public access, will remain functional to provide service access and various amenity spaces as required by each building.

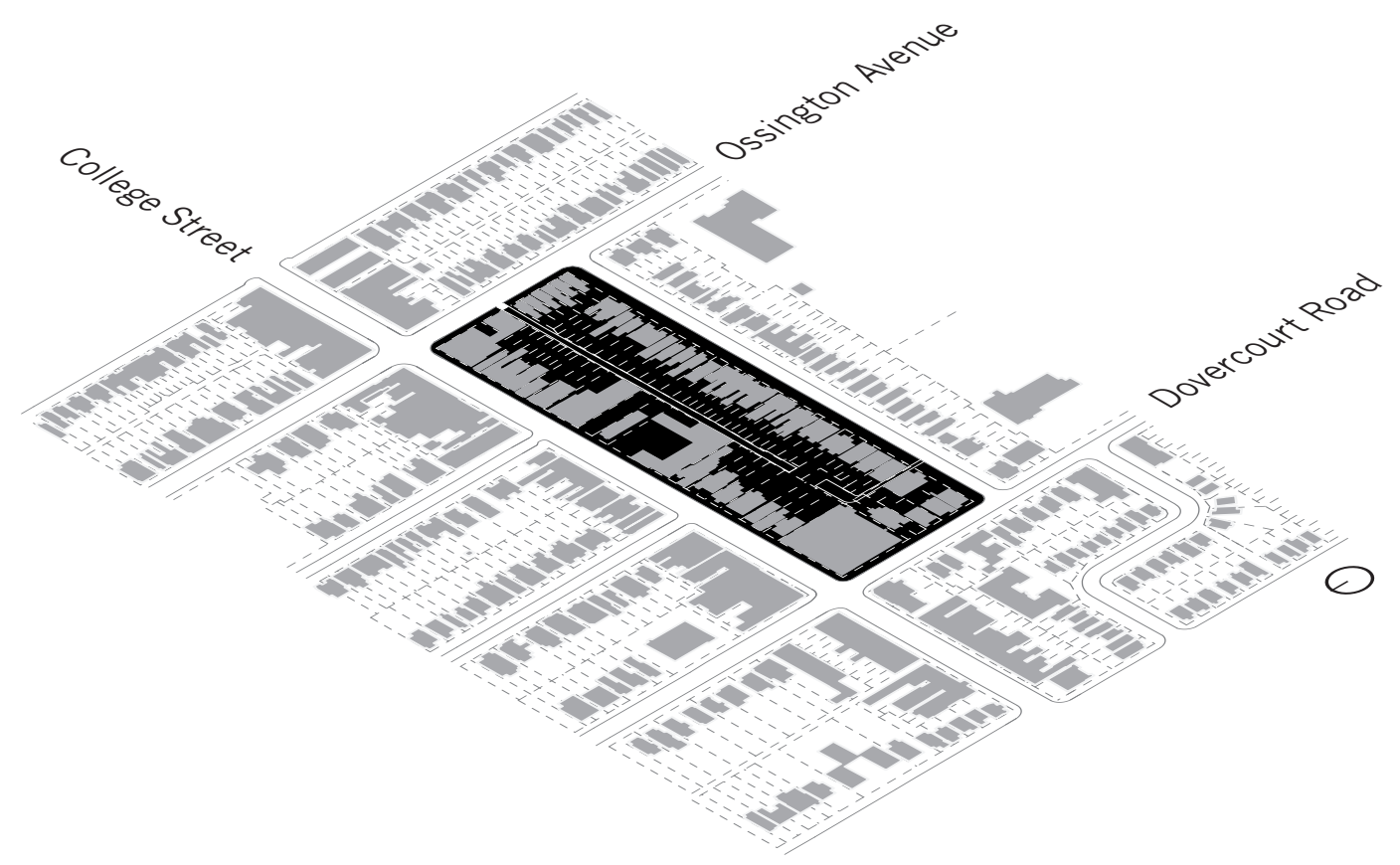

Figure 6.4: Map of a city block between Ossignton Ave. and Dovercourt Rd. 


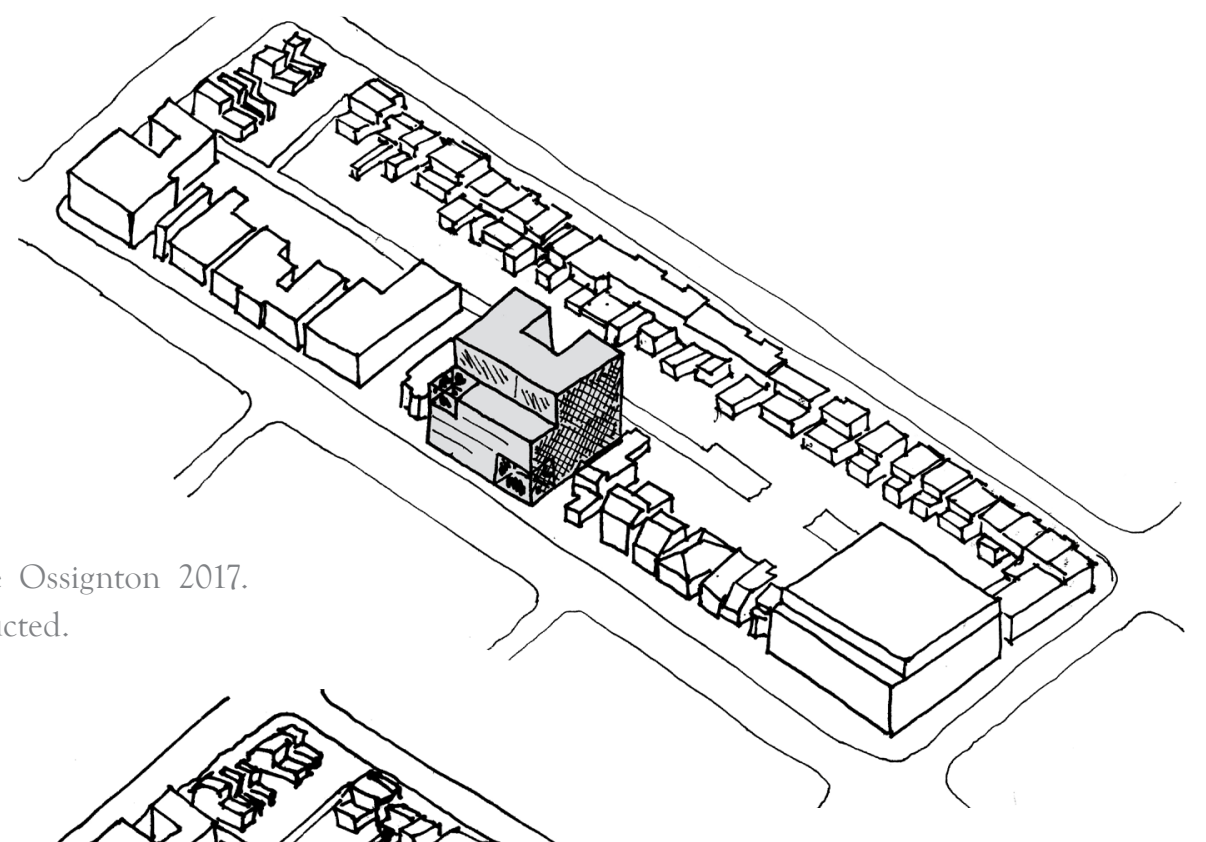

Figure 6.5: College Ossignton 2017. First building constructed.

Figure 6.6: College Ossignton 2037.

20 years development, expansion of fabric West. Through site access created.

Figure 6.7: College Ossignton 2060. 40 years development, expansion of fabric south and east. Multipule change of occupancy occures.

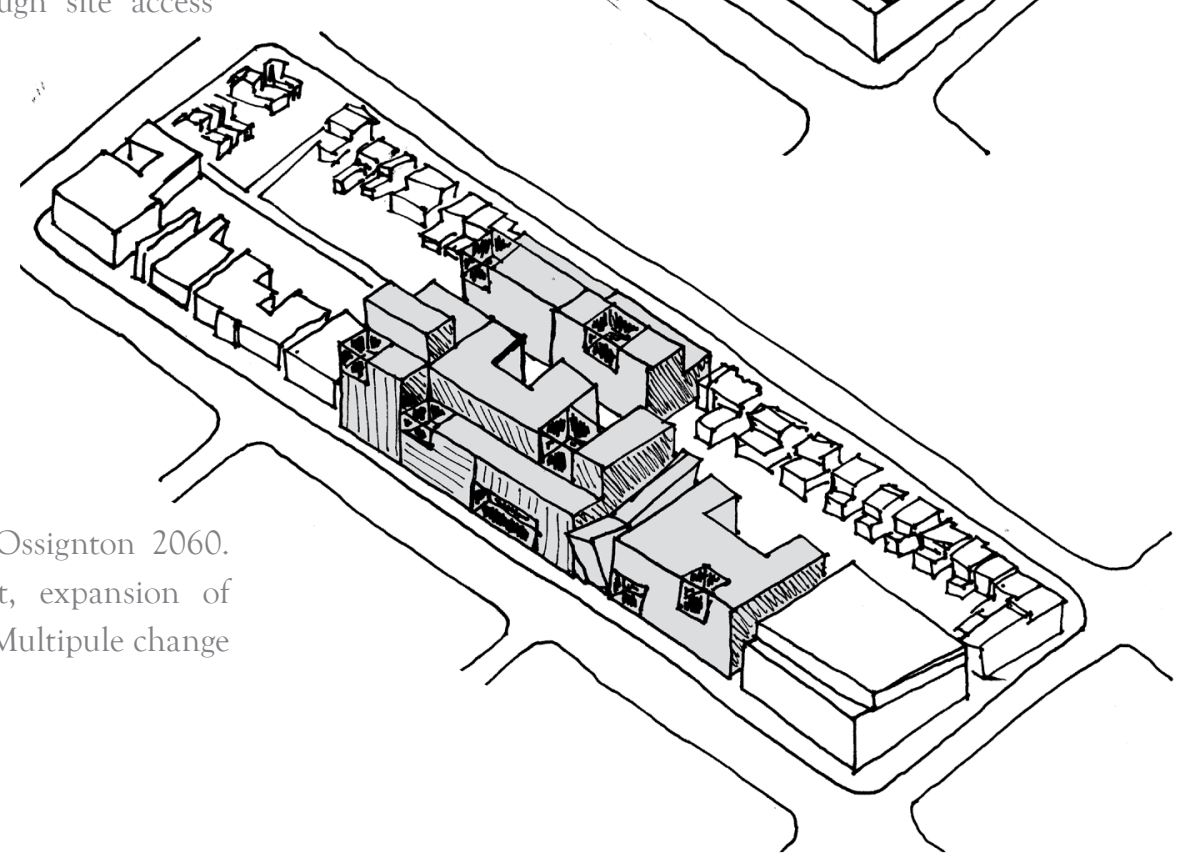




\section{King Dufferin}

Located at the north-east corner of King Street and Dufferin Street, figure 6.8, a gateway into the well-known Liberty Village neighbourhood in Toronto, Ontario, Canada, is a mixed-used building designed for the function and enjoyment of residents, businesspeople and neighbouring community members, and is proposed to test the comprehensiveness of the guidelines in this thesis over time.

Dividing the site into the primary units figure 6.9 shows a mass of forty two primary units assembled into a three-dimensional fabric grid. At the time of initial design and construction, the project incorporated fifteen residential units each divided into four levels, eight commercial units divided into two levels, and nine office units divided into three levels. Six units were left to service the upper floors of both office and residential areas with circulation and amenity space. Four units were distributed throughout the building as garden and hardscape leisure spaces. In addition to spaces within the grid organization, three elements of circulatory and communal space are offset from the grid as permanent fixtures on site.

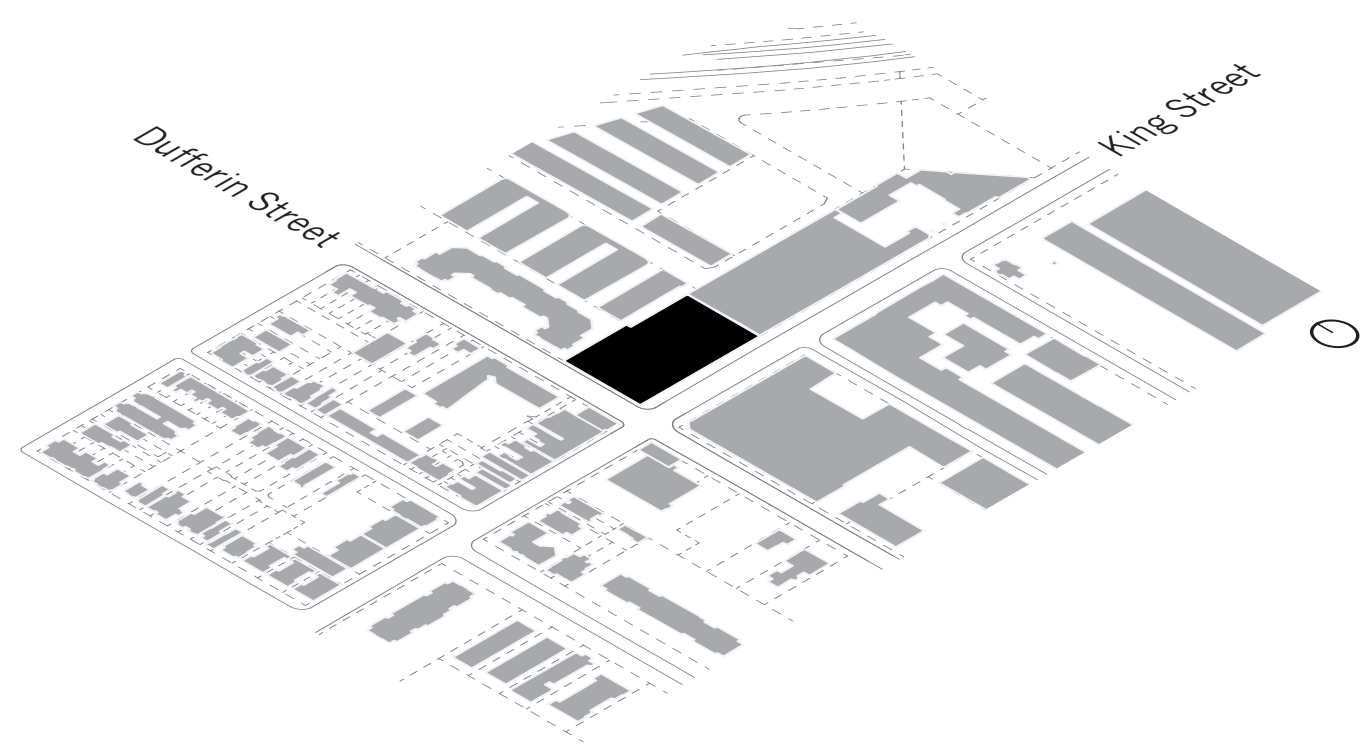

Figure 6.8: Map of city block between King Street and Dufferin Street. 


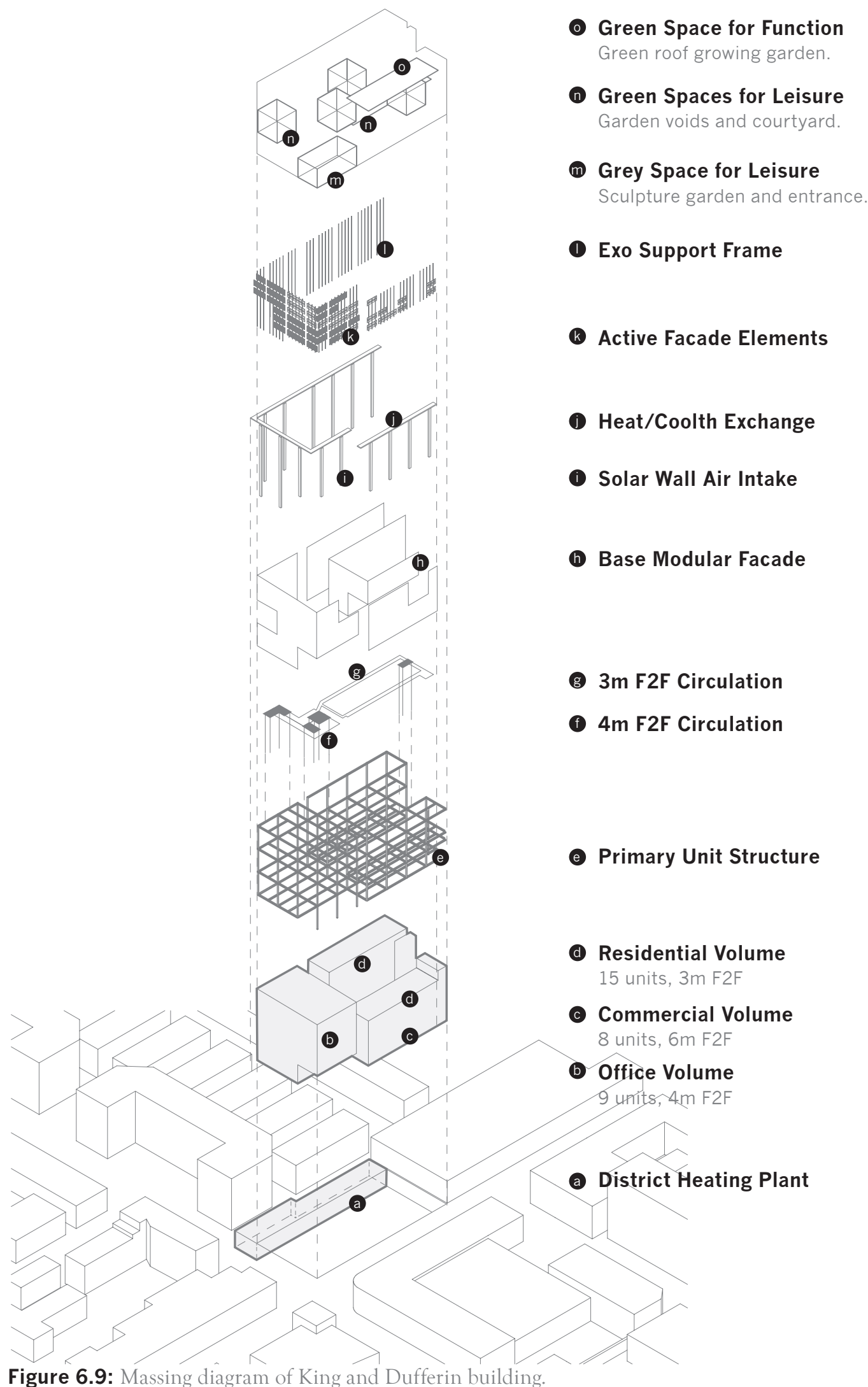




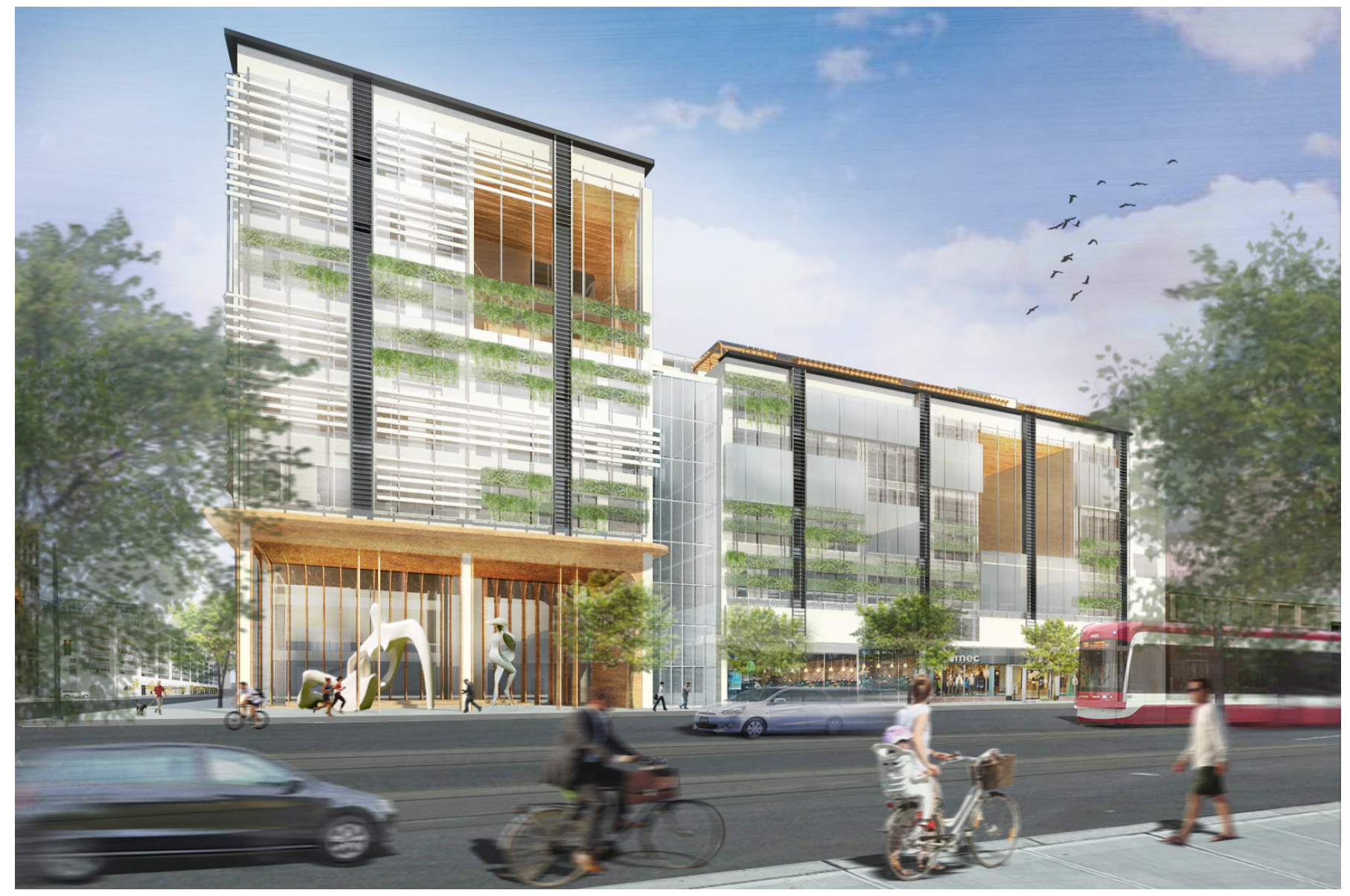

Figure 6.10: South façade along King Street. 
The building at King and Dufferin has a series of inter-connected spaces that reinforce the potential for growth and unique identity that is rooted in a coownership development and drives the continuation of repurposing of the building from the Design For The Cycle guidelines that enabled its creation. This connection is first experienced at the ground floor void as an entrance sculpture gallery, figure 6.10 , into the central atrium void and continues up through the courtyard, gardenvoids and green roofs; the connectivity of the spaces allows for the union of the seemingly disconnected programs and activities throughout the building. This series of connected spaces expands the definition of enclosure from the common understanding as delineation between interior to exterior boundaries, to a tractable element of architecture that can be modified to facilitate the changing needs of the building's occupants. This reinforces the ideas of designing for repurposing and designing for the full life-cycles of the cities fabric buildings. 


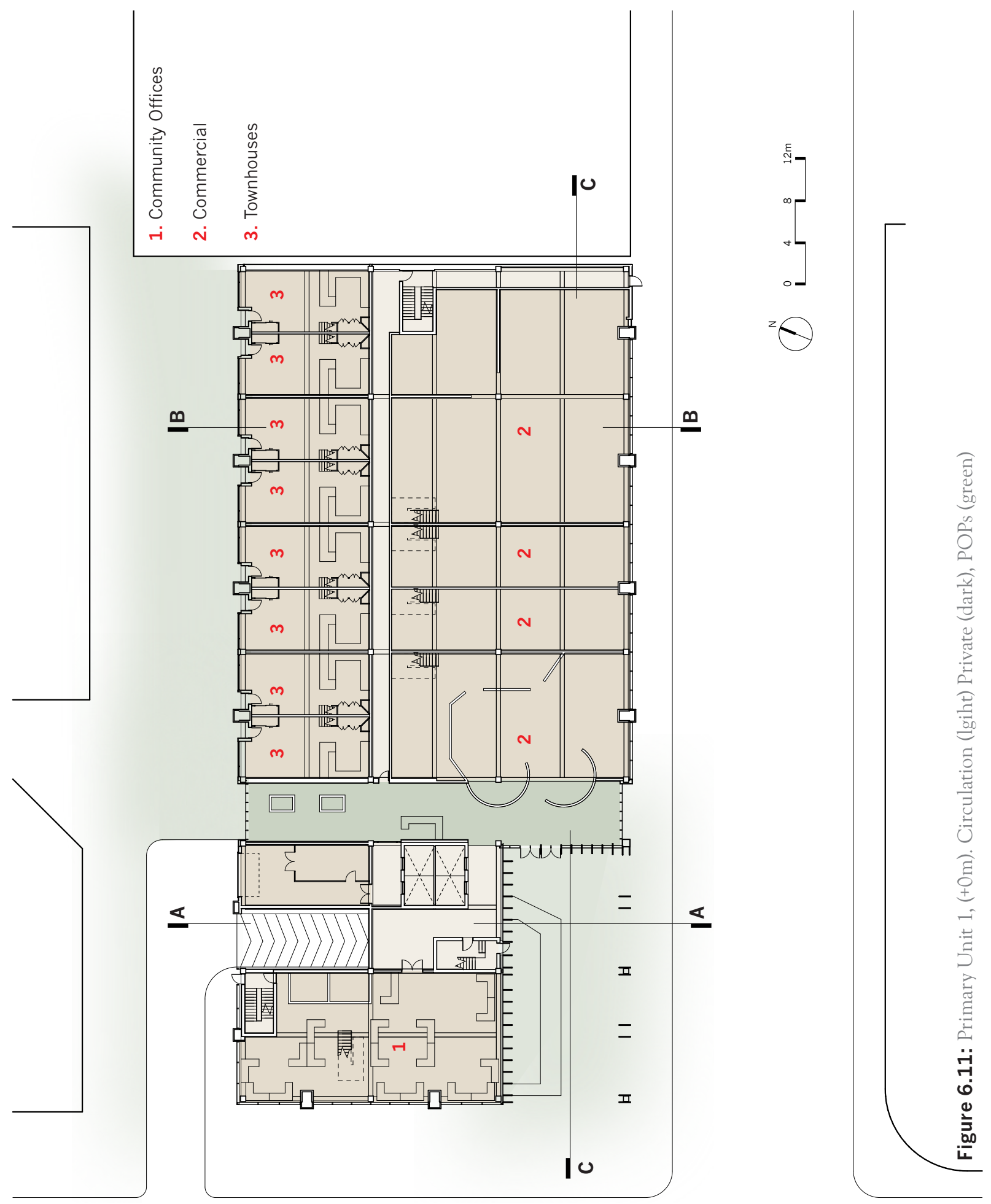



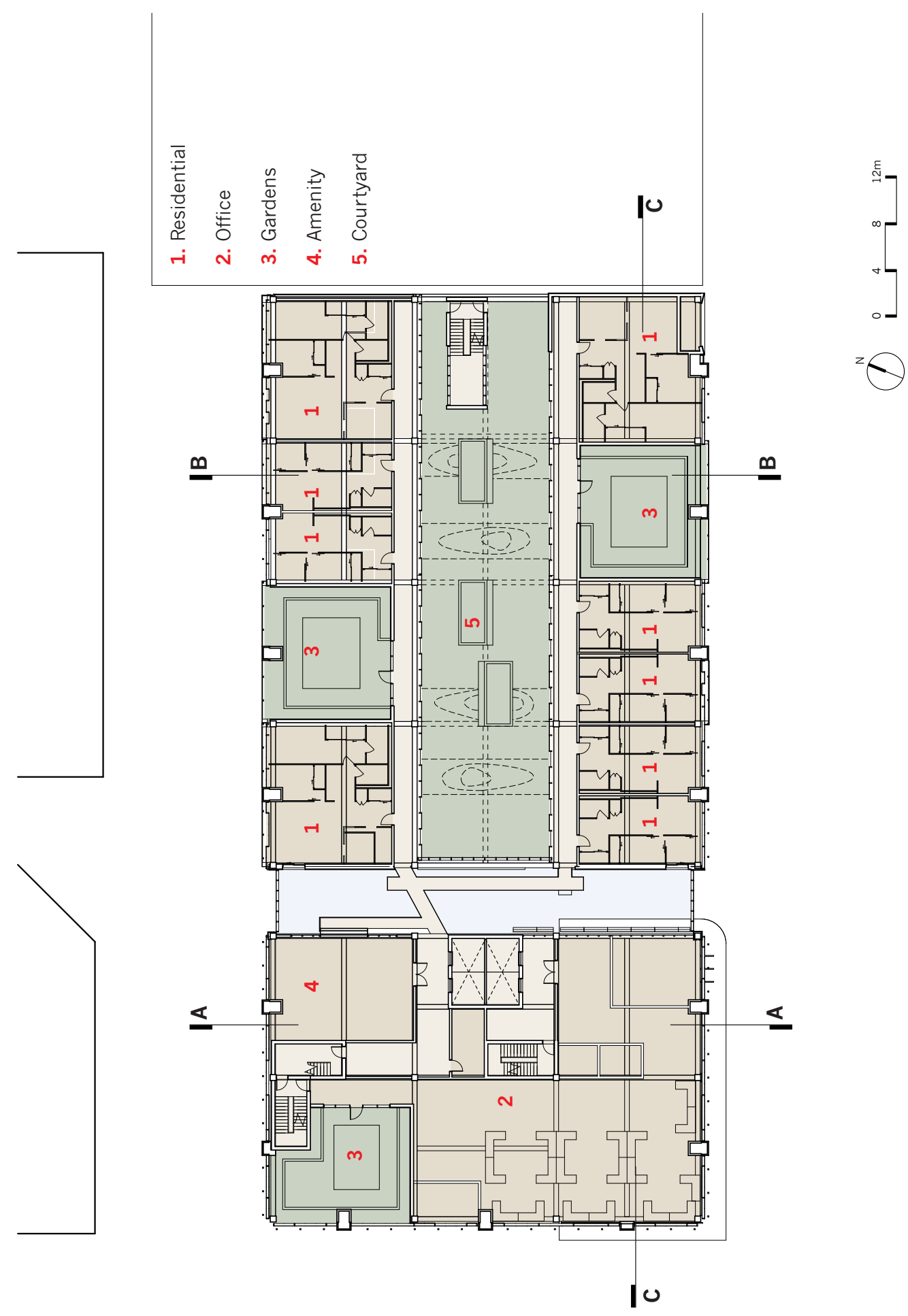


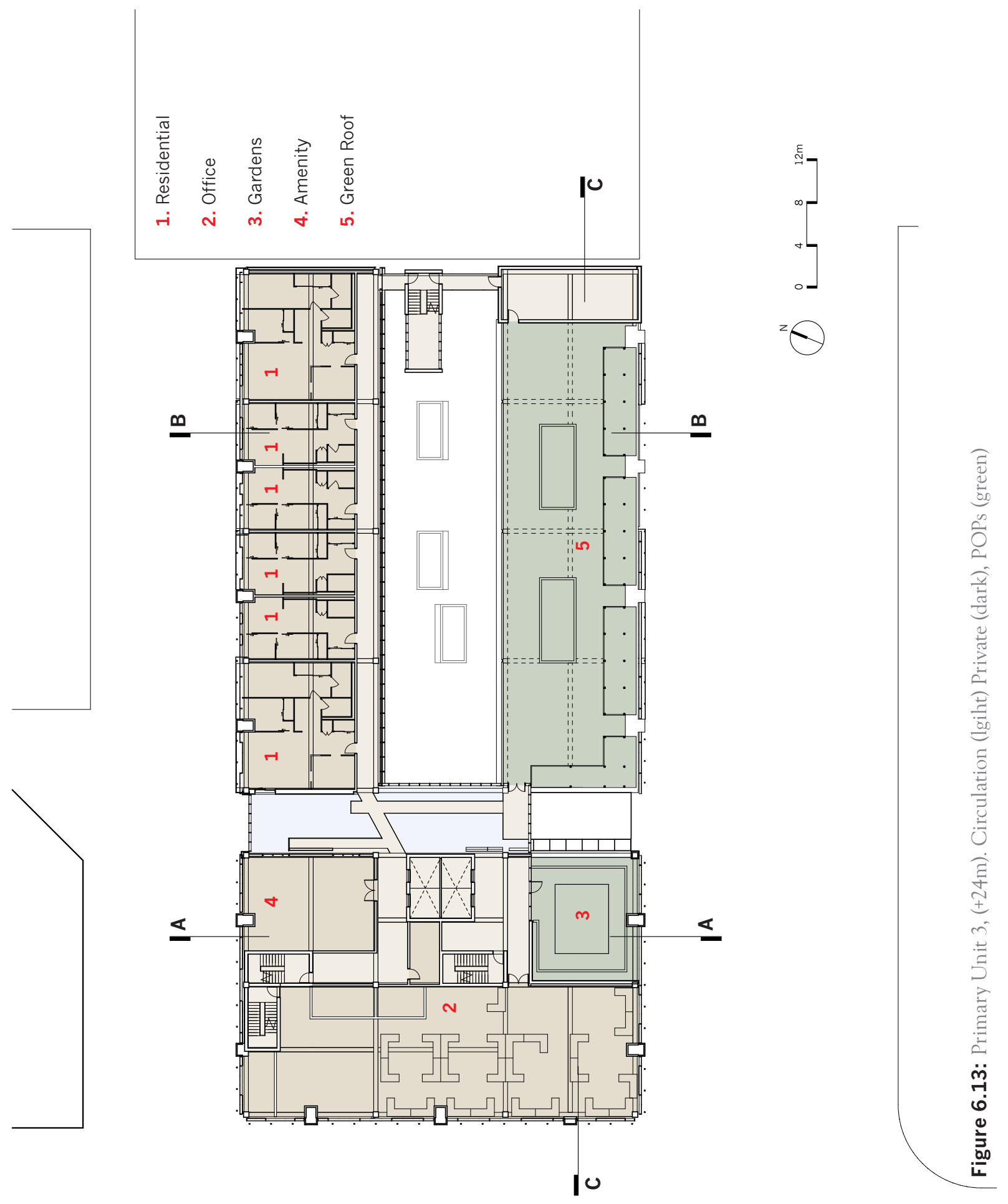




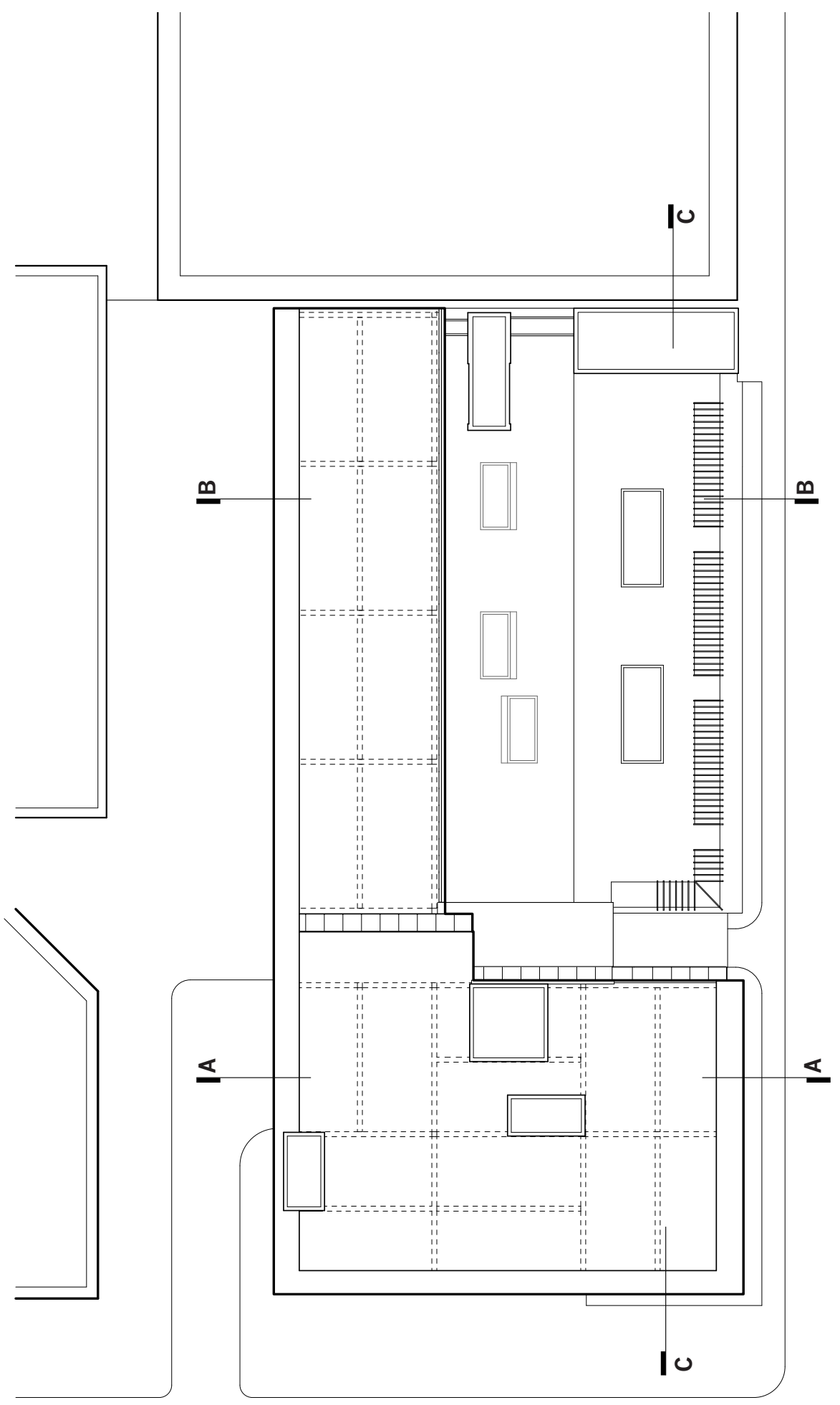

$\left[\begin{array}{l}{ }^{+} \\ 0 \\ 0 \\ 0\end{array}\right]$
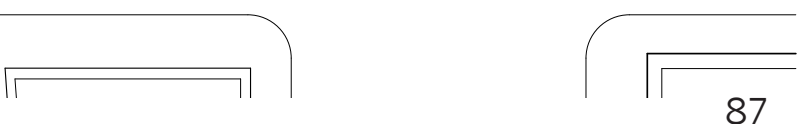


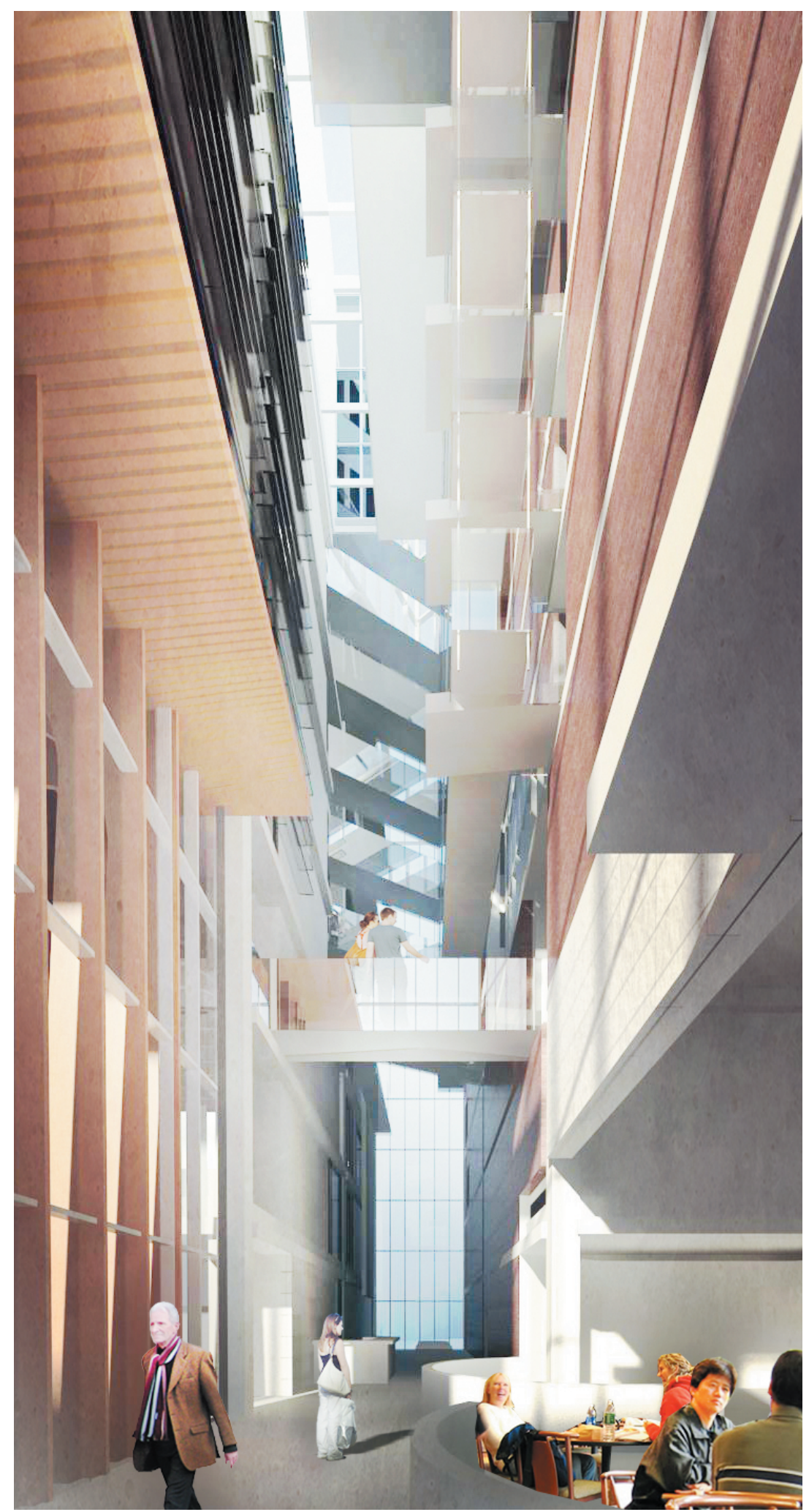

Figure 6.15: Atrium looking to the North 
The underlying principles expressed throughout the building are best found at the intersection of the units' fabric with a counterpoint feature. Looking through the main atrium, figure 6.15, the two masses of the building are visible on each side, pulled apart to allow access through to the laneway at the north. Flanking the elevators for both the residential and office units, lightweight suspended walkways bridge the void in a circulation free-space providing interconnected access from each various level within the primary units to the vertical circulation. Due to the lightweight nature of the steel frame walkways, their placement can be modified to provide access to features within the atrium needing service, such as the green wall located on the north-west side of the atrium, figure 6.16. The void allows for public access not only to the laneway behind, but also directly from the units on each side. Visual permeability from the offices on the west side and residents on the east side, as well as physical ground level connections from the commercial occupants, spill out from the linearity of the frame into the atrium creating diverse connections of activity among the various programs within the building.

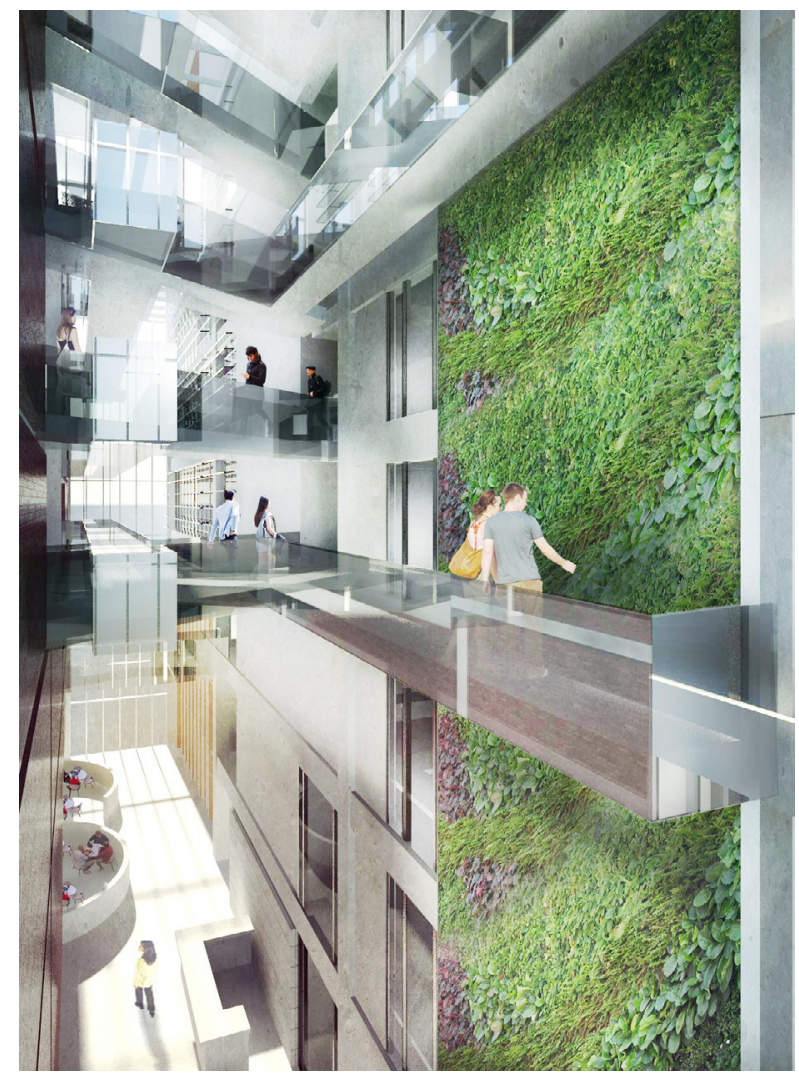

Figure 6.16: Atrium looking to the South 


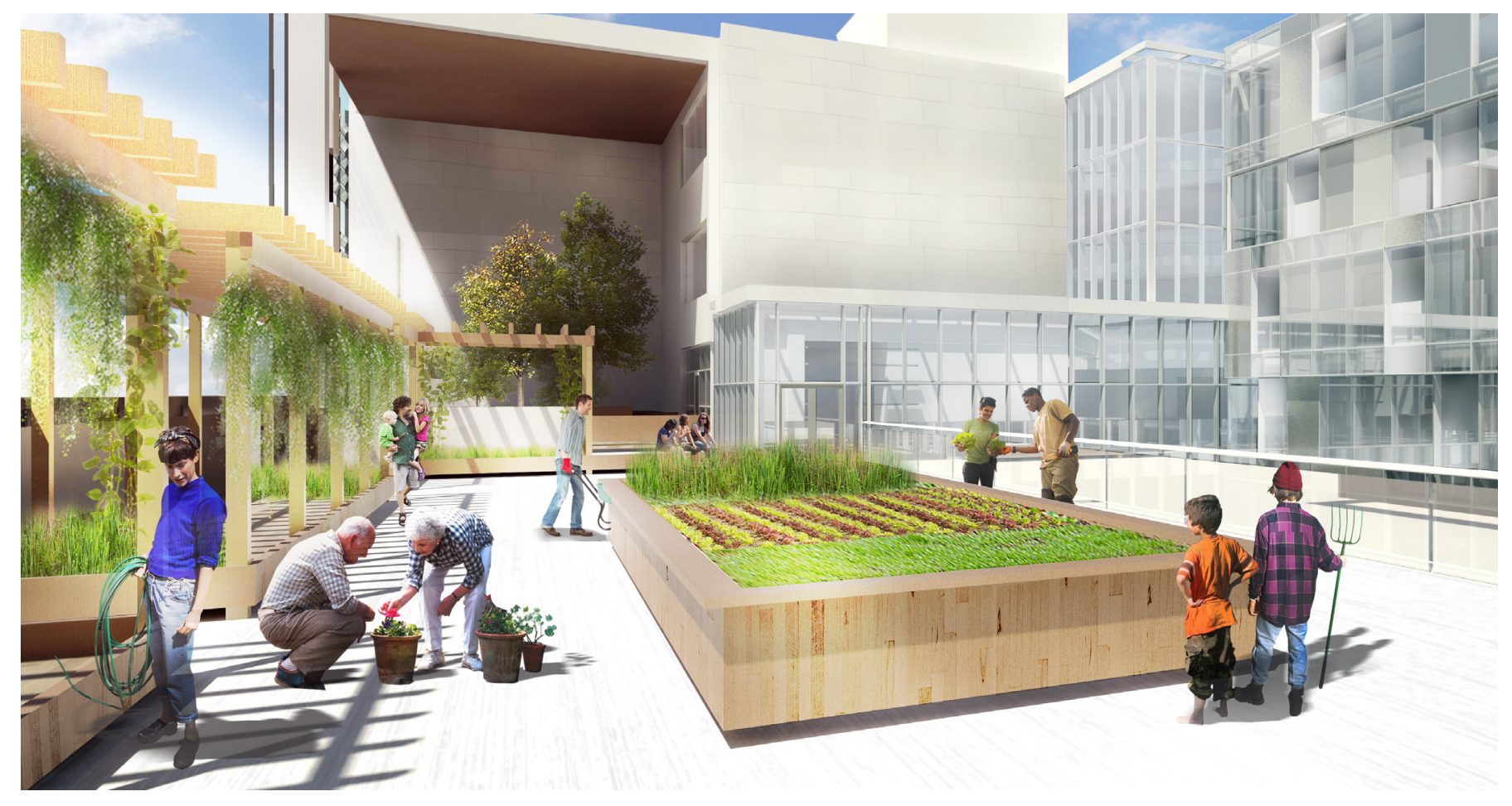

Figure 6.17: Green roof garden looking North West. 
Spaces such as rooftop and garden voids utilized for growing produce and for leisure, allow for the interaction of the building's community members throughout various locations of the building. The rooftop garden, accessed via a walkway and door from the central atrium, provides an occupiable green roof in which to partake in community building activities, such as a community garden, figure 6.17. Similar examples exist around the city of Toronto, such as the green roof at the 401 Richmond building, which is accessible to its tenants. Alternative garden-voids permeate the building as primary unit voids and are occupied as leisure space that mirror activities, such as backyard green space and public parks shown as one iteration in figure 6.18. The diversity of the primary unit is best seen in the juxtaposition between these open garden-void spaces and the traditionally occupied residential or office spaces, all of which fill the volumes created by the primary frame.

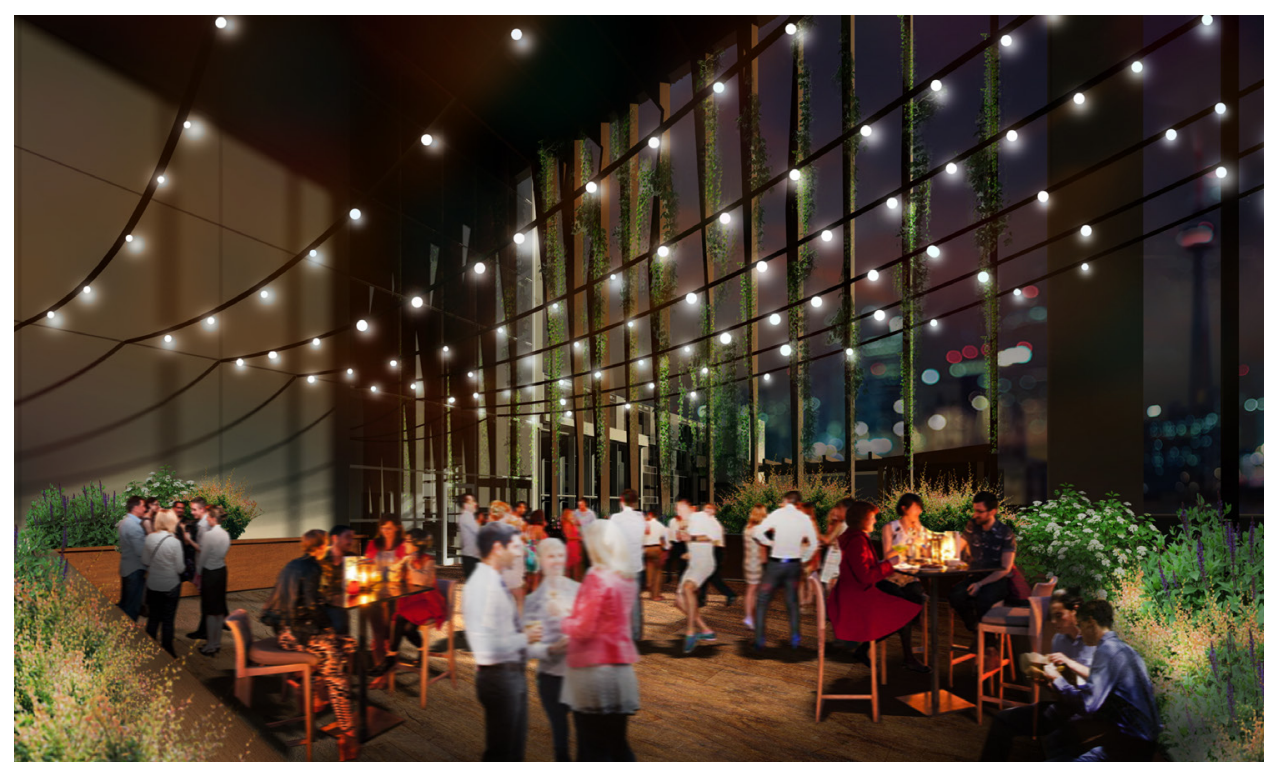

Figure 6.18: Garden void on level 3A looking North East. 


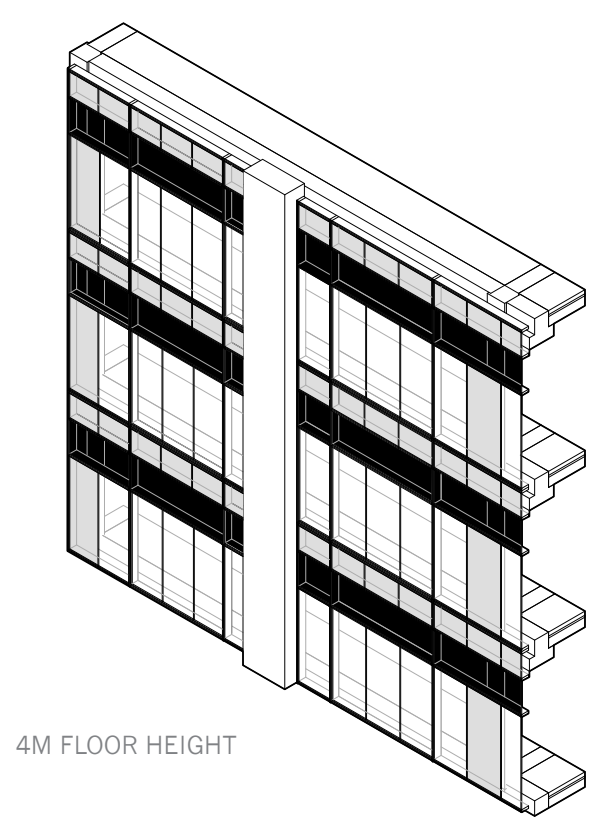

Figure 6.19: Base façade of one primary unit.

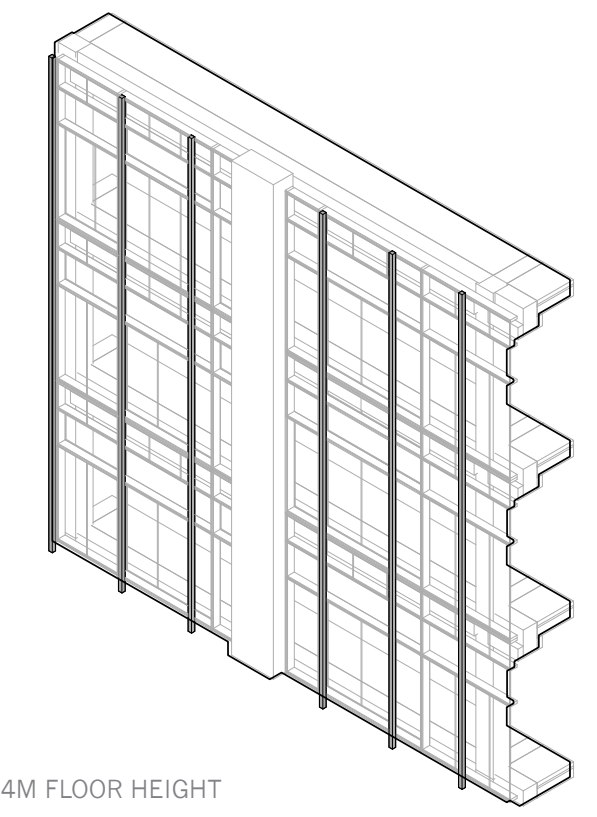

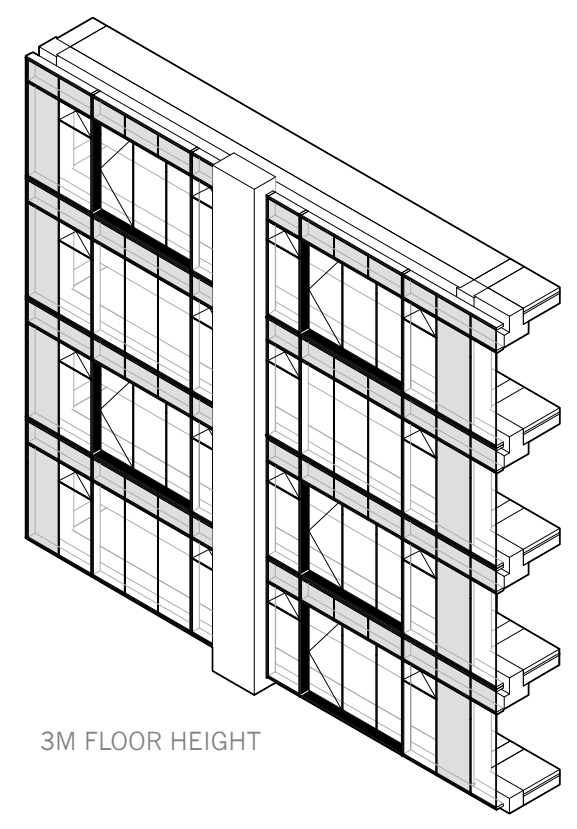

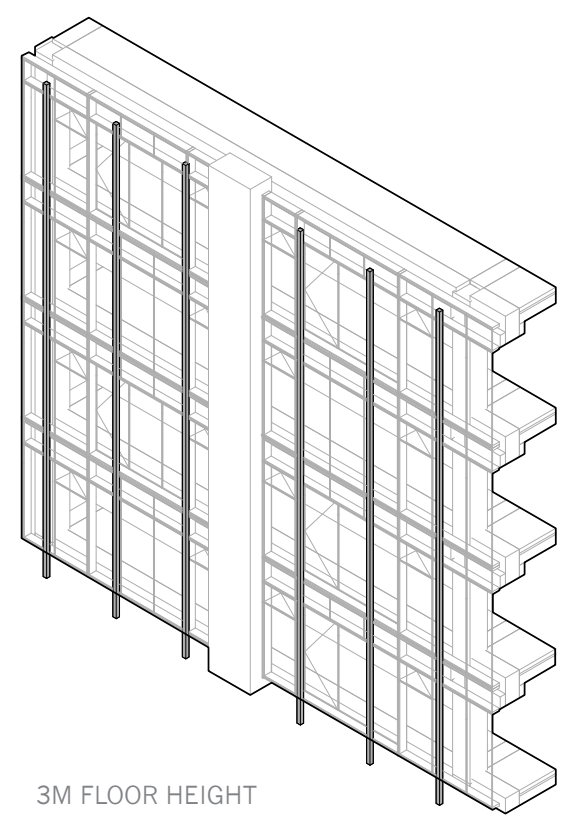

Figure 6.20: Steel frame stretches across the base façade to provide support to additional active facade elements. 
Wrapping the exterior of the building is the base curtain wall system established from the guidelines of repurposing. Composed of transparent glass, opaque spandrel and translucent insulated panels, they are distributed across the façade within a stick assembled mullion system. For each type of occupancy, various levels of recession of the panels for the addition of balconies, or to highlight the horizontal bands that differentiate the variations in floor height across the building, figure 6.19. The steel frame, figure 6.20, is offset from the base façade and provides a second layer of support for active systems supporting the function of energy production through solar voltaic panels, creating shade with various louvered screens, as well as supporting the extension of living spaces through enclosed or open balcony spaces within the volume of the façade, figure 6.21. By allowing the variations technological advances, testing of new systems, and frequent occupancy changes to occur over time, the skin of the building develops organically in the same way that the overall frame of the building facilitates complex growth over time.
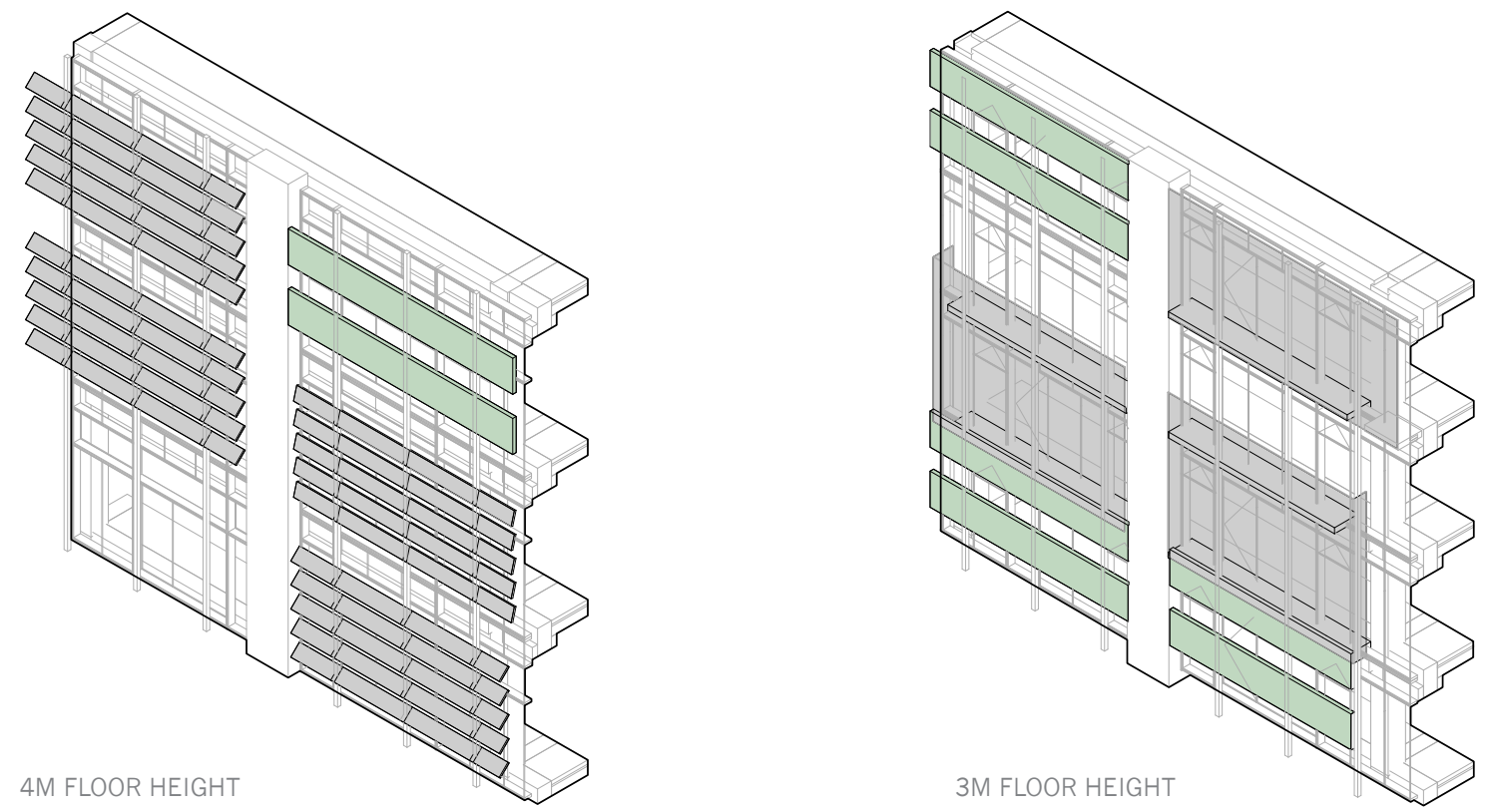

Figure 6.21: Active façade elements such as green wall panels, solar louvers, or occupied solariums are structured off of the steel frame allowing demountable components to be changed over time. 


\section{Repurposing: Scenario 1}

Accessed from the garden-voids on the second tier of primary units (Level 2a) the interior open-air courtyard, figure 6.22 and 6.23 , connects the community spaces throughout the building with visually and physically wherever possible. Facing the courtyard, sliding glass panels enclose the circulation paths that provide access to the residential units, creating a visual and physical connection into the courtyard. The ability to completely open the façade softens the connection between inside and outside spaces at the building's interior, yet provides complete enclosure when necessary. The envelope panels are kept to the same dimension as the exterior façade to allow them to be relocated if necessary, should the courtyard be enclosed as completely interior space in the future (as demonstrated in this scenario). By acting as a soft boundary, the façade of the courtyard can also be kept or maneuvered with the intent of providing alternative on-site means to define interior space in the future, figure 6.24 .

Potential to raise the courtyard level, enclosing the space shown in figure 6.20 .

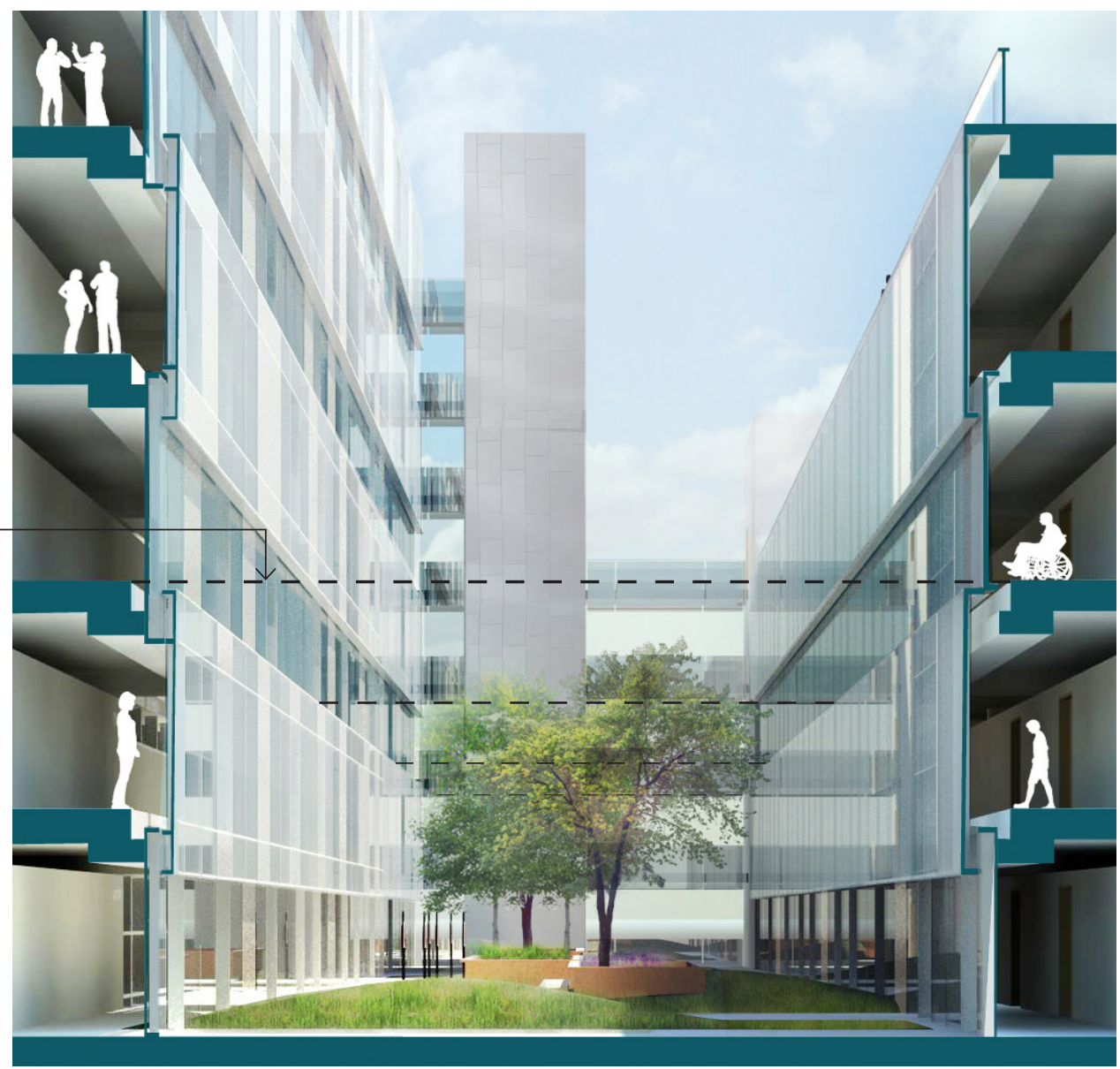

Figure 6.22: Sectional perspective through courtyard. 


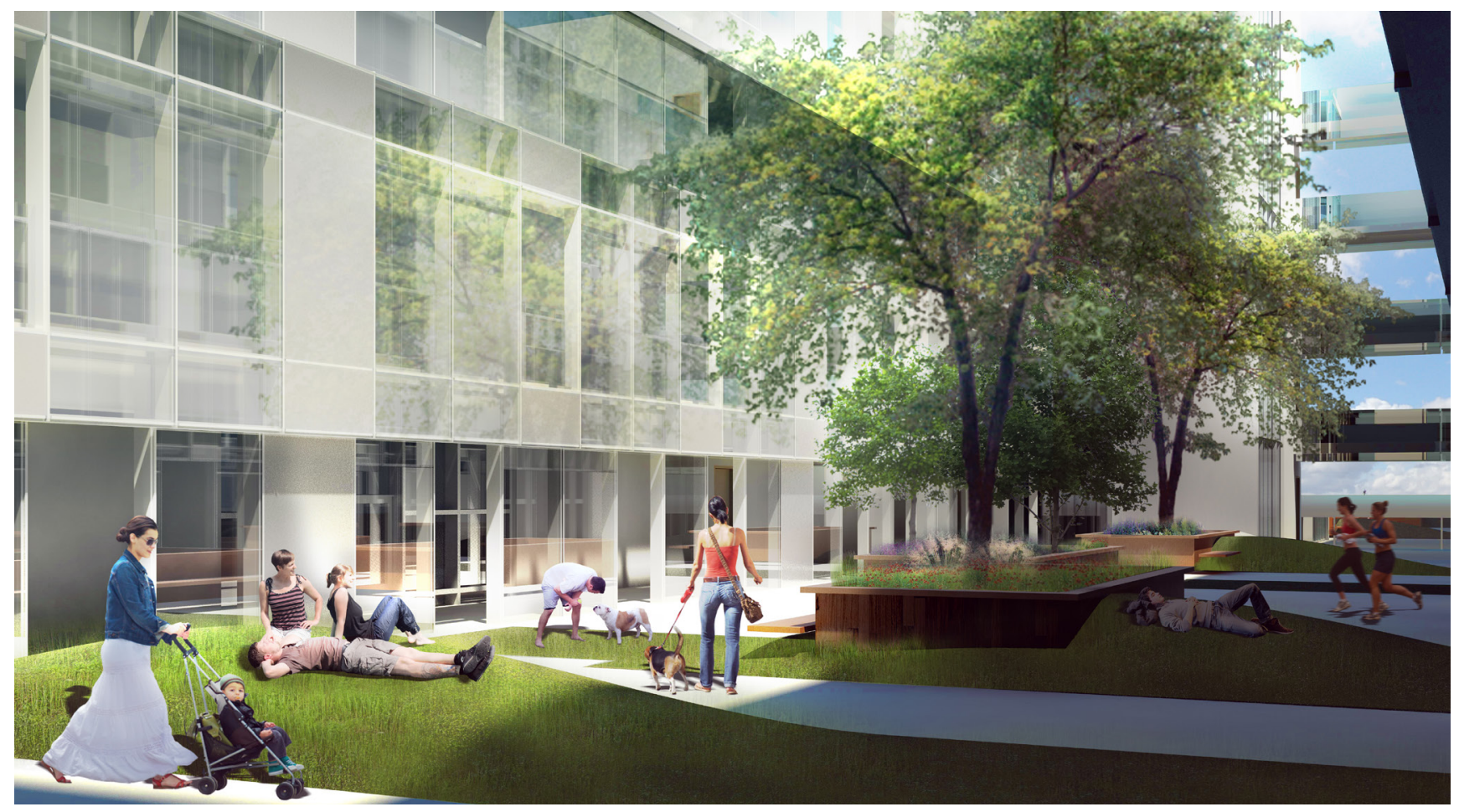

Figure 6.23: Courtyard looking North East.

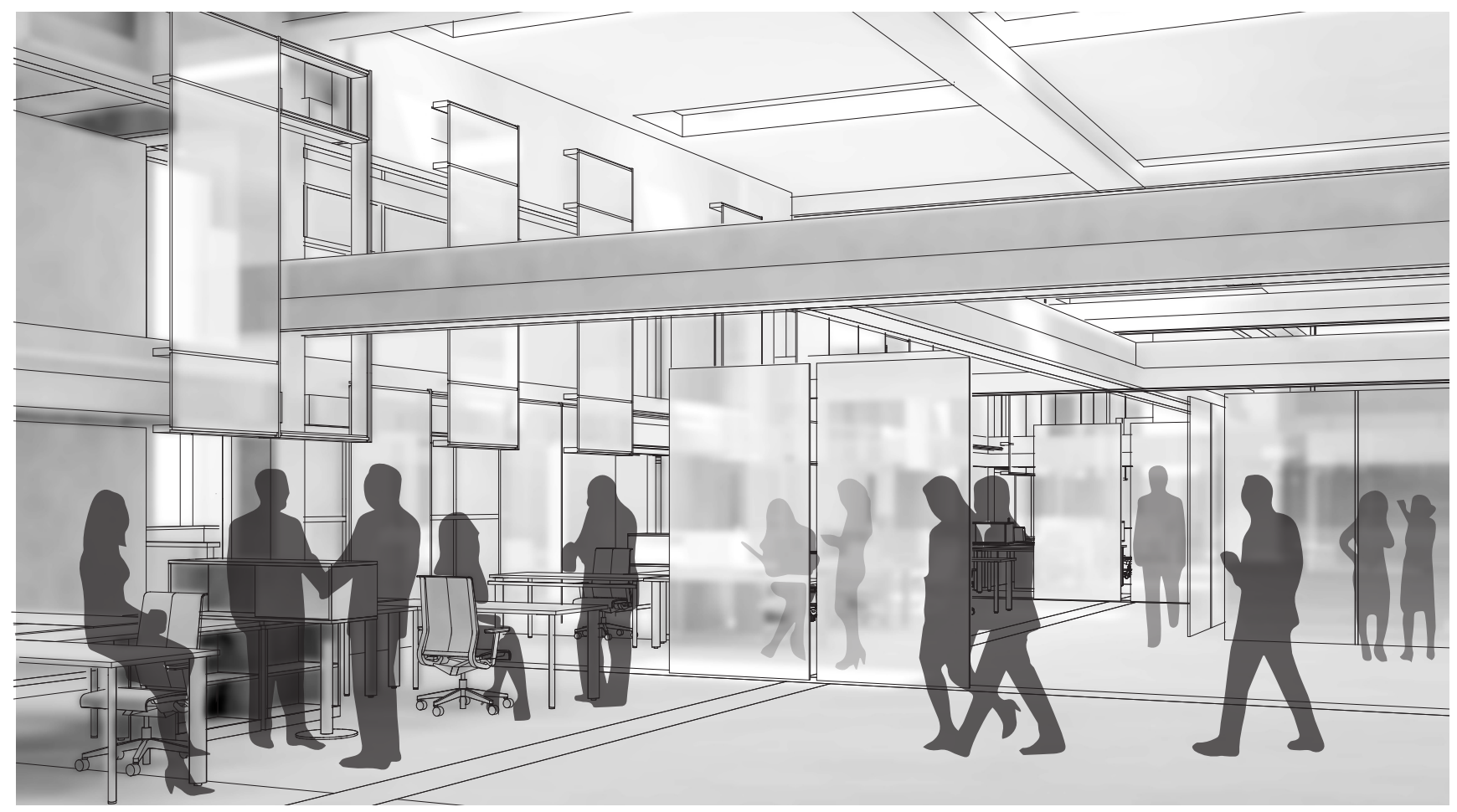

Figure 6.24: Looking North East at an office space converted from the courtyard in figure 6.19. Façade elements remain in the newly enclosed space as artifacts to divide interior floor areas. 


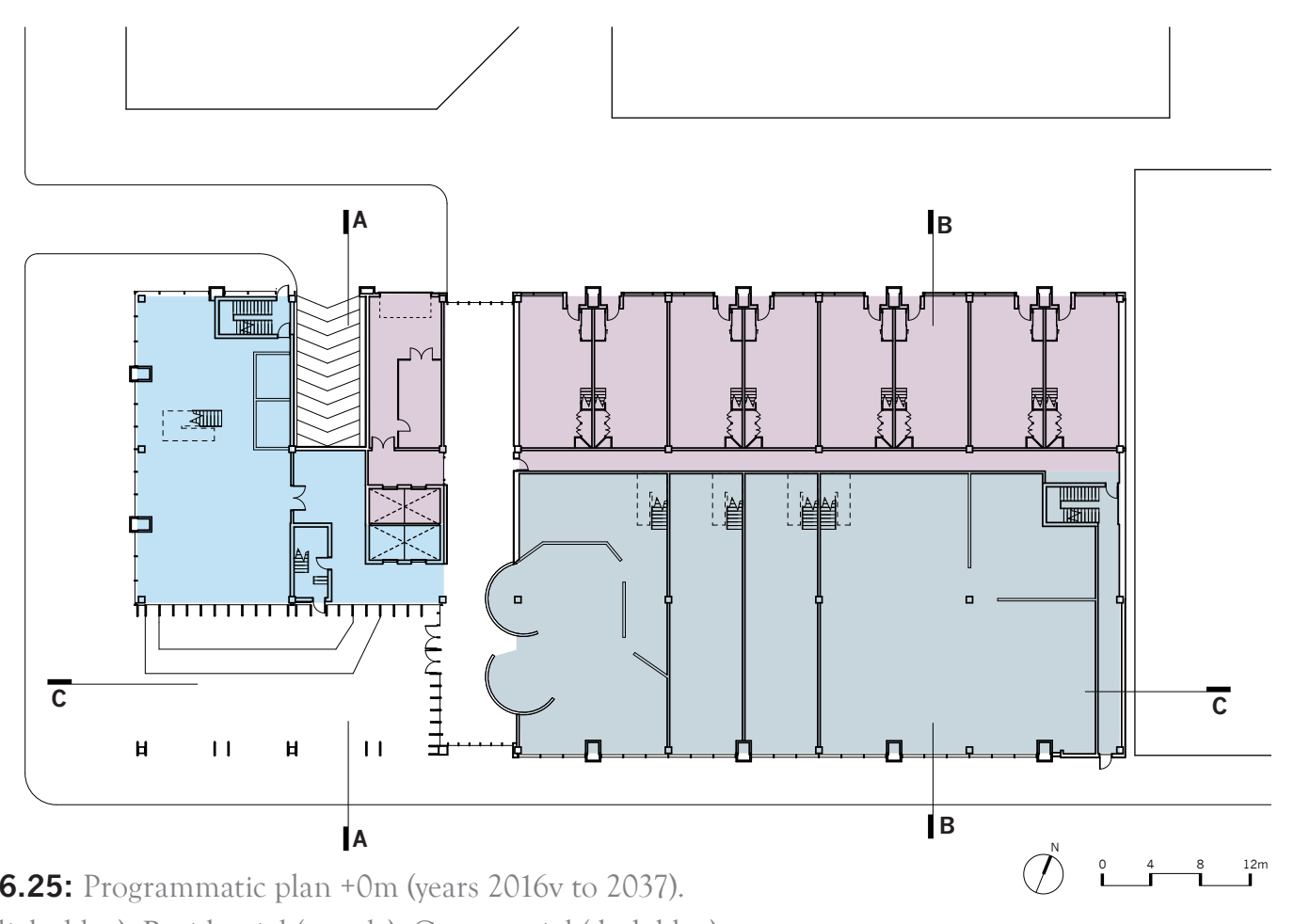

Figure 6.25: Programmatic plan $+0 \mathrm{~m}$ (years 2016v to 2037).

Office (light blue), Residential (purple), Commercial (dark blue)

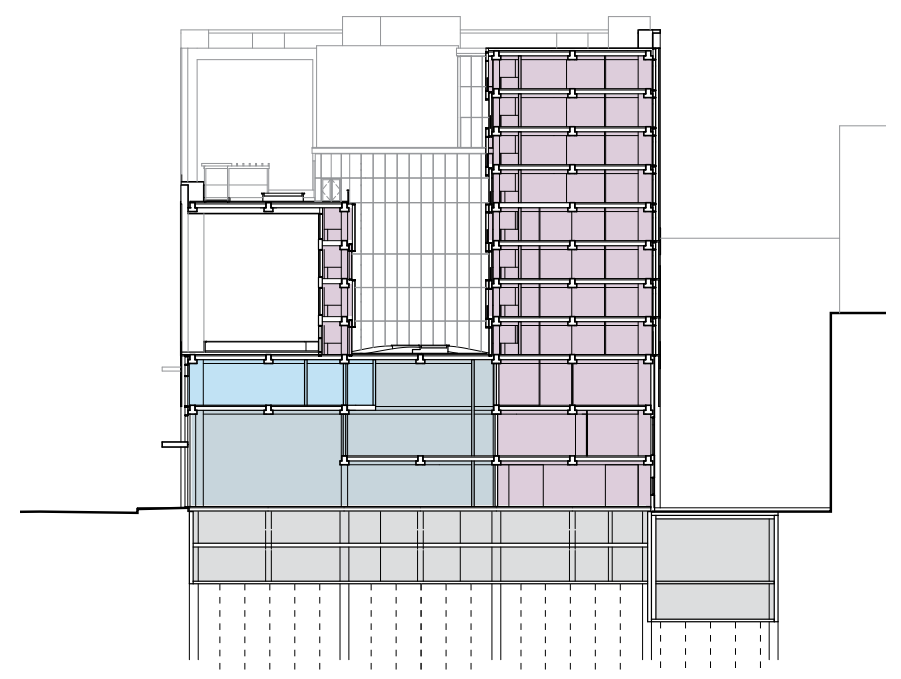

Figure 6.26: Programmatic section BB (years 2016 to 2037).

Office (light blue), Residential (purple), Commercial (dark blue) 


\section{Repurposing: Scenario 2}

An alternative scenario exists in the buildings development. By the year 2036, according to Duffy, 20 years after the building's completion in 2016, the building would undergo its first major change-of-use. It is proposed that the micro manufacturing industry will have overwhelmed local production of goods, and the demand for light industrial production will have become desirable. Projecting the building forward to the time period between 2036 and 2056, with a potential repurposing of the occupancy from mixed-use residential, commercial and office, we

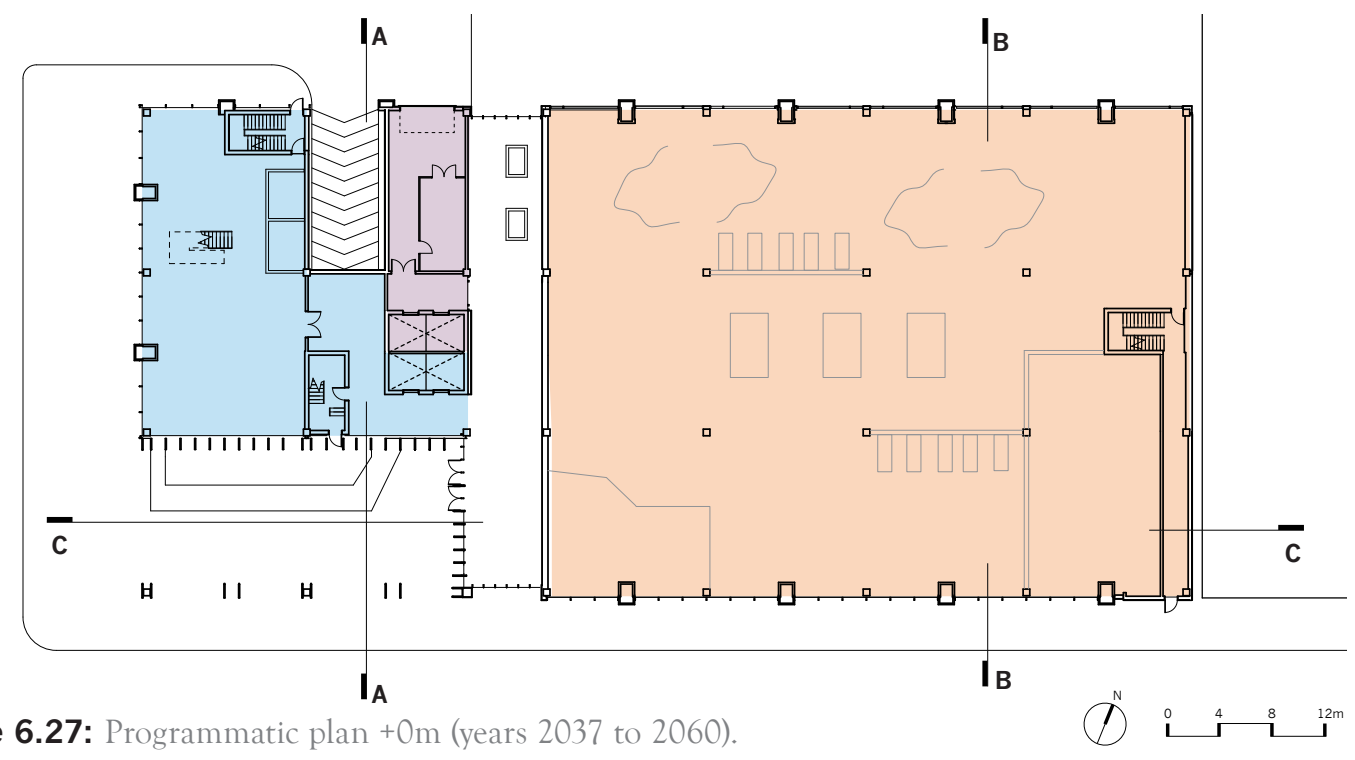

Figure 6.27: Programmatic plan $+0 \mathrm{~m}$ (years 2037 to 2060).

Office (light blue), Industrial (orange)

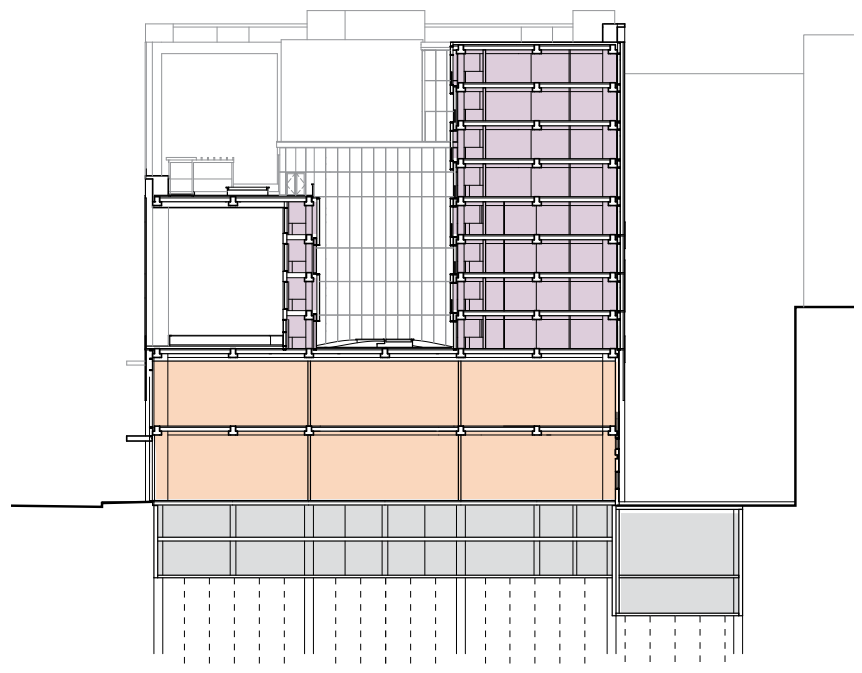

Figure 6.28: Programmatic section BB (years 2037 to 2060), : 


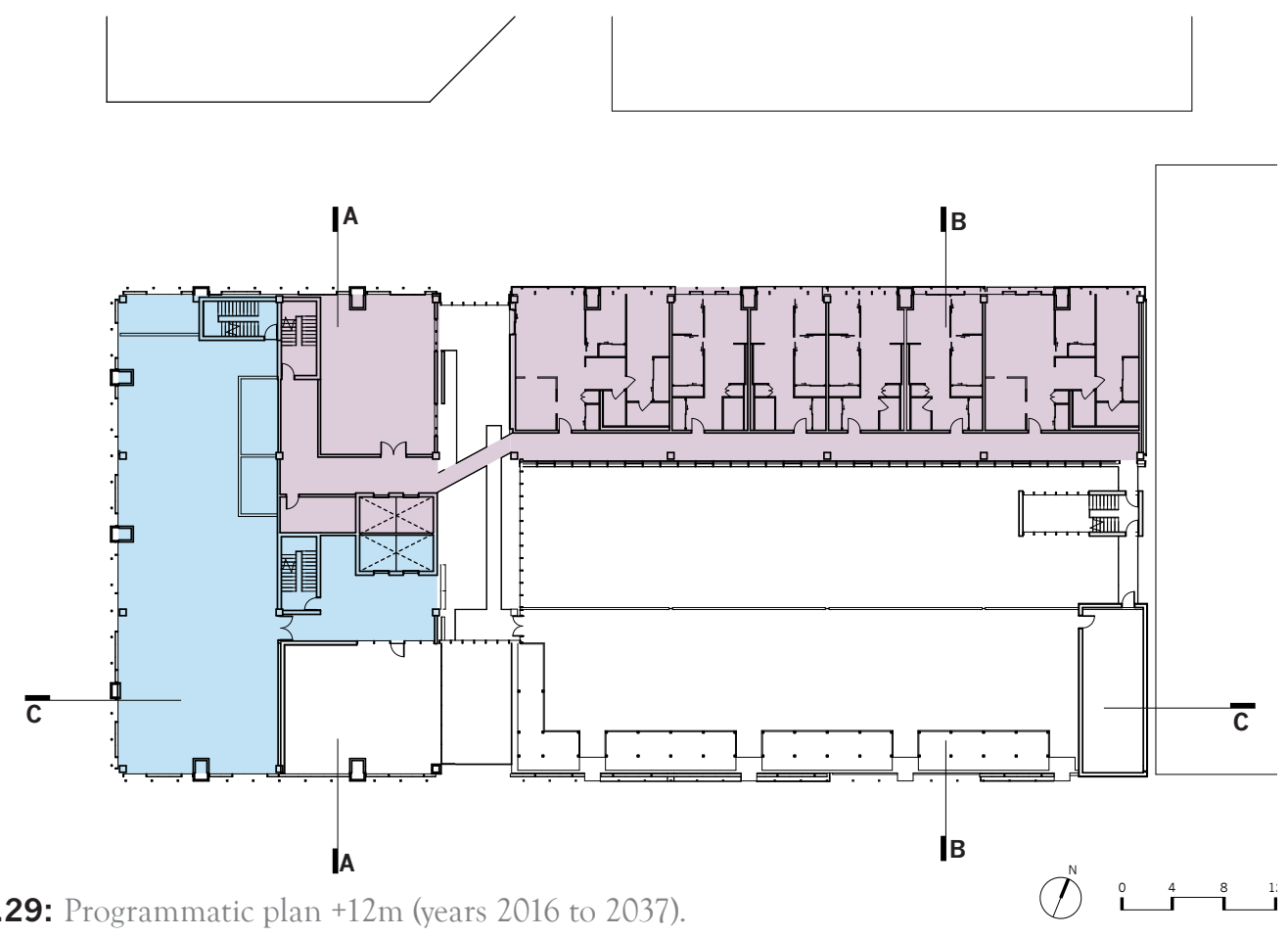

Figure 6.29: Programmatic plan $+12 \mathrm{~m}$ (years 2016 to 2037).

Office (light blue), Residential (purple).

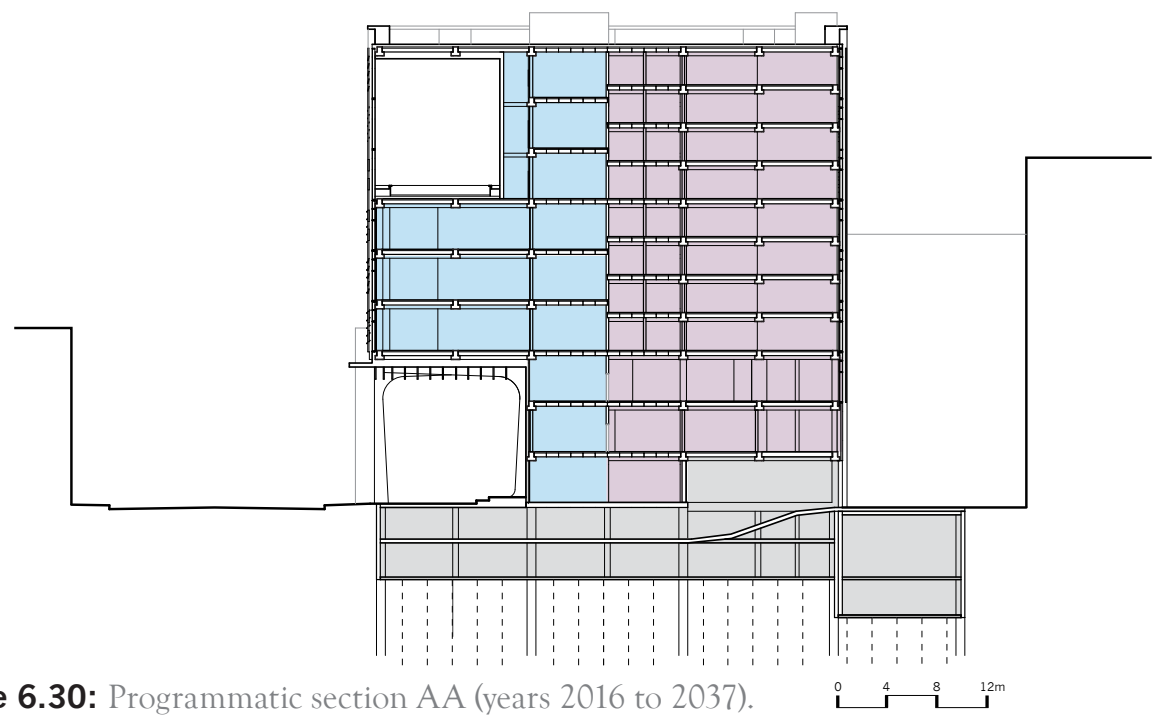

Figure 6.30: Programmatic section AA (years 2016 to 2037). Office (light blue), Residential (purple), 
would start to see residential and industrial occupancies taking over the spaces of the others. For the purposes of this project, the change would start with the turnover of commercial spaces on the first row of primary units to light industrial, figure 6.25 to 6.28 (on the previous page), as well as the top floors of offices converted to residential, figures 6.29 to 6.32 . This would have a major impact on the façade of the building, where panels would be reorganized to accommodate the change in floor divisions throughout with personal façade options changing between louvers, growing panels and solarium spaces.

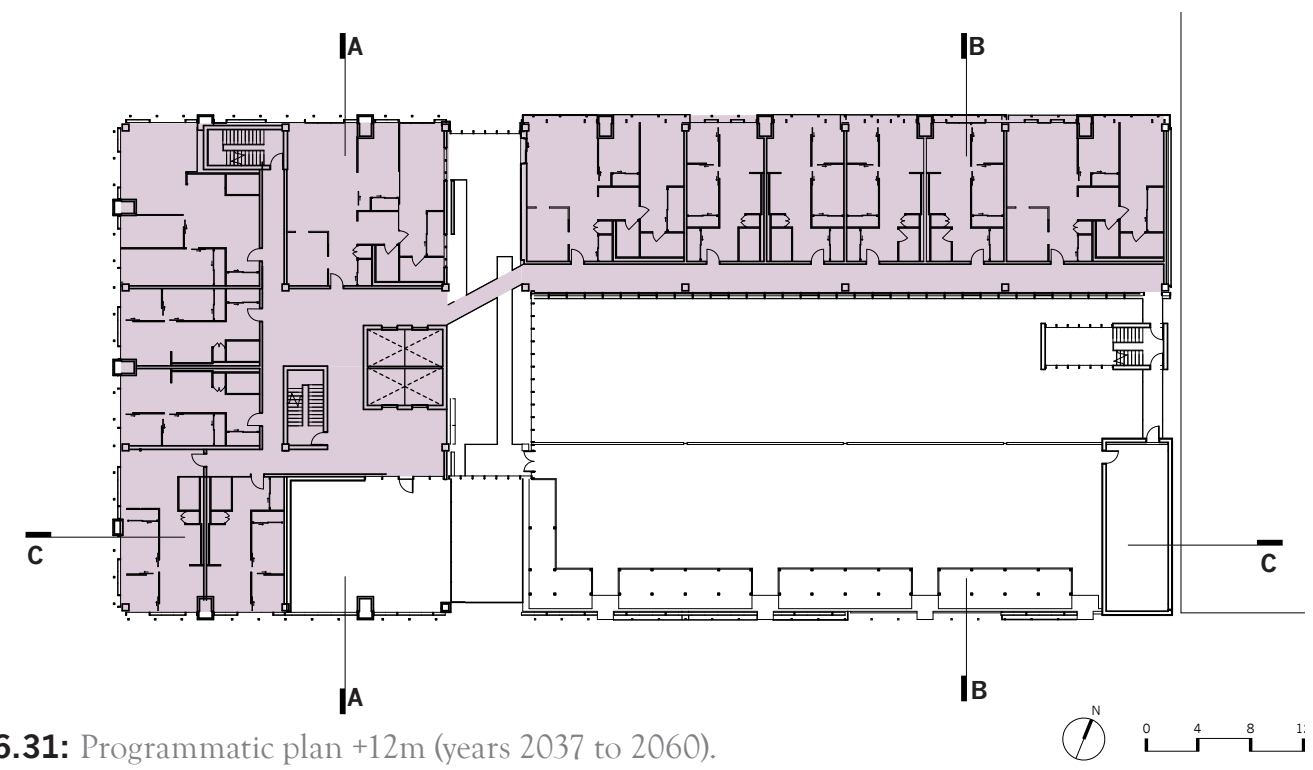

Figure 6.31: Programmatic plan $+12 \mathrm{~m}$ (years 2037 to 2060).

Residential (purple).

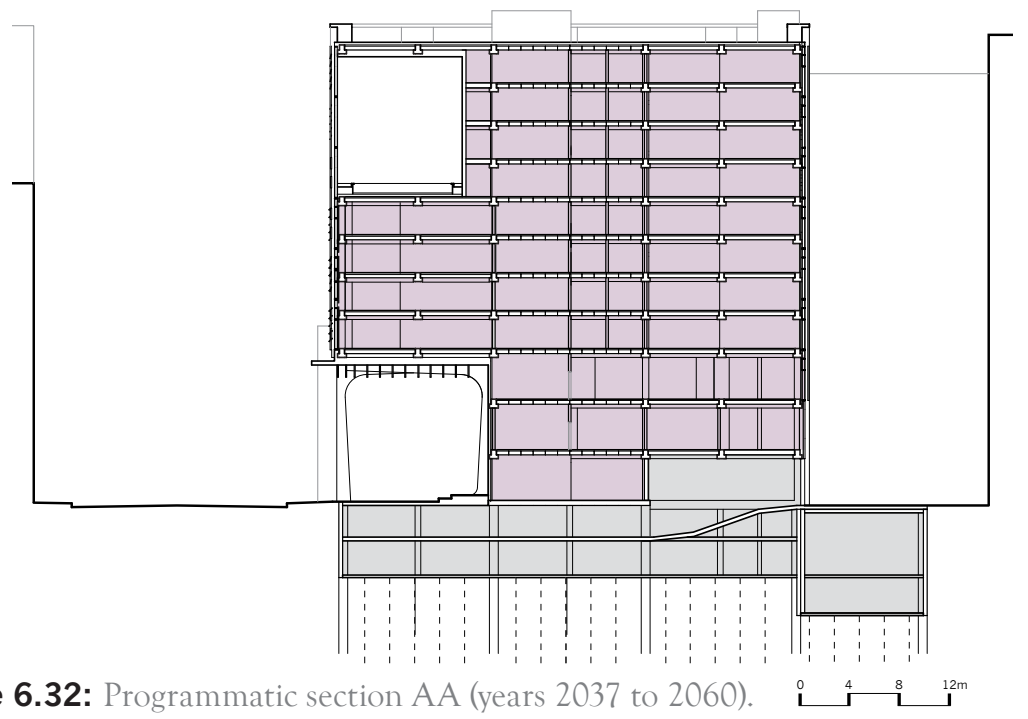

Figure 6.32: Programmatic section AA (years 2037 to 2060).

Residential (purple). 


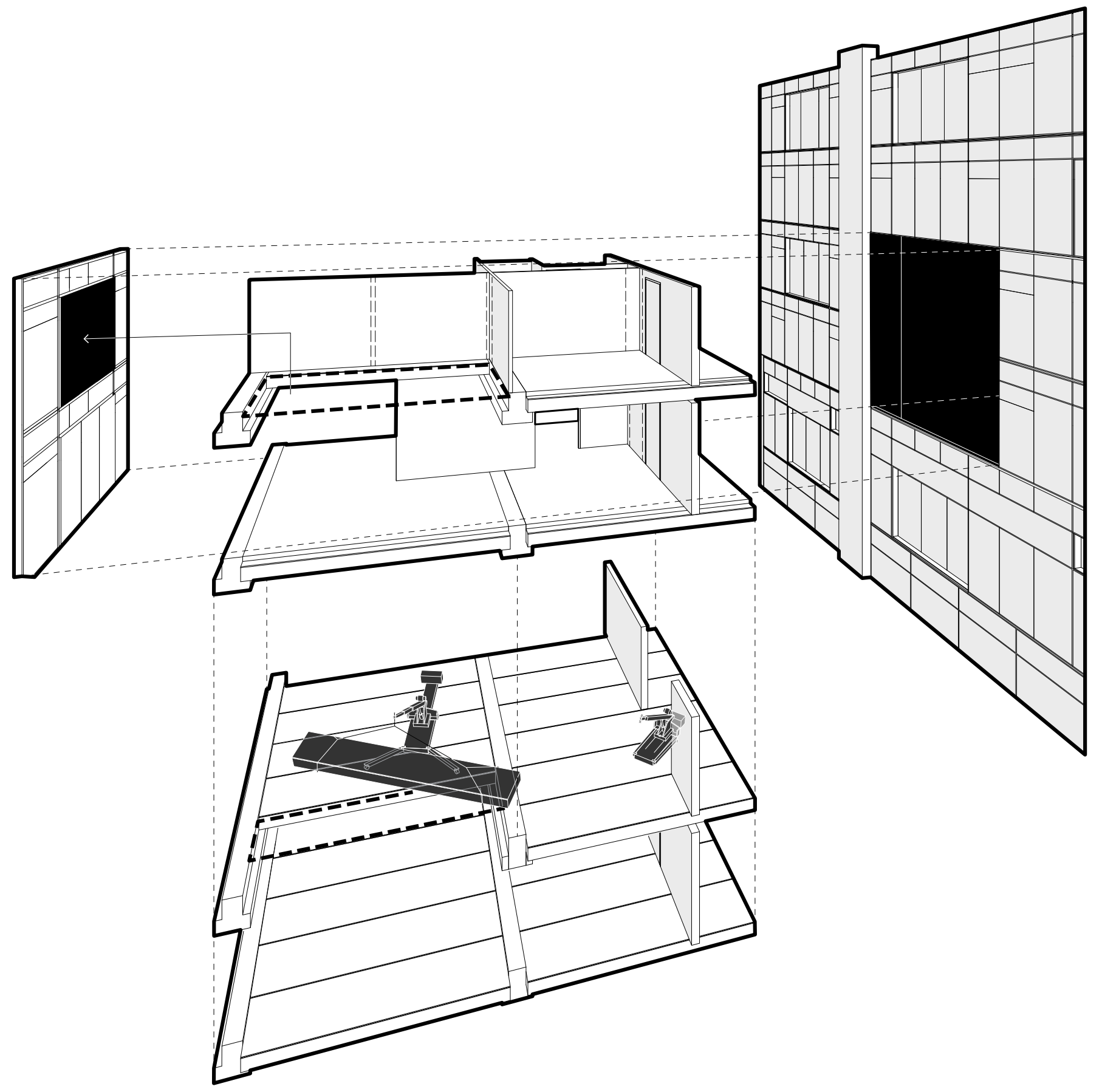

Figure 6.33: $1 / 2$ Residential unit exploded to show the removal of hollow core floor slabs through the street façade with the use of mini cranes. Interior modular partition units can be seen dashed on the walls which would be removed and replaced after a change has occurred. 
In addition to the facade being modified to accommodate changes in occupancy, each primary unit with a residential occupancy can develop to create a complex set of residential relationships. Primary unit contains up to 8 single bedroom residential units and can be combined in various ways to provide larger units either horizontally with the removal and relocation of wall panels, or vertically with the removal of floor slabs. Figure 6.33 shows how variations in the size of the residential unit can created by converting a single hight unit to a double height unit through the manipulation of the various components. With the ability to rotate wall panels and adjust floor heights, the building makes use of this flexibility through the variations of residential, office, and commercial occupancies on various floors. The speculated conversion of one occupancy to another using the components of this building would be dealt with through the removal of select façade elements and small machinery with the ability to move into the units to manually lift and extract floor slabs and rotate walls where necessary. Various types of mini cranes such as the ones shown in figure 6.33 typically used for installing curtain wall units are small enough to be brought into the building through existing doorways and elevators, yet strong enough to lift the precast floor panels (Smart-Rig Cranes, 2015).

As the area around King and Dufferin develops, the building, under continuous management from the non-profit organization, escapes demolition 40 years after its construction. This has been accomplished by the addition of 2 additional primary residential units placed on top of the existing structure along King Street, figure 6.34 to 6.37 , moving the roof panels up to the new roofline, and using the removed glazing panels from the atrium as window panels for the new residential units. The ground floor remains animated amid the ground level hardscape entrance at the corner of King and Dufferin, with daytime employees working in the design and industrial spaces, and occupants returning home to their apartments in the evenings. 


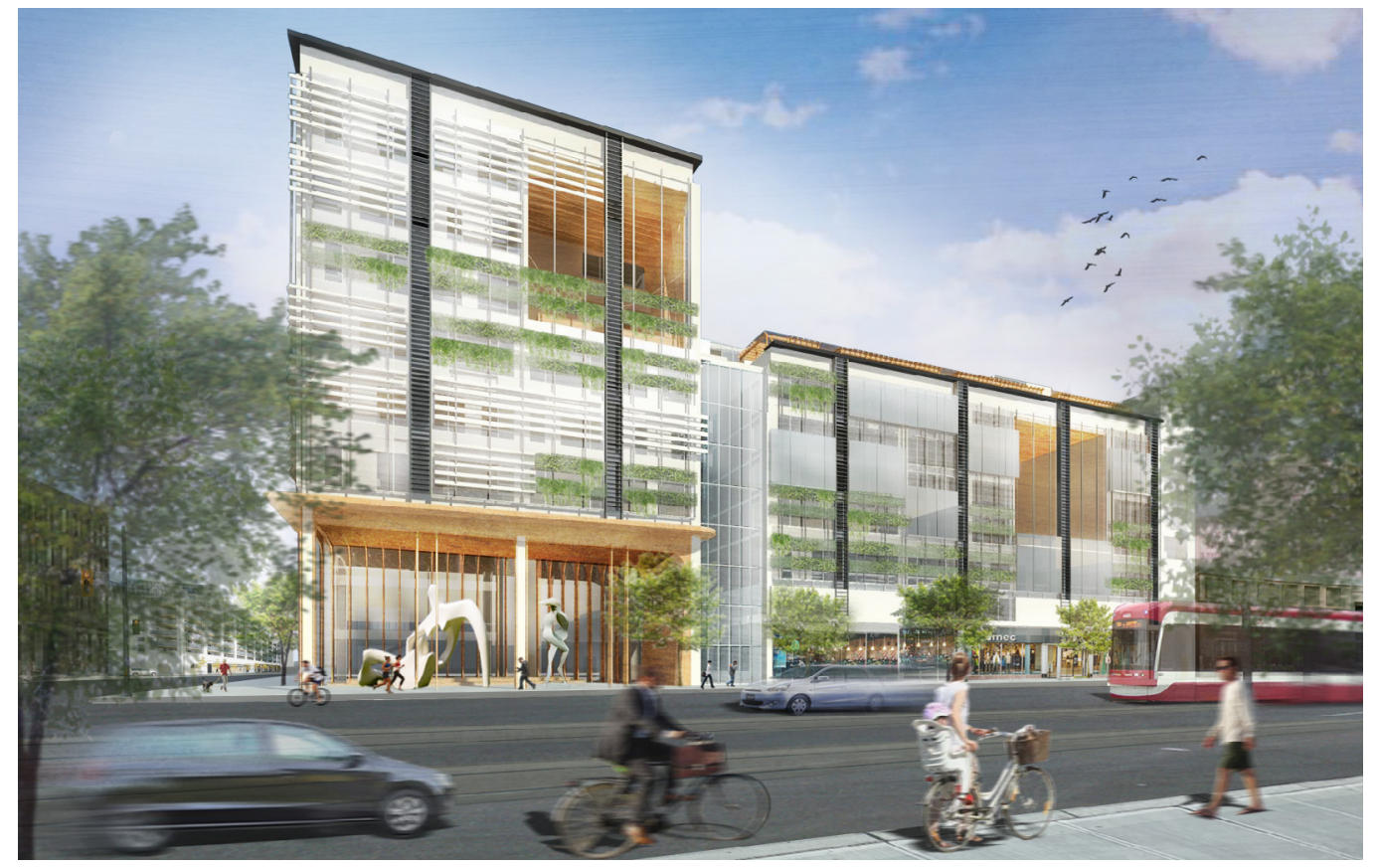

Figure 6.34: South façade after initial construction phase.

(Years 2016 to 2036).
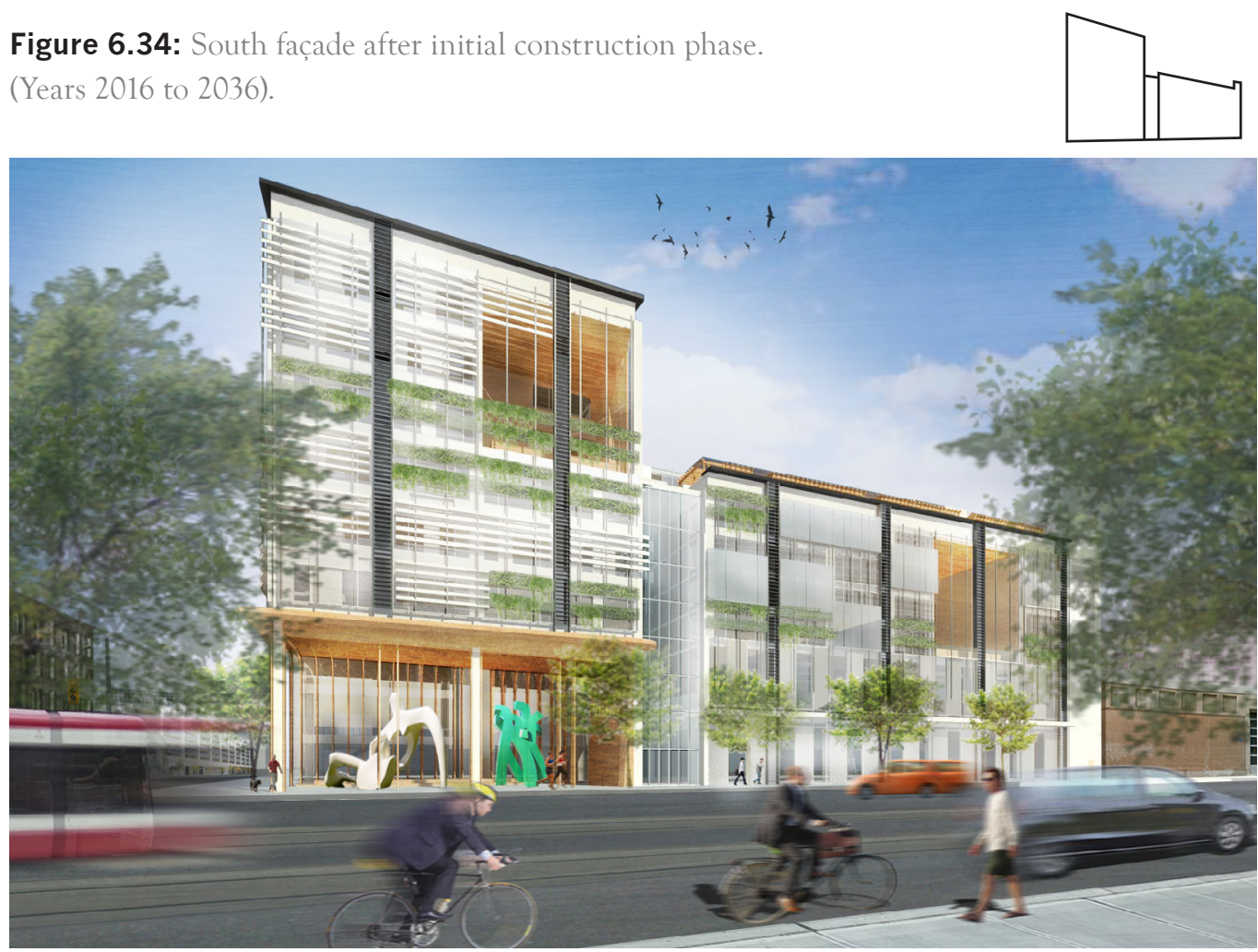

Figure 6.35: South façade after conversion from commercial to industrial occupancy. (Years 2036 to 2046).

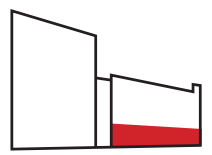




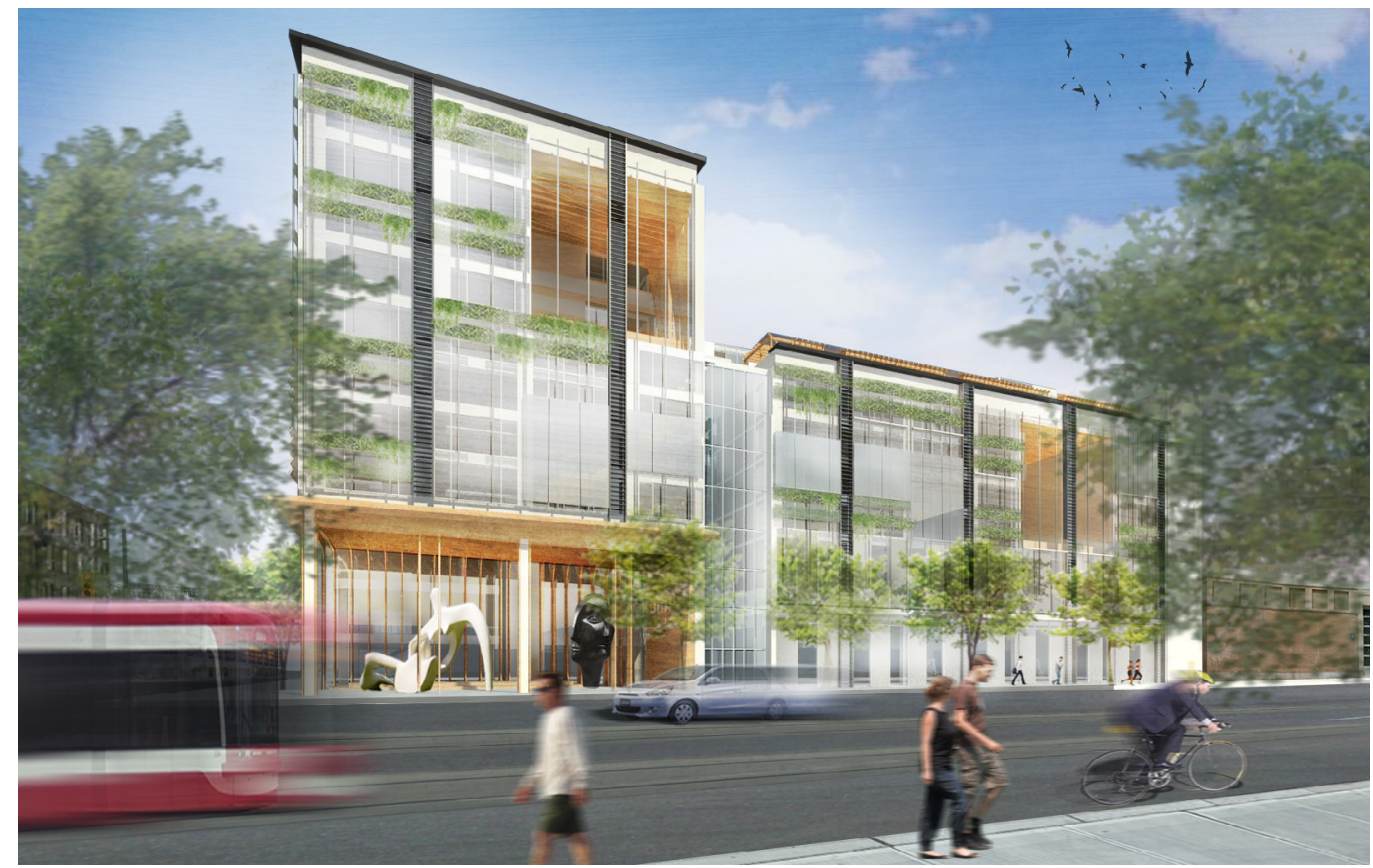

Figure 6.36: South façade after conversion from residential to office occupancy. (Years 2046 to 2056).
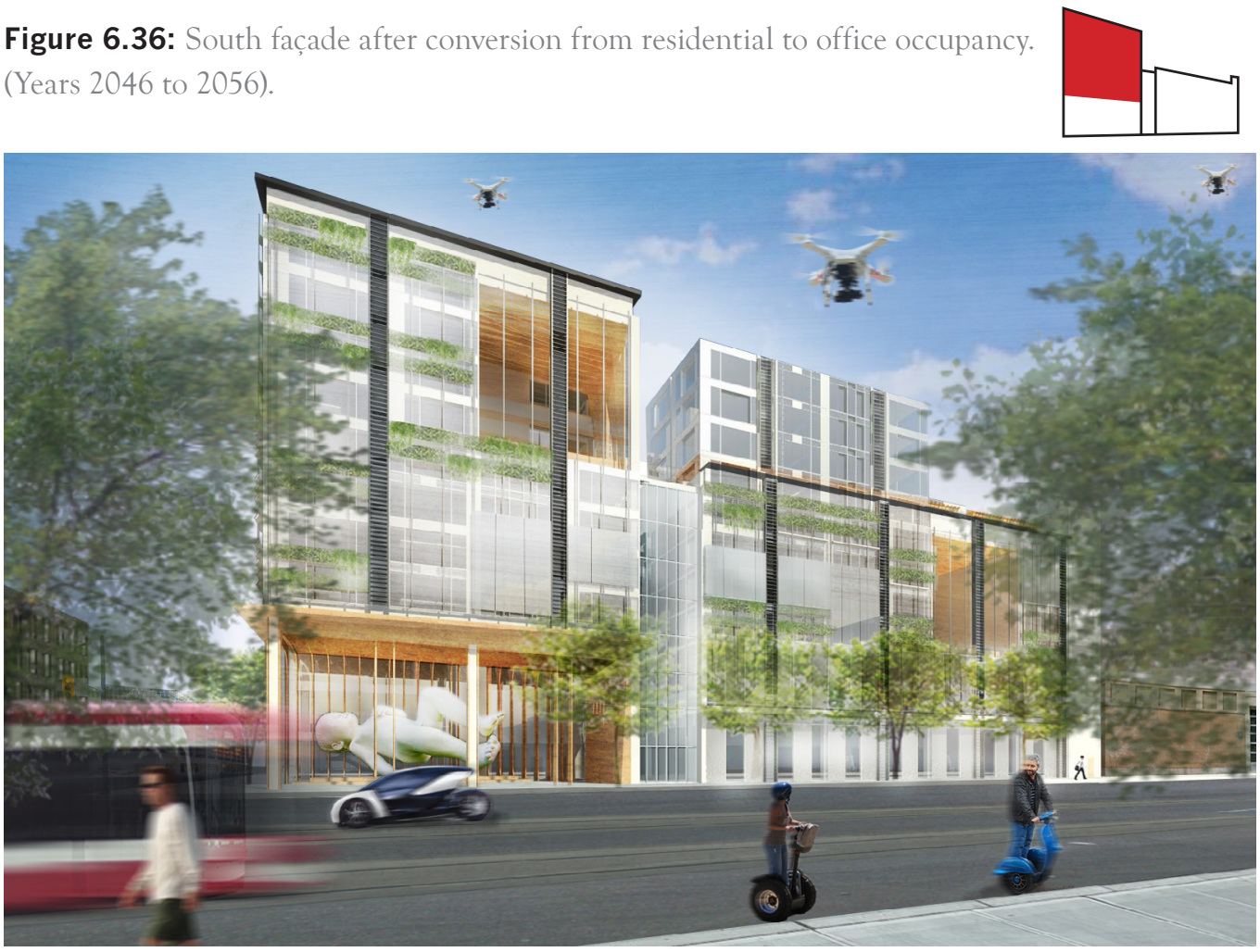

Figure 6.37: South façade after additional primary units are added over the South East side.

(Years 2056 and beyond).

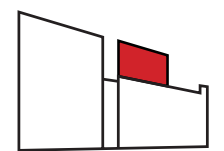




\section{CONCLUSION:}

The outcomes of Design For The Cycle were dependent on a number of postulations that resulted in a design process directed towards mid-rise projects that are well suited to challenge conventional ways of reducing embodied energy and waste, while shaping an enhanced public realm within a city's fabric. The management of material resources and embodied energy is postulated to be the biggest dilemma for the current and future generations of architects and engineers. In the future, society may place a higher value on the conservation of physical materials used and wasted in the construction and deconstruction of our buildings due to the continued advancement of technologies that may render building envelopes and mechanical systems to be more efficient.

Recognizing that architecture deals with the dynamic axis of technology, the physical context, the cultural context, and materials, the Design for the Cycle system can maneuver future innovations, quickly replacing conventional systems and ideas over time. This has the potential to create a new subset of the building industry that focuses on the moving, deconstruction, and reconstruction of materials throughout the life of a building. To speculate, there are a few examples in the current state of the building industry which are gaining momentum within the realm of possibility and can act as a precedent: Structurally Insulated Panels are filled with organic material grown to provide insulation and may eventually replace interior wall partitions, thus forming the base system for a modular wall panel that can be moved and reconfigured to suit changing needs; Advanced methods of engineered timber construction may one day span distances workable within the dimensions that were determined for the strategies in this thesis, allowing the ability to be moved, repurposed, and integrated in many more ways than concrete could allow; New mechanical systems could continuously shrink the footprint necessary for space conditioning and servicing, freeing up floor and façade space for increased usability and access to daylight. Alternatively, mechanical systems may become superfluous and be removed altogether.

This unpredictable ability to change the material and physical form through a process of moving is the premise of what would allow the Design For The Cycle system to weave a dynamic social and cultural fabric of the city. 
APPENDIX A - EFFECTS OF REGULATION 


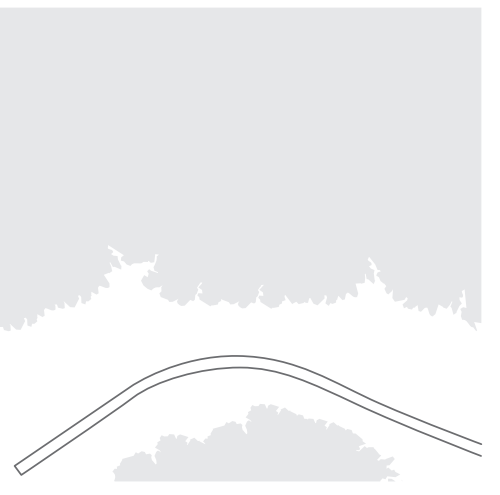

1818

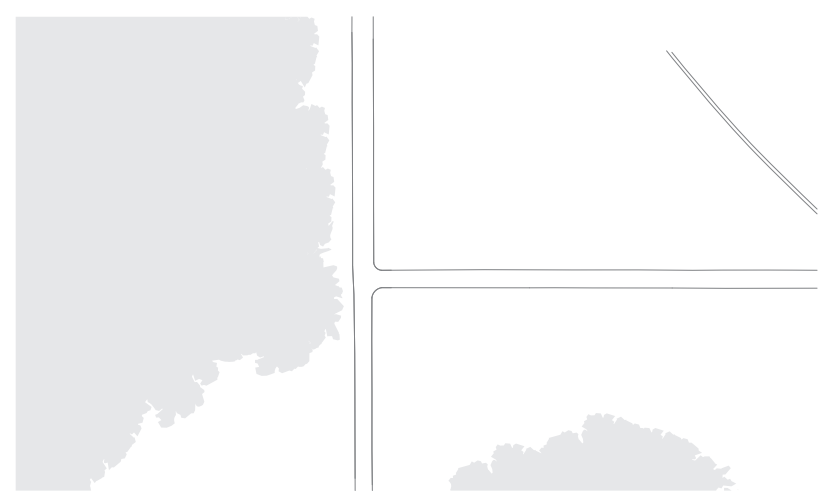

1842

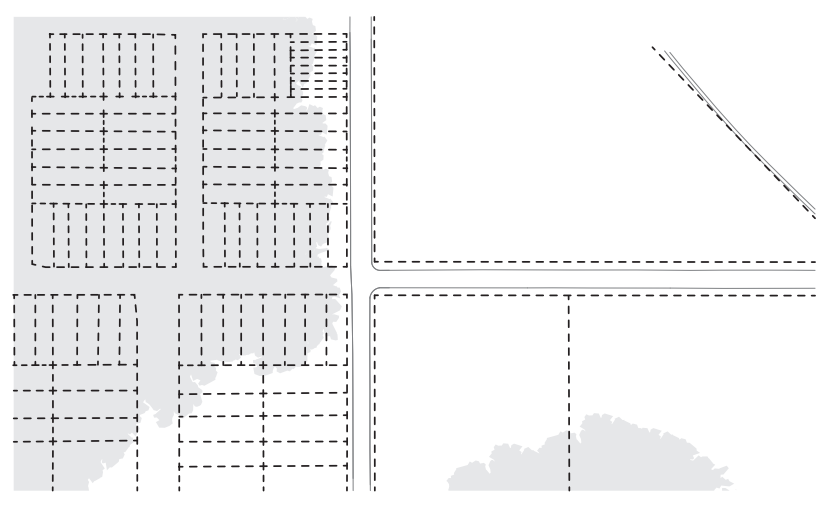

INITIAL PROPERTY LINES

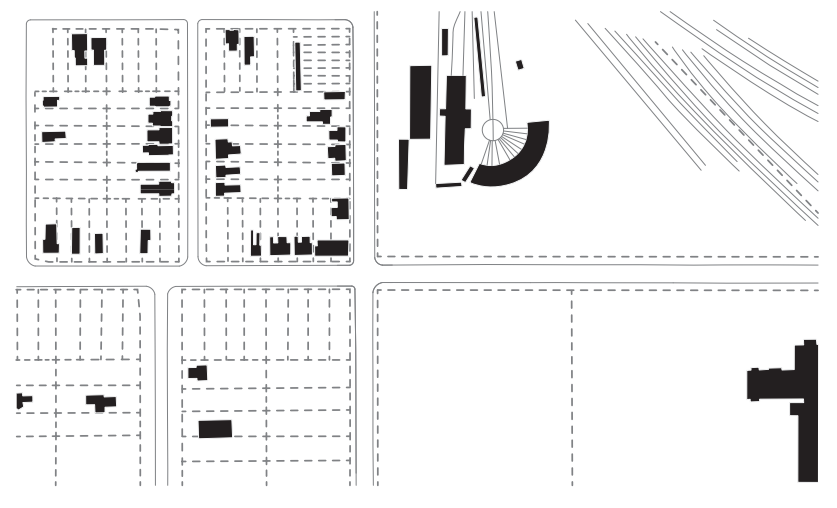

1884

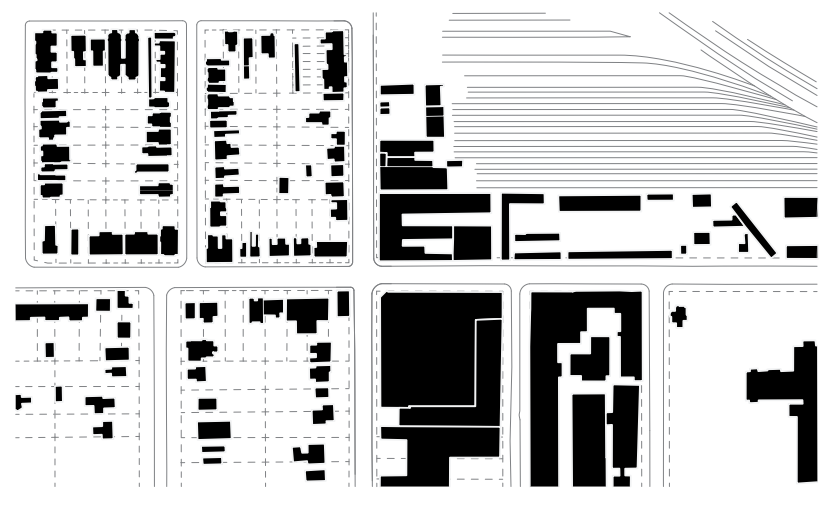
1924

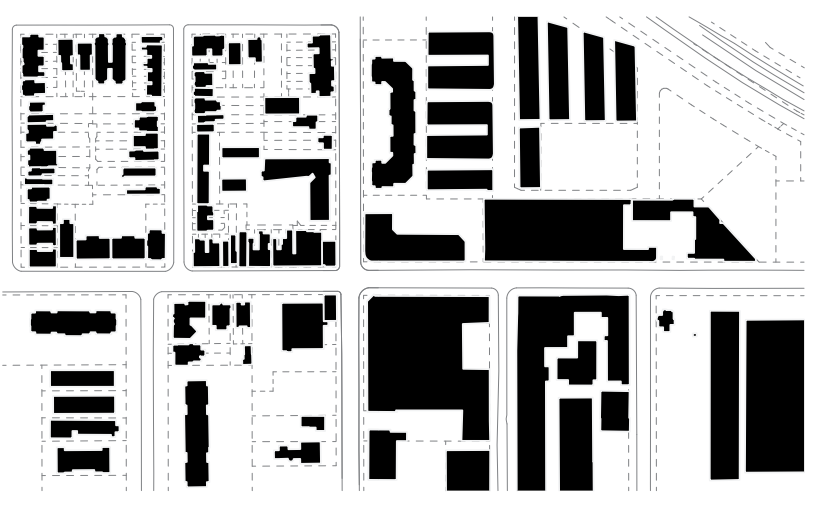
2013 
Toronto Neighbourhood development at the King Street and Dufferin Street intersection over a 195 year time period. The overlay of property division during the late 1800 s shows the influence it has had on the texture of the building development.

In the old town of York (currently the City of Toronto) and its surrounding areas, land was divided into large parcels (1818 to 1842). With the development of modern corporations, along with the migration of people to the city, land was further subdivided and a defined texture of property-division was established (1842 to 1884). Through the development of city blocks, the density that was built took on a texture that reflected the regulatory systems that were established well before buildings began to populate the landscape (1884 to present). The texture of built fabric is directly related to the regulation set by the policies in place at the time of construction. 


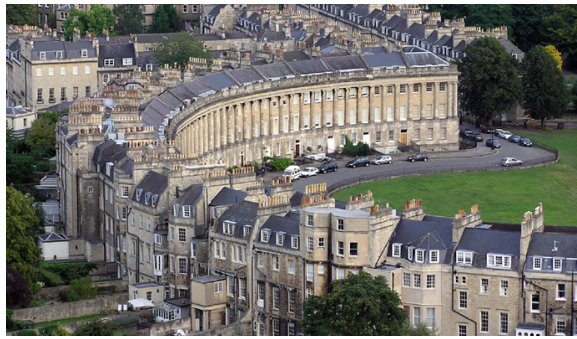

BATH

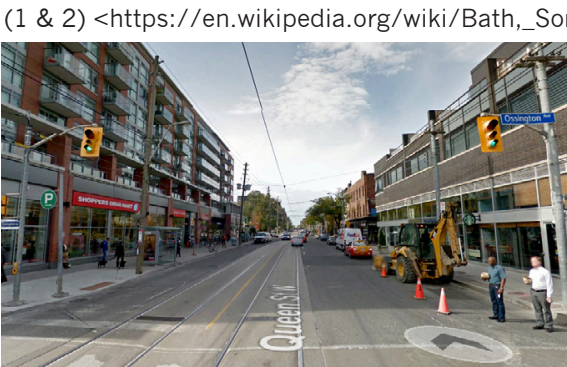

TORONTO

(1) Google Maps, Image Capture Oct. 2014. <www.google.ca/maps> (2\&3) Google Maps, Image Capture Sep. 2014. <www.google.ca/maps>

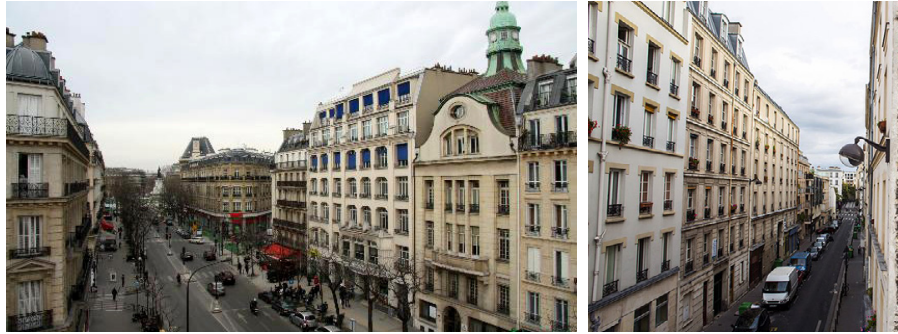

PARIS
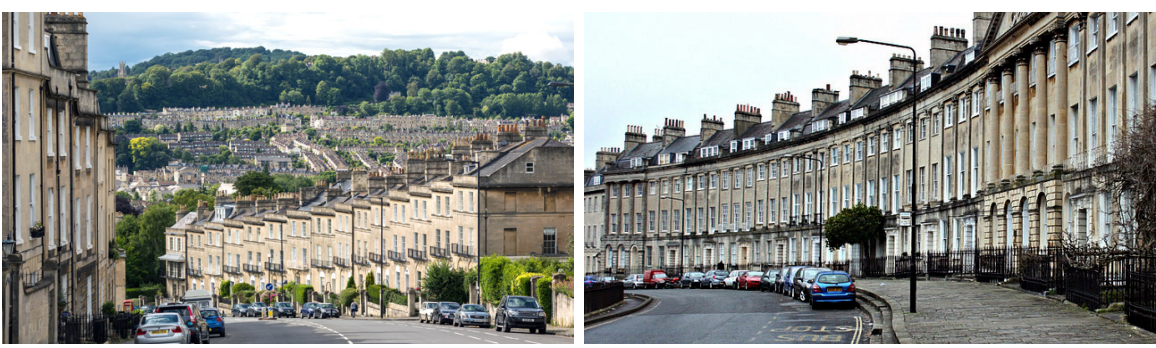

SINGLE OWNER | UNIFORM FACADE
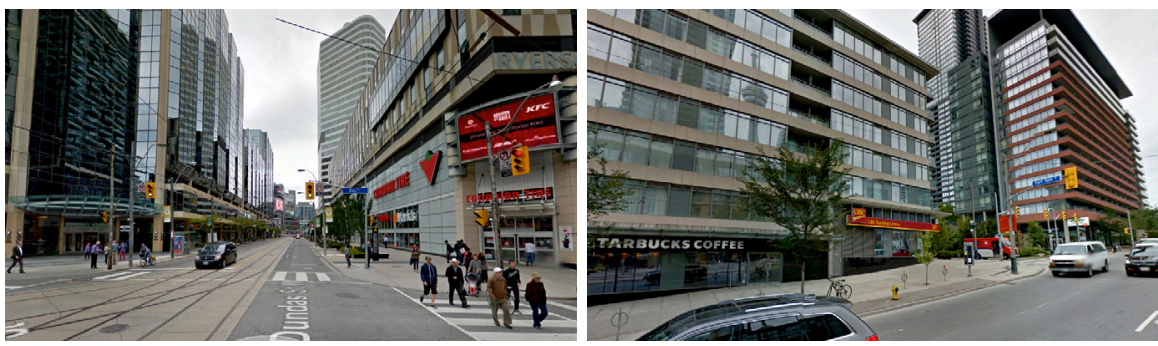

SINGLE OWNER | UNIFORM FACADE
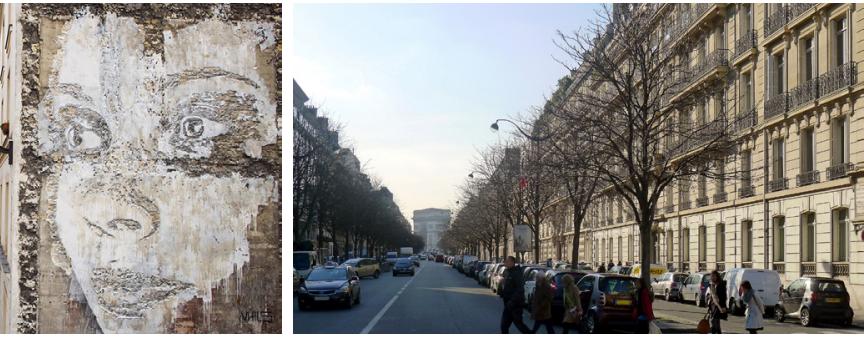

MULTI OWNERS | UNIFORM FACADE

(1) <https://commons.wikimedia.org/wiki/File:P1080478_Paris_VIII_avenue_Hoche_rwk.JPG> (2) < http://www.demilked.com/scratching-the

surface-wall-street-art-alexandre-farto/> (3) <www.tripadvisor.ca/Hotel_Review-g187147-d295185-Reviews-Grand_Hotel_de_L_Avenue_Paris-Paris_

lle de France>

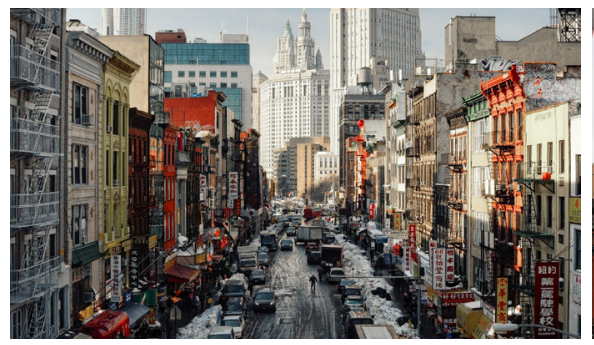

NEWYORK CITY

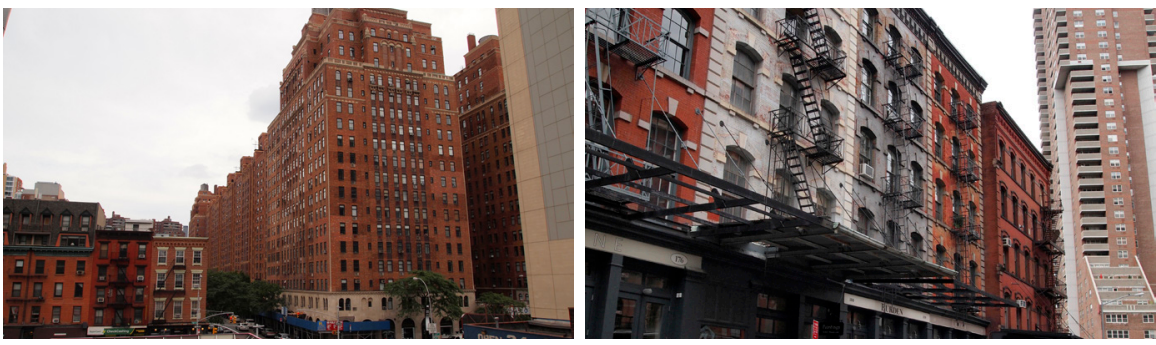

MULTI OWNERS | VARIABLE FACADE

(1)< http://www.hdwyn.com/new_york_city_top_view_street_skyscrapers_hd-wallpaper-52791/> (2) Jeffrey Mitchell (3) Jeffrey Mitchell

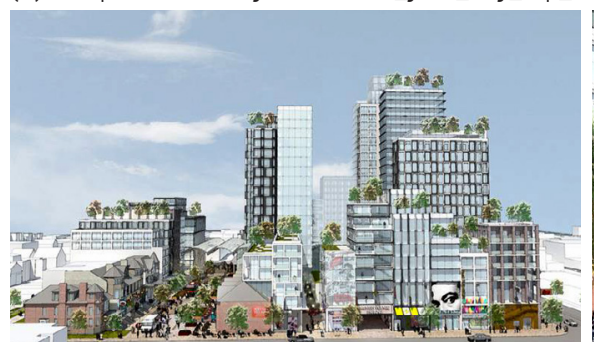

FUTURE CITIES
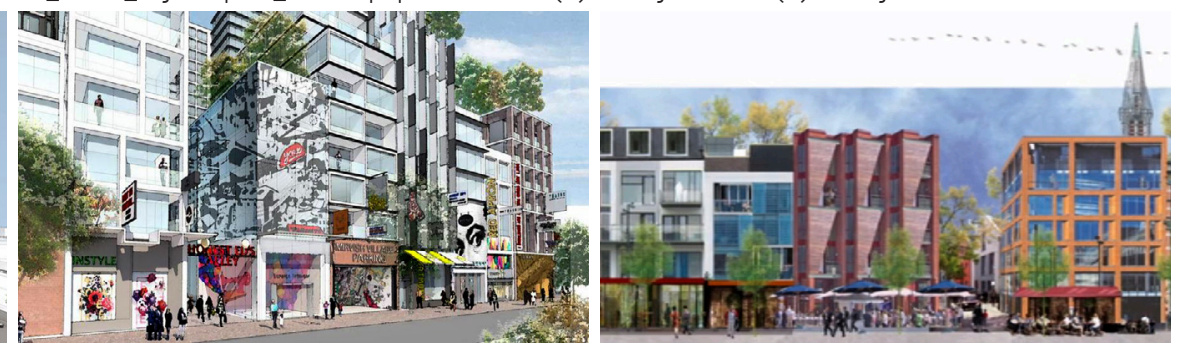

(1 \& 2) <http://www.theglobeandmail.com/news/toronto/redevelopment-of-honest-eds-in-toronto-holds-several-surprises/article23274452/>

Dalsgaard, A. 2012. The Human Scale. [Image Capture] 
Photo collage of street facades: Baths, Paris, New York and Toronto. This photo comparison is used to show the differences and similarities between various ownership types and the resultant city fabric of existing cities and possible futures.

As seen in the comparison, the modern city of Bath is an assembly of a very specific fabric with a very strict regulated pattern driving the façades of its buildings. This is directly reflective of the development of Bath as a place for leisure, developed by King George I in the $18^{\text {th }}$ century. Built as a commercial endeavor, the development of the city facilitated the development of a highly regulated texture of façade, thus reflecting the direct nature of the ownership and regulation imposed upon the master plan of the area (United Nations Educational, Scientific and Cultural Organization, 2015).

The City of Paris also maintains highly regulated street façades. However, variations on the set of visually obvious principles can be seen throughout the city as unique private projects were designed in order to facilitate different occupants' needs. Although the articulation of the city fabric in Paris is regulated, the variation within that regulation indicates that a set of design principles exists for each city on which the development of these buildings occurred.

Similarly, the cities of Toronto and New York went through massive development. Albeit much later in history than the imperial cities of Paris and Bath, the commercially driven capitalist societies established very different articulations, but the ways in which the underlying regulation imposed a texture to the cities remained the same. Development of long stretches of city scape has been slow in Toronto due to the difficult task of land acquisition from each individually owned property (D. LeBlanc, 2014). However, the new full-block developments resulting from amalgamation of property have defined a much different articulation than those developed under the previous regulatory property lines and ownership situations. 
APPENDIX B - ADDITIONAL DRAWINGS 

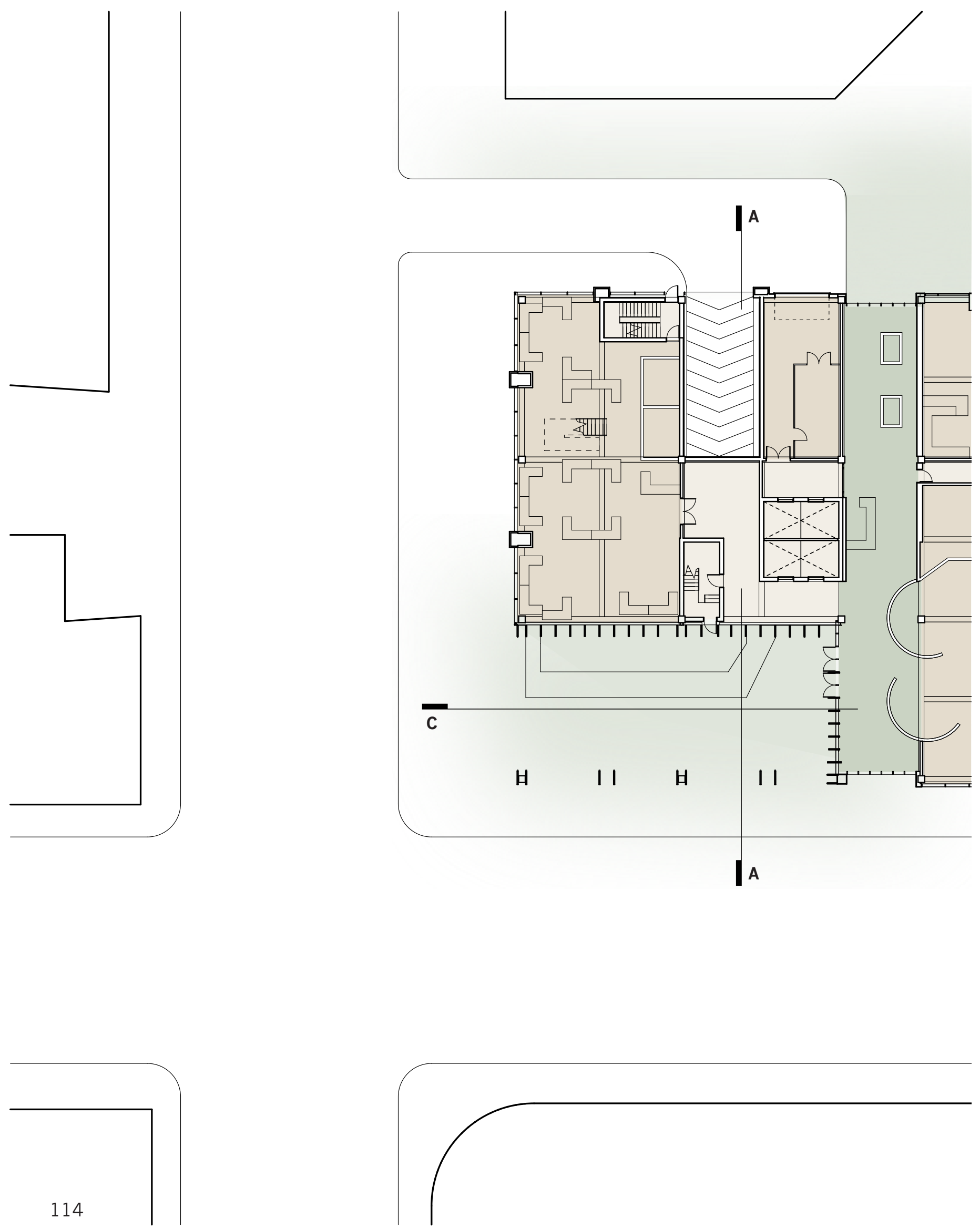

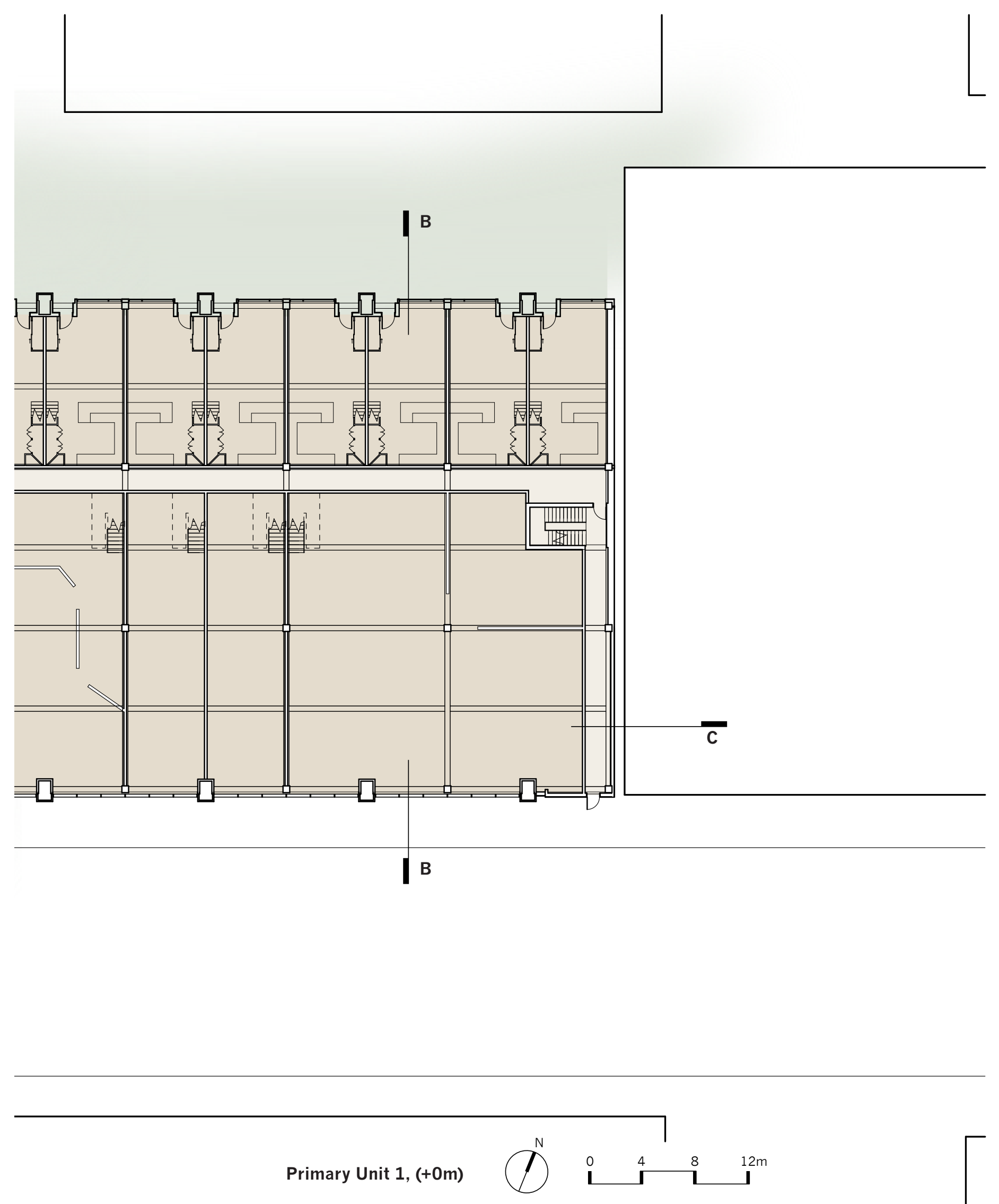

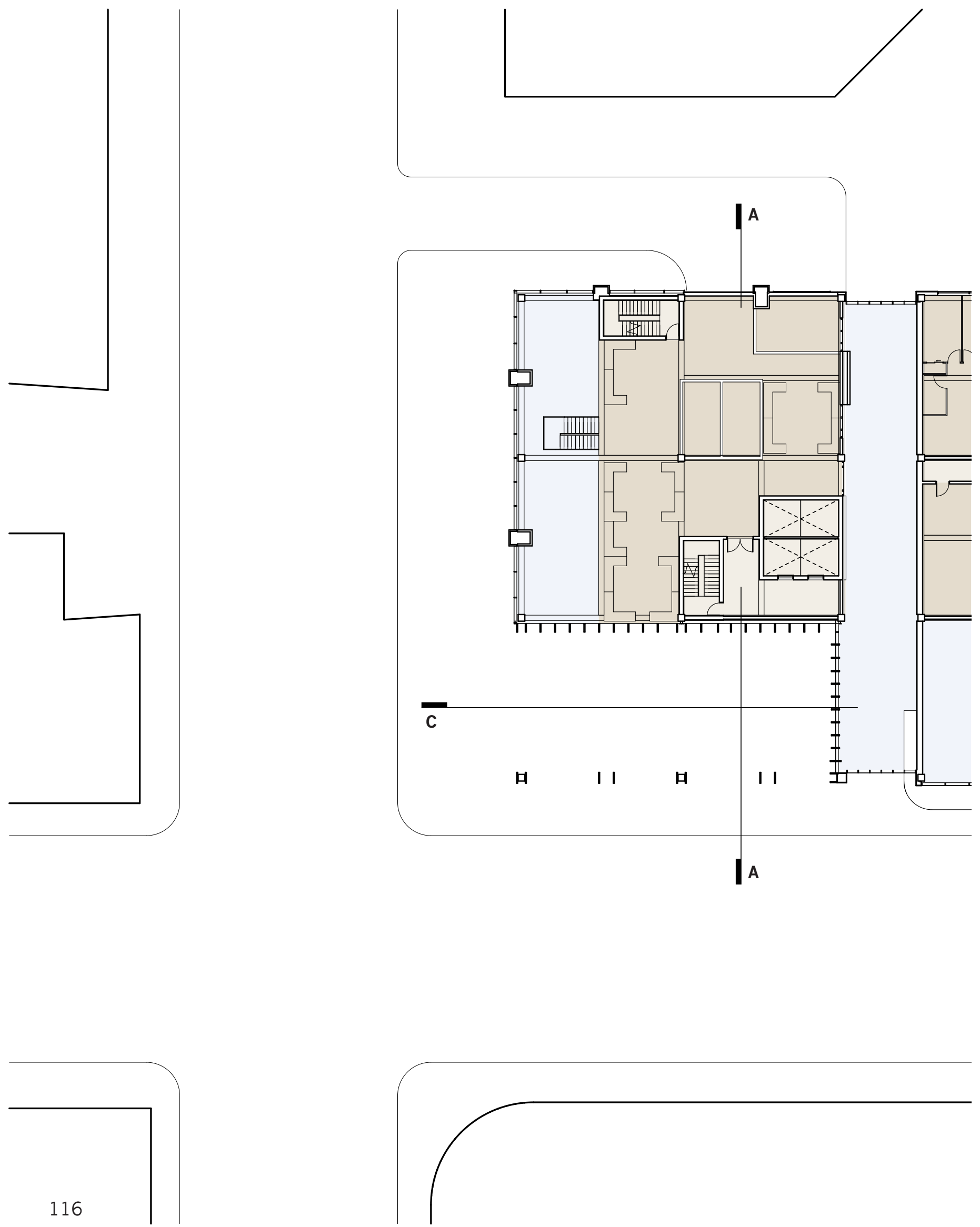

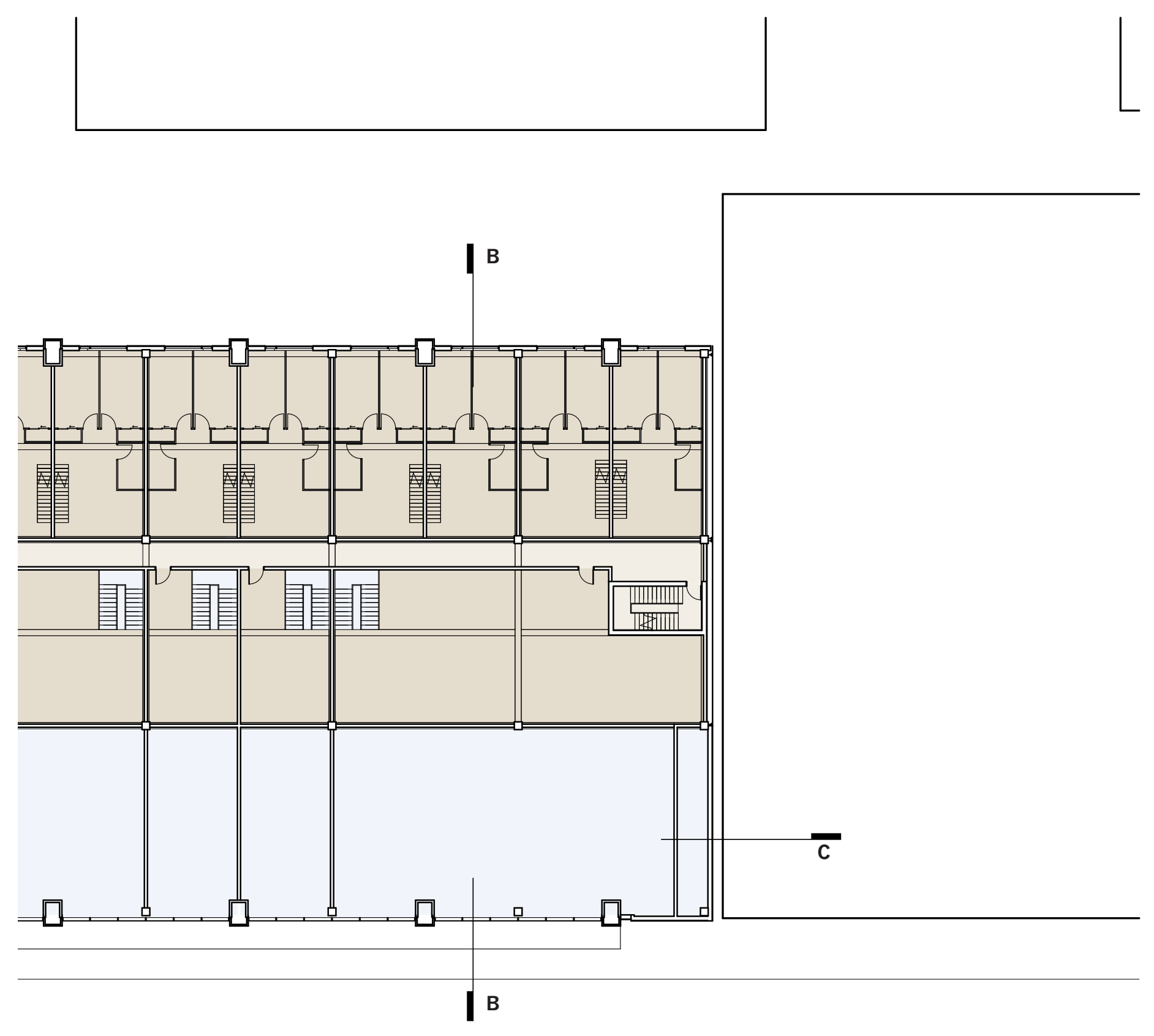

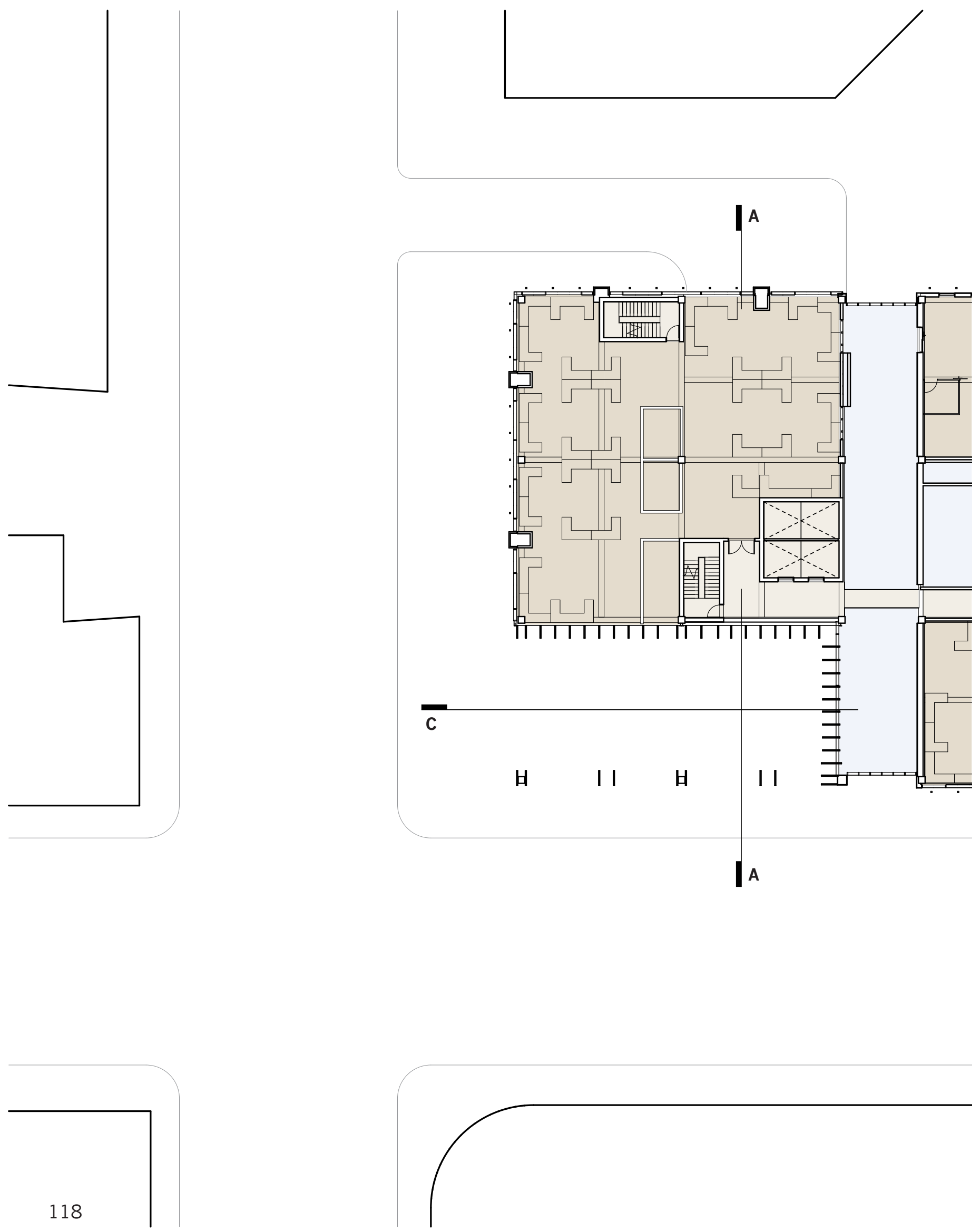

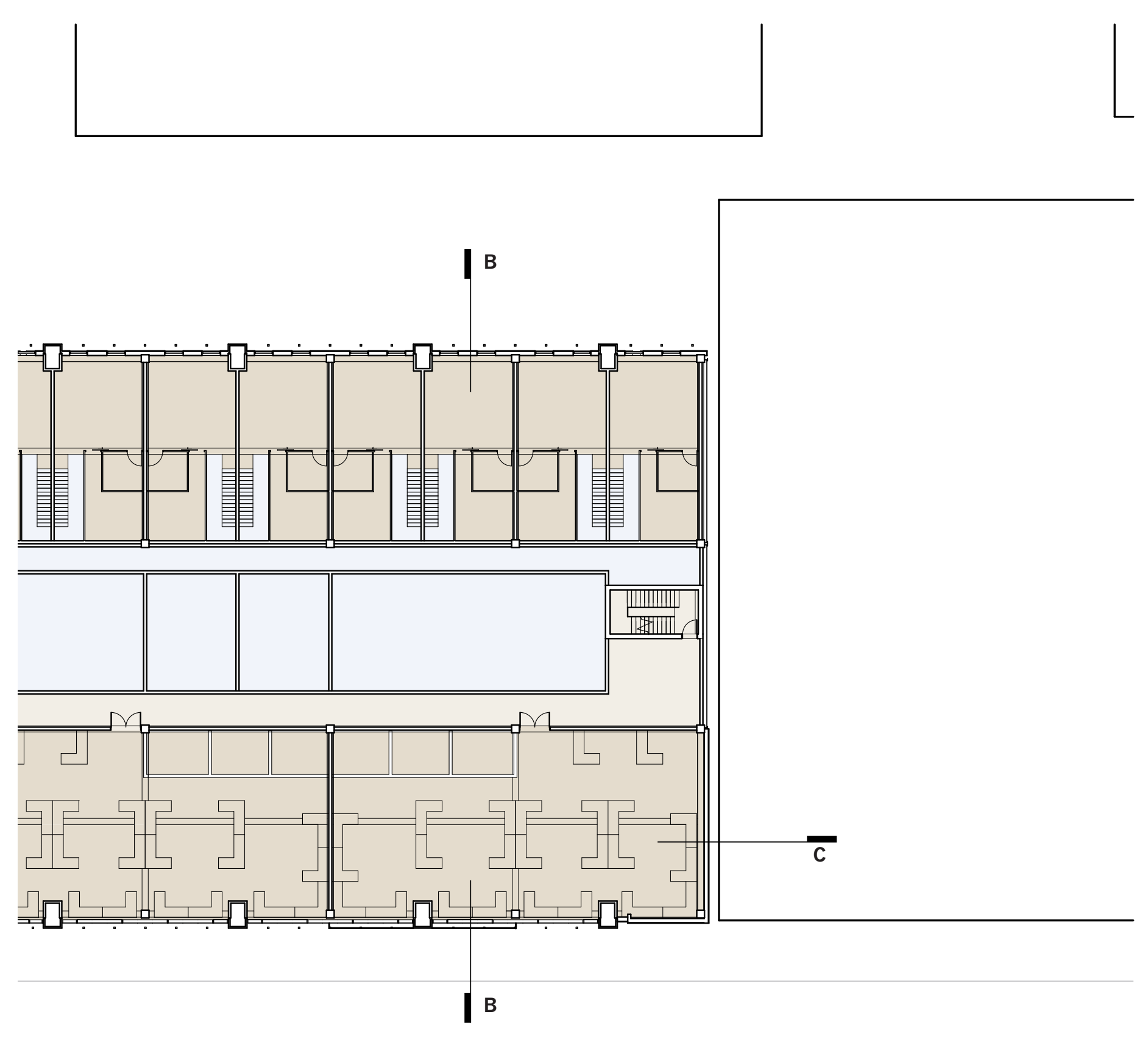

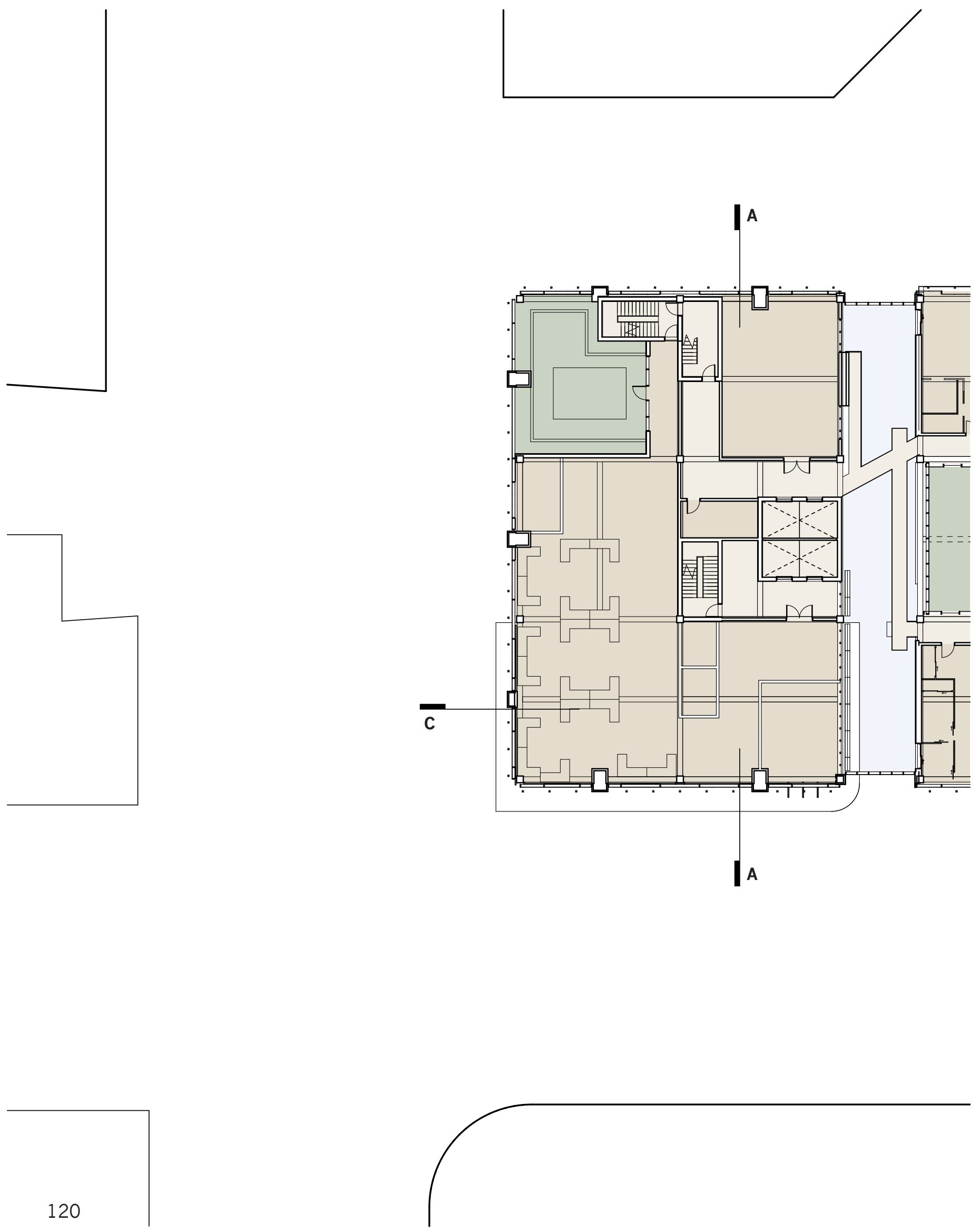

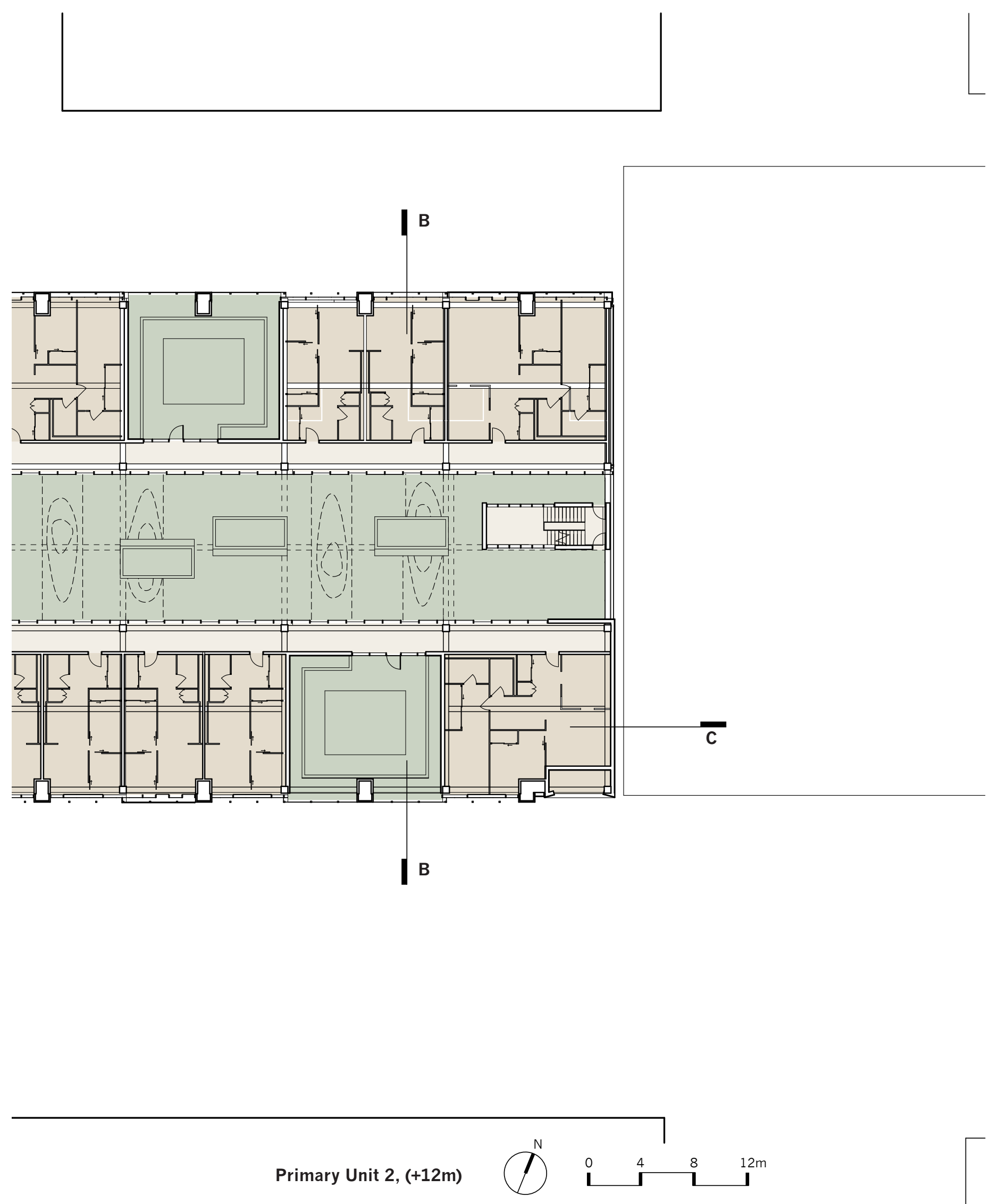

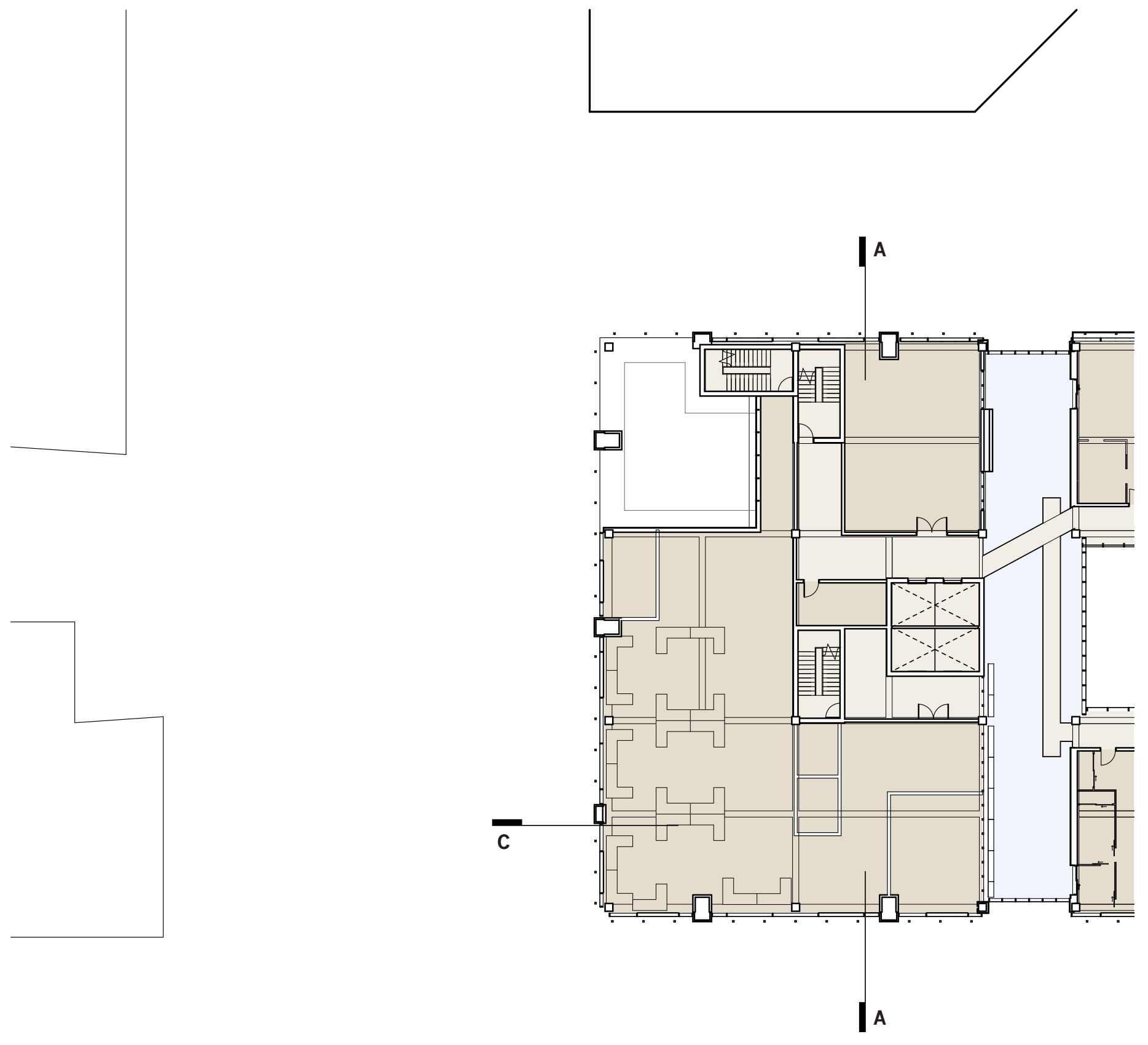

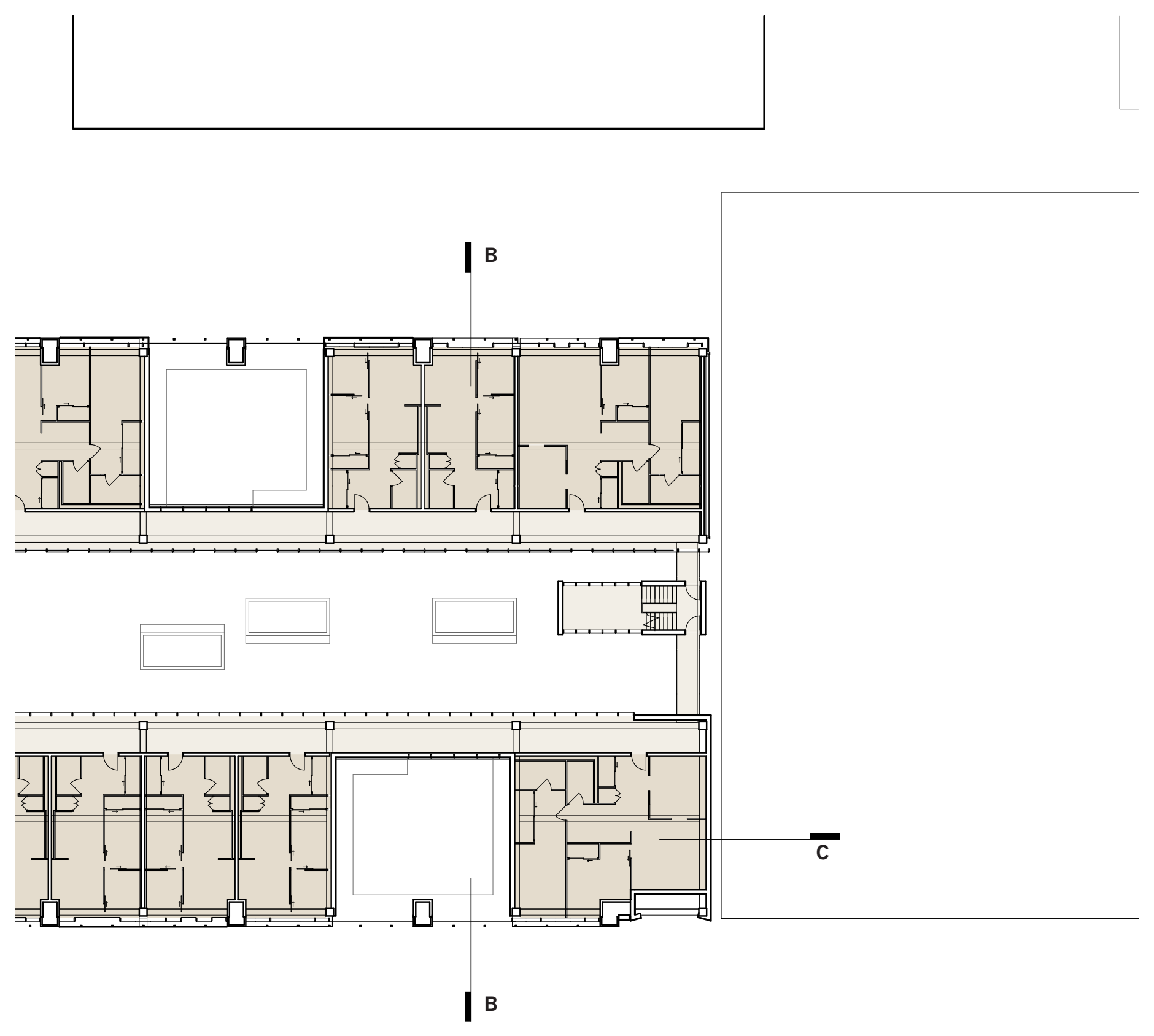

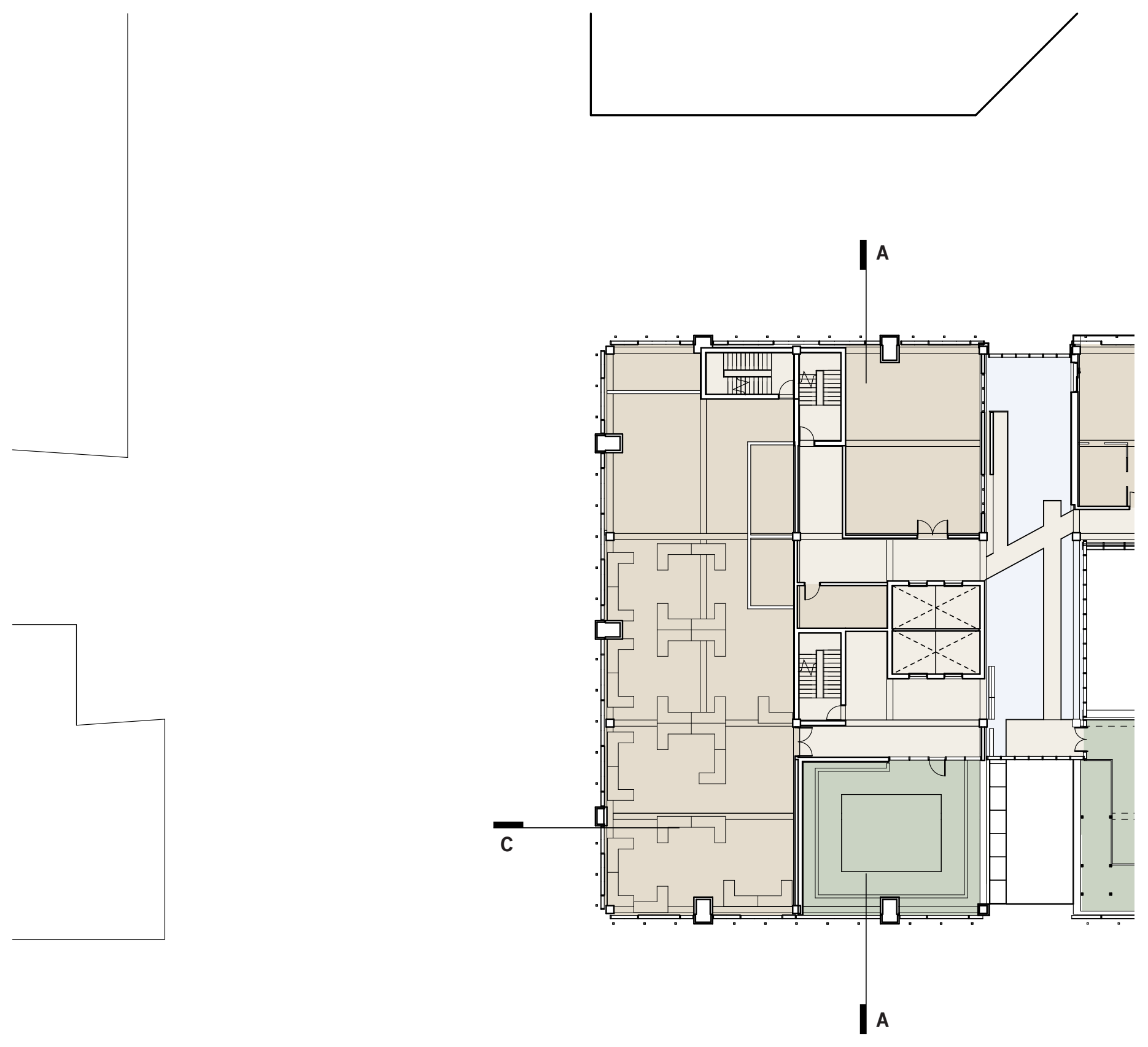

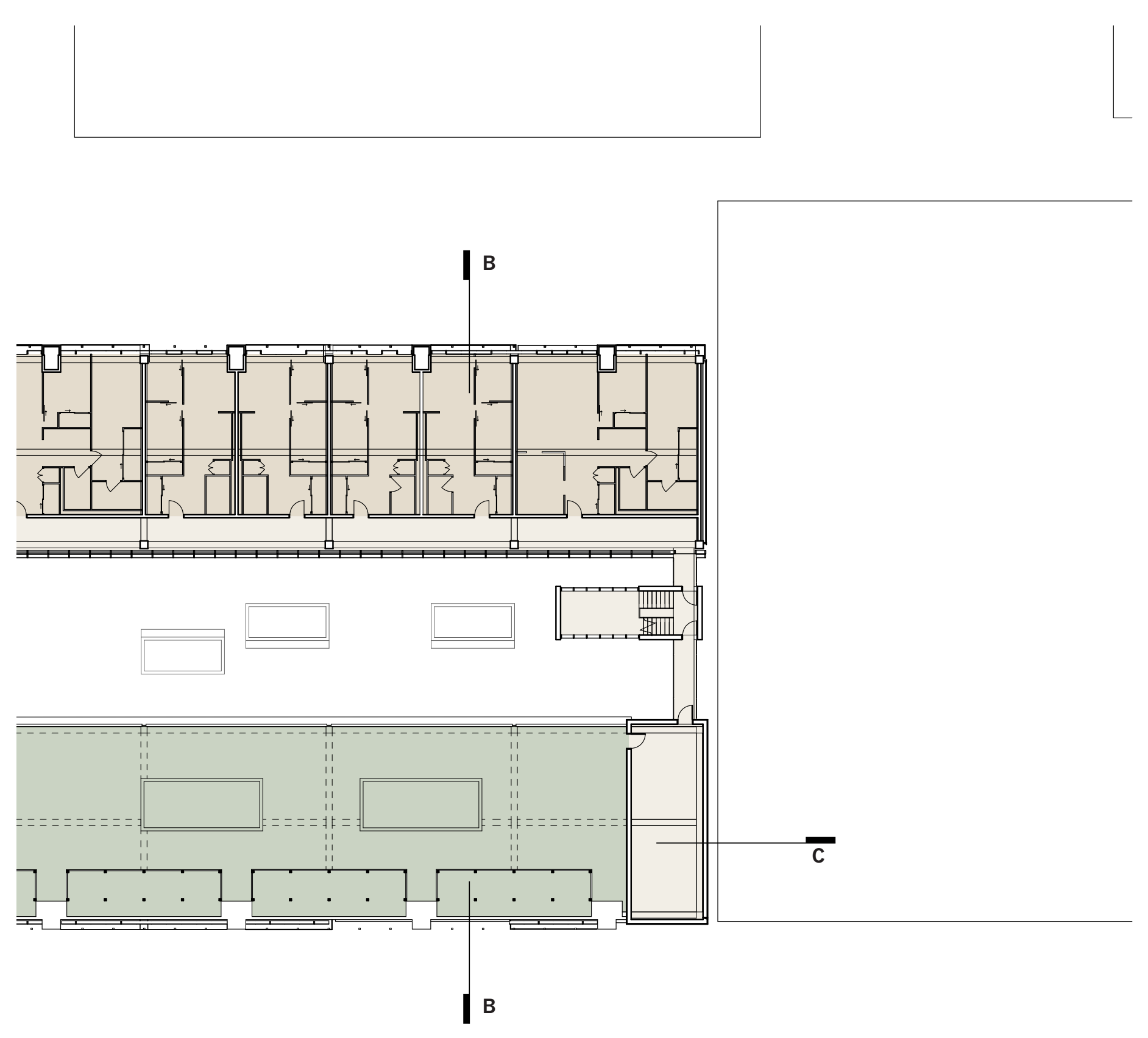

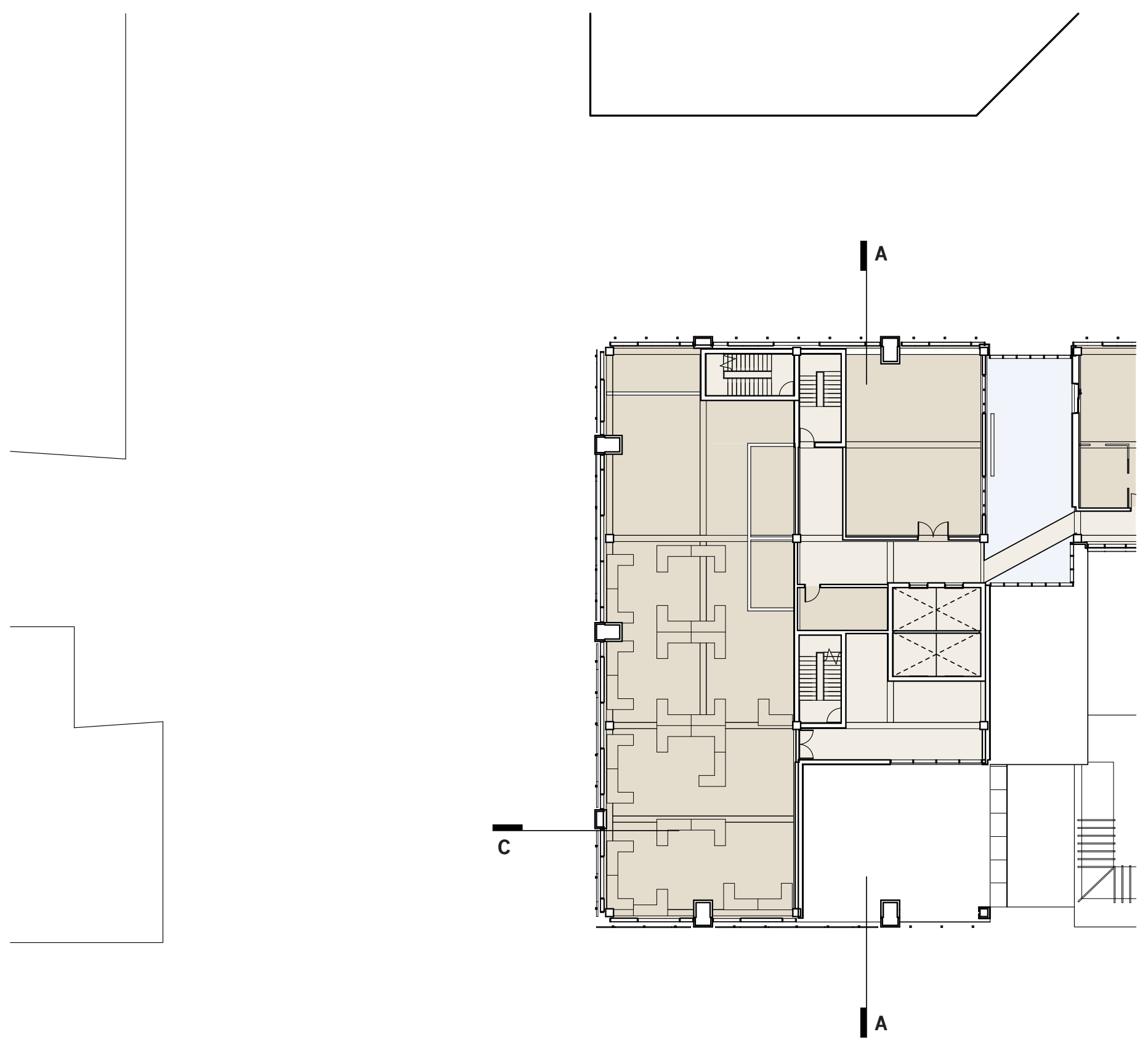

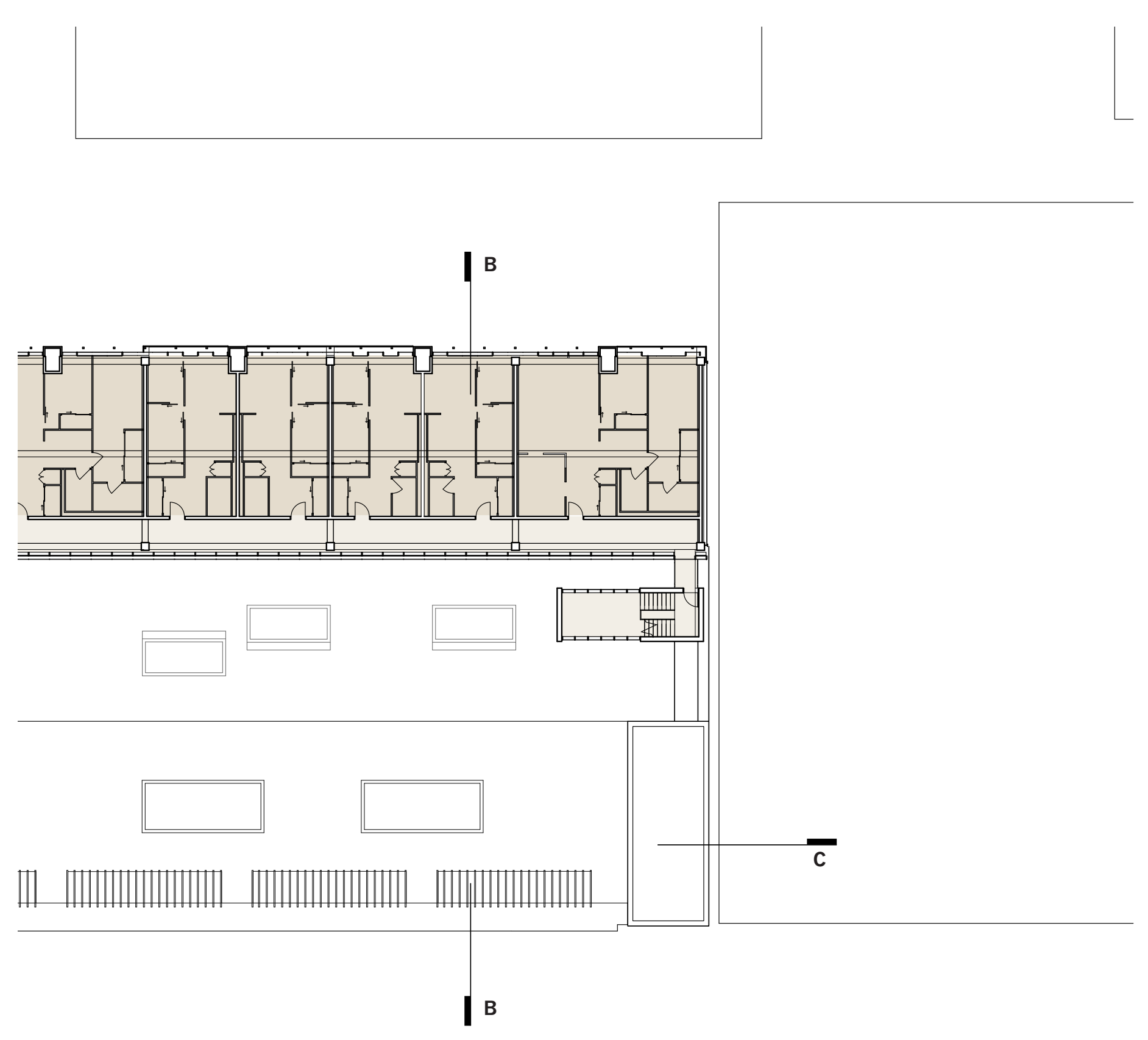

Primary Unit 3, (+33m) 

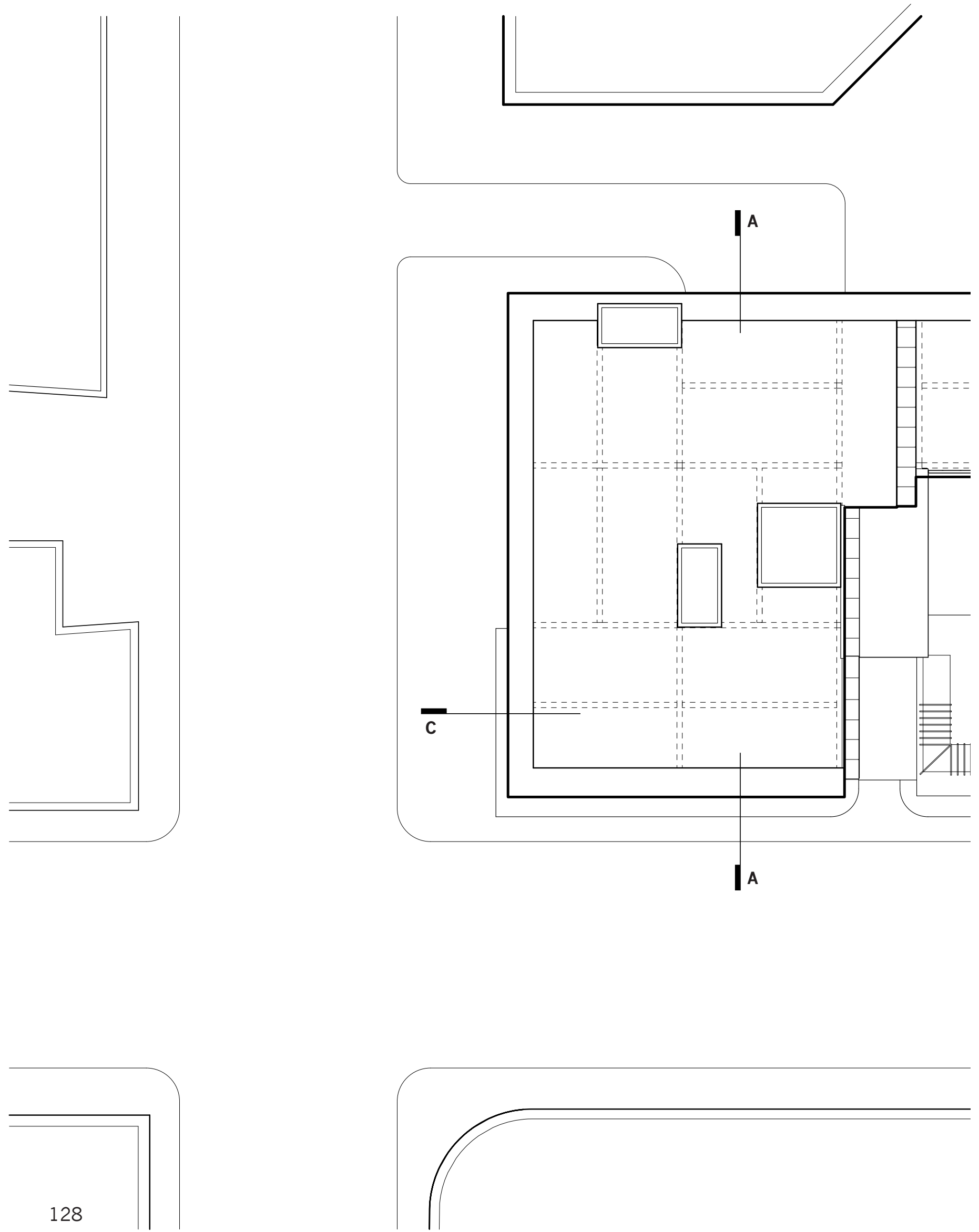

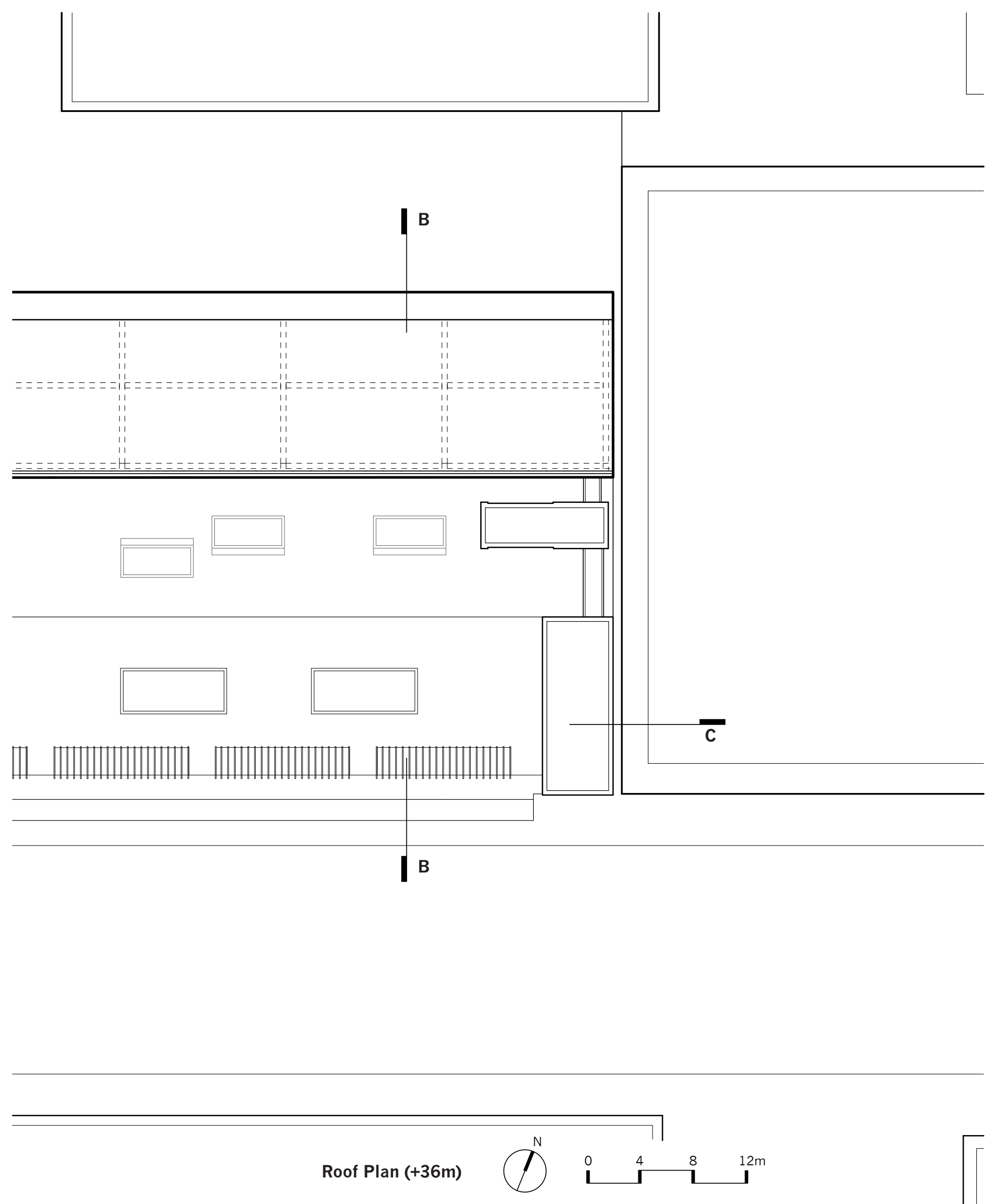


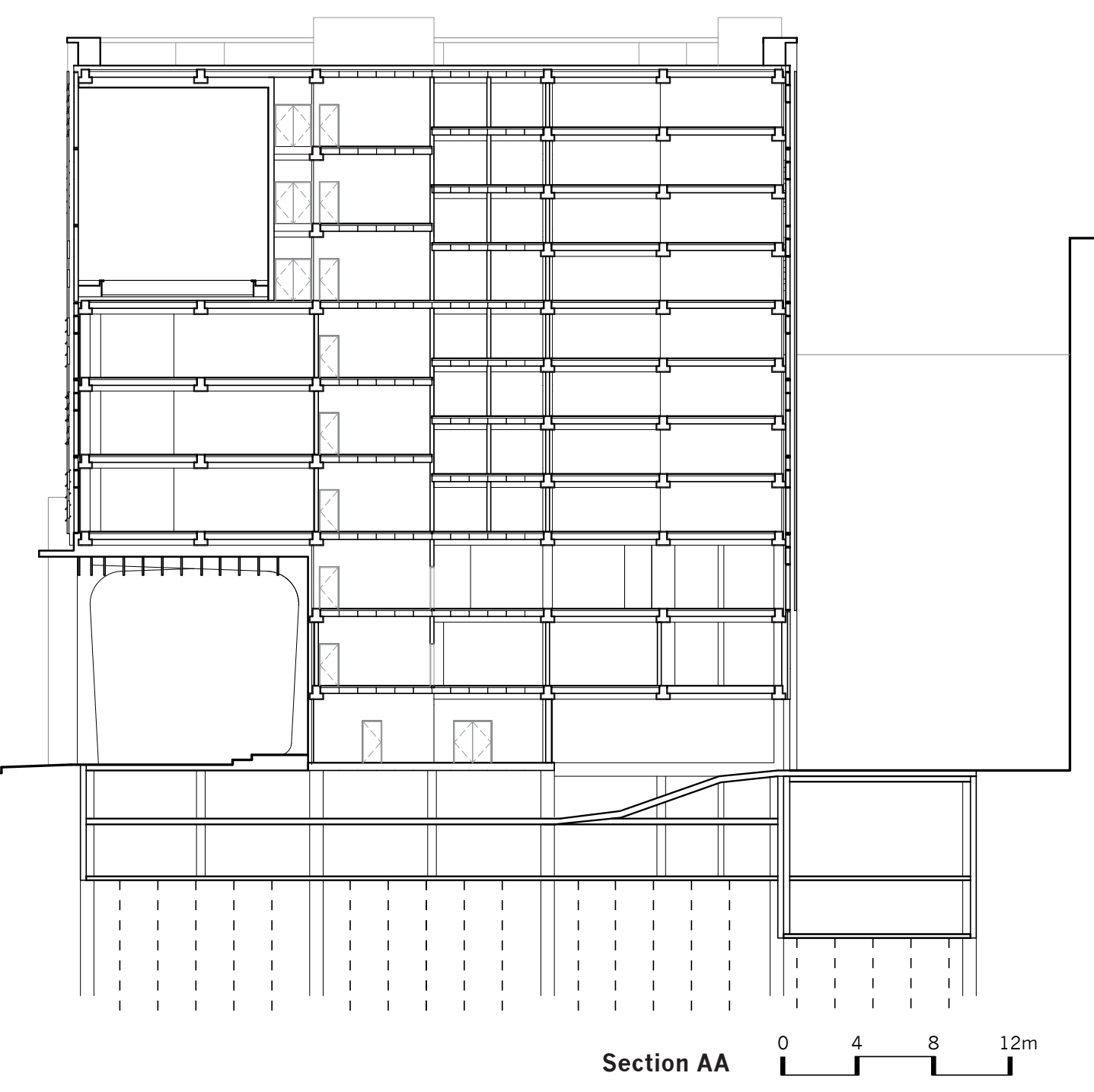




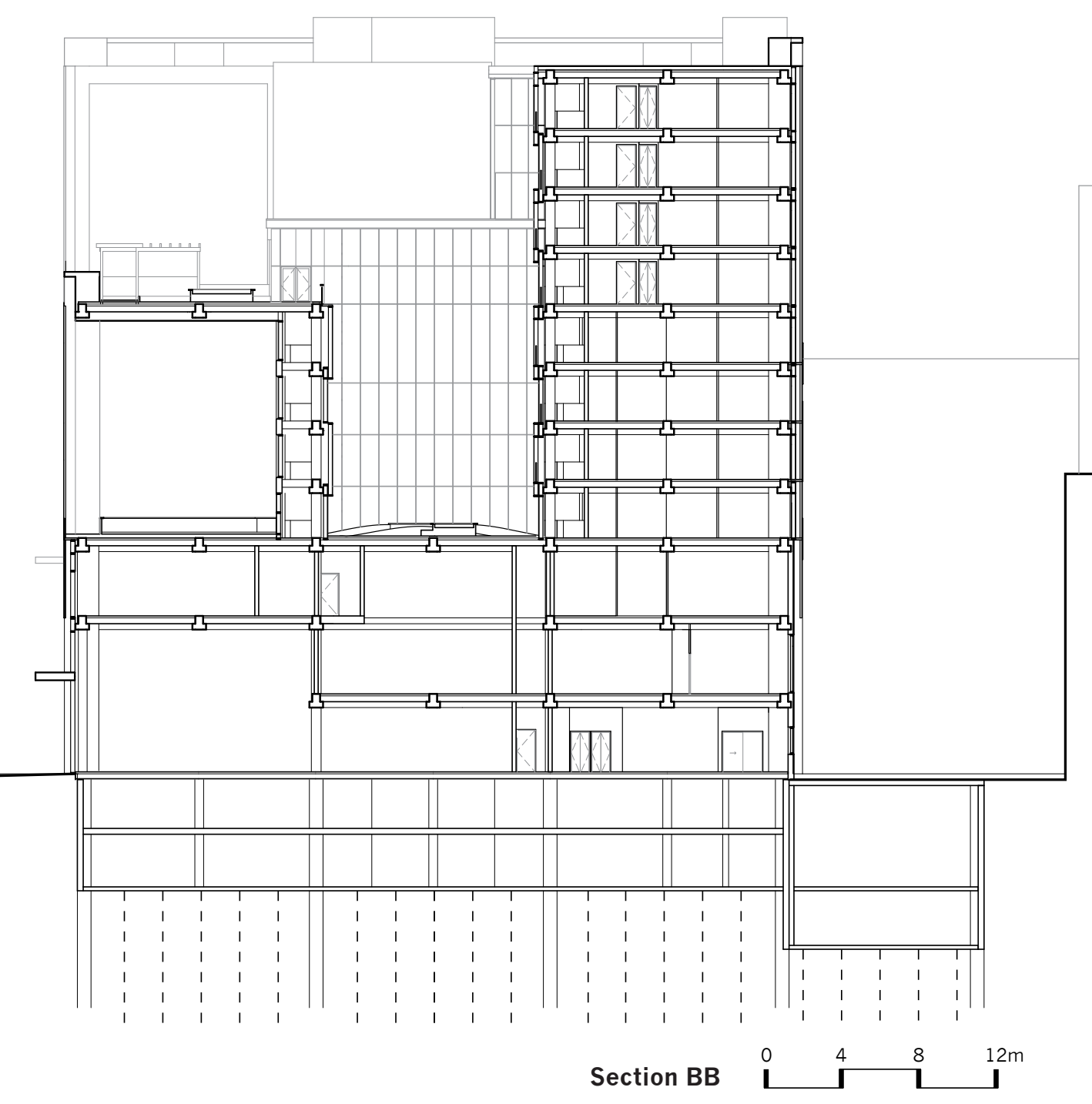




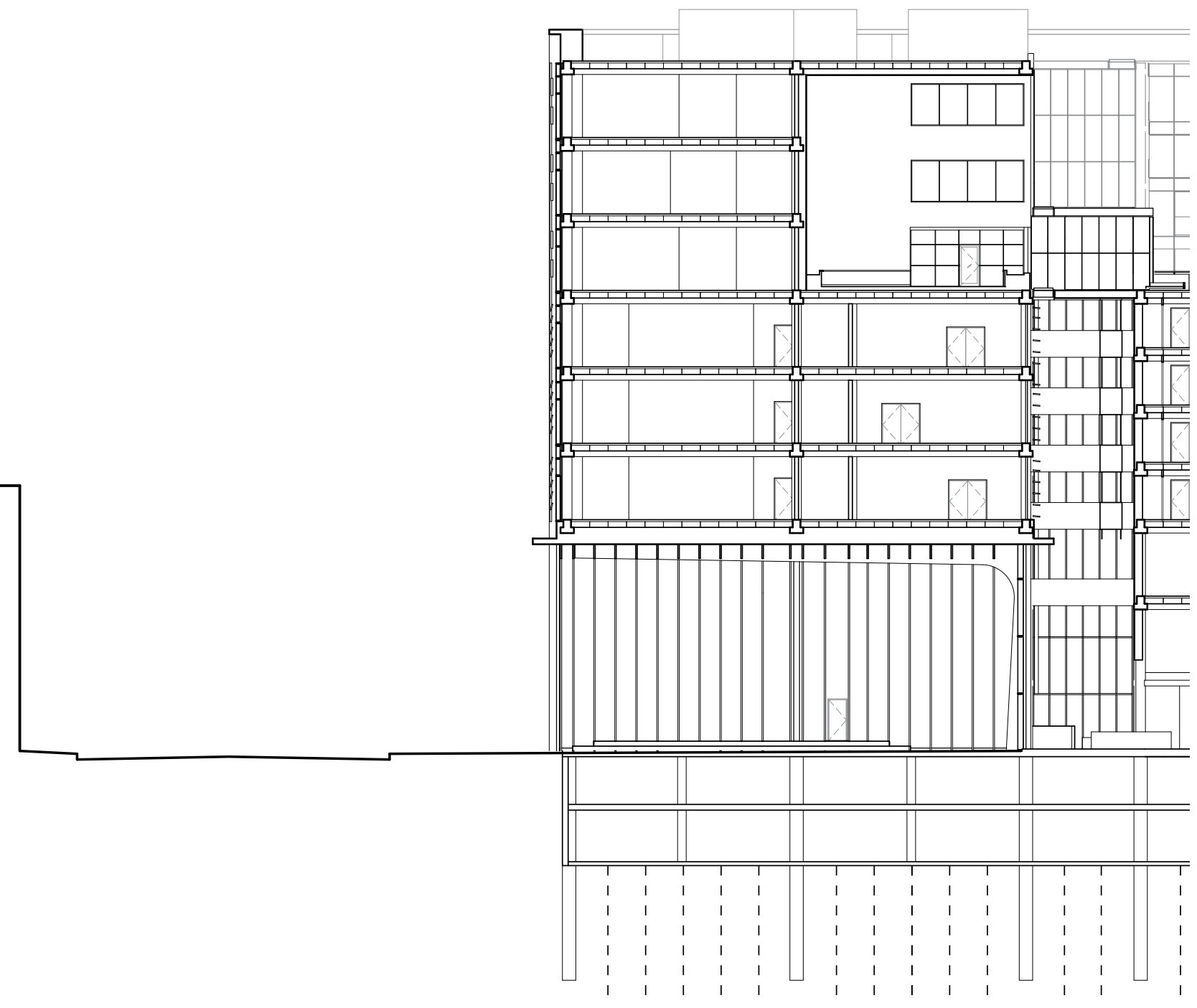




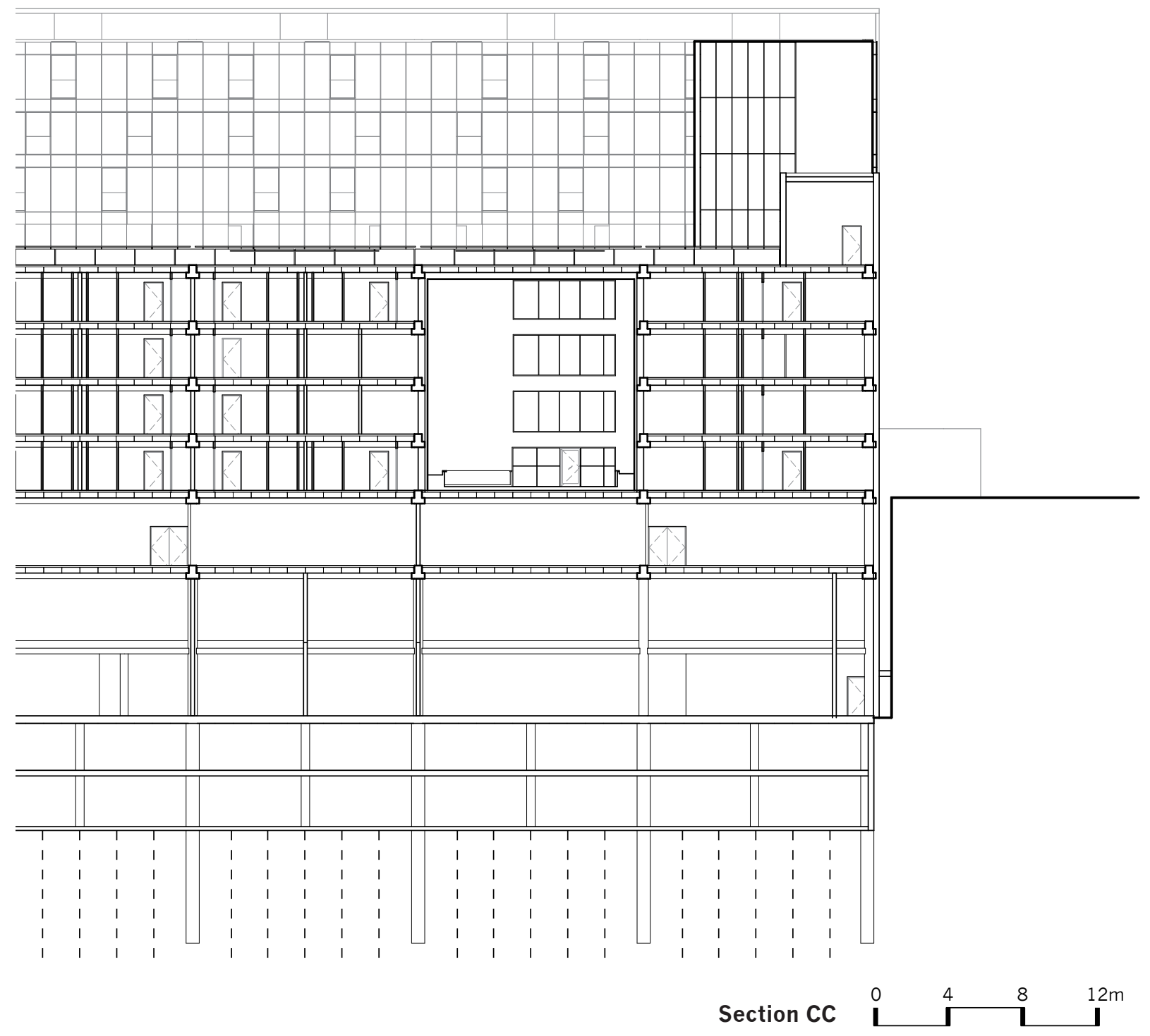




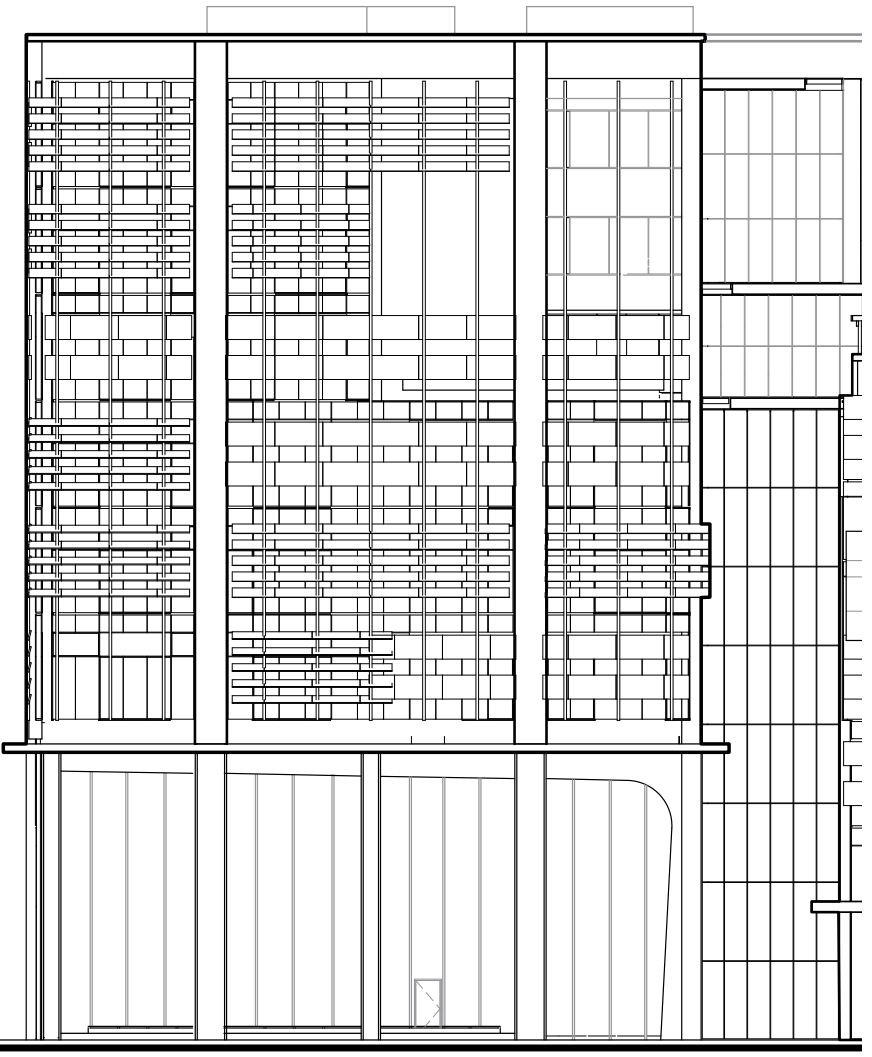




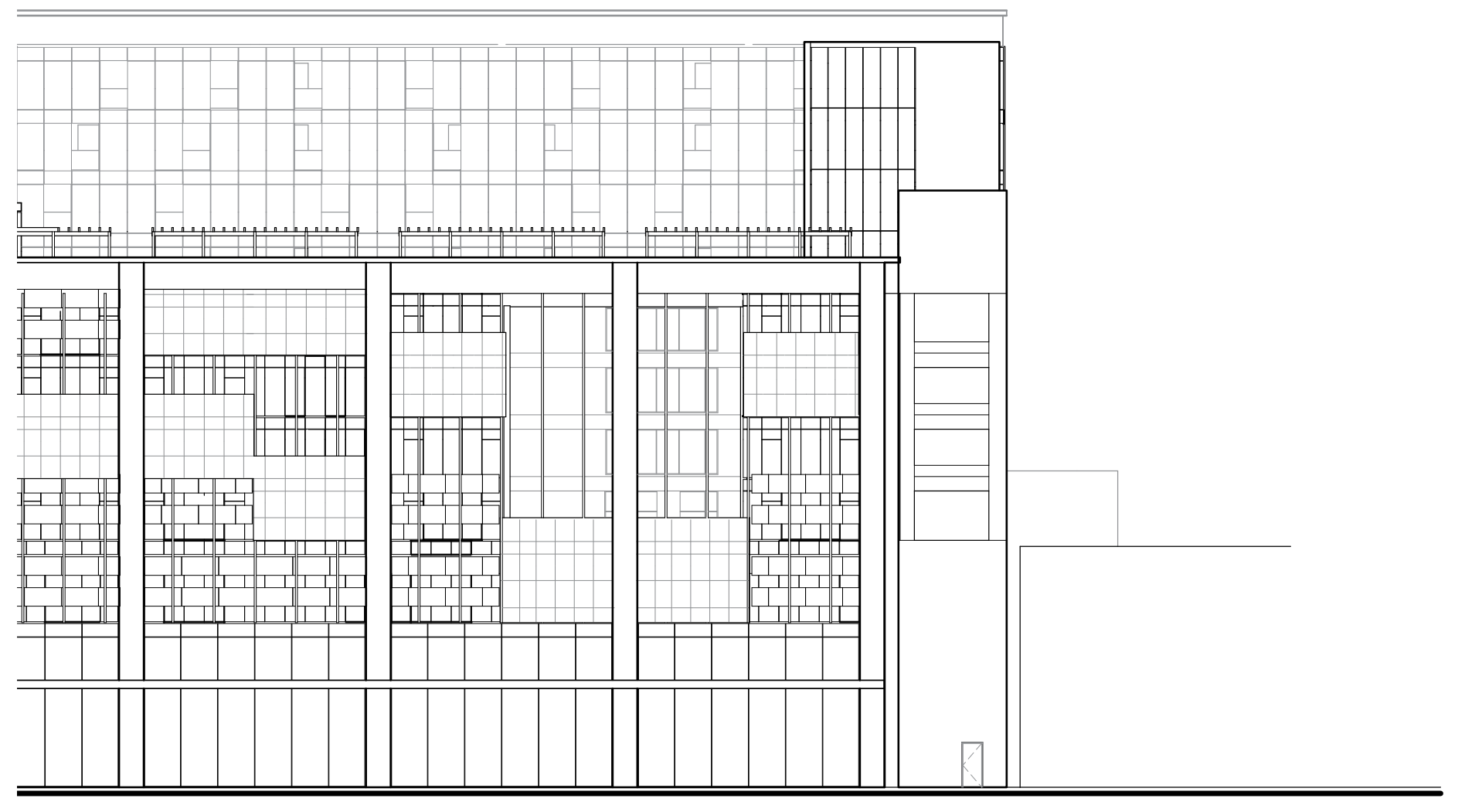

South Elevation $\quad \mathbf{L} \quad 4 \quad 8 \quad 12 \mathrm{~m}$ 


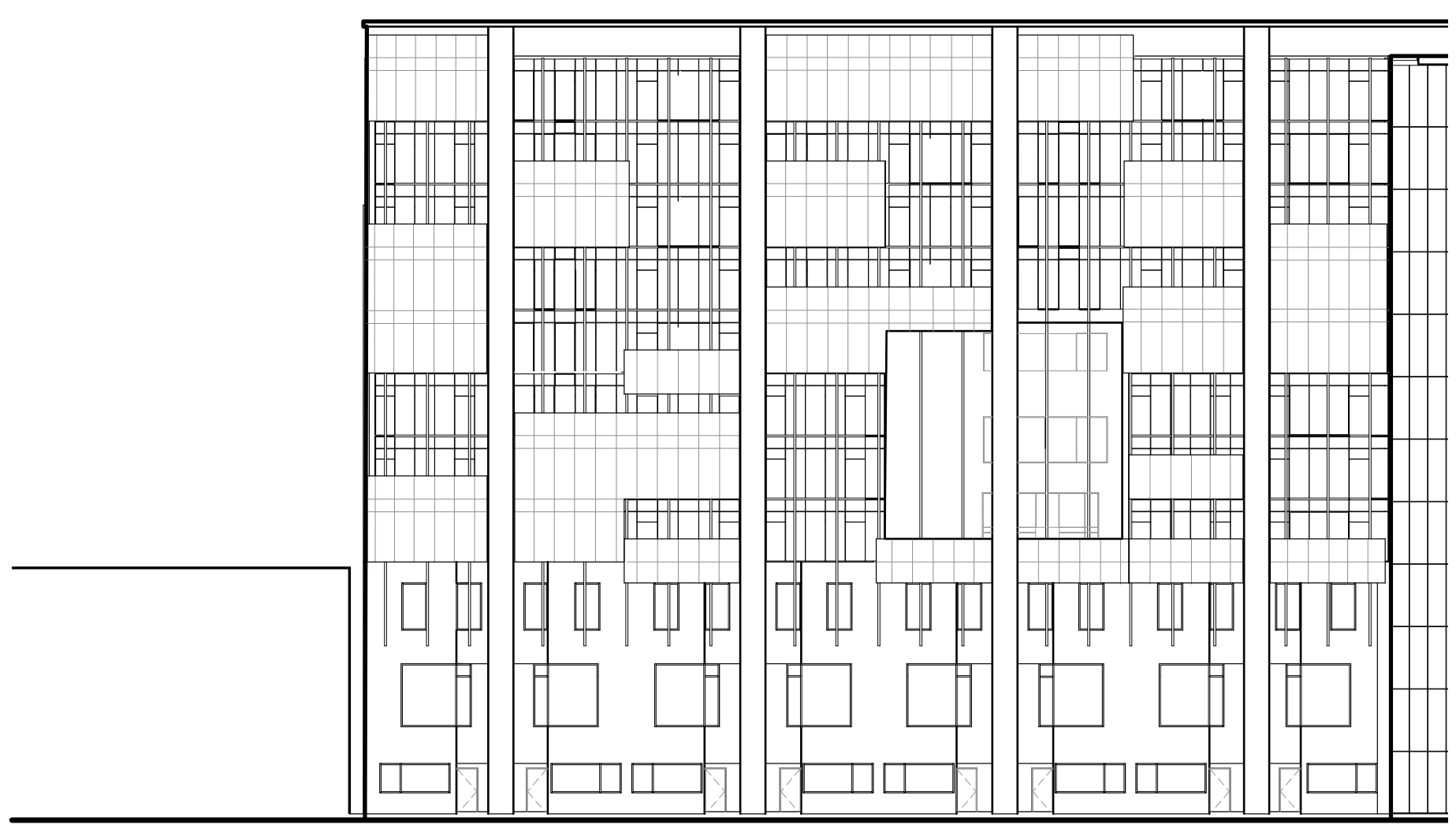




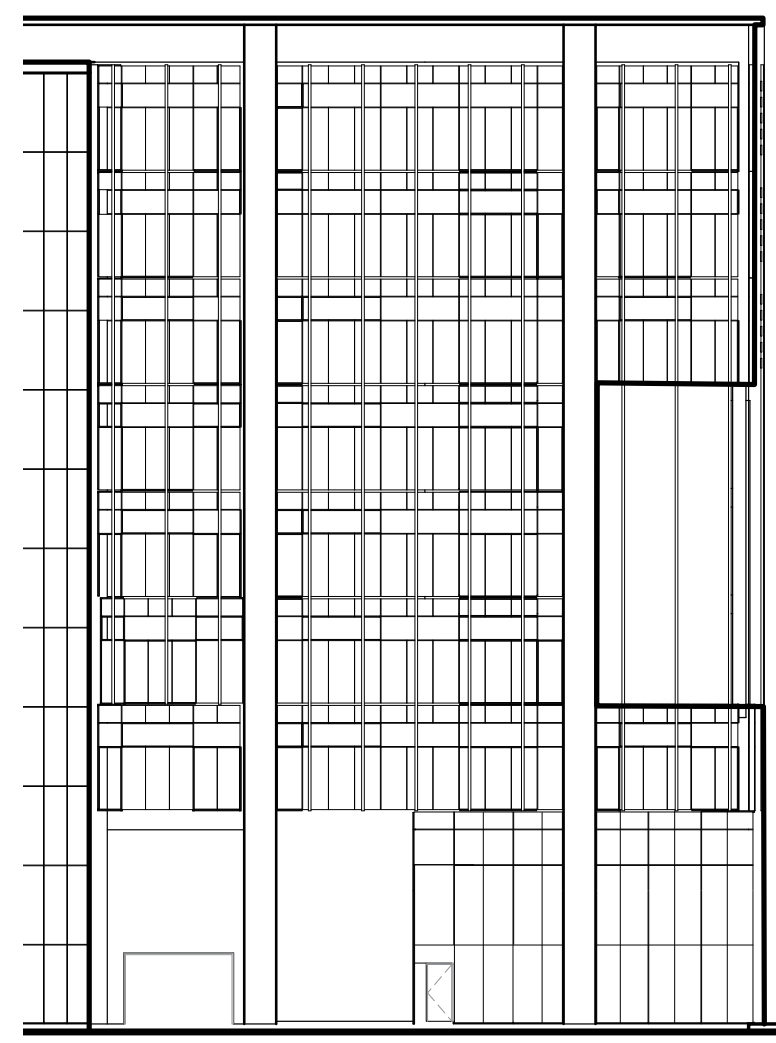

North Elevation $\begin{array}{llll}0 & 4 & 8 & 12 m\end{array}$ 

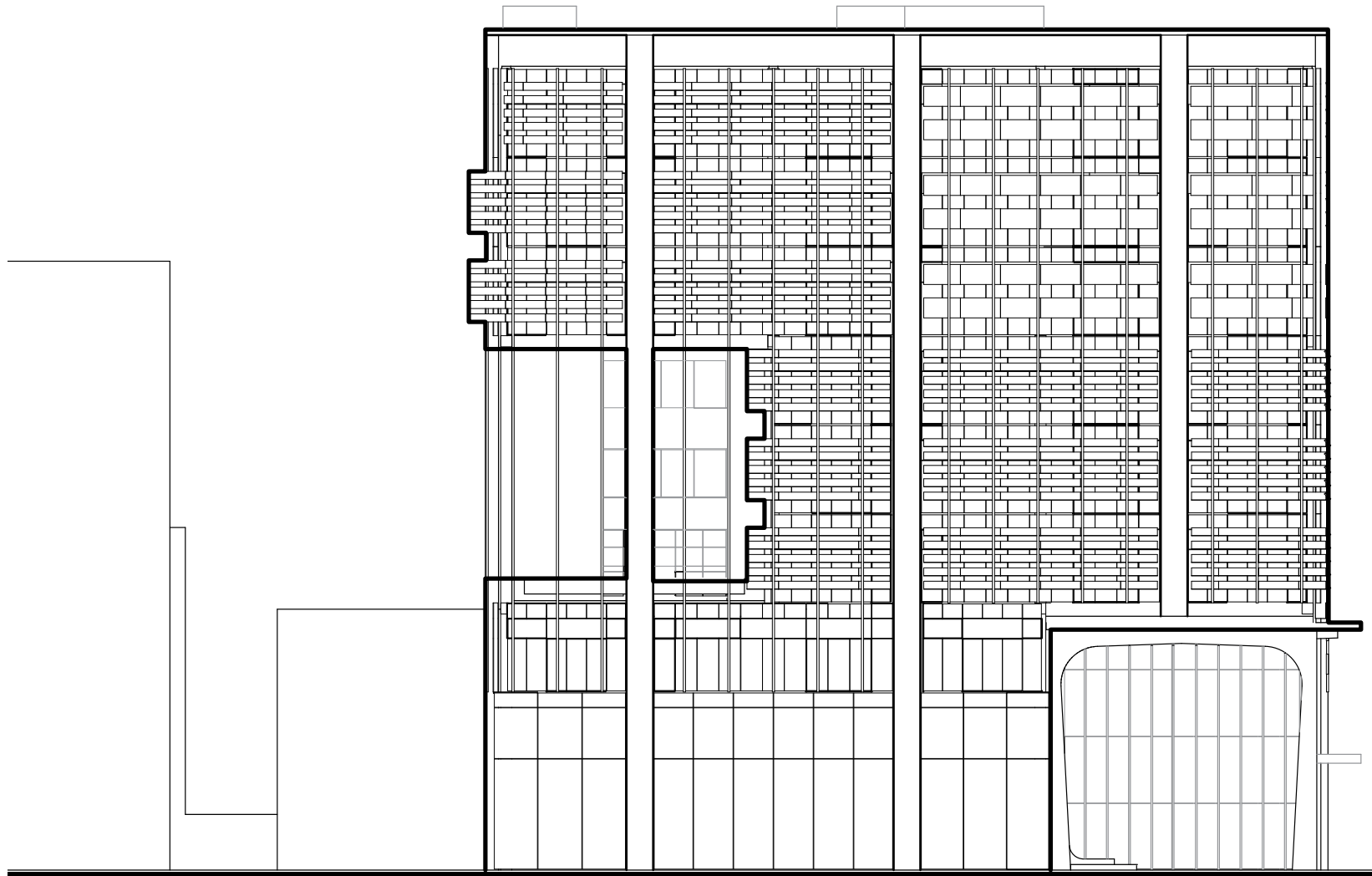

$\begin{array}{lllll}\text { West Elevation } & 0 & 4 & 8 & 12 \mathrm{~m} \\ \mathbf{I} & \mathbf{I} & \mathbf{I} & \mathbf{I}\end{array}$ 
APPENDIX C - BUILDING ANALYSIS PT. 1 


\begin{tabular}{|c|c|c|c|}
\hline Quebec Bank & 50 King Street East & 1886 & 5 \\
\hline Bank of British North America & 49 Yonge Street & 1873 & 4 \\
\hline Victoria Tin Works Building & 69 Sherbourne Street & 1883 & 5 \\
\hline E.C. Gurney \& Co. Stove Foundry & 500 King Street West & 1872 & 4 \\
\hline Barrymore Building & 109 Atlantic Avenue & 1906 & 3 \\
\hline Adams Brothers Harness Manufacturing Company Ltd. & 185 Frederick Street & 1903 & 6 \\
\hline The Cannery & 55 Mill Street & 1873 & 4 \\
\hline 401 Richmond & 401 Richmond Street West & - & 4 \\
\hline Toronto Carpet Manufacturing Company & 55.87 Mowat Avenue & 1899 & 2 \\
\hline National Casket Company Factories & 89 - 109 Niagara Street & 1884 & 5 \\
\hline Houlding Knitwear & 462 Wellington Street West & 1916 & 5 \\
\hline 8 Market Street & 8 Market Street & 1900 & 6 \\
\hline Copp Clark Publishing Co. & 517 Wellington Street West & 1909 & 4 \\
\hline W.A. Drummond \& Company Dairy Supply Warehouse & 214 King Street East & 1911 & 5 \\
\hline Queen's Quay Terminal & 207 Queens Quay West & 1927 & 13 \\
\hline Strachan House & 53 Strachan Avenue & - & 3 \\
\hline Monarch Building & 436 Wellington Street West & 1915 & 6 \\
\hline Candy Factory Lofts & 993 Queen Street West & - & 6 \\
\hline Artscape Wychwood Barns & 601 Christie Street & 1913 & 1 \\
\hline Toy Factory Lofts & 43 Hanna Avenue & - & 5 \\
\hline The Metropole & 7 King Street East & 1963 & 22 \\
\hline Park Avenue & 48 St. Clair Avenue West & 1957 & 12 \\
\hline Massey Harris Lofts & 915 King Street West & 1889 & 4 \\
\hline Tip Top Tailors & 637 Lake Shore Boulevard West & 1929 & 11 \\
\hline Merchandise Building & 155 Dalhousie Street & 1910 & 14 \\
\hline
\end{tabular}


Built As

Converted to

\begin{tabular}{|c|c|c|}
\hline 22 & 4 & 4 \\
\hline 22 & 5 & 6 \\
\hline . & 3 & 4 \\
\hline 15 & 5 & 4 \\
\hline 15 & 3 & 5 \\
\hline 24 & 5 & 4 \\
\hline 15 & 4 & 4 \\
\hline 16 & 2 & 4 \\
\hline - & 3 & 4 \\
\hline 18 & 3 & 4 \\
\hline 19 & 4 & 4 \\
\hline 22 & 4 & 4 \\
\hline 16 & 4 & 5 \\
\hline . & 4 & 4 \\
\hline 30 & 6 & 4 \\
\hline 12 & 3 & 4 \\
\hline 22 & 4 & 3 \\
\hline 26 & 4 & 4 \\
\hline 7 & 5 & 6 \\
\hline . & 4 & 4 \\
\hline . & 4 & 5 \\
\hline 47 & 9 & 3 \\
\hline 17 & 4 & 5 \\
\hline 26 & 7 & 4 \\
\hline 45 & 7 & 4 \\
\hline
\end{tabular}

4
5
3
3

$29 \%$

$15 \%$

$24 \%$

$17 \%$

$24 \%$

$27 \%$

$20 \%$

$26 \%$

$28 \%$

$28 \%$

$33 \%$

$18 \%$

$29 \%$

$38 \%$

$35 \%$

$21 \%$

$31 \%$

$39 \%$

$26 \%$

$32 \%$

$40 \%$

$32 \%$

$27 \%$

$42 \%$

$46 \%$

\section{Bank}

Bank

Industrial

Industrial

Industrial

Industrial

Industrial

Industrial

Industria

Industrial

Industrial

Industria

Industrial Office

Warehouse Office

Warehouse Office

Industrial Residential Industrial Residential

Industrial Residential

Industrial Residential

Industrial Residential

Office

Office

Office

Warehouse

Warehouse
Residential

Residential

Residential

Residential

\section{Total Average

4

4

4

$28 \%$

Commercial

Office

4
4
5

4
4
4

4
4
4

$22 \%$

$29 \%$

Residential

5

$34 \%$ 
APPENDIX D - BUILDING ANALYSIS PT. 2 


\subsection{BANK - COMMERCIAL}
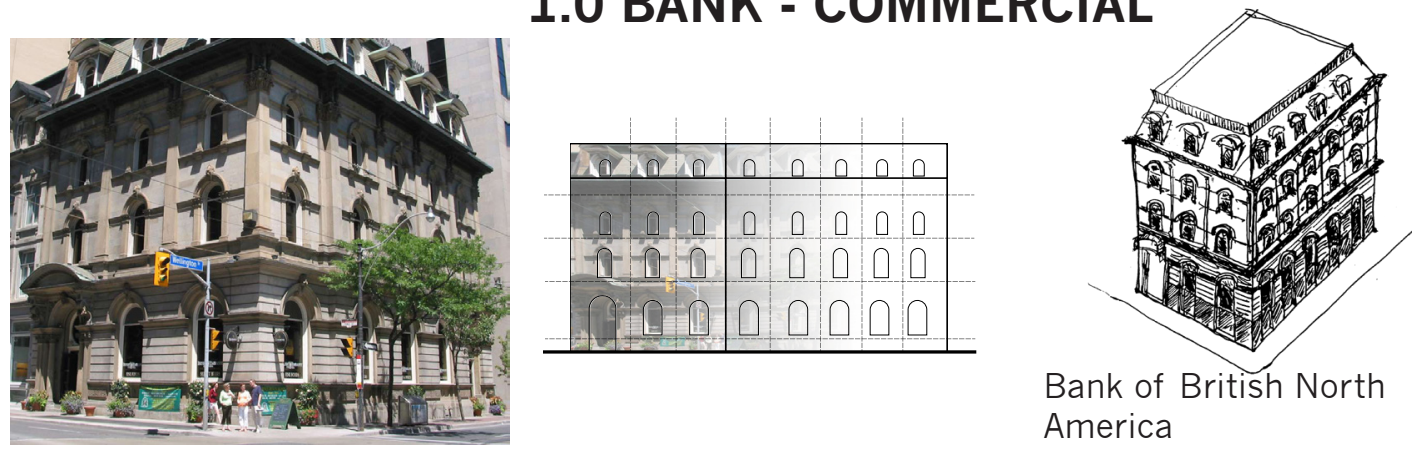

Bank of British North America

49 Yonge Street
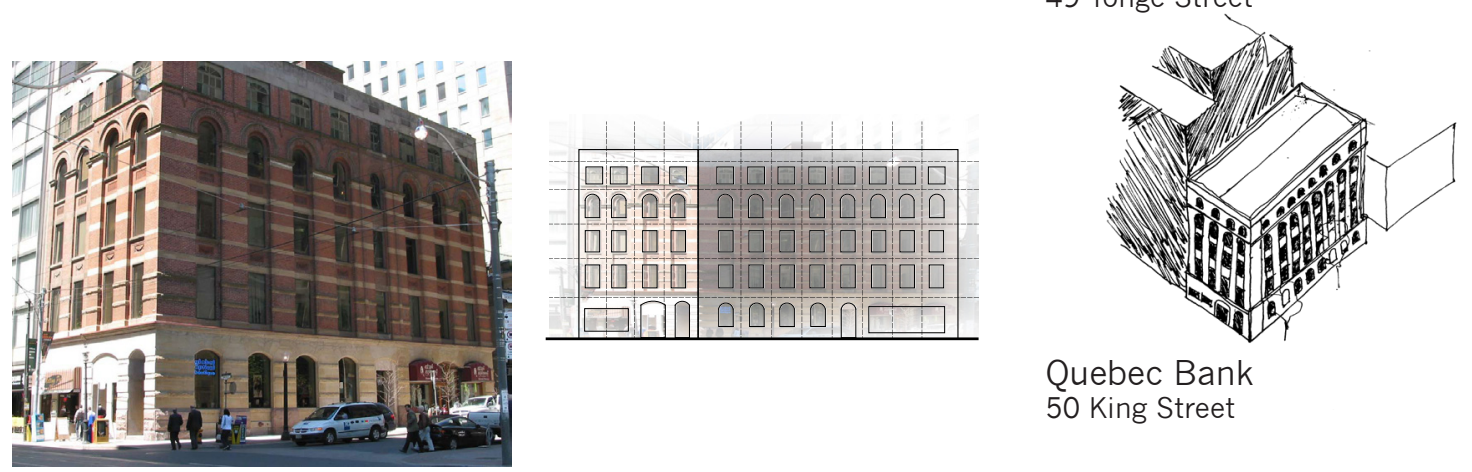

Quebec Bank 50 King Street

\subsection{EDUCATIONAL - RESIDENTIAL}

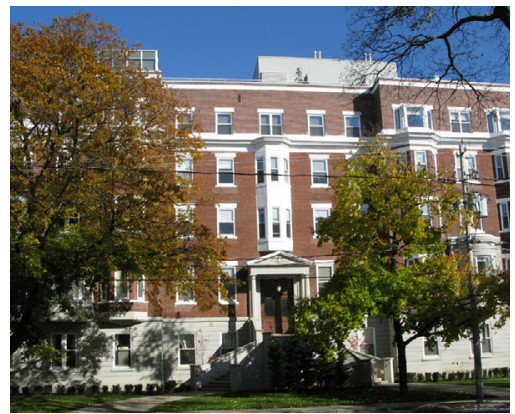

The Loretto

385 Brunswick Ave.

\subsection{EDUCATIONAL - CULTURAL}
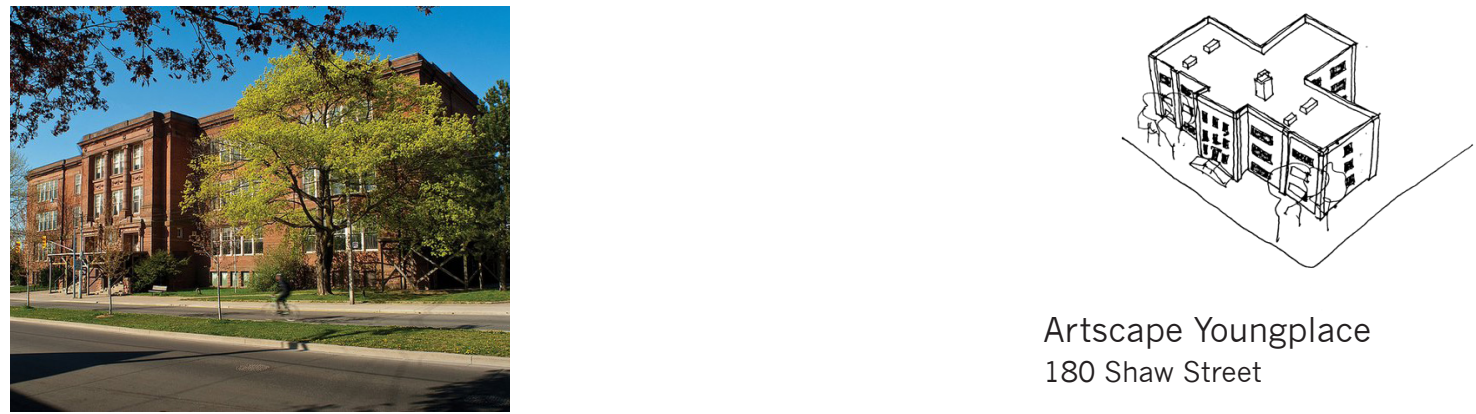

Artscape Youngplace 180 Shaw Street

photographs retrieved from <http://www.tobuilt.ca/> 


\subsection{INDUSTRIAL - COMMERCIAL}
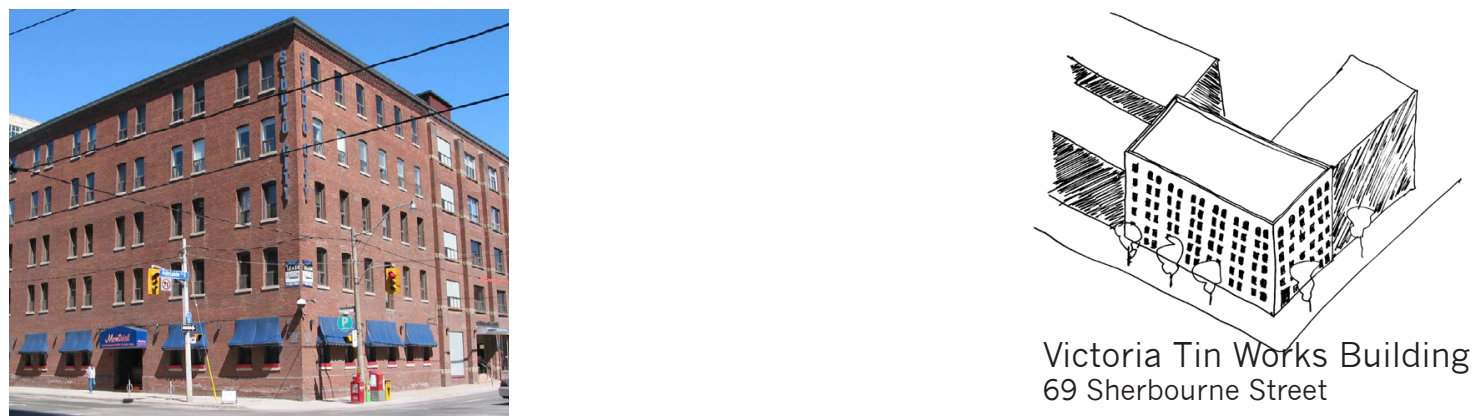

Victoria Tin Works Building 69 Sherbourne Street
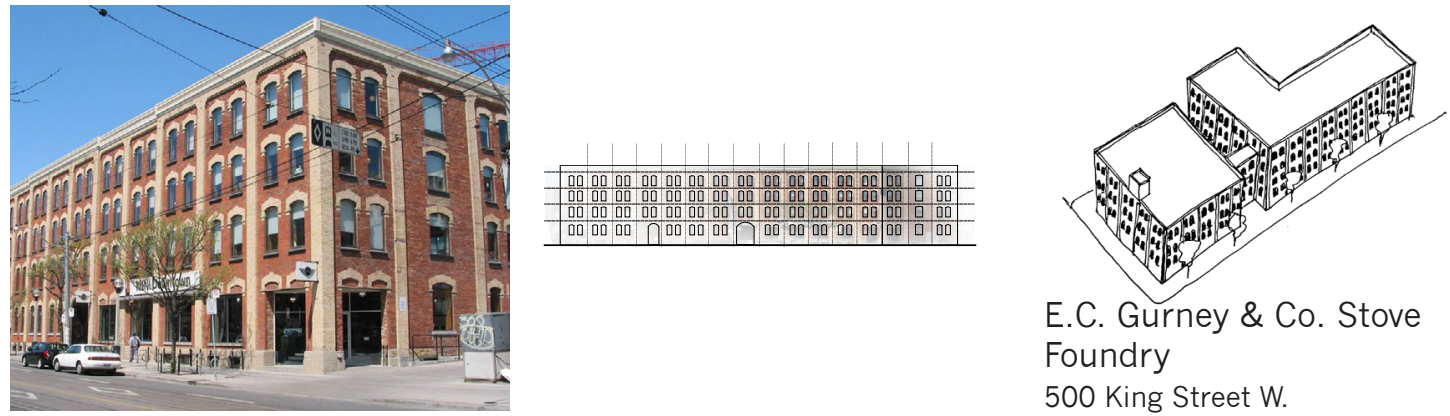

E.C. Gurney \& Co. Stove Foundry

500 King Street W.
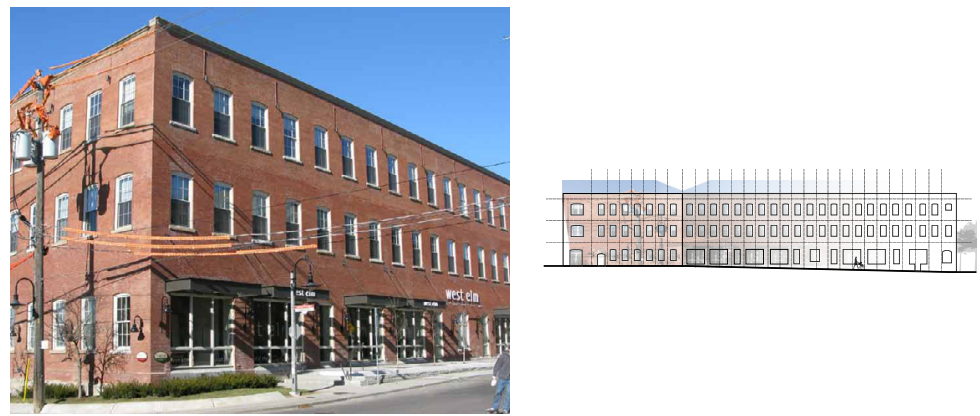

Barrymore Building 109 Atlantic Avenue
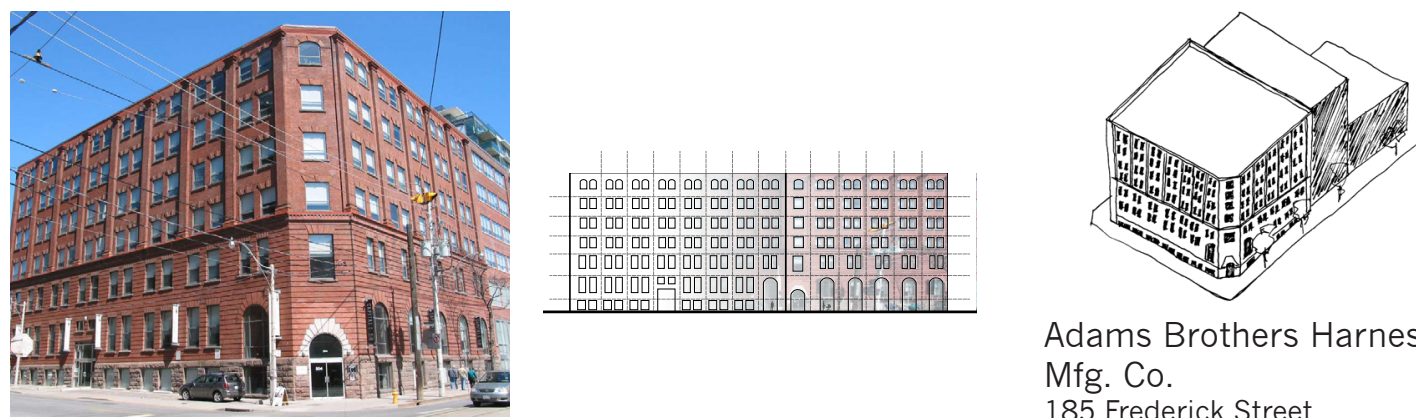

Adams Brothers Harness Mfg. Co.

185 Frederick Street

photographs retrieved from <http://www.tobuilt.ca/> 

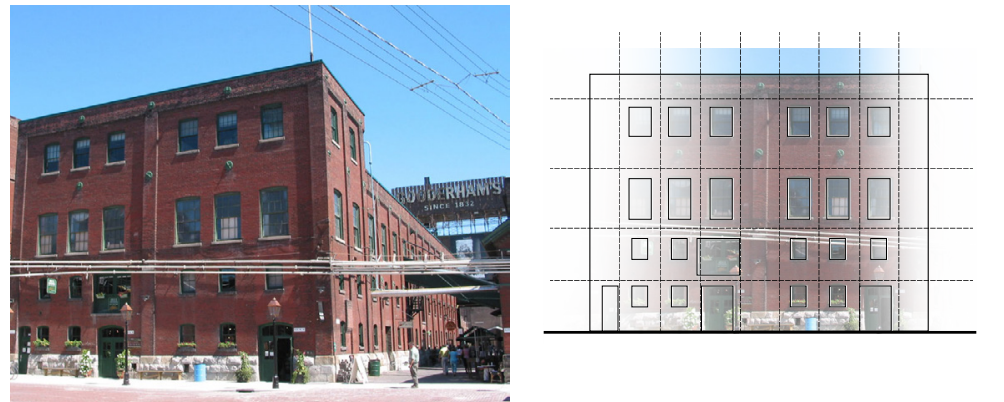

The Cannery

55 Mill Street

\subsection{INDUSTRIAL - CULTURAL}

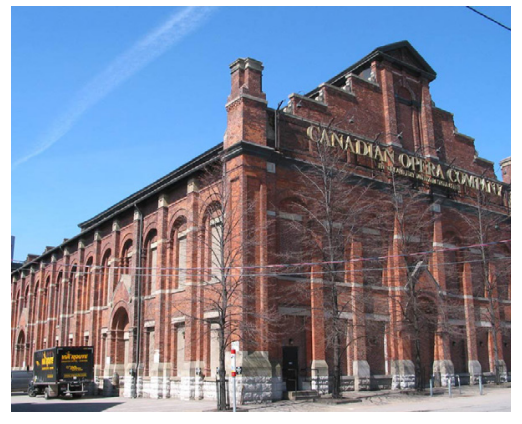

Imperial Oil Opera Theatre 227 Front Street East
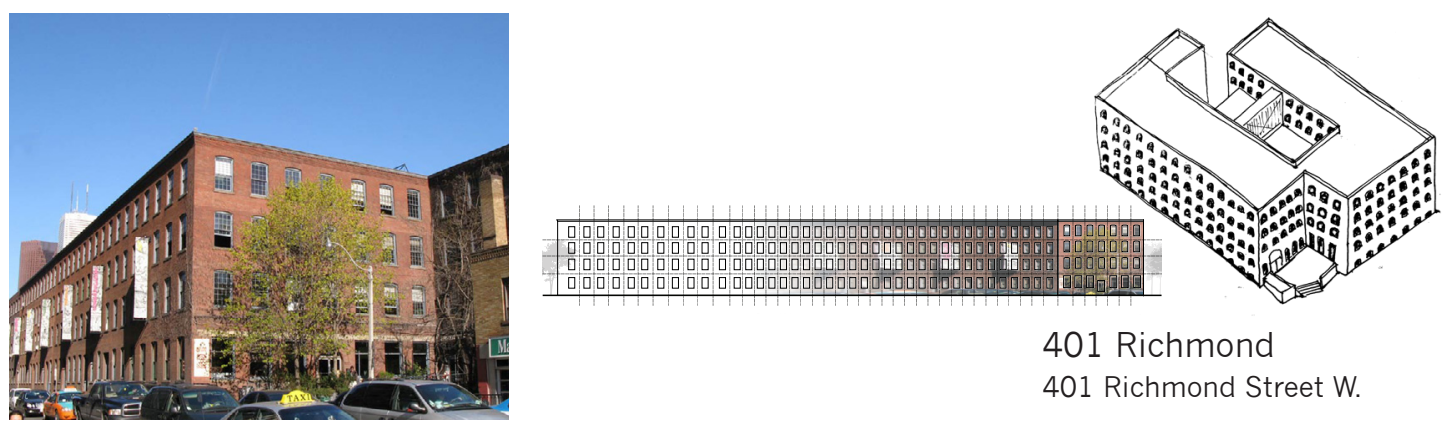

\subsection{INDUSTRIAL - OFFICE}
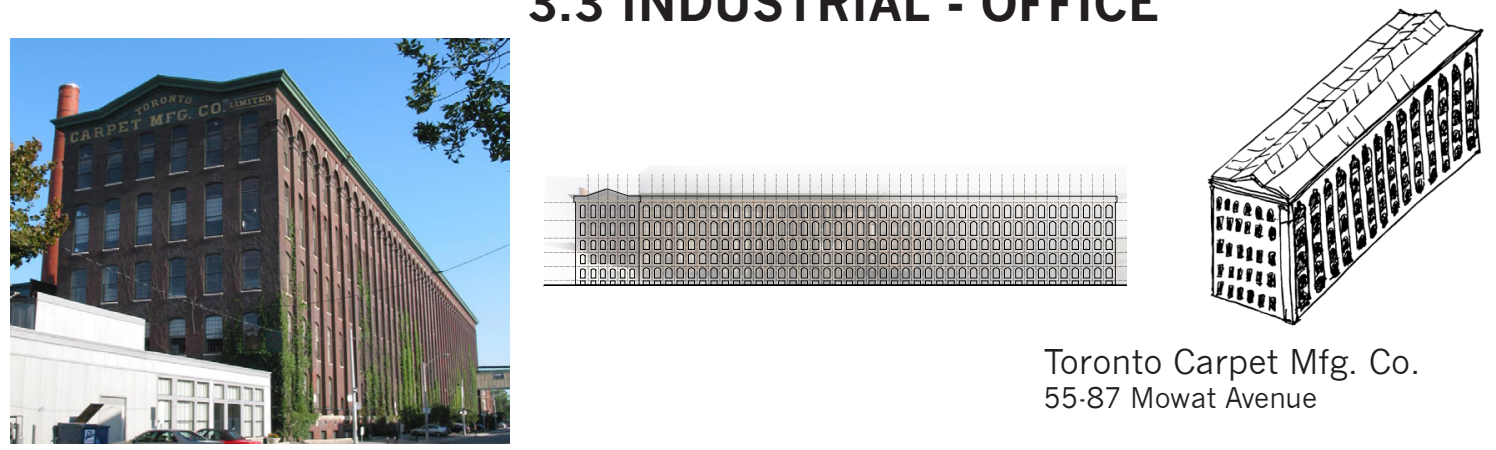

Toronto Carpet Mfg. Co. 55.87 Mowat Avenue

photographs retrieved from <http://www.tobuilt.ca/> 

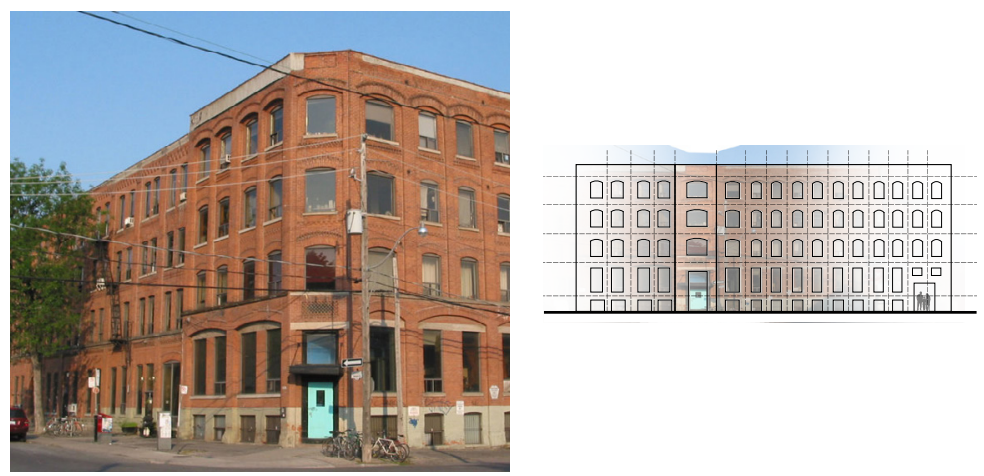

National Casket Company Factories

89-109 Niagara Street
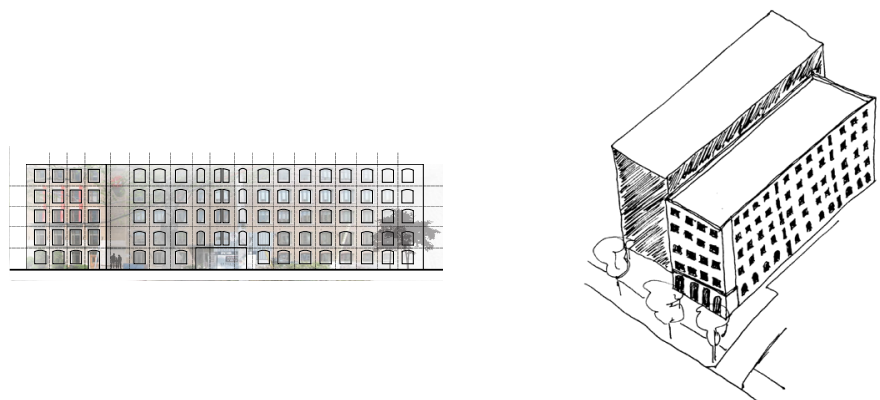

Houlding Knitwear

462 Wellington Street W.
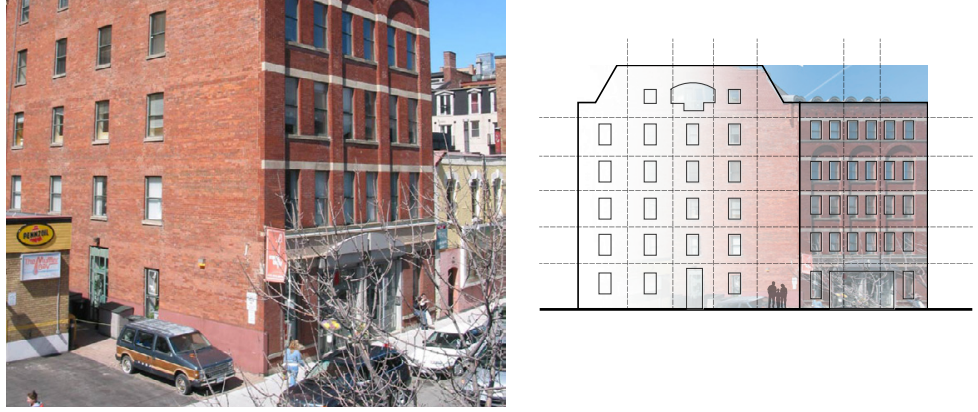

8 Market Street

8 Market Street
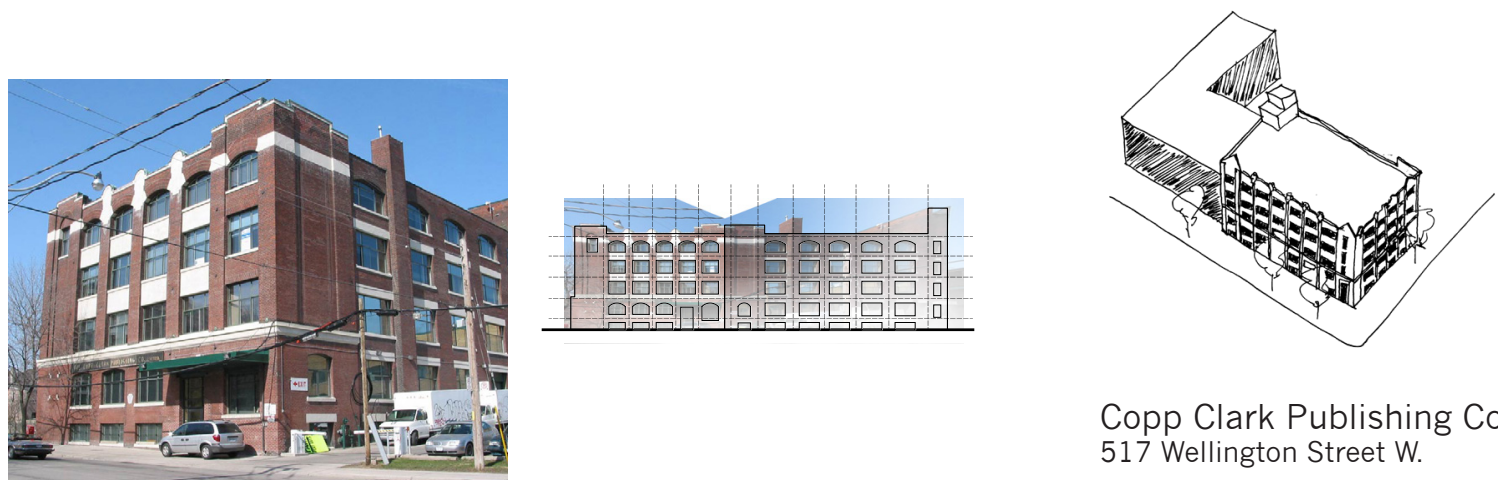

Copp Clark Publishing Co. 517 Wellington Street W.

photographs retrieved from <http://www.tobuilt.ca/> 


\subsection{INDUSTRIAL - RESIDENTIAL}
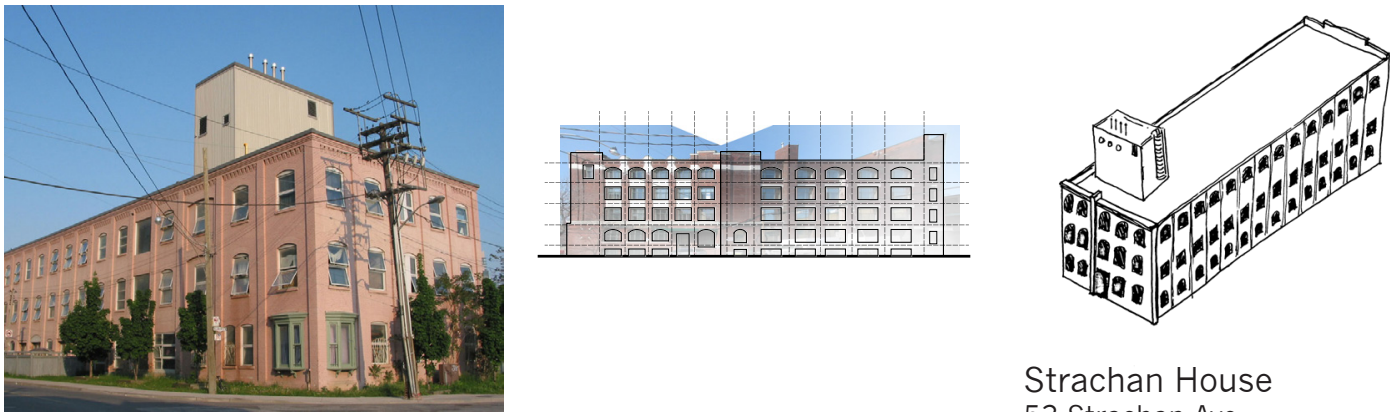

Strachan House 53 Strachan Ave.
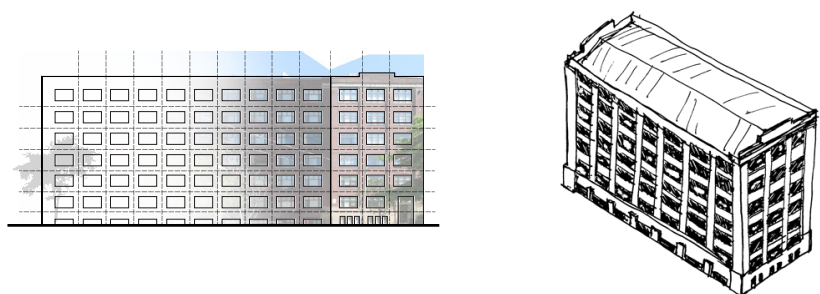

Monarch Building 436 Wellington Street W.
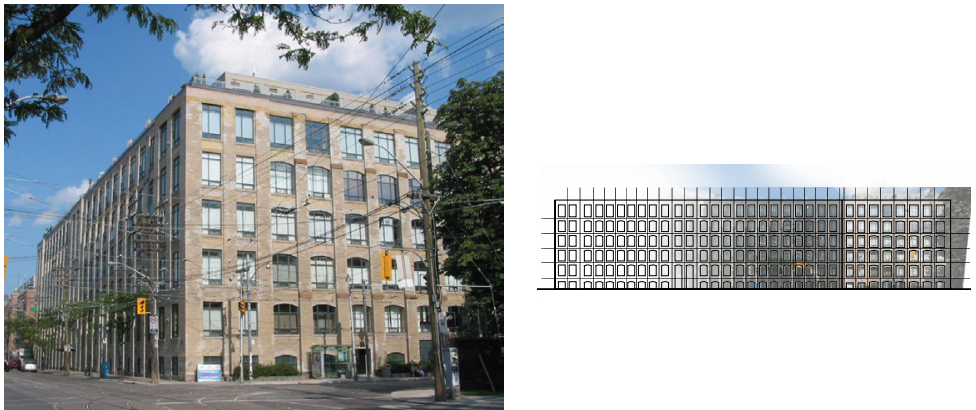

Candy Factory Lofts 993 Queen Street W.
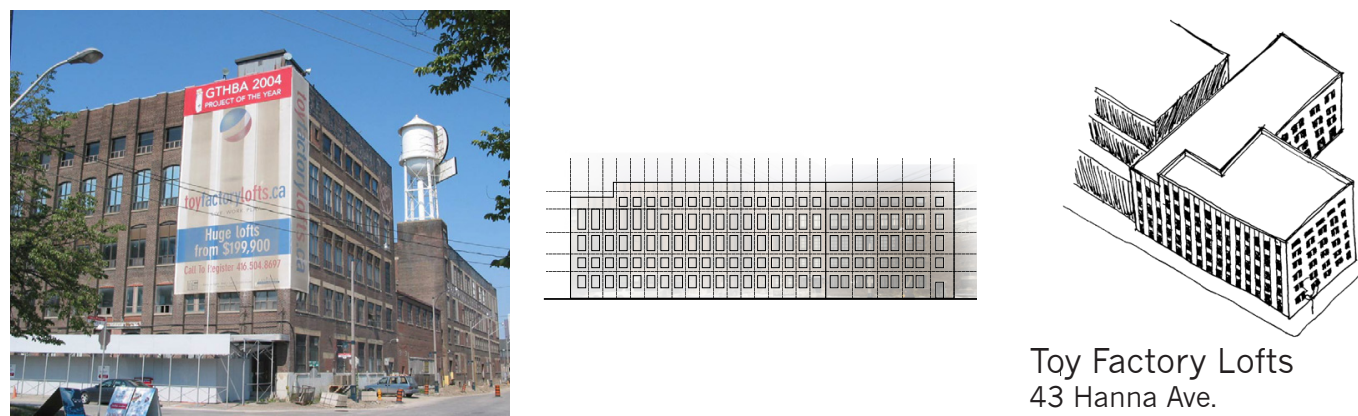

Toy Factory Lofts 43 Hanna Ave.

photographs retrieved from <http://www.tobuilt.ca/> 


\subsection{OFFICE - RESIDENTIAL}
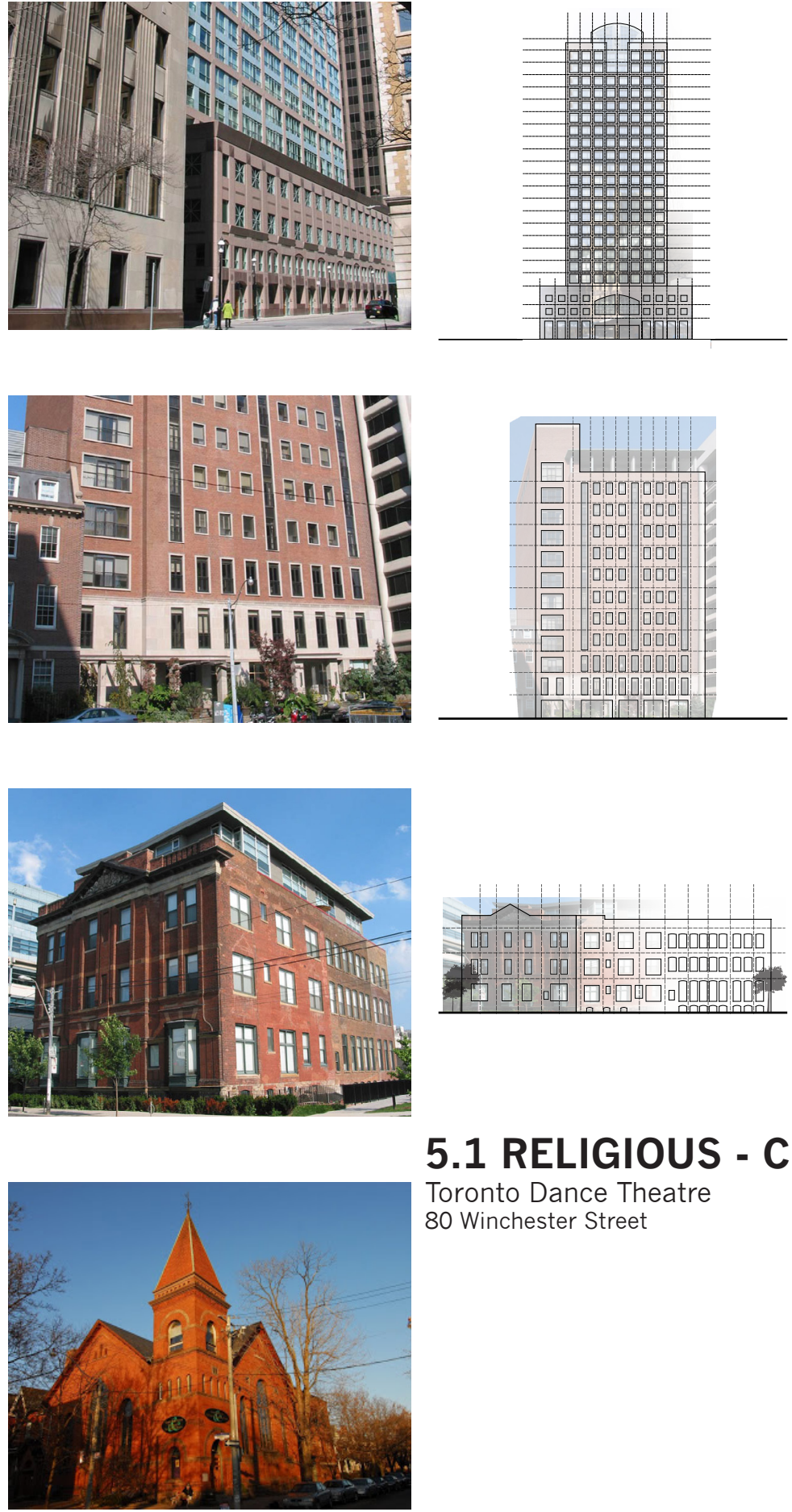

\subsection{RELIGIOUS - CULTURAL}

Toronto Dance Theatre

80 Winchester Street

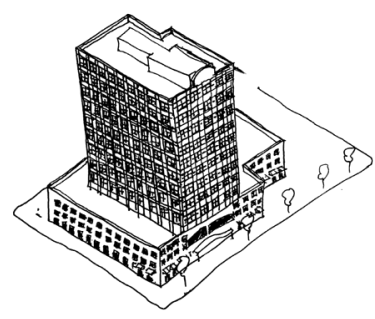

The Metropole 7 King Street E.

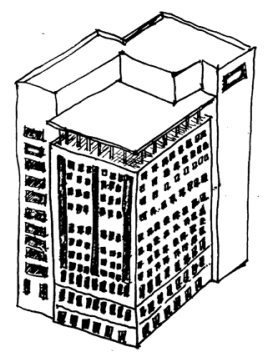

Park Avenue 48 St. Clair Ave. W.

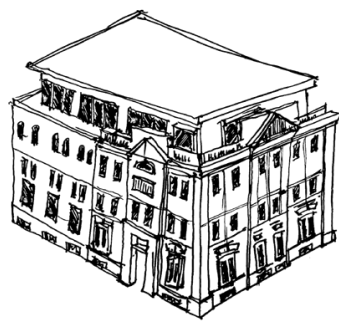

Massey Harris Lofts 915 King Street W.

photographs retrieved from <http://www.tobuilt.ca/> 


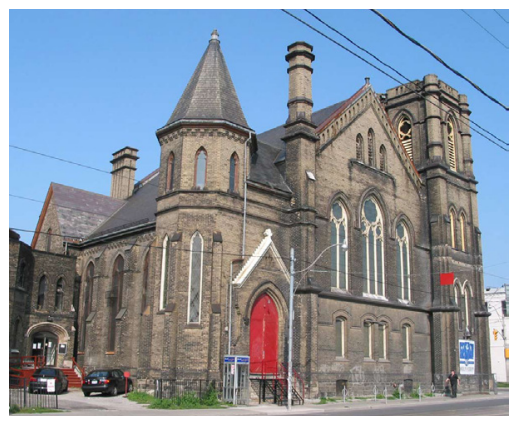

Bathurst Street Theatre

736 Bathurst Street

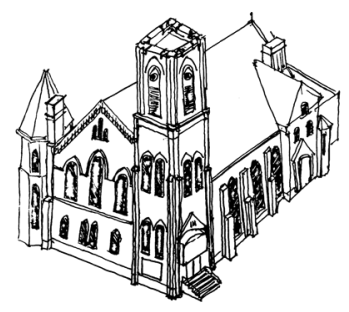

\subsection{RELIGIOUS - RESIDENTIAL}

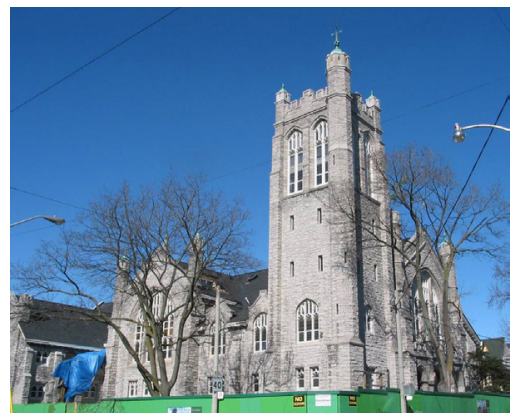

The Abbey

384 Sunnyside Ave.

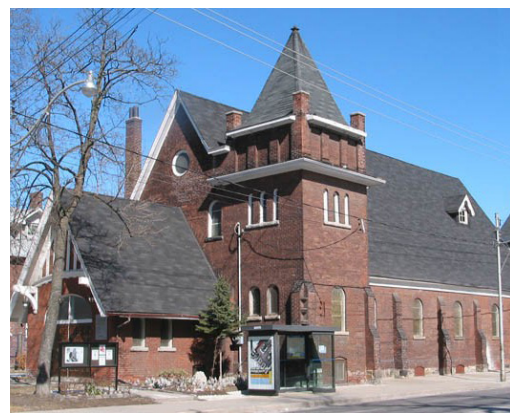

\section{Park Lofts}

200 Annette Street

\subsection{WAREHOUSE - OFFICE}
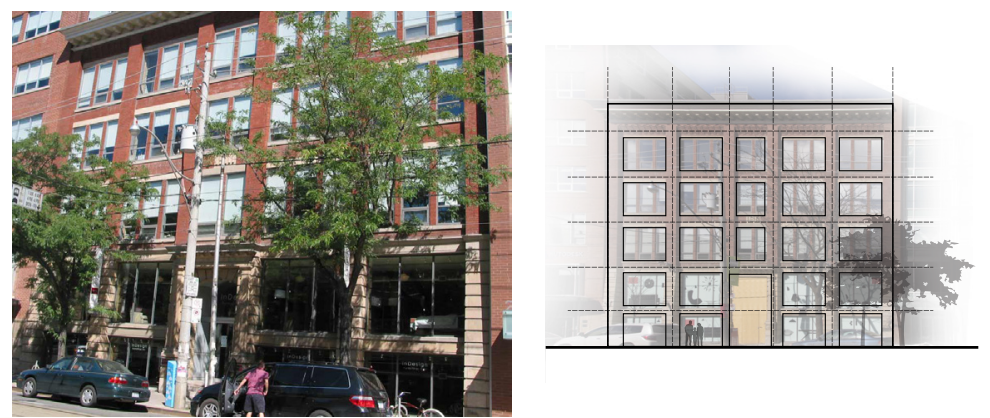

W.A. Drummond \& Co. Dairy Supply Warehouse 214 King Street E.

photographs retrieved from <http://www.tobuilt.ca/> 


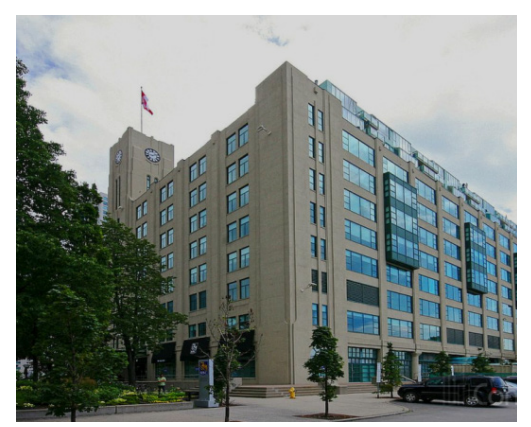

Queens Quay Terminal 207 Queens Quay W.

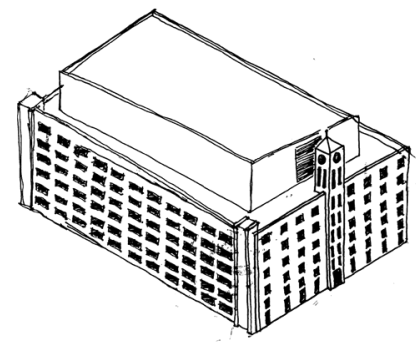

\subsection{WAREHOUSE - RESIDENTIAL}

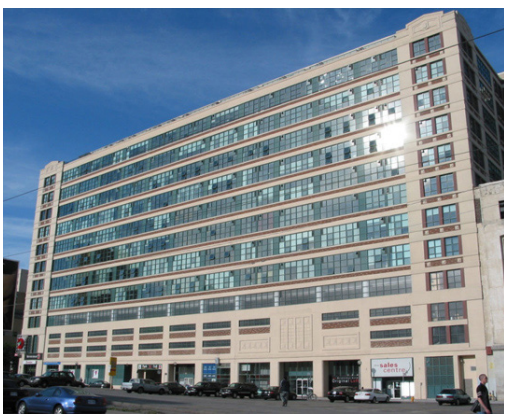

Merchandise Building

155 Dalhousie Street
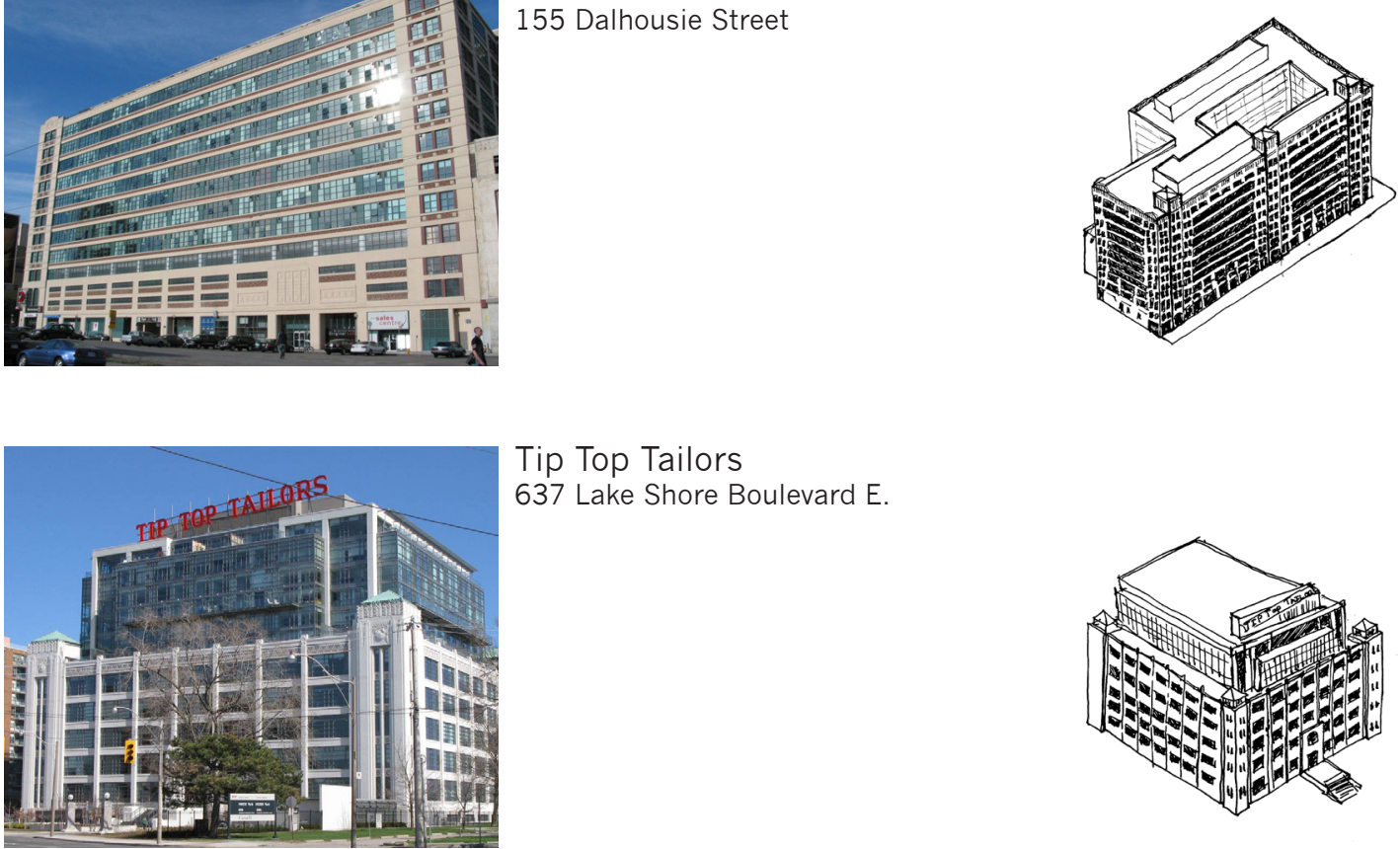

Tip Top Tailors

637 Lake Shore Boulevard E.

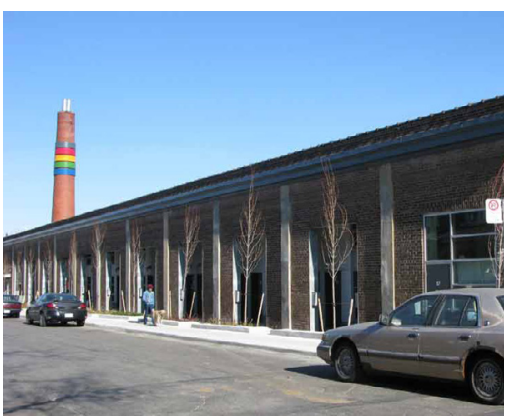

Artscape Wychwood Barns 601 Christie Street

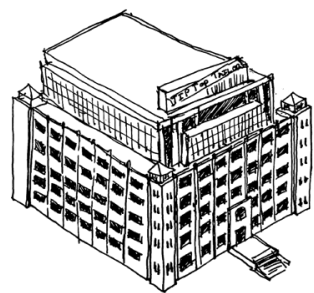

photographs retrieved from <http://www.tobuilt.ca/> 


\section{APPENDIX E - TYPOLOGY MATRIX DATABASE}




\section{NAME}

Quebec Bank

Bank of British North America

Adams Building

The Movie House

89 Queen Street East

The Loretto

The Loretto

Kensington Lofts

Wm. Shannon Co. Ltd.

Victoria Tin Works Building

The Stables

The Paint Shop

Stone Distillery Building Annex

Samuel and Benjamin Building

Rack House M

Pure Spirits Buildings

Pump House

\section{ADDRESS}

50 King Street East

NEIGHBOURHOOD

49 Yonge Street

211 Yonge Street

Downtown East

Downtown East

Downtown East

394 Euclid Avenue

Sussex-Ulster

89 Queen Street East Downtown East

385 Brunswick Avenue The Annex

385 Brunswick Avenue The Annex

160 Baldwin Street Kensington

600 King Street West Fashion District

69 Sherbourne Street Downtown East

55 Mill Street

Distillery District

55 Mill Street

Distillery District

55 Mill Street

Distillery District

468 King Street West Fashion District

55 Mill Street

Distillery District

55 Mill Street

Distillery District

55 Mill Street

Distillery District

411 Richmond Street

Gendron Manufacturing Company East

Downtown East

E.C. Gurney \& Co. Stove Foundry 500 King Street West Fashion District

E.C. Gurney \& Co. Stove Foundry 520 King Street West Fashion District

Denaturing Room

55 Mill Street

Distillery District

55 Mill Street

Distillery District

109 Atlantic Avenue

Liberty

2154 Dundas Street

West

Roncesvalles

B.F. Harvey Company Factory

Adams Brothers Harness

Manufacturing Company Ltd.

A.B. Ormsby Factory

5 St. Joseph Street

340 Gerrard Street East

27 Bathurst Street

118 Richmond Street East

The Cannery

Stone Distillery Building

Case Goods Warehouse

473 Adelaide Street West
185 Frederick Street Downtown East

1195 King Street West Liberty

5 St. Joseph Street

Downtown

340 Gerrard Street

East

Cabbagetown

27 Bathurst Street

Fashion District

118 Richmond Street

East

Downtown East

55 Mill Street

Distillery District

55 Mill Street

Distillery District

Distillery District

473 Adelaide Street

West

Fashion District
55 Mill Street

\section{CONSTRUCTED CURRENT}

AS

PROGRAM
1886

1873

1920

1913

1914

1914

1927

1900

1883

1880

1879

1860

1913

1927

1873

1895

1895

1872

1890

1887

1887

1906

1911

1903

1913

1905

1906

1873

1860

1927

5 Bank

Commercial

4

7

Bank

Commercial

Commercial block Office

3 Commercial block Residential

3 Commercial block Residential

5 Educational Residential

5

Educational

Residential

7

Educational

Residential

Industrial

5 Industrial

Commercial

Commercial

2 Industrial

1 Industrial

Commercial

Commercial

2 Industrial

7

Industrial

Commercial

Commercial

8 Industrial

Commercial

4

Industrial

2 Industrial

Commercial

Commercial

3 Industrial

Commercial

Commercial

Commercial

Commercial

Commercial

Commercial

3 Industrial

Commercial

6 Industrial

Commercial

Commercial

Commercial

4 Industrial

Commercial

3 Industrial

Commercial

1 Industrial

Commercial

Commercial

Commercial

Commercial

4 Industrial

4 Industrial

Commercial 
156 Front Street West

Riverdale Courts Heating Plant \&

Community Centre

Ruth Wilkes McCarthy Wing

John Street Roundhouse

Imperial Oil Opera Theatre

401 Richmond

George Brown College St. James

Campus

Queen's Quay Terminal

World Journal Building

Toronto Carpet Manufacturing

Company Boiler House

Toronto Carpet Manufacturing

Company

Toronto Carpet Manufacturing

Company

Toronto Carpet Manufacturing

Company

Toronto Carpet Manufacturing

Company

Sunbeam Incandescent Lamp

Factory

Studio City North

S.F. Bowser and Company Factory

National Casket Company

Factories

National Casket Company

Factories

National Casket Company

Factories

M. Granatstein \& Sons

Houlding Knitwear

Berkeley Castle Addition

Berkeley Castle

Aluminum \& Crown Stopper

Company

8 Market Street
156 Front Street West Financial District 146-148 Front Street

West

Financial District

100 Bain Avenue Riverdale

227 Front Street East St. Lawrence

255 Bremner

Entertainment

Boulevard

District

227 Front Street East St. Lawrence

401 Richmond Street Entertainment

West

District

200 King Street East Downtown East

207 Queens Quay

West

Harbourfront

415 Eastern Avenue Riverdale

1179 King Street West Liberty

72 Fraser Avenue Liberty

74 Fraser Avenue Liberty

1179 King Street West Liberty

55.87 Mowat Avenue Liberty

219 Dufferin Street Liberty

75 Sherbourne Street Downtown East

ry 39 Mowat Avenue Liberty

89 Niagara Street Niagara

95 Niagara Street Niagara 1886

101-109 Niagara

Street

Niagara

488 Wellington Street

West

Fashion District

462 Wellington Street

West

Fashion District

2 Berkeley Street

St. Lawrence

2 Berkeley Street

St. Lawrence

334 King Street East

8 Market Street

Downtown East

St. Lawrence
1910

1884

1905

1918

1914

1882

1931

1888

1874

1927

1908

1899

1899

1899

1899

1899

1871

1918

1916

1871

1908

1900
6 Industrial

Commercial

Commercial

Cultural

Cultural

Cultural

Cultural

$4 \quad$ Industrial

Cultural

Educational

Office

Office

Office

Office

Office

Office

Office

Office

Office

Office

Office

Office

Office

Office

Office

Office

Office

6 Industrial

Office

Office 
488 Wellington Street West

433 Eastern Avenue, West

Building

433 Eastern Avenue, East

Building

W. Davies and Company Pork Packing

J \& J Taylor Safeworks

Copp Clark Publishing Co.

Carrier Hotel and Data Centre

Brunswick-Balke-Collender

Factory Building

215 King Street East

164 Princess Street

Toronto Police Service 51

Division

Riverdale Missionary Church

Strachan House

Monarch Building

Monarch Building

Foundry Lofts

Foundry Lofts

Candy Factory Lofts

Candy Factory Lofts

Artscape Wychwood Barns

48 Abell Street

3 Mutual Street

Wrigley Lofts

Wrigley Lofts

Wrigley Lofts

Wrigley Lofts

Toy Factory Lofts

Tannery Lofts

Robert Watson Lofts

158
488 Wellington Street

West

Fashion District

5

Industrial

Office

1912

433 Eastern Avenue Riverdale

2 Industrial

Office

145 Front Street East St. Lawrence

145 Front Street East St. Lawrence

517 Wellington Street

West

Fashion District

Entertainment

151 Front Street West District

40 Hanna Avenue Liberty 1913

215 King Street East Downtown East

164 Princess Street Downtown East

51 Parliament Street Corktown

456 Queen Street

East

Regent Park

53 Strachan Avenue Niagara

436 Wellington Street

Fashion District

436 Wellington Street

West

Fashion District

1100 Lansdowne

Avenue

The Junction

1100 Lansdowne

Avenue

The Junction

993 Queen Street

West

Niagara

993 Queen Street

West

Niagara

601 Christie Street

Davenport

48 Abell Street

Liberty

3 Mutual Street

Downtown East

235 Carlaw Avenue

Leslieville

245 Carlaw Avenue

Leslieville

235 Carlaw Avenue

Leslieville

245 Carlaw Avenue

Leslieville

43 Hanna Avenue Liberty

736 Dundas Street

East

Regent Park

1913

363.369 Sorauren

Avenue

Roncesvalles
1912

1867

1907

1909

1954

1914

1898

1913

1887

1901

1907

1907

1907

1907

2 Industrial Office

4 Industrial Office

4 Industrial Office

4 Industrial Office

7 Industrial Office

5 Industrial Office

4 Industrial Office

5 Industrial Office

2 Industrial Police Station

2 Industrial

Religious

3 Industrial

Residential

Residential

Residential

Residential

Residential

Residential

Residential

Residential

Residential

Residential

Residential

Residential

Residential

Residential

Residential

Residential

1907
4 Industrial

5 Industrial

5 Industrial

5 Industrial

Residential 
363-369 Sorauren

Robert Watson Lofts

Richmond Mews

Richmond Mews

Queen City Vinegar Co. Lofts

Queen City Vinegar Co. Lofts

Ideal Bread Company Factory

Garment Factory Lofts

Garment Factory Lofts

Broadview Lofts

The Grand Hotel Suites

The Metropole

Park Avenue

102 Bloor Street West

SoHo Lofts

SoHo Lofts

Massey Harris Lofts

Massey Harris Lofts

Canada Foundry Company Office

Building

8 Wellesley Street East

8 Wellesley Street East

25 Leonard Avenue

1901 Yonge Street

1901 Yonge Street

1001 Bay Street

82 Church Street

Toronto Heliconian Club

Gerrard Kiwanis Boys and Girls

Club

Olivet Congregational Church

Emmanuel Presbyterian Church

Lithuanian House

Toronto Dance Theatre

Studio Theatre

Avenue

East

East

19 River Street

19 River Street

233 Carlaw Avenue

233 Carlaw Avenue

225 Jarvis Street

7 King Street East

48 St. Clair Avenue

West

East

East

8 Wellesley Street

8 Wellesley Street

25 Leonard Avenue

1901 Yonge Street

1901 Yonge Street

1001 Bay Street

82 Church Street

1573 Bloor Street
Roncesvalles

287 Richmond Street

Downtown East

287 Richmond Street

Downtown East

Corktown

Corktown

183 Dovercourt Road

Trinity-Bellwoods

Leslieville

Leslieville

68 Broadview Avenue Riverdale

Downtown East

Downtown East

Deer Park

102 Bloor Street West Bloor-Yorkville

188 Eglinton Avenue

North Toronto

188 Eglinton Avenue

North Toronto

915 King Street West Niagara

915 King Street West Niagara

15 Powerhouse Street The Junction

East Church-Wellesley

East Church-Wellesley

Kensington

Davisville

Davisville

Downtown

Downtown East

35 Hazelton Avenue

Bloor-Yorkville

101 Spruce Street Cabbagetown

126 Scollard Street Bloor-Yorkville

21 Swanwick Avenue Upper Beach

West High Park

80 Winchester Street Cabbagetown

University of

4 Glen Morris Street Toronto
1907

1908

1889

1889

1960

1964

5

Industrial

Residential

1908

1919

1914

1972

1963

1957

1966

1903

1964

1988

1882

1876

1890

1893

1891

1914
$5 \quad$ Industrial

Residential

Residential

Residential

Residential

Residential

Residential

Residential

Residential

Hotel

Residential

Residential

Residential

Residential

Residential

Residential

Residential

Residential

Residential

Residential

Residential

Residential

Residential

Residential

Office

Clubhouse

Clubhouse

Commercial

Commercial

Cultural

Cultural

Cultural 
Bathurst Street Theatre

Upper Yonge Village Day Care

Joint Centre for Bioethics

456 College Condominiums

The Glebe

The Abbey

\section{St. George Lofts}

St. Cyril and Methodius Roman Catholic Episcopal Church Church of St. Mary the Virgin \& St. Cyprian

12 MacPherson Avenue

100 Adelaide Street East

Stewart Building

Steam Plant Lofts

952 Kingston

142-144 Front Street West W.A. Drummond \& Company Dairy Supply Warehouse

Tip Top Tailors Warehouse

134 Peter Street

Tip Top Tailors

Merchandise Building

Jefferson at 11 St. Joseph

Simôn Apartments

\section{St. Clements}

Sussex-Ulster

1888

Avenue

88 College Street

North Toronto

1908

456 College Street

Downtown

1882

1989

660 Pape Avenue

Sussex-Ulster

1912

384 Sunnyside Avenue High Park

1915

65 Sheldrake

Boulevard

North Toronto

1923

40 Claremont Street Trinity-Bellwoods

1941

Avenue

Dovercourt Park

12 MacPherson

Avenue

Summerhill

100 Adelaide Street

East

Downtown East

149 College Street

10 Wellesley Place

952 Kingston Road

142.144 Front Street

West

Financial District

214 King Street East Downtown East

260 Richmond Street Entertainment

West

District

Entertainment

134 Peter Street

District

637 Lake Shore

Boulevard West

Harbourfront

155 Dalhousie Street

Downtown East

11 St. Joseph Street

32 Grenville Street

Downtown

Downtown
1894

1953

1936

1903

1911

1930

1915

1929

1910

2004

1929
0 Religious

Cultural

Educational

Educational

Residential

Residential

Residential

Residential

Residential

Residential

Residential

0 Religious

4 Residential Commercial

5 Residential

Office

5 Steam Plant

Residential

5 Theatre

Residential

Commercial

$7 \quad$ Warehouse

5 Warehouse Office

6 Warehouse Office

4 Warehouse Office

11 Warehouse

Residential

Residential

Residential

Residential 


\section{APPENDIX F - INTERVIEW TRANSCRIPTS}




\section{Chris Radigan Interview Teeple Architects, Toronto}

$\mathrm{J}:$

The thesis I'm working on is to take a sustainability approach to retrofitting buildings looking at policies and guidelines that we would build into new buildings that would allow the process for retrofitting 10 to 50 years down the line to be streamlined to become a less wasteful process and make it a more sustainable type of idea.

I have a selection of 36 buildings now. Artscape is one of the main projects because it was originally a school that went through a bunch of processes of change into the new school and then you guys obviously took it and changed it into artscape. So the questions that I have about the project and what Im looking into are, was there stuff that was inherent in the building to begin with that would allow the project to become artscape, was it that the building had structural properties about it that made it easy to convert was there something quantifiable or non quantifiable elements to the building like historical importance or cultural sentimentality related to the building that made it more desirable to keep and retrofit oppose to demolishing it and building a new building and building it somewhere else?

C:

Maybe I will just give you a brief history of it, as you know it was a school since about 1914, and until 2000 when it was closed by tdsb at the time they were trying to close both this and the adjacent 1960 school, but the community fought back and kept the site, I live right across the street so I was a member of that. So at that time that was a little before 2000 we renovated the newer school and to accommodate the whole student population and also renovate this enough to bring it up to code and let it become what ever it was to become. But it didn't become anything, it was empty for about 10 years, it had basic heating and lighting etc. but it was never really used. Then at various times, tdsb, I think they were trying to as they did with many buildings, get rid of excess buildings, they offered it around to various divisions of government, but nobody really wanted it for anything. At one point they were thinking of demolishing it but the local community came up and said we would like to try and do something with this, so they approach Artscape, who was interested, but they didn't know what they wanted to do with it. They were always very much involved in community consultation and building up neighbourhoods, so they set up a series of meetings and workshops to get opinions from the community of what wanted to do, it could have been anything. I don't think they would have wanted condominiums but it was discussed at some point. But obviously artscape is in the business of providing space for artists. After some time it kind of coalesced into an idea about artists studios, maybe non-profit groups for office space, galleries, and theaters. They didn't know who their final tenants would be 
when we [Teeple] were retained to do this, I was apart of the community and therefore the workshops and I offered our services to Artscape and they accepted.

We didn't really have a program as we were developing the drawings for the building, they were to do to what ever needed to be done, obviously there was a need to put in mechanical systems which were very rudimentary heating systems but no air-conditioning existed so we basically re-did all of the mechanical and electrical systems. There were structural issues with providing certain support and we discovered very interesting structure that we didn't know about, concrete in the main corridors, wood floors, and concrete in the main public circulation, but all of the classrooms were wood structure, some of which needed reinforcing. There were also potential uses that would create acoustic issues so we did various acoustic treatments on some of the floors. It was quite a process going through and certainly many unknowns and things discovered throughout the process. We had to design generically enough so that certain spaces could be used for certain things although we didn't know what they were, some of them could be like classrooms, or could be individual artists studios, or musicians. There was a possibility for a daycare, which eventually went into the basement area. So it was designing without really knowing who was going into it. In a sense like an office building when you don't know who your tenants are, but a little more tricky in this case knowing that you had some need to provide artists uses, potentially noisy uses that wouldn't go well with each other, and a lot of stuff to research. It was only once they started construction and they had their funding they put out RFPs out to the world to see what kind of responses they would get. Ideally they wanted to sell as many of the units as possible, it creates the best funding opportunity for them, but I'm not sure what percentage they ended up with, I think $50-60 \%$. Some of the other spaces are leased spaces, and some of the spaces on the ground floor are for any artists. Coffee shops off of the gallery, parent and child care, sketch studios in the basement, homeless youth support place, Eve Egoyans has a piano studio and various office type spaces. We did a couple on the third floor, one for illumiato, and a small space on the 3rd floor for Inspirit Foundation, they are a group that give grants to people to develop community based stuff. So we had some involvement mostly in the base building retrofit, but we did a few couple of spaces for these groups as well. So that's a brief history.

\section{J:}

Were there any technical aspects that made the retrofit difficult to deal with? For example how did making the floors acoustically sound have an affect on the design process?

C:

Well, First on the structure there were some areas, some areas, generally because we didn't know who the tenants were, we decided to make sure the floors could withstand, not everything, but general office uses, studio uses, but there were couple areas such as in the back here that we discovered couldn't support those, so we needed structural support. So 
that happened in some of the areas. We decided that some of the big spaces, public spaces, probably would become more theater type or dance type that would need acoustic floors, I believe areas in the back this was done. We made sure that any, in some cases the classrooms were divided in half to make smaller studios, and needed acoustic treatment to make that happen.

$\mathrm{J}:$

Because you didn't know what the specific program was to be, was there a unit of measurement that you were aiming for?

C:

Not particularly, Artscape knew that a full classroom that use to serve 20-30 kids was probably too large for any individual artist so they were taking a guess at how many large vs small studios they might be able to sell or lease, so that really came from the client.

$\mathrm{J}:$

Was it like jumping through hoops to get new mechanical systems in the building?

C:

YEP. There was only existing boiler system and perimeter radds around the windows and very basic ventilation, no air conditioning. These were old masonry shafts that went up through the building. There were fans that were in the basement that basically gave fresh air but very minimal, so that was abandoned and new air handling systems and all throughout the corridors new ductwork was put in to bring fresh air to the spaces, each individual unit has its own heat pump suspended from the ceiling that controls the environment individually instead of the common control that the school use to have. So yea it was quite challenging. As well as getting in mostly new power, lighting. That's where a lot of the money went, was into the mechanical and electrical systems and new sprinklers throughout as well which was fairly challenging

$\mathrm{J}:$

Given the whole building project, would you say it was cost effective to do the renovation like this verses a similar program and client and everything given with doing a new project. 
C:

For sure, given the amount of space, although they spend a lot more than they anticipated given that they didn't have enough contingencies and not withstanding our recommendations, they just didn't have the money so they said do your best. It ended up costing quite a lot of money. Including the masonry restoration and replacing all of the windows with new wood windows, which we were quite happy that worked out. We hadn't thought about the relative cost, but it would have been a lot cheaper to do what they did than building new and obviously retaining a fairly nice building at the same time, which through the process was listed with the heritage department which certainly helped the process through the city to keep the building and do some restoration work.

$\mathrm{J}$

How would you say materiality played an aspect with the preservation of the old building verses bringing in new elements? Was there a lot of waste associated with the renovation of this building, was it a situation of "we need to save as much of it as possible" or was it a case of façade-ism and we have what ever we have and lets work with what's there

C:

Well certainly there was a notion that the school was a bit dilapidated it was pretty nice spatially, wide corridors, although that made it somewhat difficult in terms of financing because you have such a lot of circulation space but Artscape certainly wanted to keep as much as possible and it was certainly much more expensive to start wiping out a lot of spaces. They kept the general format, structure, classroom idea, of the school image, but that was more of a necessity because it would be too expensive to start ripping out walls, especially after discovering the nature of the structural system etc. so I think, not withstanding that Artscape liked the idea of a school, an image everybody did, they loved the building, it was the tall ceilings, wide corridors, there were certain areas that had been renovated that became a bit messed up like the ground floor library, all of that was a more recent renovation etc. so that was all cleared out. So certainly where we needed to we cleared out the building down to its original structure, not just the structure but the basic image of the building. 
$\mathrm{J}:$

At the beginning you talked about being involved with the community aspect. Were there any reasons other than for the obvious, its in our neighbourhood and its our building, were there any specific reasons for the community gathering together, this building we have to keep and we don't want, even it's a great project and a project that we can define what that project is, if it's a new building, why do we want the old building?

C:

Everybody loved the building; it was a center of the community for so long as the school and the history of it, the community is very appreciative of that history so I think they wanted to do what ever they could. It's a neighbourhood that is probably among the forefront of sustainable ideas so they were working on that concept as well rather than ripping it down and replacing it with anything else although certainly all of those ideas were discussed at various points. It made the most sense in terms of the image of the building in the city its very, even just physically in relation to the street, the park, its very iconic, so why not keep it if at all possible.

At the beginning of the project Artscape was very interested in what ever we could do sustainability wise, LEED wise, energy savings, we looked at solar panels, solar voltaic, but ultimately the budget couldn't take it, so we did what we could with putting in better windows and using as little energy as possible but not a lot more than that. It just became too onerous to achieve any recognized LEED rating or anything.

$\mathrm{J}:$

Not specific to this building, but if you were to, in a hypothetical situation, had the choice between retrofitting vs not retrofitting, what would be a key element that would make it worth keeping vs something that would be demolished and build something new.

C:

That depends on the type of building, and the type of final use that someone might want. We are looking at one, very standard warehouse building in the Richmond 
west area and we looked at it for potential residential condominium. We did quick studies and in terms of fire ratings and what kind of image the client was looking for and everything the building needed, and decided that it just wasn't financially feasible. It's a great idea to keep but to their benefit rather than ripping it down they are going to look at converting to office uses instead which is much easier. They are a fairly responsible kind of developer and they are looking at that. Other developers might not and just rip it down and build a condo so it ultimately, aside from the lofty goals that somebody might have, building owners are often guided by budget and what they might make on it as oppose to someone like Artscape. But any other land owner, building owner would tend to look at the bottom line and we would try to talk them through doing the best environmentally and sustainable approach as possible, but ultimately it comes down to dollars and if it works it works and in this case it will probably work as an office development. 


\section{Jana Levitt Interview}

\section{Levitt Goodman Architects, Toronto}

$\mathrm{J}:$

I'm putting together a database of buildings in Toronto that have been retrofitted and been changed in use to something else. For the purposes of putting together strategies or guidelines for new construction that allow the building to be re-purposed more efficiently it's the sustainability argument - more efficiently, 50 to 100 years down the road.

Jana:

So a kind of retrofit....Adaptive Re-use.

J:

It's based on the design for deconstruction movement which is like you should disassemble everything. But this like a pre-emptive design into it saying "Well, we disassemble everything... we don't do that necessarily, right? So let's design things that we can re-purpose and let's design it from the beginning so it can be re-purposed."

Jana:

Right, right.

$\mathrm{J}$ :

So the strategy right now is to look at all the buildings in Toronto that successfully have been re-purposed.

Jana:

Like this one! (referring to the Levitt Goodman Architectural offices building) $\mathrm{J}:$

Exactly. And pull out what are those key elements that made the retrofit successful, what made it easy, what made it difficult, what should we be designing into buildings, what shouldn't we. That's kind of the premise of the research.

So this is one of the projects, which is why I'm here, and the questions that I have are kind of over the initial design of the project - what made it a project that you looked at to re-purpose. Is it a particular building versus building something new? I know cost is a big component of it and generally a client would just have a building that they have available to them that they would like to re-use instead of building something new because of the cost implications. But sometimes from what I've found so far is that those buildings aren't necessarily so easily changed over and can run up high prices the spaces can be much more difficult to use. Jana:

Well I guess when you're looking at projects in the not-for-profit sector there are some different questions to ask because many times the client doesn't have a choice about 'should I buy new or should I renovate.' In the case of Strachan House, they were given - although we looked at a whole number of sites - none of them were 
new builds, they were all existing buildings that the city owned that as their contribution to the project and many times the municipalities' contribution is usually waiving fees and if they have the political will, to give a piece of land. So, this one worked out perfectly and when we built this, there was nothing in the area. So that was also desirable from the city's perspective because this is a bunch of homeless people so they didn't really want to take on a big neighborhood going ballistic. So the client didn't have a choice here although we always say - rule of thumb - that it's around $15 \%$ cheaper, unless you have a really... a building in a state of disrepair or if there's some odd thing about how it's sited, or where the ground floor is, it's always about $15 \%$ cheaper to renovate rather than to build new.

So they didn't have a choice, this was the building - we looked at a number of buildings - this building worked best.

J:

In the design of how you were retrofitting the building, were there any aspects that you could talk about - the sentimentality of the building, on the place of the building, and how that would have played into how you... I read an article about this project in Azure from 1997 and part of it was about this idea of designing in sentimentality or a place of purpose for the people who would be living here. Can you talk a little bit about that and how that worked into the design?

Jana:

Yeah like you can see (looking at drawing set) in these two images here... when we started to work on the project we realized there's actually 3 different grid systems which move from Strachan over towards Tecumseth. What we realized that this was a very typical pattern of building development, particularly in the late $19^{\text {th }}$ century and 20th century, where you would build at the best corner and the existing building - when they did it you see that the bay windows here - that was the office. What we realized is that they'd built one piece and then two pieces and then three pieces. And what it meant was that there were certain masonry lines of the exterior wall that were all - (gesturing to drawings) like here's the last one, and there's another one somewhere - so we thought that was really interesting. The structural system was similar but not the same. This chimney was at one point outside the building and then the last appropriation had been enclosed so we wanted to do this town hall space.

We decided when we got there and realized that there were all these existing openings like this (pointing to drawing), we decided that they were actually located in the perfect place that you can actually weave your way around using these as the openings. And then it would help develop a parti for this scheme which was bringing the outside in. It was literally the way this thing had developed but it was also a kind of metaphor for the process of these clients.

Having coming from the outside in and having to negotiate that. So it actually worked in 
our favor and then we really liked the toughness of the existing building and it had a kind of patina and a very worn finish that was we thought would suit this client group. I mean, this was before lofts were really big but what everyone wants is exposed brick and stuff. But it also programmatically because these are generally clients who are pretty tough on the buildings and so part of the whole - it's very different now in terms of how it's managed at the time it was an extremely enlightened housing provider. Then it would encourage, if you were having a really bad day, really pissed off, don't hit a person, go hit the wall, you know? So this was like perfect - just bulletproof. And the other thing was, over time, so we could use this as the kind of background so we curated a sequence of materials so that the big overall container was really tough, robust and durable. Pretty well showed all the ages of everything that happened to it. So it became a kind of story because a lot of these people have multiple issues with drug addiction, health, mental health. So we spent a lot of time hanging around or hanging out, figuring stuff out.

There's lots of stories to read in here amid all the markings. Lots of things to focus on as supposed to having nothing to start to propel an idea or a stream of consciousness thinking. Then we decided that as moved towards the more finished areas, which are the bedrooms and the kitchens, we'd start to introduce a few more finished materials. It thelped create the baseline for then developing a palette of materials that went from more - like this is kind of to us an urban design strategy - that becomes a residential strategy. So then we tuned the materials to work with that.

J:

Interesting, thanks. So is there any way that you would, if you were able to in a sense quantify the materiality of the building, the texture of the building, would you be able to quantify it in any kind of imaginable sense... in terms of repetition, of patterning, within the building, was there any strategy in that sense?

Jana:

I'm not sure what you mean.

$\mathrm{J}:$

I'm not sure I know what I mean specifically because it's a big question right now of how to take these more emotional aspects of a building and turn them into things that can be repeated in other buildings other than just speaking to a particular building.

These things are very characteristic within this building so would you say that the act of the repetitious units of residential in this building allowed for this progression to take place as a counterbalance to that kind of urban strategy. Like you said, this urban planning point of view versus the residential thing. If you were to take the occupancy out of this building and it was a different building, would it be a similar strategy in terms of for this building in particular, the urban design principles worked in with the residential?

Jana:

The principles we have done elsewhere, like having a main street and houses off of that street - we've certainly done that. We've built new buildings like that. That's, 
I guess, a combination between program and parti. And it is totally transferable. What isn't transferable are the specific nuances of how you adapt that program and that parti to a given width, length, building material. Certainly, we couldn't build anything like this new. We wouldn't, particularly now, in the not-for-profit sector, you could not building something like this now. You wouldn't be allowed. J:

On a more technical side of it - the mechanical renovations - were there any structural changes that made this conversion particularly difficult? I know mechanical systems in old buildings are a nightmare in terms of what's there and then bringing new stuff in?

Jana:

Well it wasn't a nightmare here because basically it's a warehouse, right? So it's just a big open plan. It's like the Domino House. Running all the mechanical, it's all exposed. What posed problems here which is typical when you're renovating or doing an adaptive re-use from industrial, from turn of the last century, is there was mold remediation in the basement. There was lead paint everywhere. So we had to do a significant amount. That's very typical of this kind of adaptive conversion proposition.

And everyone used - especially in industrial buildings -lead-based paint. Oh and in this one, it'd been vacant for I don't know, 15 years, so there was about a couple inches of pigeon shit and it carries - actually you can die from it - so to remediate it form that you had to be completely suited up.

J:

Have you guys done a post-occupancy evaluation since the project was built? Have you gone back and spoken with people who lived there or the clients? Was there anything in particular that they said about the project that was especially successful in kind of the core of the design?

Jana:

Everyone really liked the town hall and the space around here (points to drawings) for sitting and hanging out. It's a difficult project. We did do a post evaluation occupancy and it was generally very successful. I think the thing that was least successful was we used gypcrete to level the floors and it's not a very good long-lasting material. We did track it but the Harris government came in when this was under construction. What he did was, he cut back so much funding for the not-for-profit, that by the time this was up and running for a couple of years and it was super successful, this was when his government kind of found them and made them do things as mean-spirited as taking community building out of their mandate and mission statement and took away any funding that would allow them to run it. 
Their whole thing was, you work for people individually and it's sort of the antitheses of the Seaton model. When we designed this with the housing provider, there was a little office on the ground floor but really, there were offices that were open - not closed - on every floor. So that on very floor, everyone knew where to go and someone was there all the time. It was another form of surveillance but one where it worked both ways. If you were having a hard time, you knew where you could always find someone. But vice versa, if I hadn't seen you in a couple of days I'd actually know to go up to your room, to your door and say, "Hey Jeff" and find out what's going on basically. But they took away the funding for all that so the staff would only start to congregate here (points to drawing) and only leave if there was a problem. There were a lot of problems up here (points to drawing) that no one saw or did anything about. And now the whole thing should be torn down as far as I'm concerned. Yeah because it's run like a jail.

$\mathrm{J}:$

In a context where this particular building didn't exist and it was torn down to begin with, would you say just based on the kind of the management of the project, if it was a new construction building and you had done a similar strategy, just based on the management, even with a new construction project would fall under the same issues that they're having now?

Jana:

In my experience, you can't have a successful project like this without managing it different. If you don't have a manager who's on board to manage things differently, then projects like this will only - I actually think it's more dangerous than Seaton House is. You're very far away and you have private bedrooms. You know, in Seaton house, this (points to drawing) would be one dormitory. You could police that easily. By aggregating a few large rooms to put everybody in, you can hear a lot more. Here if you're here all the time, you've got walkie-talkies, which is what they do, if something's happening up here in this bedroom, that's a long time before you know something's going on. So you have to have the management on board. There are things like here (points to drawing), there are people who try and jump. Well, we added this extra band to help mitigate that and that was great and we worked with artists so it didn't look like an institution but again, if you're not around... So it goes back to attitude and who you surveyed.

$\mathrm{J}:$

In a theoretical situation, given a theoretical existing building and you had the kind of opportunity to either retrofit it or tear it down and build something new, what would be kind of the key components that would - program aside, client aside - what would be the key components of an existing building that you would look for that 
would kind of make or break the project. In kind of an ideal architectural sense. Jana:

Like, if we were to look for a new building to re-create this building.

$\mathrm{J}$ :

A non-program based project. Like, if you took the program of we're creating a residents' house for homeless people, and you took that out of the project. And you were given an existing building and you had a checklist or so of things you had to go through to say 'we can either retrofit this building, or not' would be there be anything intrinsic in a particular building that would make or break that?

Jana:

Oh! Structure.

J:

Yeah, structure?

Jana:

Load bearing walls versus columns. Columns are way better. High ceilings, because you're gonna want to run your ductwork whether it's exposed or not exposed. It's most likely going to be - because of the costs involved in the not-for-profit sector - you don't have a whole lot of choice about HVAC so you're going with some sort of rooftop system and distribution of air. So you'd look for tall ceilings. One thing - this would be something that would be a compelling feature to take one thing over another - are there any tall spaces in there that exist in it or inexpensive. If it's a wood structure or heavy timber, it's really inexpensive to cut a big hole out. If it's concrete, it's really expensive. And so what would be a very compelling thing would be having a kind of building where you can do that.

J:

And in the space, was that a space ...was it existing? Did you cut this space out? Jana:

Yeah. You can see the, that's the line of the plate and that's the joists, where the joists were coming out. So you could tell when you look at an old building and you survey and analyze, you can say 'Oh, this chimney wasn't always inside' and you start looking a bit and you realize, wait a minute, the grid's not the same. You know. 


\section{Michael McClelland Interview}

\section{E.R.A. Architects}

$\mathrm{J}:$

Right now I'm working on a thesis and an aspect of research that's dealing with existing buildings in a way to develop guidelines for building new buildings that are more retrofit-friendly for the future. A large portion of this was researching the existing buildings in the Toronto building stock that have undergone a retrofit process. A lot of those buildings obviously E.R.A. has worked on. So buildings like - the Loretto, the Abbey. One of the discussions was on the design for disassembly aspects of the ROM, and Wychwood Barns and projects like that.

So I'm just looking for insight from you on some of the inherent properties of these buildings. On what made them a successful retrofit versus a decision to tear them down either at the design stage or construction stage.

M:

It's kind of a complex set of questions. One is, are old buildings adaptable and are there some buildings that are more adaptable than others. I think our sense of each building type provides different kind of opportunities and constraints. But that they're all equally adaptable. There are certain things some people call 'loose fit' which means that something wasn't so designed, so purposefully designed for one use that it's really hard to adapt to any other use. There are building types that are really very difficult to adapt. Hospitals, extremely difficult to adapt. Because the design constraints are so tight that you can't really put a new hospital in an old building.

$\mathrm{J}$ :

Yeah, fair enough.

M:

But most things are adaptable. And we're doing a project which you can see on the website, which is called the Gemini Project, which is testing exactly that, to see if you can take a really interesting house and turn it into a success.

Well that's an interesting project that was a test taking strictly an engineering point of view to deliver certain constraints, certain performance levels from the building, could you actually do that in the envelope of a nice looking building. And that was really an experiment that was a good test for what I think you're actually talking about. We found that there were some very difficult constraints which Russell dealt with as well.

Other buildings like the Wychwood Carr Barns or even the buildings at the Distillery District, were tricky to adapt in a certain way because they were never meant for human habitation. They were industrial spaces so they weren't insulated, they were just raw brick shells. That was totally fine.

The interesting thing is that there is a way that people used to build, I think you can actually learn many things from that. Interestingly, we now have a bit of a conflict in that 
older buildings were meant to breathe. And they had really slow migration of water through and things like that. So, it's a very interesting thing. It included opening windows in office building and things like that. And then we've worked with our building code to tighten all that up and almost go the reverse of that, to try and make a super-performing envelope that would seal everything tight.

I think there's an interesting issue where we are now doing several things that are getting sophisticated about that and recognizing that the super tightness really works or rarely works. And that we actually need to look at other technologies and one of those would be the low-tech approach to buildings. We did open windows when you wanted some ventilation. There's a bit of a return other in a low-tech way or actually in a super high-tech way. We're introducing those things but in a very controlled manner.

And it's interesting that the Gemini House - very high tech - but it really comes very close to the traditional technology, traditional low-tech approach of having porches and sunrooms and things like that, that you inhabit in the summer time and you don't inhabit in the winter time. So it's almost like learning the patterns of activity in buildings. And connecting those patterns of activity to built form is really important to how people use buildings. People still tend to use buildings the same way it's always been used. I think you learn more about how to build by kind of understanding that a little bit better. So we sometimes have concerns - and fights actually - with the building code folks over demanding too high performance on buildings. They'll say 'Oh you can't use these bricks because they don't meet the compression tests that bricks meet.' Well, it doesn't matter, they've been serviceable for 100 years, so what's the problem?

Museums have a standard for $50 \%$ relative humidity inside the museum but that was a standard arbitrary for England where it's more humid, it's damp. It's really hard to achieve $50 \%$ relative humidity so it has a big impact on the building.

$\mathrm{J}:$

The aspect you mentioned about kind of learning these patterns of use of buildings, would you say that they're completely specific to the programmatic use of the building - if it's a house, it's a house and it's used that way, or are there some universalities?

M:

I was thinking more along the lines of things like older houses used to use storm windows, shutters, lots of small rooms and you close the door so the room you're in stays warm. So that was one way people actually inhabited, put on a sweater. That's the way traditionally people used houses. We have an assumption now that you just turn on the energy and everything's toasty and it doesn't matter if you're never going in this room or not, and we're set that way.

Whether we get to a point on how do we advance on that, well maybe different technologies. Could we have our houses more sensitive to the zones so it's really heating the rooms that you're in. Are there other ways to make provisions in the house so that works like that as well. That's just a small example but there's lots of looking for mold in buildings. I'm still very interested in building technologies where the envelope breathes rather than seals. Like 
would we use materials that are have a certain density to it, there's moisture migration.

Not a great example but in Italy they have a series of pretty terrific floods 20, 30 years ago and the older buildings were left standing and the new buildings got wiped away. The older buildings basically broke down a door and the water went right through but in the end of the day, they were left standing but several new buildings got completely wiped away because they were just solid, impenetrable things.

I would think that when you tie older buildings with issues of sustainability and longevity, there's lots we can learn about how to build things. There are people, there are some fanatics, who say that older buildings are just not performing properly, energy-wise, so let's get rid of them all. Or who cares about the aesthetics or look of them let's just cover them with Tyvek and EIFs and whatever. We'll just seal them up tight.

There is a conflict there because it's very difficult to get an older building to perform in that way. For example, the ceiling up tight really can mean you just concentrate the moisture migration so you get all kinds of things rotting in the envelope really quickly. It can even damage stonework, that's always kept moderately temperate and if all of a sudden you seal it up and let it go through freeze and thaw in a way that it's not used to doing, it can get damaged.

There's a lot of errors saying how people work with older buildings assuming they can just perform in a modern way. I think the other thing is when people make assumptions that the building code standards that we use or the environmental standards we use are kind of god's message to us or something but they've also developed historically so they're also subject to consideration with it. We may develop or change those things but we may disagree with the philosophical underpinnings of what those standards are about. Like the $50 \%$ relative humidity in museums are like arbitrary yet you can't get a travelling collection unless you're signed on to abide by that arbitrary standard.

Older buildings allow you to challenge what our current standards are doing and why they're there. How effective they are and are there alternatives to dealing with these things. The building code actually in a lot of ways there's a lot of leeway but I think there could be more. I think that the Gemini House was really interesting because it was high-tech meets lowtech kind of thing and I was hoping we could do more work like that. Also what's in old buildings we're doing a lot of work now on studying 1960s apartment towers which have no insulation and per unit, they're actually more wasteful than a single family house from the same period. So very very bad performance. We're interested at looking at those and the adaptive re-use would simply be to upgrade them so they come closer to standards that we have now. They're not something we can terrifically learn from in terms of engineering or construction, they're really primitive.

$\mathrm{J}:$

Would you say that there's any quantifiable information regarding the cultural or sentimentality of a building. Is there any way to quantify that into say, into a materiality aspect, into a pattern aspect or a repetitious aspect? Is there anything that you've - even if it's an abstract form of quantifying? 
M:

There's a lot of literature about that. It's kind of in a nutshell - in the early 1800 s people were saying we must save old buildings but by old buildings they meant ancient monuments. And by the 1870 s or so they'd actually say, well maybe in England the Elizabethan buildings maybe. We'll save Elizabethan buildings because there became an agreed-upon cultural value that these things were worth. By the 1890s, 1900s, they said 'Actually Georgian buildings are pretty interesting historically too.' By 1950s, Victorian buildings were interesting. Previously they were not. People assume that values are inherent in buildings but they're actually values that contemporary people apply to buildings. So now we look at Sam the Record Man signs, right? There's continual different evaluations of what's significant. There are legal ones that province of Ontario has - if you meet these criteria, you can get designated. Everyone has different sets of views and the more you talk to people, the more different they are.

We did a book called Concrete Toronto which deals exactly with that kind of issue. It deals exactly with that kind of issue - the sense of, are people appreciating... what buildings they're appreciating and what buildings they don't appreciate. And it's something that gets developed over a period of time. So there's no fixed rules.

J:

Would you say on the similar topic, would you say that there's been a drastic change in the way we use occupied buildings since say, the 1900s when we built these industrial buildings that we're renovating now today. Would you say that we've changed how we use buildings? M:

In the 50s, 60s, 70s, there was an idea that we would just have a booming economy and we could build stuff. They were very irreplaceable buildings. We were just going to be wealthy forever. I think we're now re-evaluating that. I think you get pretty mixed messages now where the buildings are built to last a long period of time and ideas of them being sustainable buildings or in fact, they're not. I think we're building smarter now than we have been. Previously I think it was a big deal to build buildings, it was expensive, it was labour intensive. So people just assumed you were going to keep it around until some larger pressure hit you.

J:

With the aspect of my research, the sustainability aspect comes in terms of waste reduction in retrofitting buildings. So the technical aspects - mechanical systems that are generally added in or removed, or the scenery and furniture of the building, without going to an open floor plate warehouse and then just cubicles placed in, are there any things in your experience that have allowed these buildings to adapt to multiple programs? Are there certain characteristics of a space that allow it to be more flexible yet specific?

M:

Not sure I can answer that but the bigger industrial spaces, the big useable spaces. That allows the loose fit scenario and presumably it's a character-filled kind of space, an interesting space, people like being in spaces like that. So that makes them more adaptable. But if you get a huge volume, like the spaces at Downsview Park, they're so large that then forms another 
kind of problem like the generating plant for this gigantic building forms the notion of how do you exactly use all that. So there's a big spectrum of factors that make them as adaptable and not adaptable. We tend to adapt the architecture, we don't adapt the systems, we don't adapt the electrical. They completely get taken out because that's something we don't appreciate culturally. And their adaptation often means simply replacing the systems within the building, providing exits and those kinds of things that make a space useful.

$\mathrm{J}:$

The ROM? My second reader for this project is Marco Polo and he had mentioned that you guys did the ROM - you did the historic aspects of the ROM but the new construction was a designed for disassembly system?

M:

There's actually a bunch of things going on there. The new part of the ROM is a separate structure and so it could be taken away. The actual ceiling and connection between the two did cut the stone so you'll have to do a repair but it's not to say it hasn't been done before the terraces there. They came back and installed them in a way that wasn't without causing all the damage to the building.

So that's one technique that we try to use. It's also called minimal intervention so you try to work with what's there while causing as little damage to us as possible. So long term building is still there and you're recognizing your adaptation may last 50 or 100 years or maybe not. The really cool thing about the ROM is that they actually had this museum issue so how would you control environment. So in the basement of the addition are the big traveling exhibits and that's all environment controlled for what you need for traveling exhibits. The rest of the ROM is not. What's controlled environment are the cases. Every case is expensive exhibit cases are environment controlled specific to the kind of things in them. This means that there's no stress on the building envelope. You don't have to go and cover insulation and do damage to the buildings. That's an adaptation that's worked very well for the ROM. J:

Could you speak to the cost association with retrofitting versus new construction in the context of the life cycle of a building. Obviously there's a lot of associated costs initial construction costs with tearing down a building and building something new. But there's a lot of hidden associated costs with retrofitting an existing building. Does it affect the life cycle costs of the building? Or are the associated embodied energy costs of retaining the existing structure, existing materials, do they get kind of mitigated?

M:

There's no simple answer to that. There are so many different factors that it's kind of a wash. Many things we work on, it would be cheaper to demolish and work on a new building. In terms of how people might see it but there are other $=$ so it would be cheaper. But there are other, there might be significant $=$ where you're not going to get to do that anyway. So there's those kinds of parameters.

Embodied costs are not something that many people take seriously. Because it's a larger societal cost and frankly a lot of people are thinking 'well I'm going to build 
something out of here and it's going to be in the Cayman Islands' so it's very hard to get people to acknowledge this, these larger societal costs.

Most buildings built now are seen in terms of Life cycle costing when you actually go through and place all the component elements over a period of time and so that in many ways that is an adaptive reuse at a slow scale. Cost in buildings is always very complicated... Zeidler did something a while ago, he was arguing that improved quality of the architecture might cost $2-5 \%$ more on a project but it would mean that the inhabitants would have a better place to work, frankly the salary costs for a big office building is worth a lot more than the building ever cost. Even the taxes that get paid. The actual construction cost is very small compared to all the other kind of costs related to how the building functions. So upping it during expense shouldn't be a big deal so for example the old Don Jail, we restored its heritage building to a hospital and we could do that because the hospital costs per square foot are high. They're an expensive kind of building to build. We could easily absorb restoring the Don Jail and the square footage cost of building a hospital. The premium in spending money preparing an old building has worked out really well, the hospital's proud of their building, their fundraisers give them more money because they'll have cocktails in the jail, so it's just different. It's very hard to make any kind of calculation that makes sense so that's why you hear people say all kinds of problematic things just from their own opinion and you can say it's always easier to retrofit or it's the most expensive thing ever or you can say it's a wash. 


\section{Tom Mitchinson Email Correspondence}

\section{Board Member of 2 Sultan Street Residential Building}

$\mathrm{J}:$

How is a cooperatively owned building initially implemented?

2 Sultan was an existing building that was turned into a co-op ownership development. Does the framework that you established at 2 Sultan work for a new building proposal? What would be the difficulties of implementing this from new construction?

What factors (social, political, economic) must exist for its initial success?

What factors (social, political, economic) must exist for its continued success?

Is there government support for projects such as this? To my understanding this model is poorly supported legally and it is up to the owners to maintain legal integrity.

In your opinion, do you see this model of ownership having the ability to increase in popularity and be implemented on a much bigger scale of development?

Do you see this implemented on a higher percentage of projects in Toronto that would rival condo ownership, or is the success of developments such as yours dependent on their limited number in the city?

$\mathrm{T}$ :

Our Co-op is not a typical one. Most non-profit co-ops are financed through CMHC and are generally started through some sort of community-based initiative. Ours, on the other hand, is privately financed with no outside help. It was formed in the early 1980 s by a group of tenants who had been renting units in the building. The owner, who was an eccentric chap who actually lived in the building, died, with no surviving relatives. His considerable estate was left to charities, and the executor was planning to sell the building to liquidate the asset, with the predictable outcome of demolition. Some tenants got wind of this and started to investigate ways to stay and to protect the building. I was one of them. We considered purchasing the building as an equity co-op, but this was resisted by the city. We then focused on a non-profit co-op option, which the city was more attracted to, since it would retain affordable housing stock. The estate was looking for market value, which at the time was about $\$ 2.8$ million. That was much too rich for us, but the city held out the possibility of a density sale that could be applied to the purchase price, in return for allocating a portion of the units to an assisted housing organization. There was lots of back and forth on this, initially with an owner of adjacent property that fell through, and then with the owner of a proposed office tower at Yonge and Bloor (now the Zerox building on 
the south-east corner). We sold the density to them for $\$ 1.7$ million, that was approved by both the city and the province, which then made the net cost affordable to the organizing tenants, and the conversion went forward on that basis. (There is a much longer version of this story, which I can elaborate on if you like.) Existing tenants were given the option of becoming members of the co-op or staying on as tenants.

Initially the building was about 50-50 of each type of resident, but over the course of a number of years it became fully co-op members when tenants left and were replaced by members off of a waiting list. The co-op developed by-laws covering a broad range of issues, including maintenance, membership, finance, etc., and 5 members are elected on an annual basis to be Directors. All members, both founding and new, are required to contribute $\$ 3500$ as a "Member Loan", that is refundable on termination of membership, and housing charges are set by the membership annually on the basis of operating financial needs. Our monthly housing charges are well below market rent levels for comparable units in our neighbourhood.

As far as capital improvements are concerned, we have a Reserve Fund Study completed by an outside engineering firm every 5 years, which sets out anticipated costs over a 40-year period. $\$ 2000$ from housing charges are streamed on a monthly basis to a capital fund, and the rest of this fund is financed through a refund of principal paid on our 5 year mortgage. Our mortgage is held by The Co-operators, and is amortized over 25 years. Instead of paying down the mortgage over time, the lender agrees to kick the mortgage back up to 25 year amortization on maturity every 5 years, and to refund the paid-off principal. This allows for approximately $\$ 250,000$ every 5 years to be added to the capital reserve fund, which is enough to cover anticipated capital improvements. So far this financing arrangement has worked out very well for us.

In response to your specific question, I'm not sure that our model would work for a new building, since the only way we were able to make it work for us financially was through the sale of our unused density - I assume you know what I mean by this, but it you don't I can elaborate. Our co-op was also highly dependent on government approval, both municipal and provincial. At the time, density transfers were meant to be used only for contiguous properties, so when our negotiations with the neighbouring developer fell through, we lost some political support when we started to negotiate with the Yonge/Bloor developer who was outside the normally approved zone. We overcame this, but not without a lot of lobbying. And after that we had to get approval from the province, which also took quite a bit of effort. We would certainly never have got the approval without our agreement to set aside $15 \%$ of the units for geared-to-income members off the waiting list for assisted housing. This process has gone quite smoothly over the years, and we have a number of current members who joined us off the assisted housing list and have lived in the co-op for many years. 
Non-profit housing co-operatives are certainly not a new phenomenon - they have been around for decades, with a lot of success. There are several in the St. Lawrence neighbourhood that have operated very well, and others throughout the city. Ours is not a typical one, and if you are interested in learning about a more typical co-op you'd have to contact others that follow a more typical model. I certainly don't think non-profit coops could ever compete with condo developments, at least not in the downtown Toronto market. However, progressive provincial and federal governments, if we ever get them (some optimism provincially, but certainly not with the current federal government) there is potential for them to provide a more extensive niche.

Having lived in the co-op since it was formed in the early 1980s, I can say that it is a great model for neighbourhood building in a big city. Those of us who live there know each other very well, but at the same time appreciate the need for privacy, and we've had a number of situations where the benefits of our community has really helped individual members aging members needed help with shopping, etc.; dying members who need emotional and logistical support; getting together as a community for parties and celebrations, much in the same way that people living in neighbourhoods get together for block parties. It's a great example of community building that can work for many people, particularly those who are not driven by getting a lot of equity out of their homes.

$\mathrm{J}:$

I am very interested in the community bond that has been created at your building as it is unfortunately more of a unique case than most residence buildings in the city. The information works well with my research into community based initiatives such as district heating and energy production. I am curious about what direct potential a member of the building has to input on the types of improvements that are made. By this I mean, if someone or a group, were to become more invested into making a change towards more "green" renovations regarding the building envelope or landscape. Are you aware of any physical characteristics that exist within a co-ownership residence vs. a condo development due to the relationship your piers have with the buildings management.

$\mathrm{T}$ :

The Co-op has a number of committees, composed of volunteer members. This includes both a Green Committee and Maintenance Committee. The Maintenance Committee has been allocated a discretionary budget of $\$ 6,000$ per year ( $\$ 500$ per month) that they can use for non-essentially items that would improve the look of the building - not things that are required, which are funded through the operations account. Any individual expenditure in excess of $\$ 1,000$ requires Board approval. The Committee recently purchased a mirror for the front entrance area, which is a typical type of discretionary expenditure. If the Green Committee identified an initiative it wanted to pursue, they would have to bring the idea forward for consideration by the Board. If the Board approved it in principle, then 
the Committee could then proceed to scope the project and cost it, but it would ultimately be up to the Board to approve any initiative. Our Co-op has always had in-house property management - by that I mean that the Property Manager has always been a member of the Co-op who lives in the building. As such, there is a greater opportunity for the members to interact directly with the Property Manager on a regular basis, than might exist for condos, which would typically have off-site property management services. 


\section{BIBLIOGRAPHY}

Allen, E., \& Iano, J. (2009) Fundamentals of Building Construction: Materials and Methods. 5th ed. Hoboken, New Jersey; John Wiley \& Sons.

Archindont (n.d.). Queen's Quay Terminal. Architectural Index for Ontario (Database) Retrieve from <http://archindont.torontopubliclibrary.ca/Arch/buildingName. do?name=Queen\%27s+Quay+Terminal $>$

Blake, P. (1974). Form Follows Fiasco. Toronto, ON; Little, Brown, \& Company Limited.

Bozikovic, A. (2015, March 3). Redevelopment of Honest Ed's in Toronto Holds Several Surprises. The Globe and Mail. Retrieved from <http://www.theglobeandmail.com/ news/toronto/redevelopment-of-honest-eds-in-toronto-holds-several-surprises/article23274452/>

Braham, W. (2000). After Typology: The Suffering of Diagrams. Architectural Design. 70(3), 9.

Brand, S. (1995). How Buildings Learn: What Happens After They're Built. London, England; Penguin Books LTD.

Braungart, M. \& McDonough, W. (2002). Cradle to Cradle: Remaking The Way We Make Things. North Point Press.

Brownell, B. (2006). Transmaterial: A Catalog of Materials that Redefine our Physical Environment. New York, NY; Princeton Architectural Press.

Building Code Act: Ontario Building Code (OBC). (Regulation 332/12). (2014). Retrieved from the Ontario Ministry of Municipal Affairs and Housing Website <http://www.e-laws.gov.on.ca/html/regs/english/elaws_regs_120332_e.htm>

Burton, L. (1979). A Choice Over Our Heads. Westfield, New Jersey; Eastview Editions Inc. 
Brook Mcllroy Planning + Urban Design/Pace Architects, E.R.A Architects, Quadrangle Architects Limited, Urban Marketing Collaborative. (2010, May). Avenues \& Mid-Rise Buildings Study. City of Toronto. Retrieved from <http://www1.toronto.ca/wps/ portal/contentonly?vgnextoid=7238036318061410VgnVCM10000071d60f89R . CRD>

Christ, E. \& Gantenbein, C. (Eds.). (2012). Typology - New York, Hong Kong, Buenos Aires, Rome. ETH Zurich and Park Books; Zurich, Switzerland.

Cole, R.J. \& Kernan, P.C. (1996), Life-Cycle Energy Use in Office Buildings, Building and Environment, Vol. 31, No. 4, pp. 307-317.

Deleuze, G. \& Guattari, F. (1987). A Thousand Plateaus. Capitalism and Schizophrenia. Minneapolis, MN; University of Minnesota Press

Duffy, F. (1990). Measuring Building Performance. Facilities. 8(5), 17-20. Retrieved from <http://dx.doi.org/10.1108/eb006518>

Forsyth, A. \& Crewe K. (2009). A Typology of Comprehensive Designed Communities Since the Second World War. Landscape Journal. Board of Regents of the University of Wisconsin; Wisconsin. pg 56-78. Retrieved from <lj.uwpress.org/content/28/1/56. full.pdf+html>

Foster, N. (2007). Norman Foster: My Green Agenda for Architecture. Retrieved from <http://www.ted.com/talks/norman_foster_s_green_agenda.html>

Frederick, M. (2007). 101 Things I Learned in Architecture School. Cambridge, Massachusetts; The MIT Press

Graham, P. (2003). Building Ecology: First Principles for a Sustainable Built Environment. Blackwell Publishing. 
Guy, B. \& Shell S. (2002) Design for Deconstruction and Materials Reuse. [White Paper]. Retrieved from <http://www.deconstructioninstitute.com/files/downloads/75508728_DesignforDeconstructionPaper.pdf>

Höjer, M. \& Gullberg, A \& Petterssons, R. (2011) Images of the Future City: Time and Space For Sustainable Development. Sweden; Springer Science+Business Media. Retrieved from <http://www.springer.com/us/book/9789400706521>

Krawczyk, B. (2010). TOBuilt: A Database of Building in Toronto, Canada. Retrieved from < http://www.tobuilt.ca/>

Kuhn, C. (2012). Typology Quarterly Schools. The Architectural Review. Retrieved From <http://www.architectural-review.com/essays/typology-quarterly-schools/8625738.article?blocktitle=Typology\&contentID=10992> LeBlanc, D. (2014, September 25). Yonge Street Developers are Embracing Time-Worn Storefronts. The Globe and Mail. Retrieved from < http://www.theglobeandmail. com/life/home-and-garden/architecture/yonge-street-developers-are-embracingtime-worn-storefronts/article20793315/>

Metcalfe, B. (2013, July). In Nelson, Local Food Co-op Becomes Bigtime Developer. The Tyee. Retrieved from < http://thetyee.ca/News/2013/07/31/Kootenay-Co-Op/> Moneo, R. (1978). On Typology. Oppositions: A Journal for Ideas and Criticism in Architecture. (13), 22-45. Retrieved from <http://doarch101.files.wordpress. com/2011/10/moneorafael_ontypology_oppositions13.pdf>

Penoyre, G. \& Prasad, S. (2014). Retrofit for Purpose: Low Energy Renewal of Non-Domestic Buildings. London, UK; RIBA Publishing.

Salden, S.L. (2010). Building a Sustainable Language of Typology. Traditional Building. 23(3), 12. Retrieved from <http://www.traditional-building.com/Previous-Issues-10/JuneFeature10.html> 
Shalden, D. (1983). Queens Quay Resurrection. Canadian Interiors. 20(2), 13-16.

Smart-Rig Cranes. (2015). A Smart Glass Lifting Solution. Smart-Rig Cranes. Retrieved from <http://www.smartrigcranes.com/>

Sørensen, S. B. (Producer), \& Dalsgaard, A. (Director). (2013). The Human Scale [Motion Picture]. Denmark: Final Cut for Real.

Sterling, B. (2013). The Last Viridian Note. Viridian. Retrieved from <http://www.viridiandesign.org/notes/451500/the_last_viridian_note.html>

United Nations Educational, Scientific and Cultural Organization. (2015). City of Bath. UNESCO. Retrieved from < http://whc.unesco.org/en/list/428> 


\section{GLOSSARY}

Biosphere: The regions of the surface, atmosphere, and hydrosphere of the earth occupied by living organisms.*

Community: A group of people living together in one place, especially one practicing common ownership.*

Correalism: Defined by Frederick Kiesler as "the dynamics of continual interaction between man and his natural and technological environments".

Diachronic: Concerned with the way in which something has developed and evolved through time.*

Derived from: “mid 19th century: from dia- 'through' + Greek khronos 'time.".*

Deconstruction: The opposite of construction. Used in this context to describe the disassembly of a building into its parts without destroying the materials used.

Destruction: The action or process of causing so much damage to something that it no longer exists or cannot be repaired.*

Flexible: The ability to be easily modified or respond to altered circumstances or conditions. *

Guidelines: A general rule, principle, or piece of advice.*

Handbook: A book giving information such as facts on a particular subject or instructions. *

Hierarchy (Hierarchical design): An arrangement or classification of things according to relative importance or inclusiveness.*

Life-cycle: The series of changes in the life of an object or organism.*

[Re] Manufacture: To (Re) Invent or fabricate (from existing).*

Neighbourhood: City of Toronto officially classifies neighbourhoods as having 7000-10000 people living within defined areas bound by natural or manmade boundaries such as rivers or major roads. [retrieved from: City of Toronto, 2014, Neighbourhood Profiles. www1.toronto.ca.]

Obsolescence: Falling into disuse.*

Preemptive Design: To design something with the intent of forestalling something, to prevent an undesired outcome.

Robustness: Able to withstand or overcome adverse conditions.*

Recycle: Return (material) to a previous stage in a cyclic process. 
Repetition/Repeating: The action of repeating something that has already been considered. ${ }^{*}$ In the context of this book, repetition is not used to describe the direct copy of something, merely the repetition of an idea.

Reproduction: The action or process of making a copy of something.*

Repurpose: Adapt for use in a different purpose.*

Resiliency: The capacity to recover quickly from difficulties.*

Retrofit: Add (a component or accessory) to something that did not have it when manufactured.*

Reuse: To use again or more than once.*

Synchronic: Concerned with something, as it exists at one point in time.*

Taste: The ability to discern what is of good quality or of a high aesthetic standard.*

Tractable: The ability for something to be easily controlled, influenced, or dealt with. Derived from: "Early 16th century: from Latin tractabilis, from tractare 'to handle"”*

Transient: Lasting only for a short time.*

Type: A category of things having common characteristics.*

Typology: A classification according to general type.*

Viridian (Viridian Design Movement): This refers to the movement initiated by Bruce Sterling after his presentation on the need for the mass population to adopt a sustainable mindset. Viridian refers to a shade of green-blue which Sterling relates to his sustainable design movement.

* All marked definitions were retrieved from Oxforddictionaries.com, 2015, Oxford University Press. 
